\title{
CHARACTERIZATION OF NATURAL FRACTURES IN MESAVERDE CORE FROM THE MULTIWELL EXPERIMENT
}

BY

S. J. FINLEY AND J. C. LORENZ

September 1988

\begin{abstract}
Natural fractures dominate the permeability of tight sandstone reservoirs in the Mesaverde Formation of the Piceance Creek Basin, northwestern Colorado. Roughly 1900 natural fractures, detected in $4200 \mathrm{ft}$ of Mesaverde core from the U.S. Department of Energy's Multiwell Experiment (MWX), have been differentiated into 10 different fracture types on the basis of fracture morphology, inclination, the presence of slickensides, the presence of dickite mineralization and/or host 1ithology. Approximately 75 percent of the MWX core fractures are dewatering planes in mudstone and are probably unimportant to reservoir permeability. The remaining 25 percent of the MWX core fractures include 275 mostly calcitemineralized, vertical extension fractures, 61 irregular, dickitemineralized extension fractures, 27 mostly calcite-mineralized, horizontal extension fractures, and 90 slickensided, occasionally mineralized shear fractures. These extension and shear fractures are all potentially important to reservoir permeability and consequently productivity.
\end{abstract}

\section{MASTER}



DATABASE AVAILABILITY

The MWX fracture database is available as an ASCII file on a 5$1 / 4$ inch formatted floppy disk. If interested contact Sharon J. Finley, John C. Lorenz, or Norman R. Warpinski at: Sandia National Laboratories, Division 6253, P.0. Box 5800, Albuquerque, NM 87185. 


\section{DISCLAIMER}

This report was prepared as an account of work sponsored by an agency of the United States Government. Neither the United States Government nor any agency Thereof, nor any of their employees, makes any warranty, express or implied, or assumes any legal liability or responsibility for the accuracy, completeness, or usefulness of any information, apparatus, product, or process disclosed, or represents that its use would not infringe privately owned rights. Reference herein to any specific commercial product, process, or service by trade name, trademark, manufacturer, or otherwise does not necessarily constitute or imply its endorsement, recommendation, or favoring by the United States Government or any agency thereof. The views and opinions of authors expressed herein do not necessarily state or reflect those of the United States Government or any agency thereof. 


\section{DISCLAIMER}

Portions of this document may be illegible in electronic image products. Images are produced from the best available original document. 


\section{ACKNOWLEDGMENTS}

We would like to acknowledge the initial descriptions of natural fractures in MWX core performed by J. A. Clark, D. D. Madsen, and L. W. Teufel. We especially thank N. R. Warpinski, who assisted in the computer aspects of the data base and F. E. Hensley, who assisted by washing, moving, and sorting roughly $70,000 \mathrm{lbs}$. of rock. Thanks also go to D. A. Northrop, J. T. Neal, and N. R. Warpinski for their helpful reviews of this report.

The Multiwell Experiment is part of the U.S. Department of Energy's Western Gas Sands Subprogram which is managed by the Morgantown Energy Technology Center, Morgantown, WV. 
A. INTRODUCTION

B. METHODOLOGY

Extension Fractures

8

Shear Fractures

9

C. DISCUSSION OF FRACTURE TYPES

1. Extension Fractures

a. Extension Fractures (Type 1 and Type $S$ )

b. "Frac Blast" Fractures (Type 8)

35

c. Horizontal Fractures (Type 7) 40

d. Other Extension Fractures (Type $C$ and Type N)

a. Low-Angle Shear Fractures in Sandstone or Siltstone (Type 4)

b. High-Angle to Near-Vertical Shear Fractures in Sandstone or Siltstone (Type 5)

c. Shear Fractures within Carbonaceous Mudstone Laminations in Sandstone or Siltstone (Type 2)

d. Dewatering Fractures in Mudstone (Type 3) 65

e. Shears in Mudstones (Type 6) 



\section{A. INTRODUCTION}

The Mesaverde Formation is fractured throughout the section at the Department of Energy's Multiwe11 Experiment (MWX) site. Well tests indicate that the natural fractures dominate permeability and, therefore, are the primary mechanism of gas production in these low-permeability sandstones. About $4200 \mathrm{ft}$ of mostly 4-inch-diameter core was cut from three closely spaced wells at the MWX site. A comprehensive database of core fractures is presented in this report, and all natural fractures identified in the MWX core are described and discussed.

The three MWX we11s are located within the Rulison Field (natural gas) near Rifle, Colorado. Figure 1 shows the well spacings, and the cored intervals are listed in Table 1. Approximately 30 percent of the core was oriented using standard multishot techniques. In addition to the characterization of core fractures presented in this report, a detailed sedimentologic description of the core was made (Lorenz, 1987). Also, numerous routine and special core analyses were conducted on the MWX core by several commercial and government laboratories (Sattler, 1984).

The top of the Cretaceous Mesaverde Formation is at a depth of roughly $4000 \mathrm{ft}$ and the Mesaverde section is approximately $4300 \mathrm{ft}$ thick at the MWX site. The Mesaverde is comprised of rocks from five different depositional environments as illustrated in Figure 2. In descending stratigraphic order, these environments include the upper, paralic zone (4000 to 4400 $\mathrm{ft}$ ), characterized by distributary and estuary sandstones; the fluvial zone (4400 to $6000 \mathrm{ft}$ ), characterized by wide meanderbelt sandstones; the coastal zone or upper delta plain (6000 to $6600 \mathrm{ft}$ ), characterized by lenticular distributary channel sandstones; the paludal zone or lower delta plain ( 6600 to $7450 \mathrm{ft}$ ), characterized by lenticular distributary channel sandstones and coals; and the lower marine-shoreline zone (7450 to $8300 \mathrm{ft}$ ), characterized by blanket sandstones (Lorenz, 1987). 


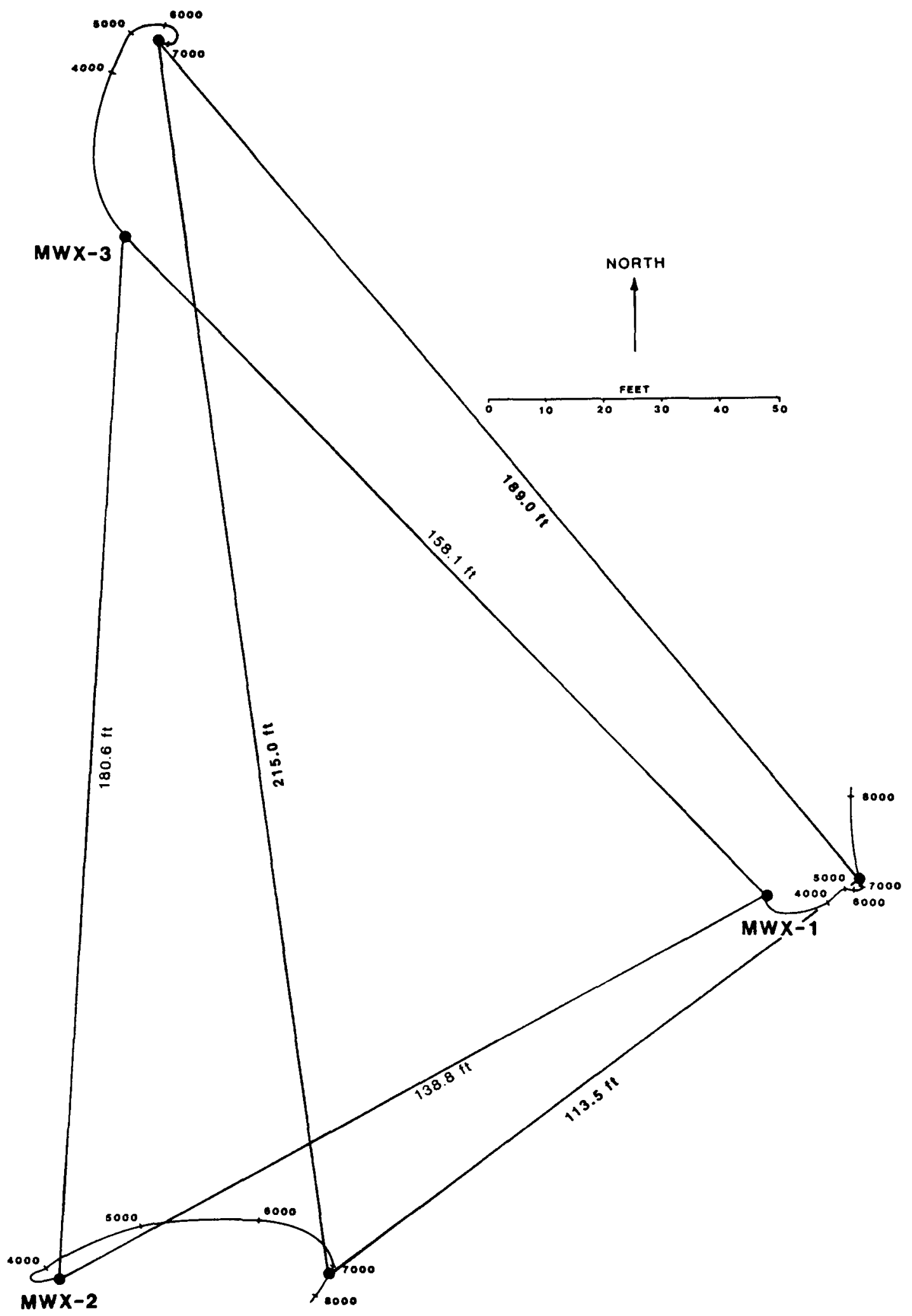

Figure 1. Relative Well Spacings at Surface and at $7300 \mathrm{ft}$ (the deepest survey in all three wells). 
Table 1

Core Intervals in MWX Wells

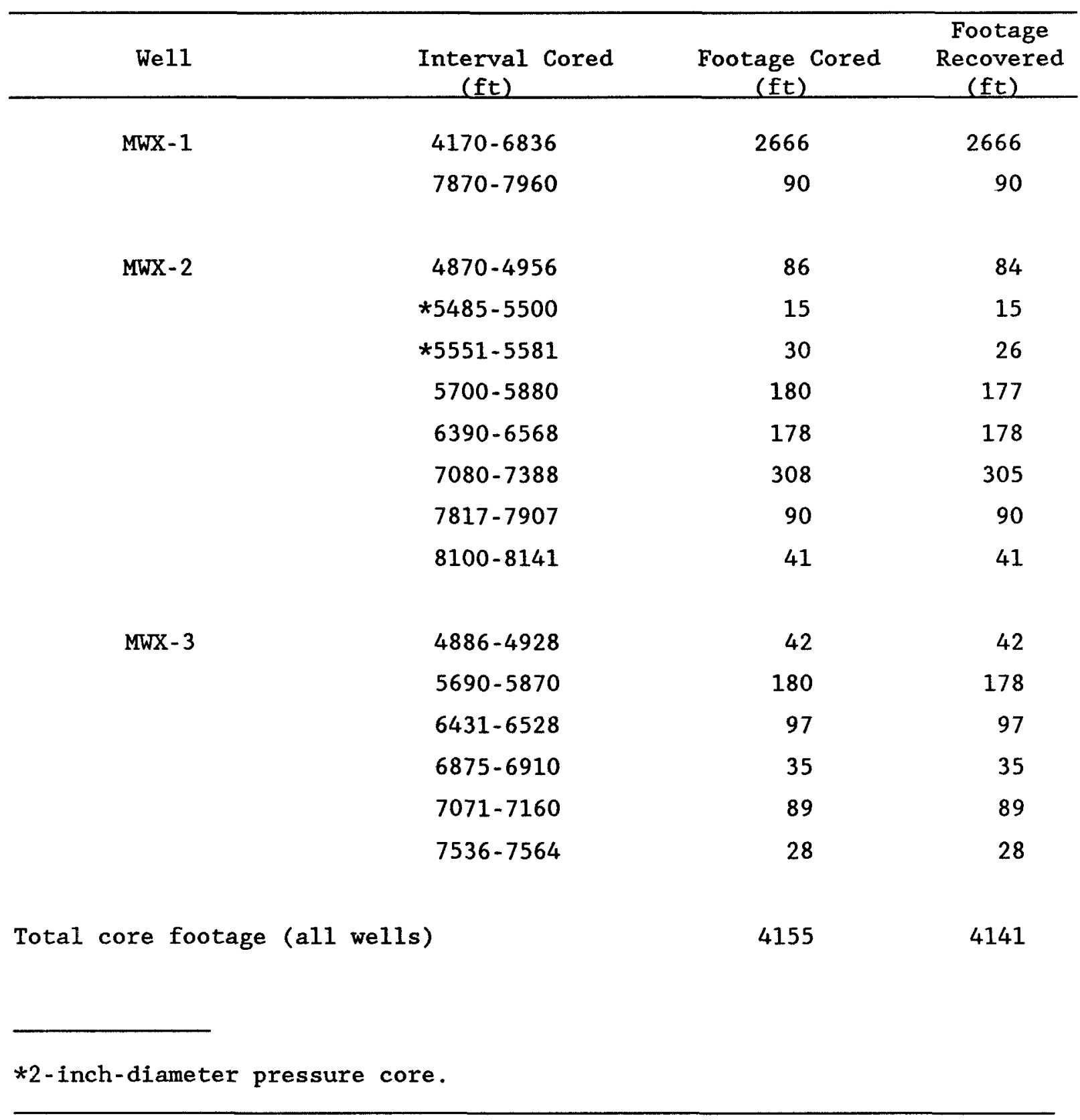




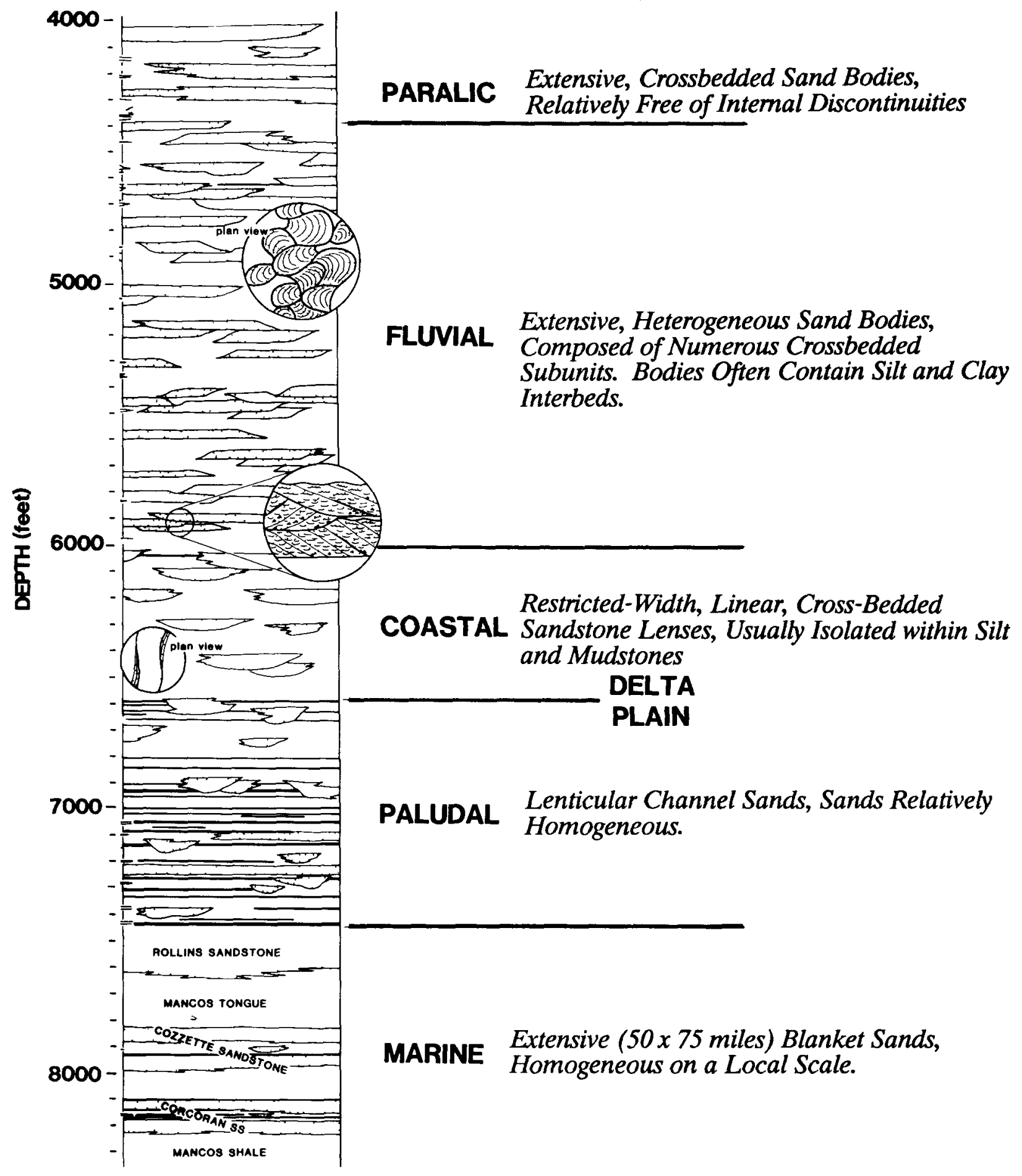

Figure 2. Geologic Characteristics of Mesaverde Formation Sandstones in the MWX Wells (J. C. Lorenz, 1987) 
The MWX fracture database, discussed in this paper and presented in Appendix A, is comprised of all the naturally occurring fractures identified in the MWX core plus two types of drilling-and/or coringinduced fractures. Roughly 110 drilling-induced petal fractures and 16 scribe-line fractures are included in the MWX fracture database. They are designated type $P$ and type $B$, respectively, in Appendix A. These mechanically induced petal and scribe-line fractures have been discussed in detail in Lorenz and Finley (1988) and will not be discussed further in this paper. All of the natural fractures that have been identified in MWX core are either mineralized to some extent and/or slickensided.

\section{B. METHODOLOGY}

All of the available core from the three MWX wells was scrutinized for natural fractures and all fractures were classified and described in detail. Due to core sampling for various analyses prior to fracture logging, an occasional fracture may have been overlooked. However, every effort was made to minimize such omissions. D. D. Madsen prepared an informa1, preliminary set of fracture notes on MWX-1 and MWX-2 core ( $J$. A. Clark, 1983), and data from these notes were used in the MWX fracture database presented in this report if the core was unavailable for reexamination.

Each piece of core was washed and scrubbed thoroughly prior to examination for fractures. Fracture measurements were carefully made, and occasionally the core was cut to determine the relationship between individual fracture strands or fracture orientations. Most of the core had been previously slabbed for a sedimentology review, making detection of very thin fractures easier. A binocular microscope was used for the identification of fracture mineralization; however, occasionally the use of a petrographic microscope, $x$-ray diffractometer, or scanning electron miscroscope was necessary to confirm the presence of mineralization or determine its composition. Classifying the MWX core fractures by fracture type was a tedious and cumbersome task. Large intervals of core were 
examined and reexamined several times in order to assure that the fractures were classified consistently, and that all fractures were noted.

Describing and classifying fractures in core is by no means a completely empirical process. For example, some of the fractures consist of a number of individual fracture strands. Since the relationship between fracture strands was often impossible to verify, we used arbitrary but consistent interpretations. If the strands appeared to be an echelon or closely spaced ( $<0.1 \mathrm{ft}$ apart) and oriented the same, they were considered to be part of the same fracture. Other interpretations that affect fracture descriptions are identified later in this paper, when the fracture type affected is discussed.

The fracture database in Appendix A includes the following, where applicable, about each fracture or fracture group:

- we11 number

- fracture depth

- number of fractures

- fracture height

- fracture width

- fracture strike

- dip inclination

- dip direction

- slickenside bearing

- type of motion

- type and amount of mineralization

- fracture terminations

- rock type

- fracture type.

The well number designates the well that the core came from. The fracture depth is the depth of the top of the fracture; both core and log depths are given. The number of fractures indicates how many fractures fit the description given. If the number of fractures is greater than one, the 
database provides a general description of the fracture group, which may not fit every individual fracture within that group. Fracture height refers to the height of the fracture in the core (depth of bottom of fracture minus depth of top of fracture). In the case of a fracture group, fracture height refers to the core length of the entire group. Fracture width in the database is the maximum width of a single fracture or of the widest fracture in a group.

Fracture strike is the true strike of a fracture, oriented with respect to north using multishot orientation data or paleomagnetic techniques (Geissman, 1988). Paleomagnetic techniques were used to determine the orientation of six MWX fractured core samples, whereas roughly $1260 \mathrm{ft}$ of MWX core was oriented using multishot techniques. Paleomagnetic data or multishot orientation data were used in conjunction with the core logs prepared by CER Corporation in order to accurately extend the orientation data beyond the piece of core where it was taken. (These core logs provide an invaluable record of breaks in and deviation of the principal scribe line, as well as tops of core runs and connections; all data that can be used to help determine the validity of any multishot orientation points.) Dip inclination is the angle between the plane of the fracture and a horizontal plane. Dip azimuth refers to the true down-dip azimuth as determined from oriented core data. Slickenside bearing, where available, is also a true orientation. Type of motion indicates a specific type of shear fracture or fault, either normal, reverse, or strike-slip.

Type of mineralization is a mineral identification of the fracture fill, and fill amount is described as either partial or complete. A notation is made if the mineralization is crystalline and subhedral. The presence of subhedral mineralization indicates that the crystals were partially unconfined during crystal growth. Fracture terminations refer to the terminations of the fracture within the core. Rock type refers to the principal lithology of the core hosting the fracture.

All of the fractures were categorized by an arbitrarily defined fracture type. Each fracture type was assigned an arbitrary number or 
letter designation immediately after identification, and since different fracture types were later grouped into larger classifications, the specific types are not discussed in numerical order. Some fracture types were only recognized in very localized core intervals. Description of these localized fractures occasionally defined a new fracture type, and previously logged core intervals were then rechecked for fractures that might best fit the new type. The fracture types were defined specifically to fit the MWX core fractures. Rather than fit the data to a preconceived classification system, the data dictated the fracture types used in this database.

All fractures of a particular type have similar morphologies and other characteristics like inclination and host lithology suggesting a similar fracture origin. However, all or some of the different fracture types may be related, whereas some fractures with similar morphologies may be unrelated. Fracture origins are briefly mentioned where data is available; they will be the subject of future research and publications.

For the purpose of this paper, the different fracture types were initially categorized as either extension or shear fractures. The extension fracture types are discussed in order of their relative abundance in MWX core. The shear fractures lend themselves more readily to discussion by host lithology. Those fracture types occurring in sandstone and siltstone are discussed before those types occurring in mudstone lithologies.

\section{Extension Fractures}

- Types 1 and S: vertical, mostly calcite-mineralized fractures (275 fractures).

- Type 8: dickite-mineralized fractures imparting a "frac blast" texture to the rock (61 fractures).

- Type 7: horizontal, mostly calcite mineralized fractures (27 fractures). 
- Type C: mineralized coal cleats (4 cleats).

- Type N: calcite-mineralized fractures within a sandstone clast encased in mudstone ( 2 clasts).

\section{Shear Fractures}

- Type 4: low angle shear fractures in sandstone and siltstone lithologies (4 fractures).

- Type 5: near vertical shear fractures in sandstone and siltstone 1ithologies (1 fracture).

- Type 2: shear fractures confined to carbonaceous mudstone laminations in sandstone and siltstone lithologies (77 fractures).

- Type 3: conical to undulating dewatering/compaction fractures in mudstone (1425 fractures).

- Type 6: planar shear fractures in mudstone 1ithologies (8 fractures).

The discussion section of this report includes comprehensive descriptions of the different types of MWX core fractures. These descriptions include core photographs, sketches, photomicrographs, distribution histograms, scatter plots of fracture widths, inclinations, orientations, and/or rosette diagrams of orientations.

Unless otherwise noted, all histograms of fracture frequency with respect to depth plus figures 14 and 27 consist of data from MWX-1, where approximately $2700 \mathrm{ft}$ of continuous core was taken. Data from MWX-2 were used only where there was no core from MWX-1. Although they are not all obvious on the histograms due to the 250-ft bar width, the following are uncored intervals in MWX-1 and MWX-2: 4000-4170 ft (paralic); 6838-7080 ft (paludal); 7388-7817 $\mathrm{ft}$ (paludal and marine); 8141 to $8500 \mathrm{ft}$ (marine). See Table 1 for cored intervals. If fracture data from MWX-2 or MWX-3 is 
used in lieu of MWX-1 data, the fracture distribution with depth is essentially unchanged.

\section{DISCUSSION OF FRACTURE TYPES}

\section{EXTENSION FRACTURES}

The extension fractures in MWX core have been divided into five different types. Here the term extension fracture is used to refer to any fracture that has been pulled apart perpendicular to the plane of the fracture, with no evidence of shear motion. The most common type of extension fractures observed in MWX core are simply referred to as extension fractures (Type 1 and Type $S$ ). The second most commonly observed type of extension fractures, although they occur in a very localized zone, are the "frac blast" fractures (Type 8), and the third subgroup of extension fractures in MWX core are horizontal fractures (Type 7). Type C and $\mathrm{N}$ extension fractures occur very rarely in the MWX core and are briefly described at the end of this section.

\section{a. Extension Fractures (Type 1 and Type S)}

Roughly 275 of Type 1 and $S$ extension fractures are identified and described in Appendix A. Figures 3, 4, 5, and 6 show photographs of typical fractures belonging to this subgroup. Type 1 fractures are vertical to subvertical, roughly planar, mostly calcite-mineralized extension fractures occurring predominantly in sandstone and siltstone lithologies. These fractures are commonly stranded or branched, and fracture strands often appear en echelon in the core. Figure 7 is an artist's conception of this typical en echelon pattern. Because observation or corroboration of the relationship of individual fracture strands is not likely in a 4-in.-diameter core, we were careful to use consistent interpretations in order to compile a meaningful database. Where fracture strands appear en echelon and essentially parallel, they are considered to be part of the same fracture. This was also the case if two 


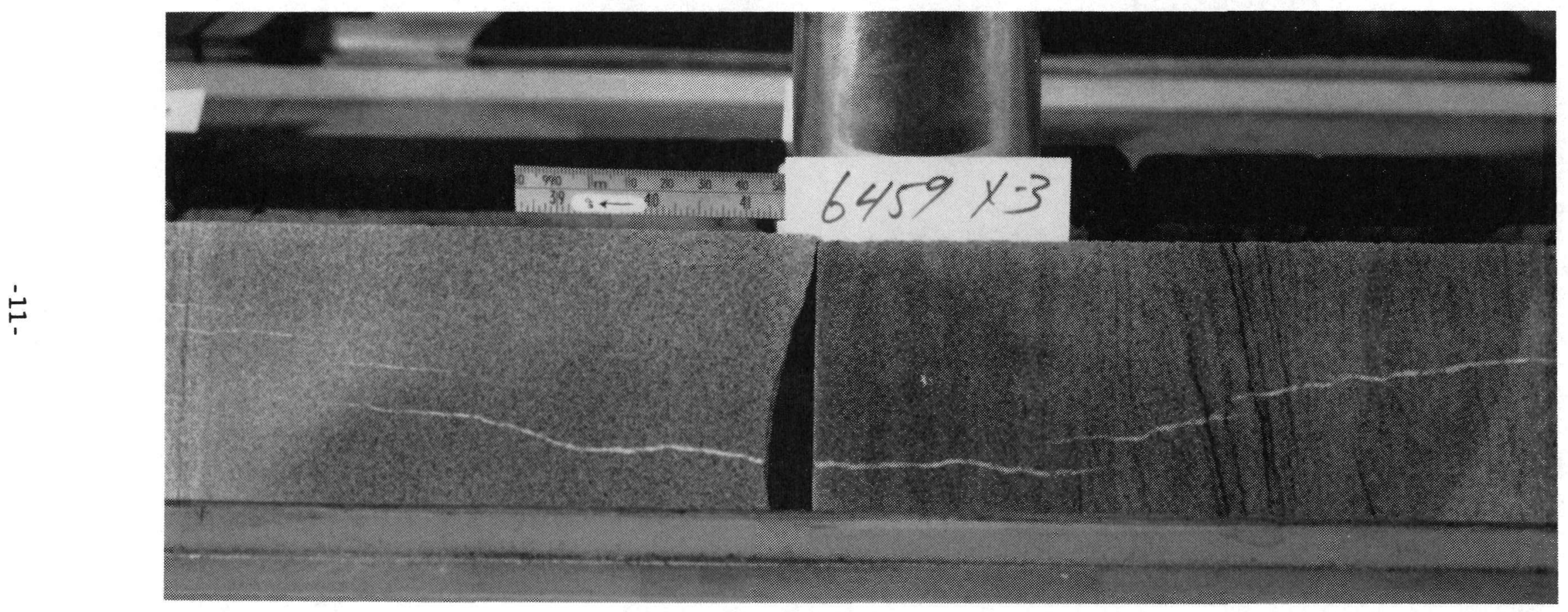

Figure 3. An En Echelon Type 1 Fracture 


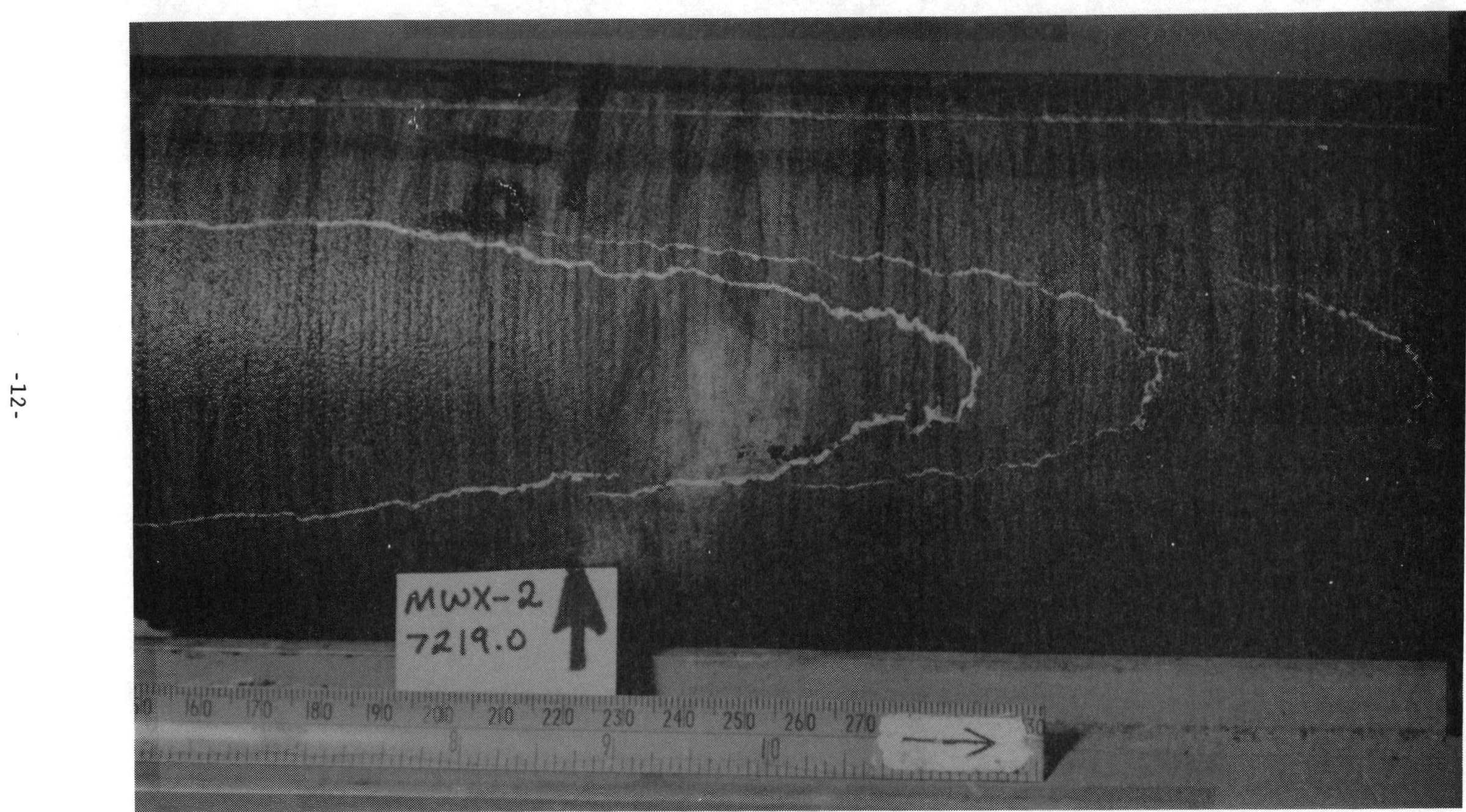




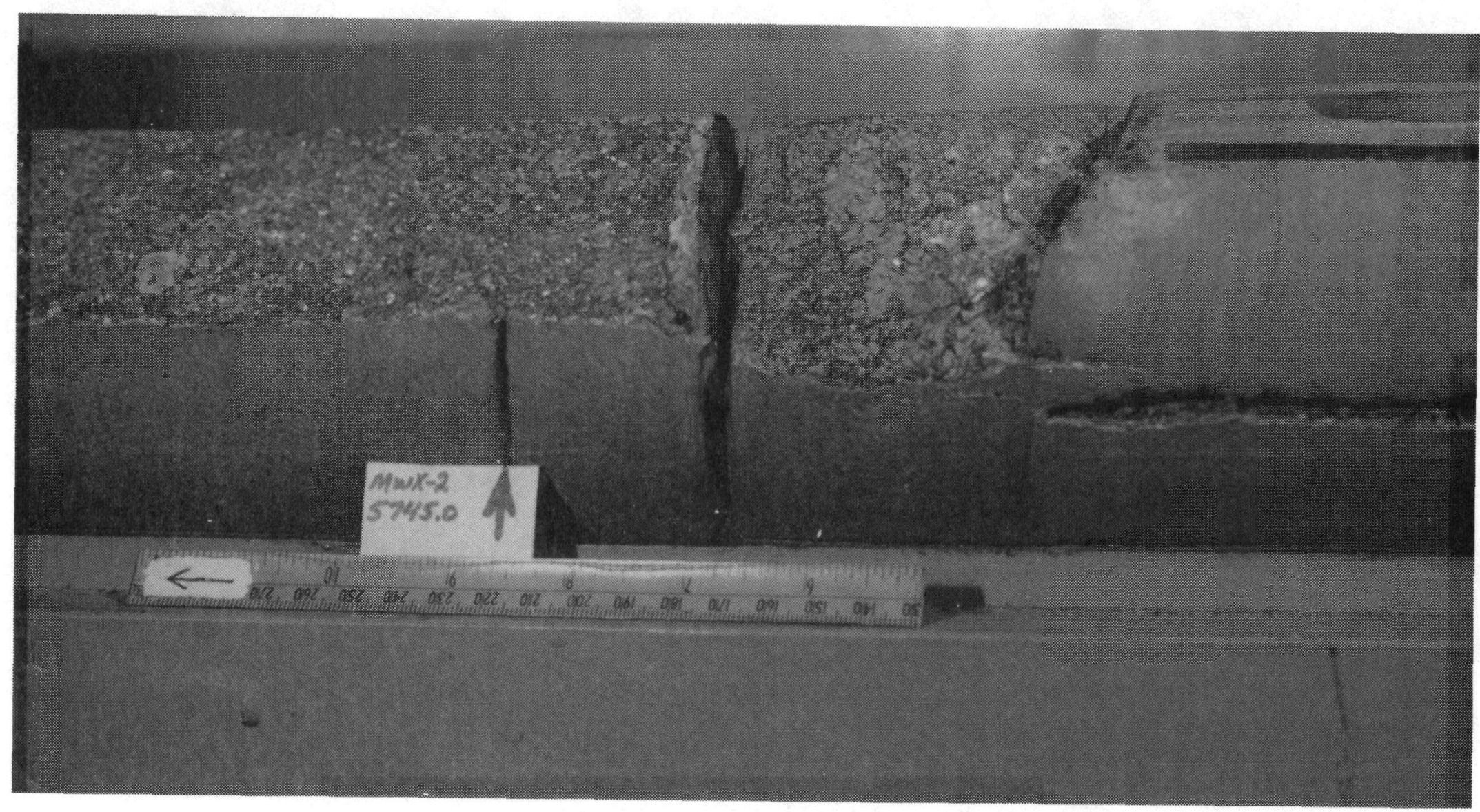

Figure 5. A Stranded Type 1 Fracture With Subhedral Calcite Mineralization 


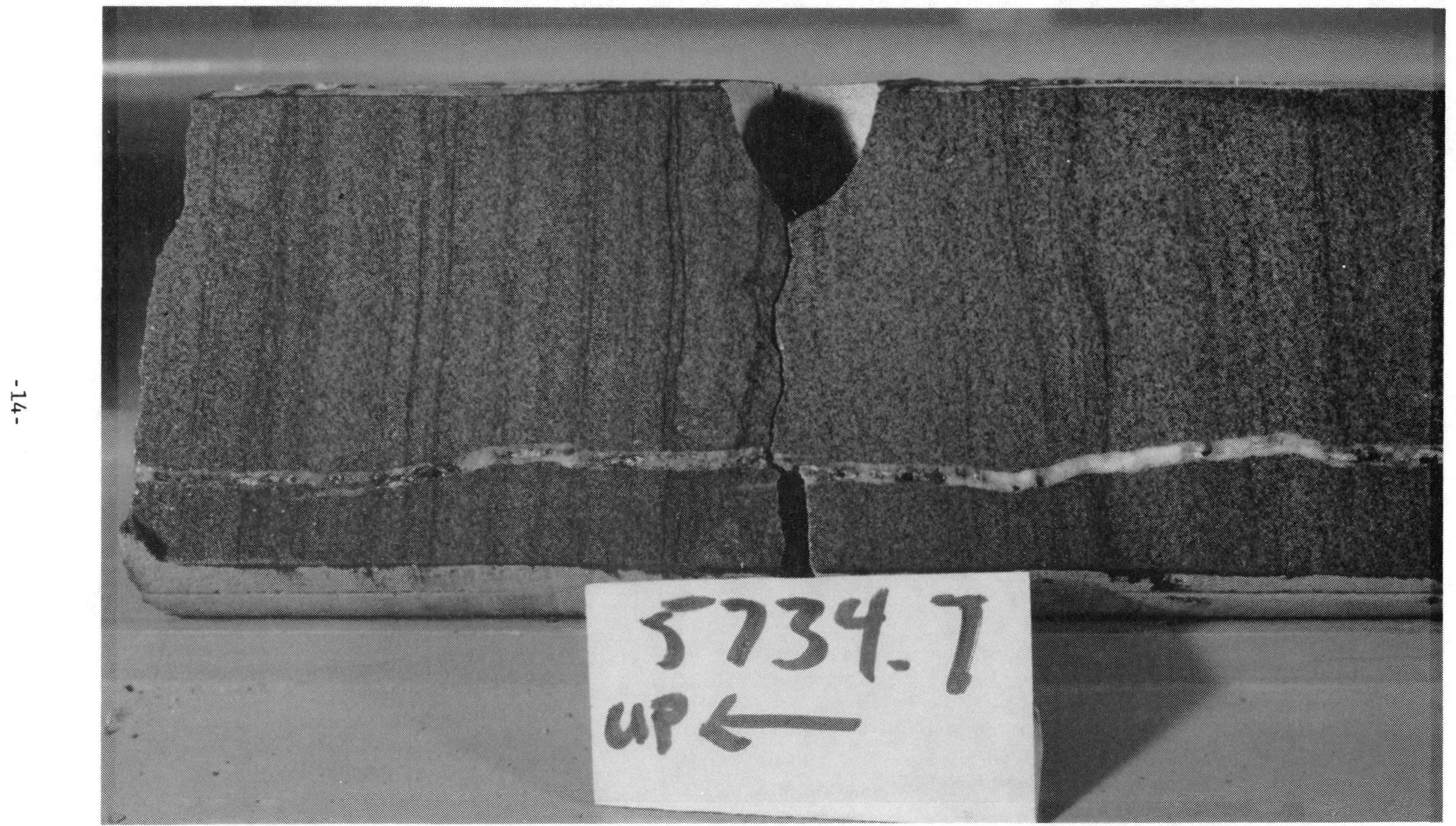

Figure 6. Type 1 Fracture in MWX-1 

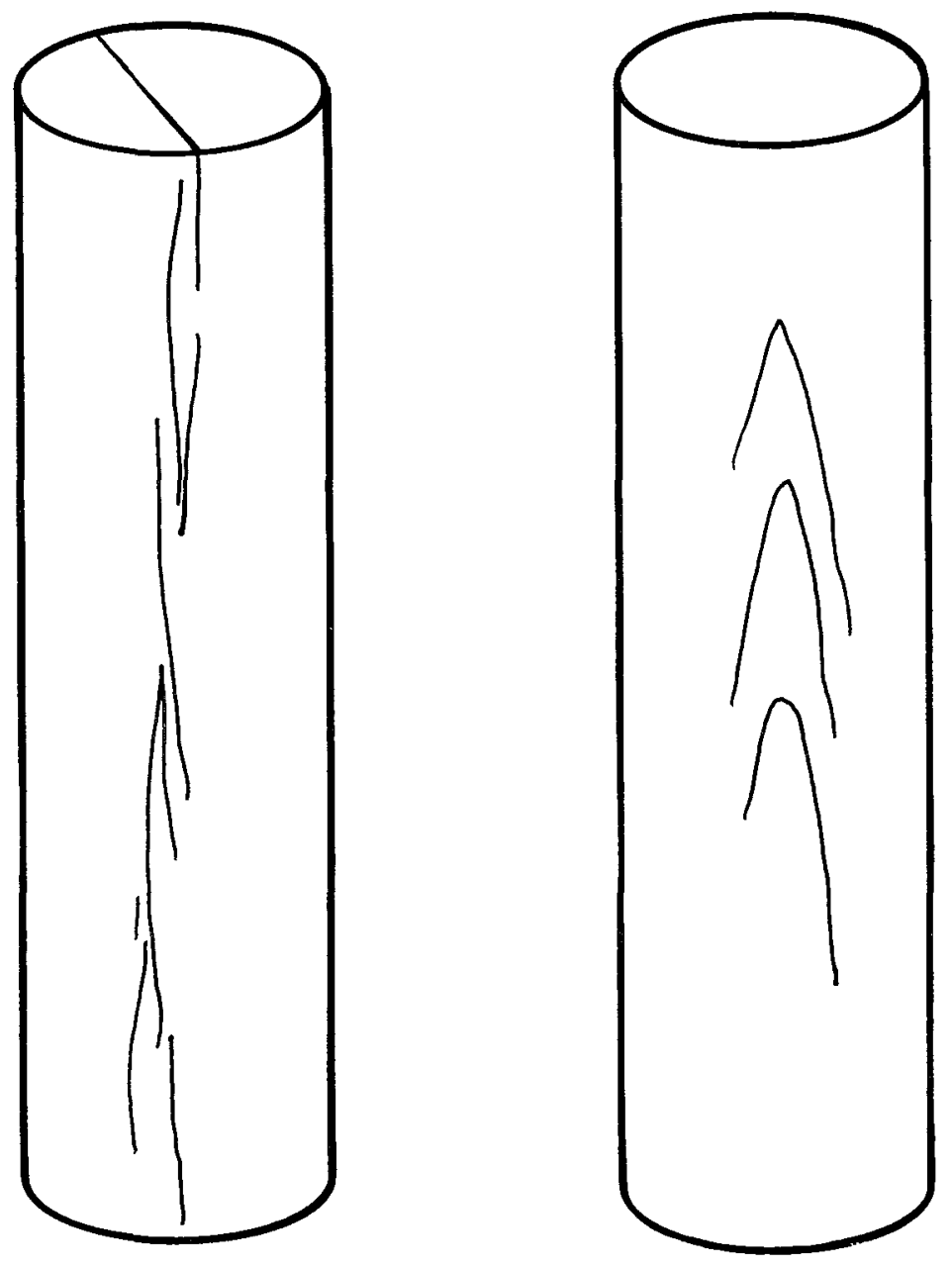

Figure 7. Examples of En Echelon Pattern of Stranded Type 1 Fractures in Core 
fracture strands are the same length, parallel and $<0.1 \mathrm{ft}$ apart. If the strands are the same length, parallel or not, and $\geq 0.1 \mathrm{ft}$ apart, they are arbitrarily counted as two individual fractures. If three or more fracture strands intersect the same piece of core such that most horizontal cross sections through the core would intersect three or more fracture strands, the fractures are collectively referred to as a fracture swarm (see Figure 8). In the observed fracture swarms, the individual fracture strands have similar widths; therefore, no single strand stands out as being the main fracture.

In the database, individual extension fractures are denoted Type 1 and swarms of these fractures are denoted Type $S$. Arbitrarily, the number of fractures is recorded as 3 for all fracture swarms. In general, all fractures within a fracture swarm have the same orientation and inclination. They may be stranded just like individual extension fractures. At a depth of $-5532 \mathrm{ft}$ in $\mathrm{MWX}-1$, there is a fracture within a fracture swarm with a strike roughly $40^{\circ}$ different than the strike of the other fractures within the swarm; this fracture was listed separately. Figure 9 shows the distribution of Type 1 and $S$ extension fractures with depth.

As is obvious in Figure 9, this particular subgroup of extension fractures is densely concentrated in the fluvial interval particularly between 5250 and $5750 \mathrm{ft}$ in the wells. These extension fractures are nearly vertical to vertical $\left(70^{\circ}\right.$ to $\left.90^{\circ}\right)$, and roughly 80 percent of those that have been oriented with respect to true north strike west-northwest. Lorenz et al. (1986) discussed the origin and significance of these westnorthwest-striking extension fractures. (Note: Orientation data for core fractures presented in this paper supersedes the preliminary orientation data presented in that paper.)

Twenty-five percent (62 fractures) of these Type 1 and $\mathrm{S}$ extension fractures have been oriented with respect to true north. Roughly one-third of these oriented fractures are associated with fracture swarms. The predominant west-northwest fracture strike shows up in all three rosette 

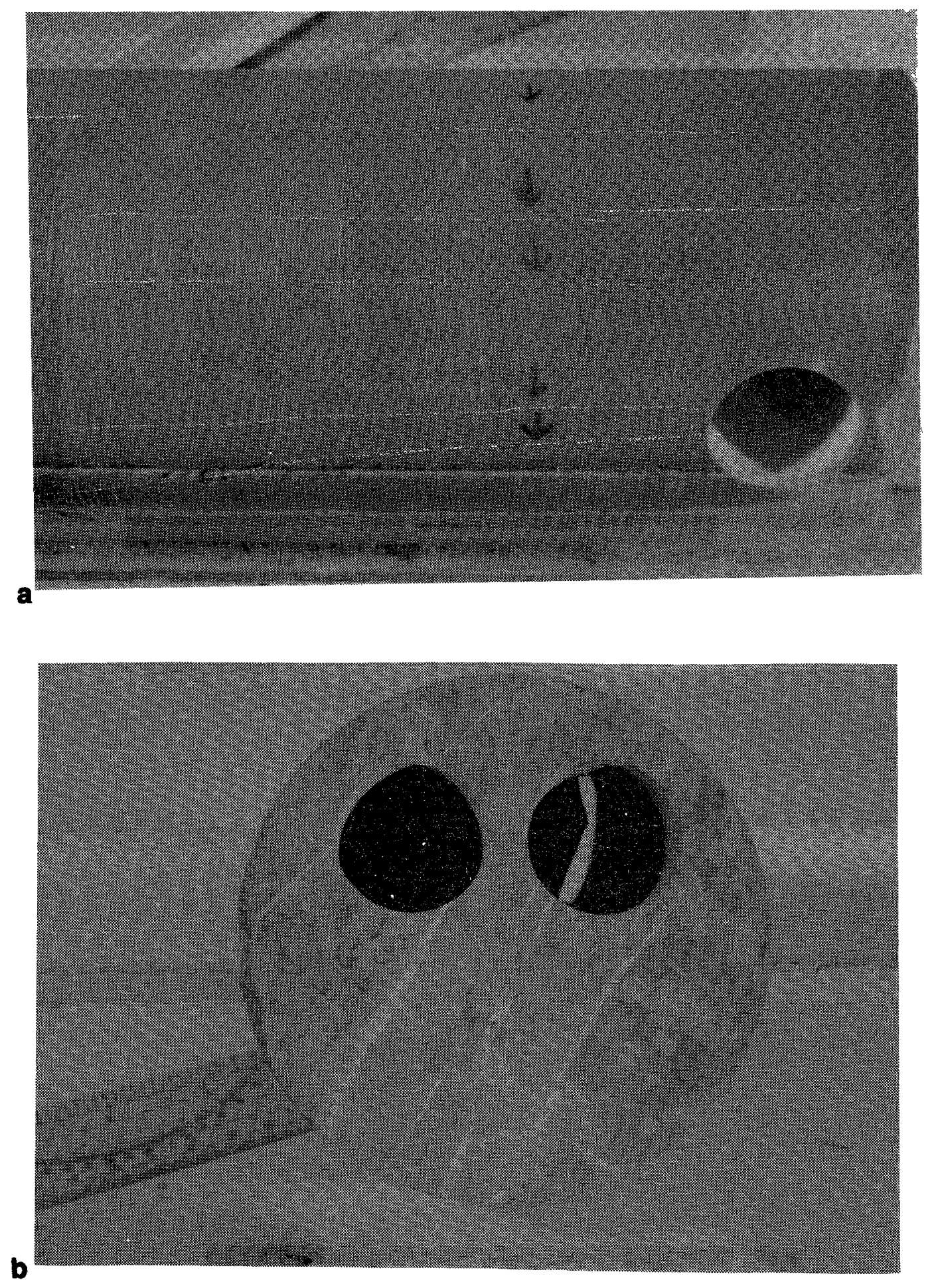

Figure 8. Examples of Fracture Swarms (Type $S$ );

(a) MWX-1, $5678 \mathrm{ft}$; (b) $\mathrm{MWX}-2,8123.3 \mathrm{ft}$ 

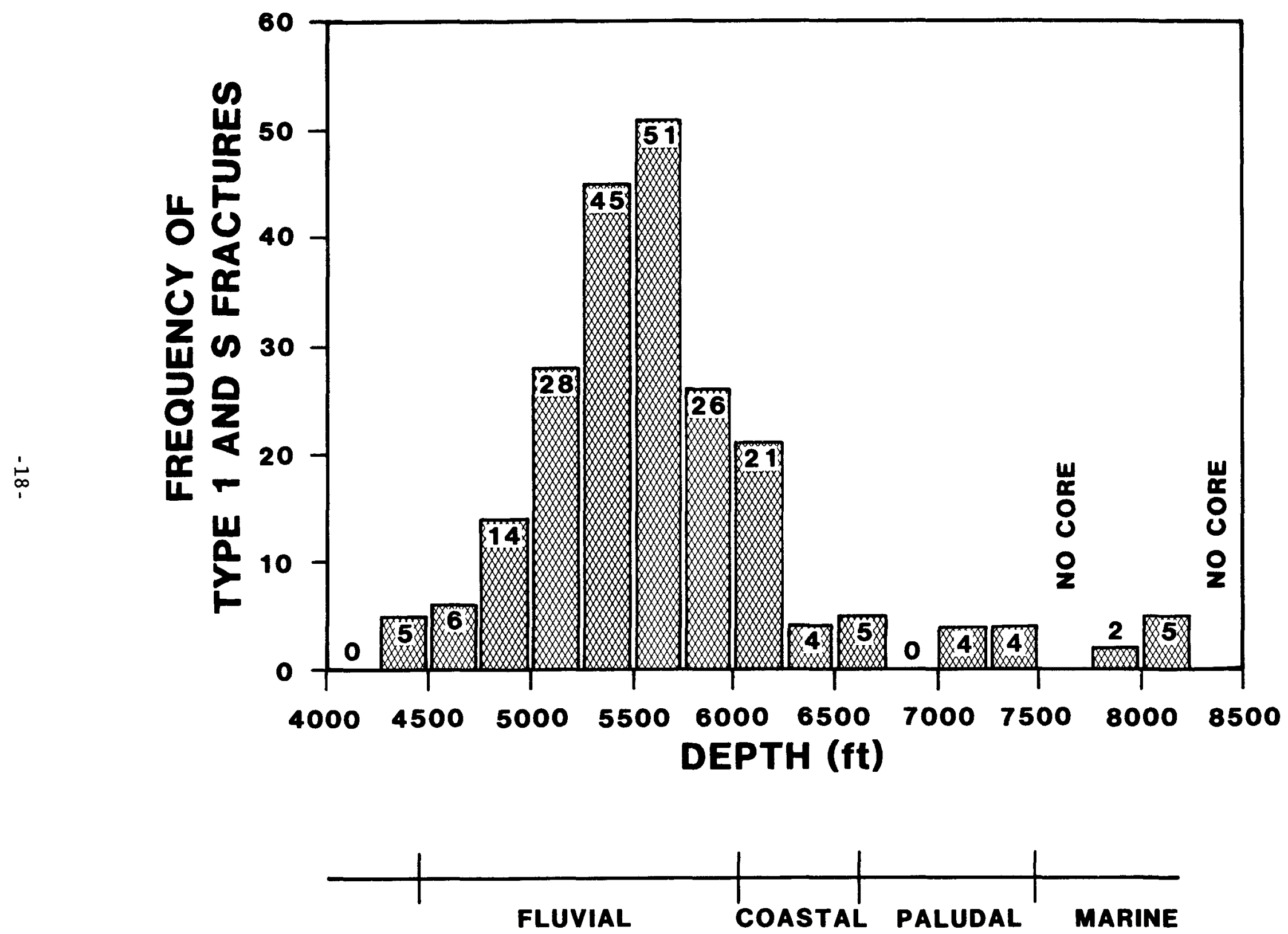

Figure 9. Frequency Distribution of Type 1 and S Fractures with Respect to Depth; Core Data from MWX-1 and MWX-2 
diagrams in Figure 10. In addition to the predominant fracture strike, the core intersected fractures striking north-northwest in the marine zone $(\sim 8120 \mathrm{ft})$ and in the fluvial zone $(-5440$ and $5530 \mathrm{ft})$. Fractures striking northeast were also detected in core from the fluvial zone ( $5505 \mathrm{ft})$. Figure 11 shows the distribution of fracture strikes with respect to depth. Data from all three MWX wells were used to generate this figure.

Although there is a good deal of scatter in the fracture orientation data due to scatter in the multishot data, the additional fracture orientations are real. The fractures striking north-northwest were either detected in the same piece of core, or in an unbroken and unrotated core run where fractures striking west-northwest were also observed. The orientation of fractures striking northeast was first determined using multishot-oriented core data and later corroborated with paleomagnetic data. In addition to the the multiple fracture strikes in the fluvial and marine zones, two extension fractures, with strikes differing by $50^{\circ}$, intersect each other in core at about $6196 \mathrm{ft}$ in MWX-1 (Figure 12). There are no orientation data available for this piece of core or any core in close proximity to these fractures.

Close inspection of thin sections across intersections of calcitefilled fractures with distinctly different strikes has offered no clue to the relative ages of these apparently different Type 1 fracture sets. No offset is observed and, with the exception of the north-northwest marine fractures, mineralization appears similar and continuous (Figure 13). The identification of chamosite in the north-northwest marine fractures suggests this fracture set may be older than the predominant west-northwest fractures.

All of the Type 1 and $S$ fractures are filled with some combination of calcite, quartz, chamosite, barite and/or dickite mineralization. Figure 14 shows the distribution of the three most common types of mineralization. Calcite is by far the most common mineral phase. Calcite occurs as either the only mineral phase present, or in conjunction with quartz, dickite, barite, and/or chamosite. The calcite crystals are 
a

INDIVIDUAL EXTENSION FRACTURES

TYPE 1

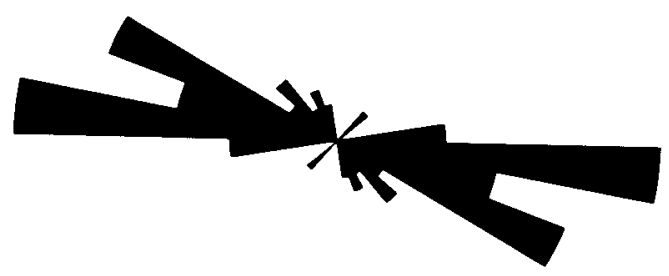

$n=41$

b

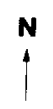

EXTENSION FRACTURES ASSOCIATED WITH FRACTURE SWARMS TYPE S

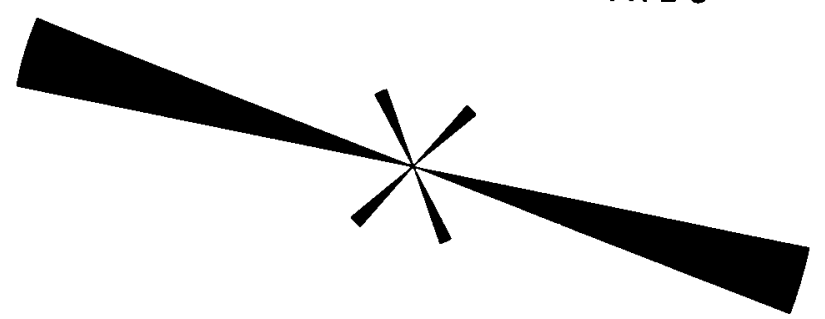

$n=21$

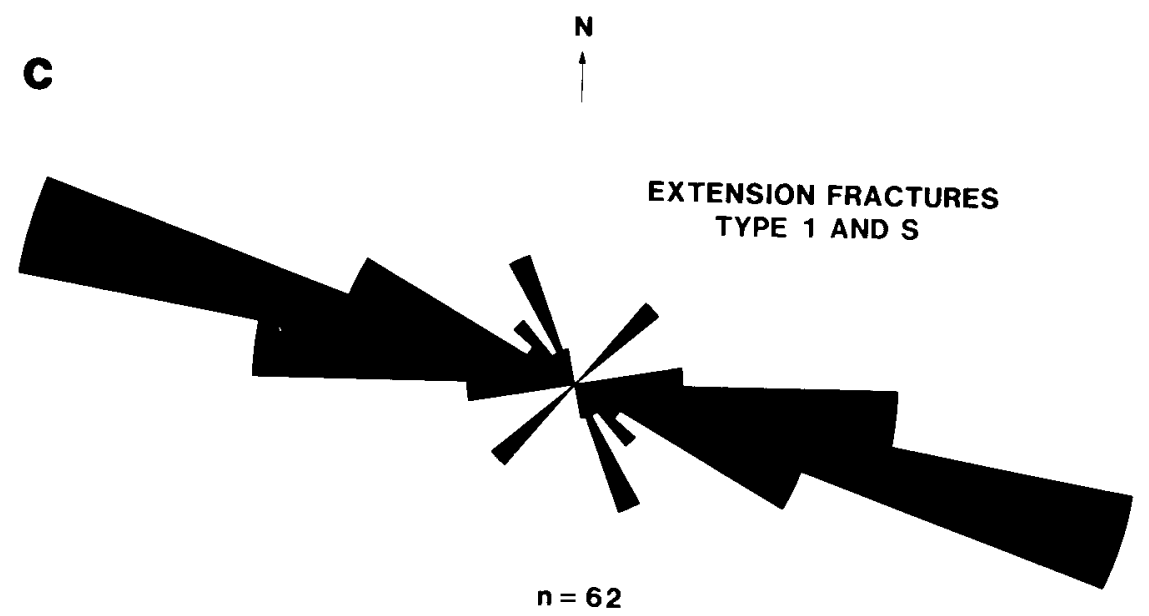

Figure 10. Strikes of Type 1 and Type $S$ Fractures Plotted in Rosette Diagrams; (a) Type 1 Fractures; (b) Type S Fractures;

(c) Both Type 1 and Type S Fractures 


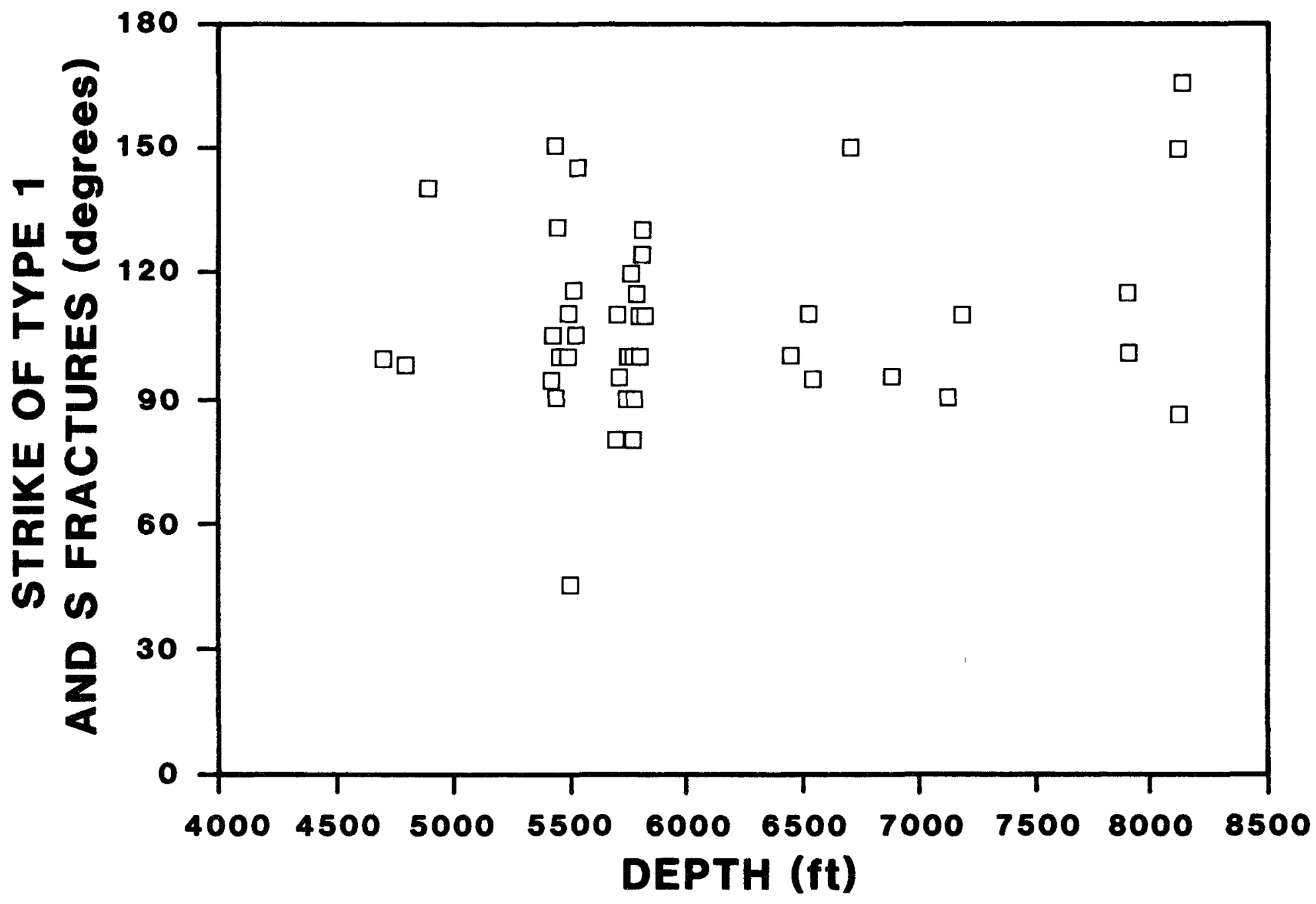

Figure 11. Distribution of Type 1 and S Fracture Strikes Plotted With

Respect to Depth; Oriented Core Data From all Three MWX Wells 

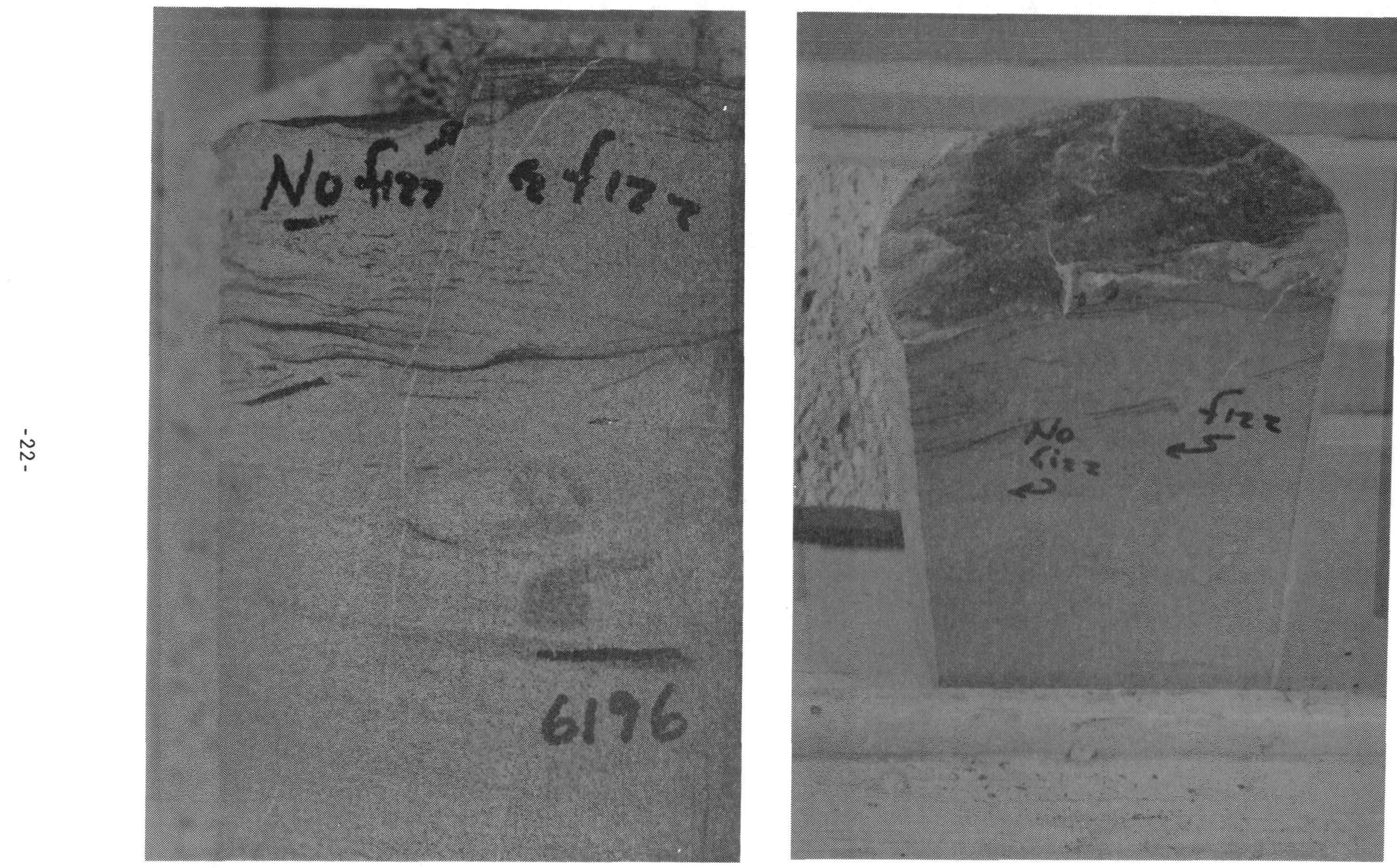

Figure 12. Intersecting Type 1 Fractures at $6196 \mathrm{ft}$ in MWX-1 

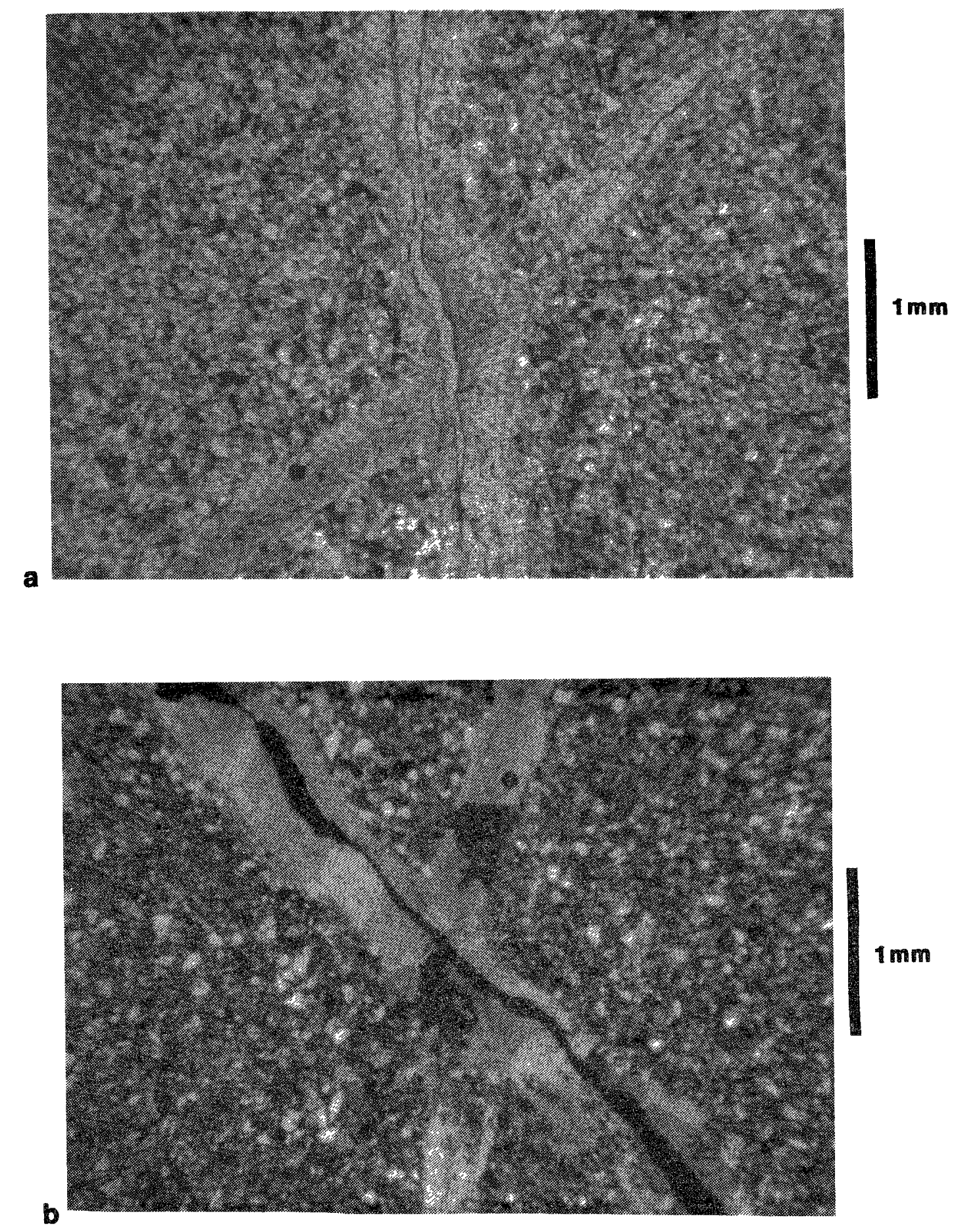

Figure 13. Photomicrograph of Intersecting Type 1 Fractures at $5532.2 \mathrm{ft}$ in MWX-1; (a) Plane Light; (b) Polarized Light 

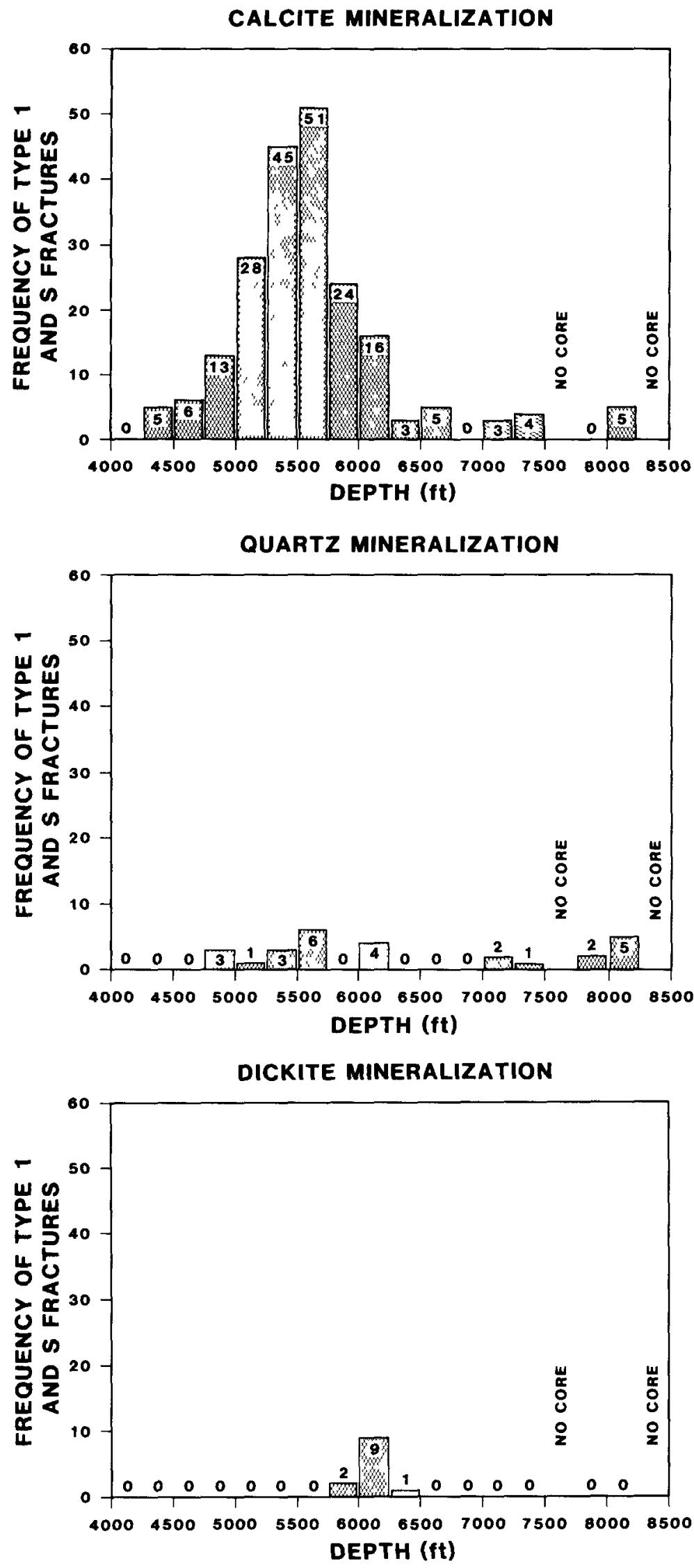

Figure 14. Distribution of Different Fracture Mineralization With Respect to Depth; Core Data From MWX-1 and MWX-2 
sometimes subhedral and frequently twinned (Figure 15). Quartz is the only mineral phase identified in one fracture in the paludal interval ( $7122 \mathrm{ft}$ ) and two fractures in the marine interval ( 7903 ft); however, in Type 1 and $S$ fractures, quartz is typically found with calcite and/or dickite and frequently appears to have been the first mineral phase to precipitate. The quartz often appears as subhedral crystals nucleated on sand grains at the fracture wall (Figure 16).

Dickite apparently completely fills fractures or fills void in fractures previously mineralized with quartz and calcite. The photomicrographs in Figure 17 suggest that at this location calcite may have been partially dissolved or altered by the fluids precipitating dickite. Calcite and/or quartz sometimes occur in only microscopic quantities in the dickite-filled Type 1 fractures. Since petrographic analysis wasn't routinely done, calcite and/or quartz may have been overlooked in some of these fractures. Dickite has been identified by $x$-ray diffraction analysis and has only been detected in 12 of the Type 1 extension fractures between 5980 and $6400 \mathrm{ft}$ in MWX-1. This particular interval was not cored in either of the other two MWX we11s. The presence of dickite is used as an identifying characteristic of the subgroup of extension fractures called "frac blast" fractures (Type 8) discussed later.

The mineral chamosite only occurs in the fractures striking northnorthwest in the marine interval in MWX core. Where it occurs, chamosite lines fracture walls or completely fills fracture strands, indicating it was the first mineralization to precipitate from solution (Figure 18). Calcite and quartz are also present in these same fractures. The presence of early chamosite in north-northwest marine fractures coupled with its absence in west-northwest striking marine fractures suggests that at least in the marine interval, the north-northwest fractures are older. (There are a number of inconsistencies in the literature regarding the mineral name "chamosite." Usage of "chamosite" in this paper is based on the definition provided by Maynard (1986). He suggests using "chamosite" to refer to Fe-rich chlorites with a measurable 14 angstrom basal spacing.) 

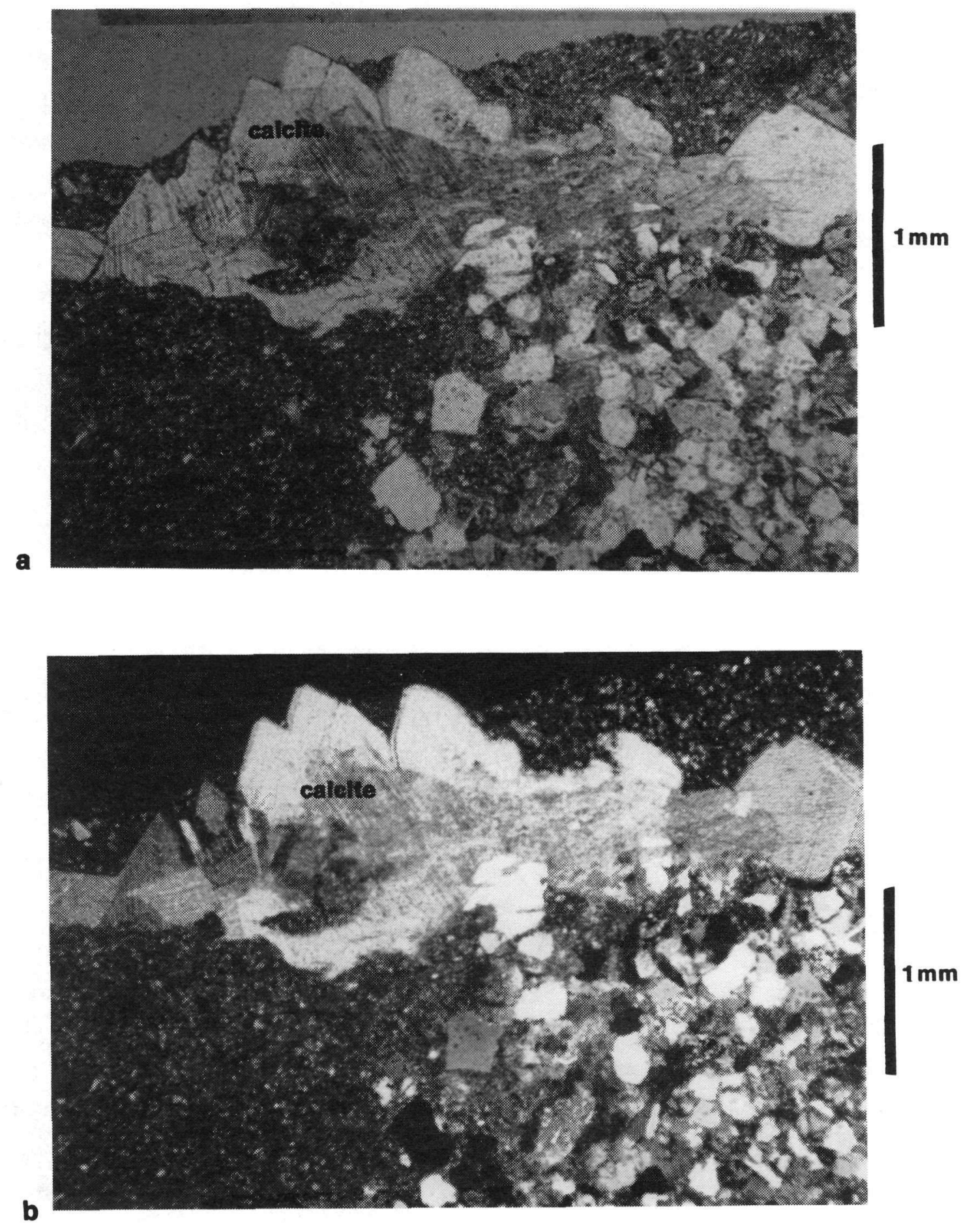

Figure 15. Photomicrographs of Subhedral and Twinned Calcite in a Type 1 Fracture $6008.6 \mathrm{ft}$ in MWX-1; (a) Plane Light; (b) Polarized Light 

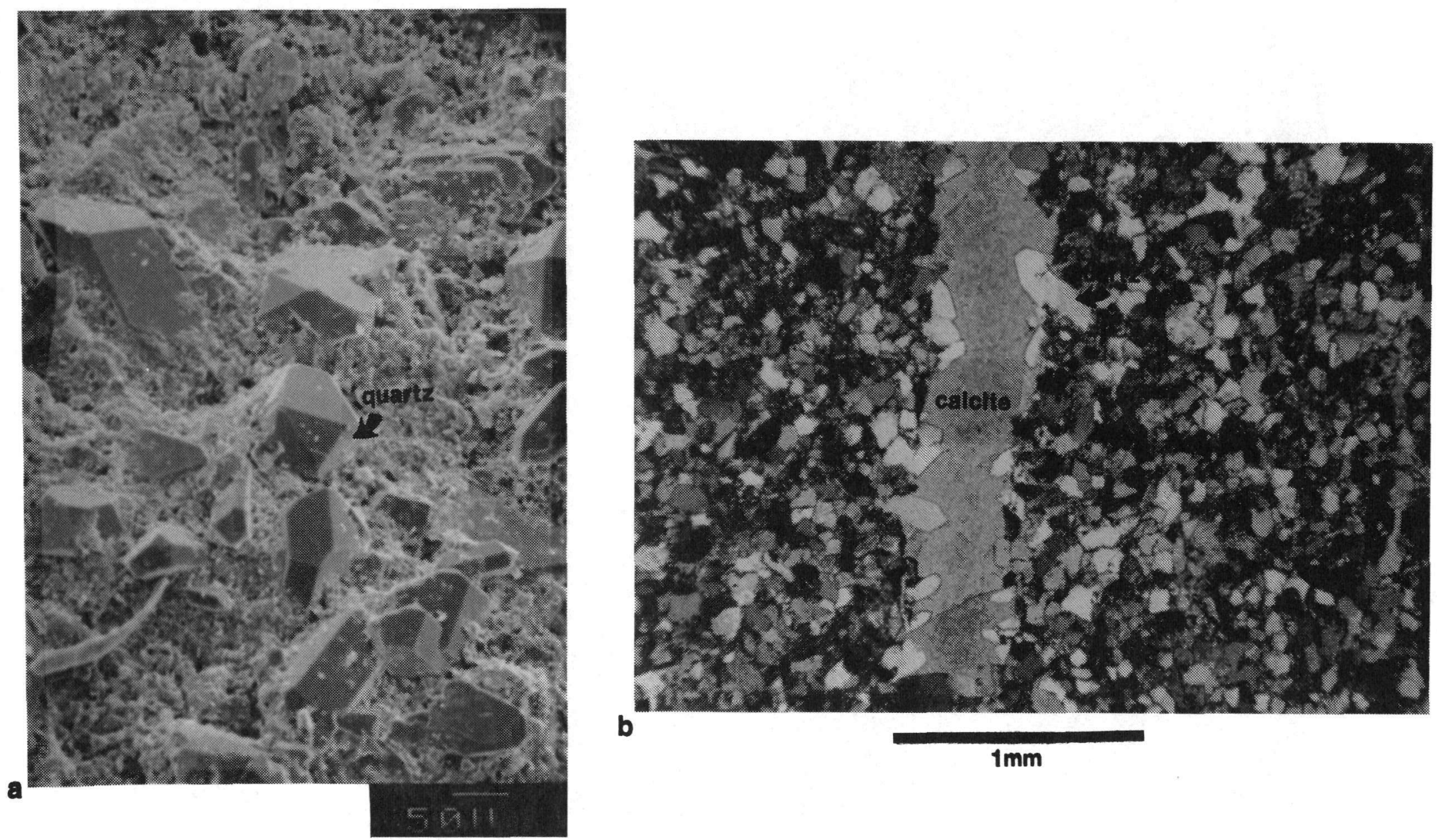

Figure 16. Photomicrographs of Quartz Nucleated on Sand Grains Along Fracture Wa1ls;

(a) SEM Photo of Subhedral Quartz in Fracture at $7122 \mathrm{ft}$ in MWX-2;

(b) Photo of Thinsection of Mostly Calcite Filled Fracture at $5504.3 \mathrm{ft}$

in MWX-1 (polarized light) 

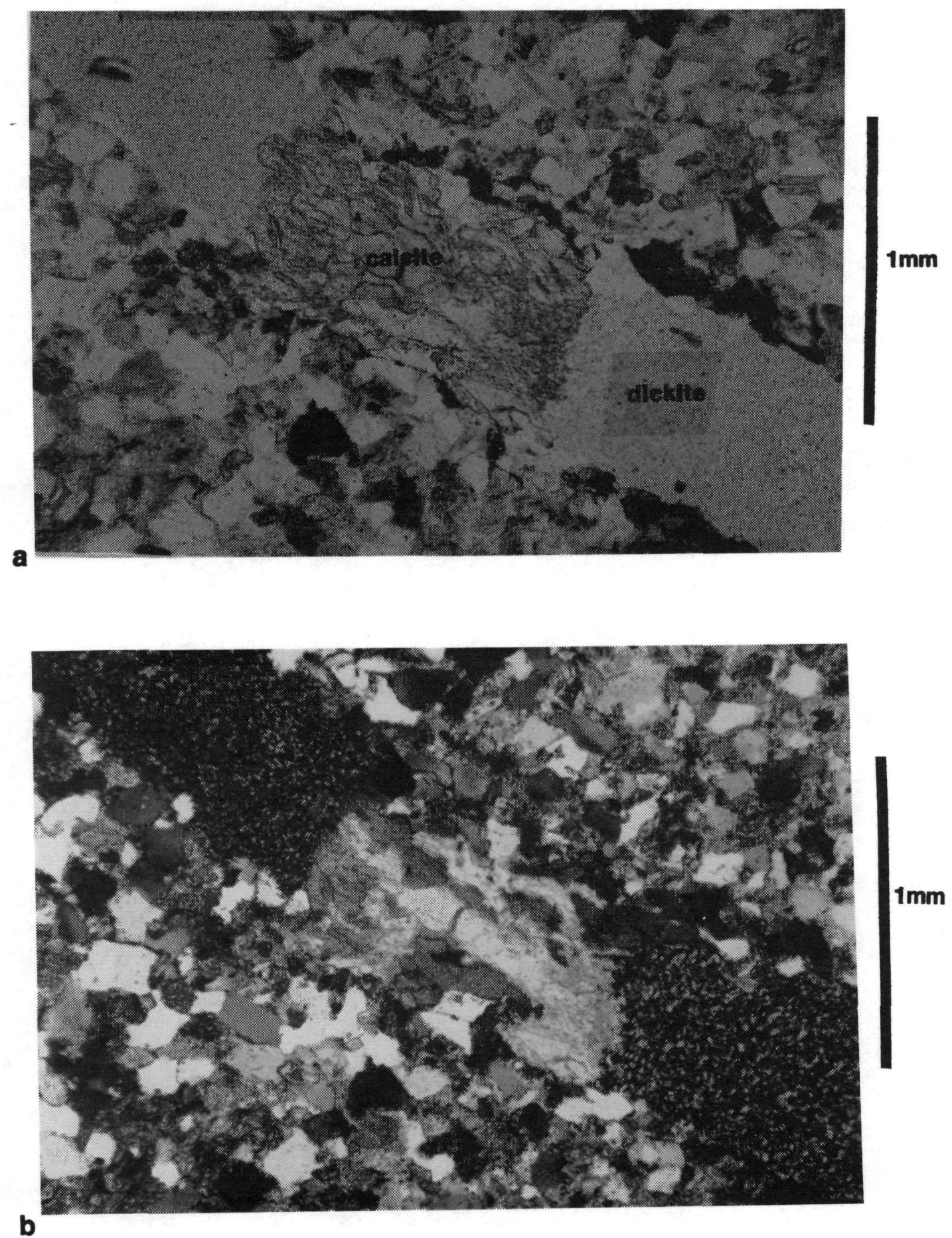

Figure 17. Photomicrographs of Calcite and Dickite in Type 1 Fracture at 6047.2 ft in MWX-1; (a) Plane Light; (b) Polarized Light 

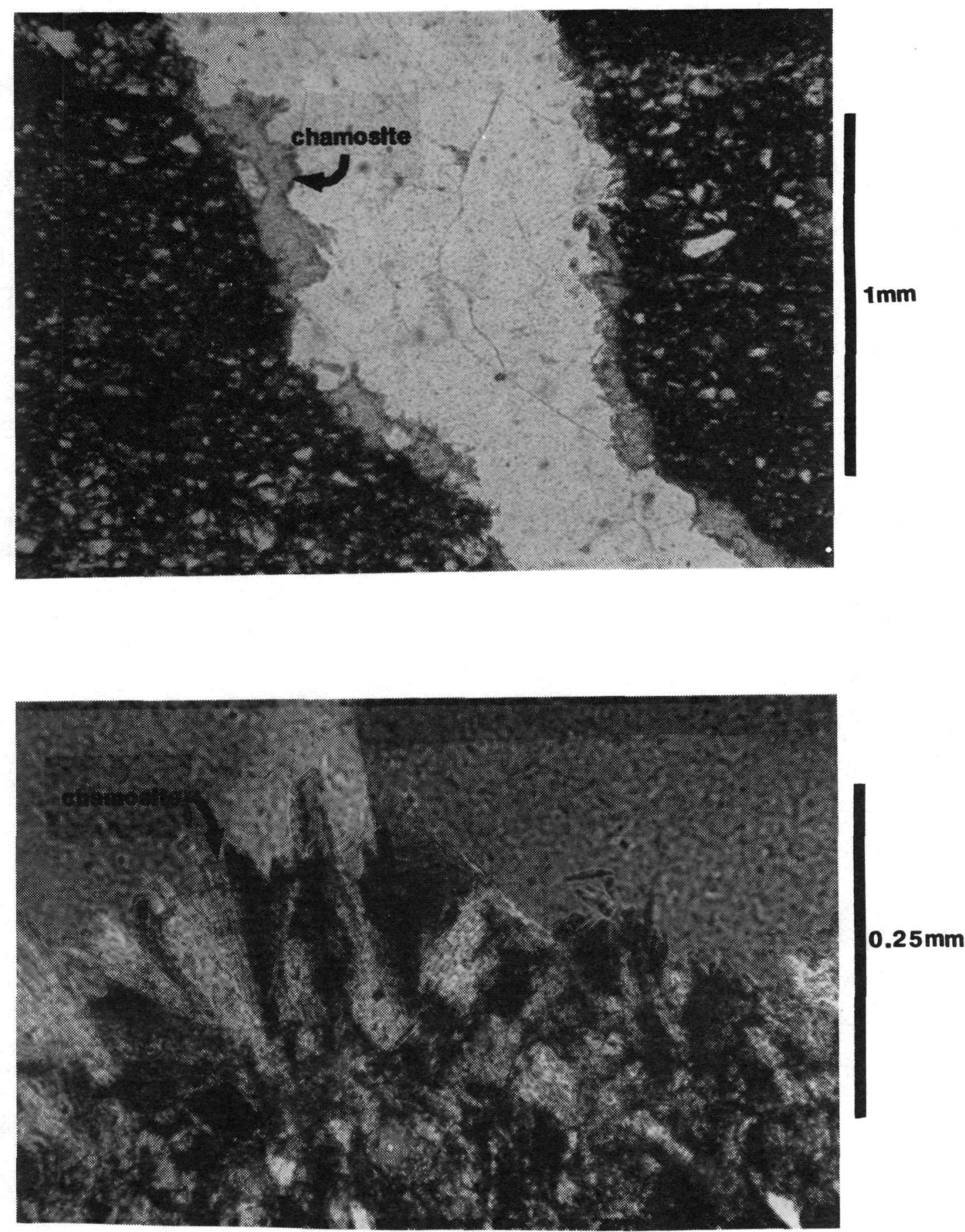

Figure 18. Photomicrographs of Chamosite Lining Fracture Walls at 8123.3 ft in MWX-2; (a) Plane Light; (b) Polarized Light 
Barite is much less commonly observed than calcite, quartz, or dickite. It has only been identified in two Type 1 fractures and only in very minimal amounts in any one fracture. Due to its paucity in fractures where it has been identified and typically microscopic crystalline habitat, the identification of barite requires $x$-ray diffraction, petrographic analysis, or scanning electron microscope work (Figure 19). These analyses were not conducted on every fracture or along the entire length of any one fracture, so the presence of barite may have frequently been overlooked. To date, the age relationship between barite and other mineralization is unclear.

Measured fracture width of these largely vertical and mostly calcitefilled extension fractures ranges from roughly a centimeter to a small fraction of a millimeter. Figure 20 shows the distribution of maximum fracture width with respect to depth. A few of the fractures were split open in the core barrel and occasionally only half of the fracture was retrieved. In most such cases, the fracture mineralization appears subhedral with well formed crystal faces that must have formed in an at least partially unconfined environment. If immeasurable, the width of fractures with subhedral mineralization was arbitrarily listed as $1 \mathrm{~cm}$, which is $1 \mathrm{~mm}$ less than the maximum fracture width measured in the core. As shown in Figure 20 the wider Type 1 extension fractures are concentrated between 6000 and $6100 \mathrm{ft}$, although they also occur sporadically throughout the Mesaverde section. A listing of wider Type 1 extension fractures with subhedral mineralization is given in Table 2. These fractures are most likely open to some extent in the subsurface.

Over 958 of these Type 1 and $S$ extension fractures are found in sandstone and siltstone lithologies in the core (Figure 21). Fracture terminations observed in core are often at lithologic (mostly mudstone) contacts, but also occur within the fractured lithology. Due to the en echelon morphology of these fractures, it's often difficult, and occasionally impossible, to determine if absolute fracture terminations are 


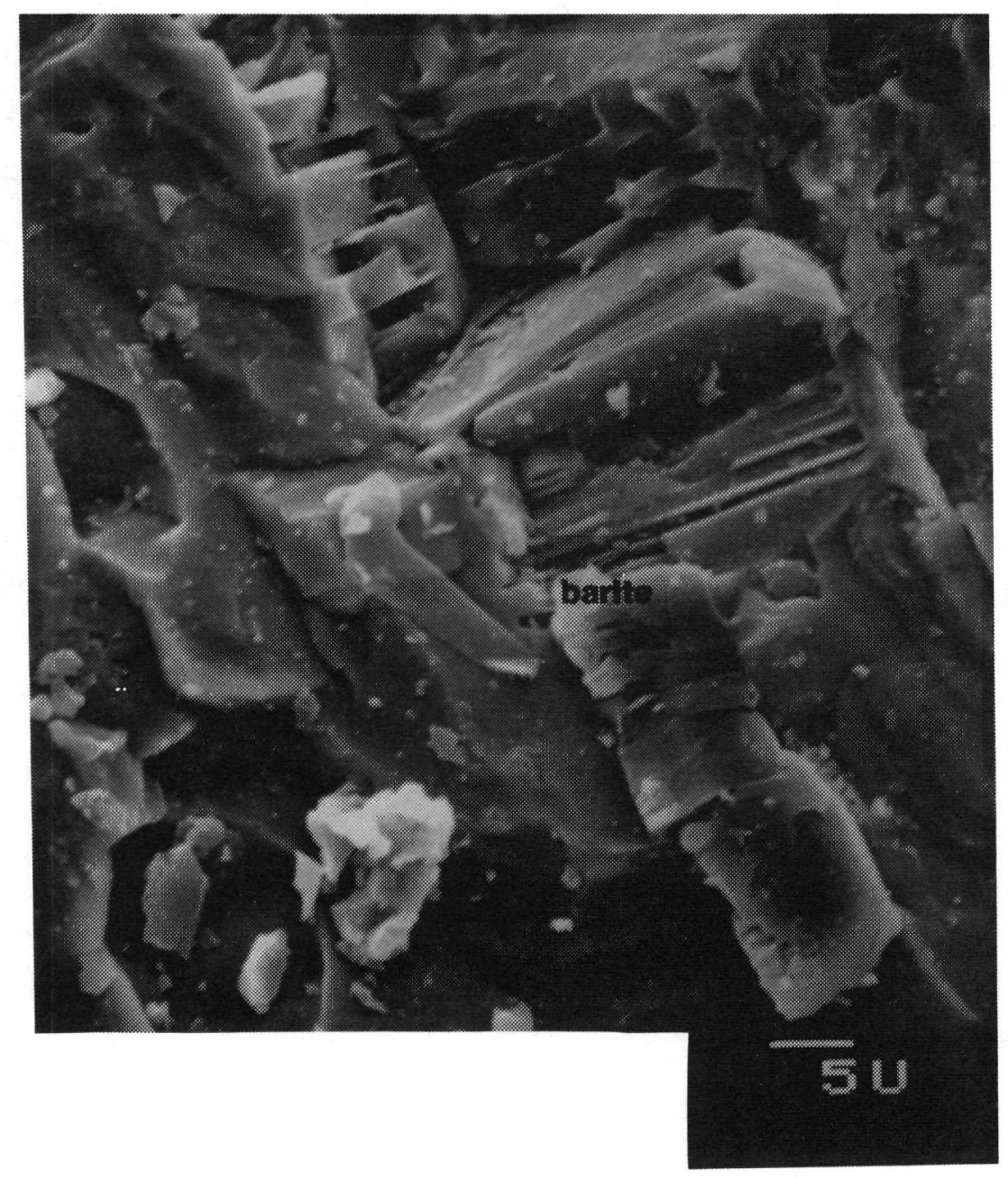

Figure 19. Scanning Electron Micrograph of Barite in Type 1 Fracture at $6047.5 \mathrm{ft}$ in MWX-1 


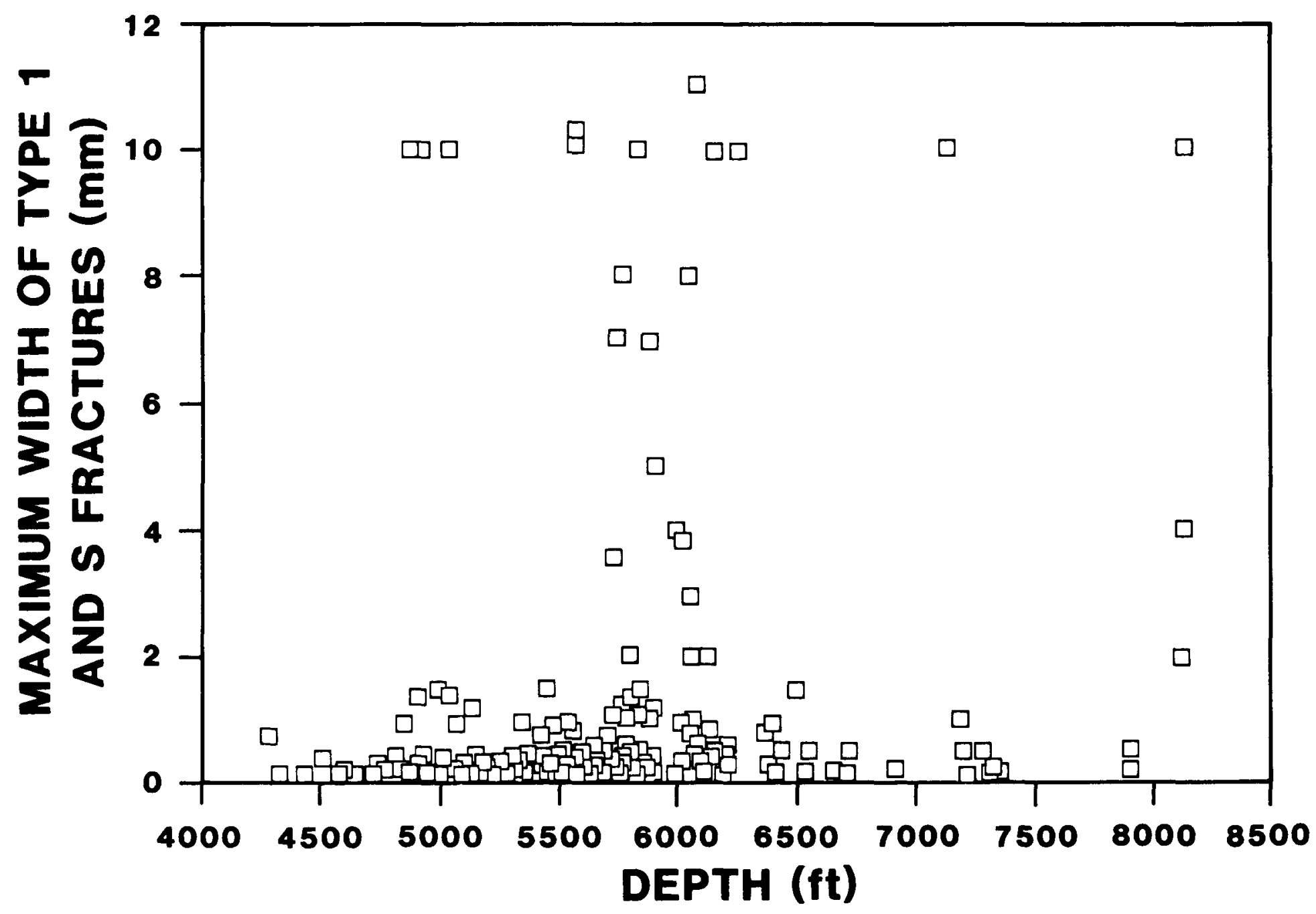

Figure 20. Distribution of Type 1 and $S$ Fracture Widths With Respect to Depth; Core Data From all Three MWX Wells 
Table 2

Type 1 and S Fractures With Subhedral Mineralization

\begin{tabular}{|c|c|c|c|c|}
\hline We11 & $\begin{array}{l}\text { Depth of Top of } \\
\text { Fracture }(f t)\end{array}$ & $\begin{array}{l}\text { Fracture Height } \\
\text { in Core ( } f t)\end{array}$ & $\begin{array}{r}\text { Maximum } \\
\text { in }\end{array}$ & $\begin{array}{l}\text { Fracture Width } \\
\text { Core (mm) }\end{array}$ \\
\hline \multirow[t]{12}{*}{ MWX-1 } & 4877.3 & 1.0 & & $10.0 *$ \\
\hline & 4904.6 & 1.6 & & 1.4 \\
\hline & 4908.0 & 1.0 & & 10.0 \\
\hline & 5016.4 & 3.5 & & $10.0 *$ \\
\hline & 5730.4 & 6.0 & & 3.6 \\
\hline & 5863.9 & 1.8 & & 7.0 \\
\hline & 5866.6 & 4.2 & & 7.0 \\
\hline & 5890.4 & 1.0 & & 4.0 \\
\hline & 6007.7 & 2.8 & & 3.8 \\
\hline & 6033.0 & 1.1 & & 3.0 \\
\hline & 6075.7 & 1.4 & & 11.0 \\
\hline & 6249.2 & 1.3 & & $10.0 *$ \\
\hline \multirow[t]{12}{*}{ MWX-2 } & 5567.0 & 0.6 & & $10.0 x$ \\
\hline & 5568.0 & 4.0 & & $10.0 *$ \\
\hline & 5743.3 & 3.5 & & 7.0 \\
\hline & 5750.4 & 1.8 & & 1.2 \\
\hline & 5761.5 & 3.5 & & 8.0 \\
\hline & 5779.6 & 2.7 & & 2.0 \\
\hline & 5793.6 & 2.1 & & 1.2 \\
\hline & 5826.2 & 2.7 & & 1.5 \\
\hline & 7122.2 & 4.0 & & $10.0 *$ \\
\hline & 7181.1 & 1.7 & & 1.0 \\
\hline & 8123.3 & 0.2 & & 4.0 \\
\hline & 8124.2 & 0.5 & & $10.0 *$ \\
\hline MWX - 3 & 5809.5 & 0.3 & & $10.0 *$ \\
\hline
\end{tabular}




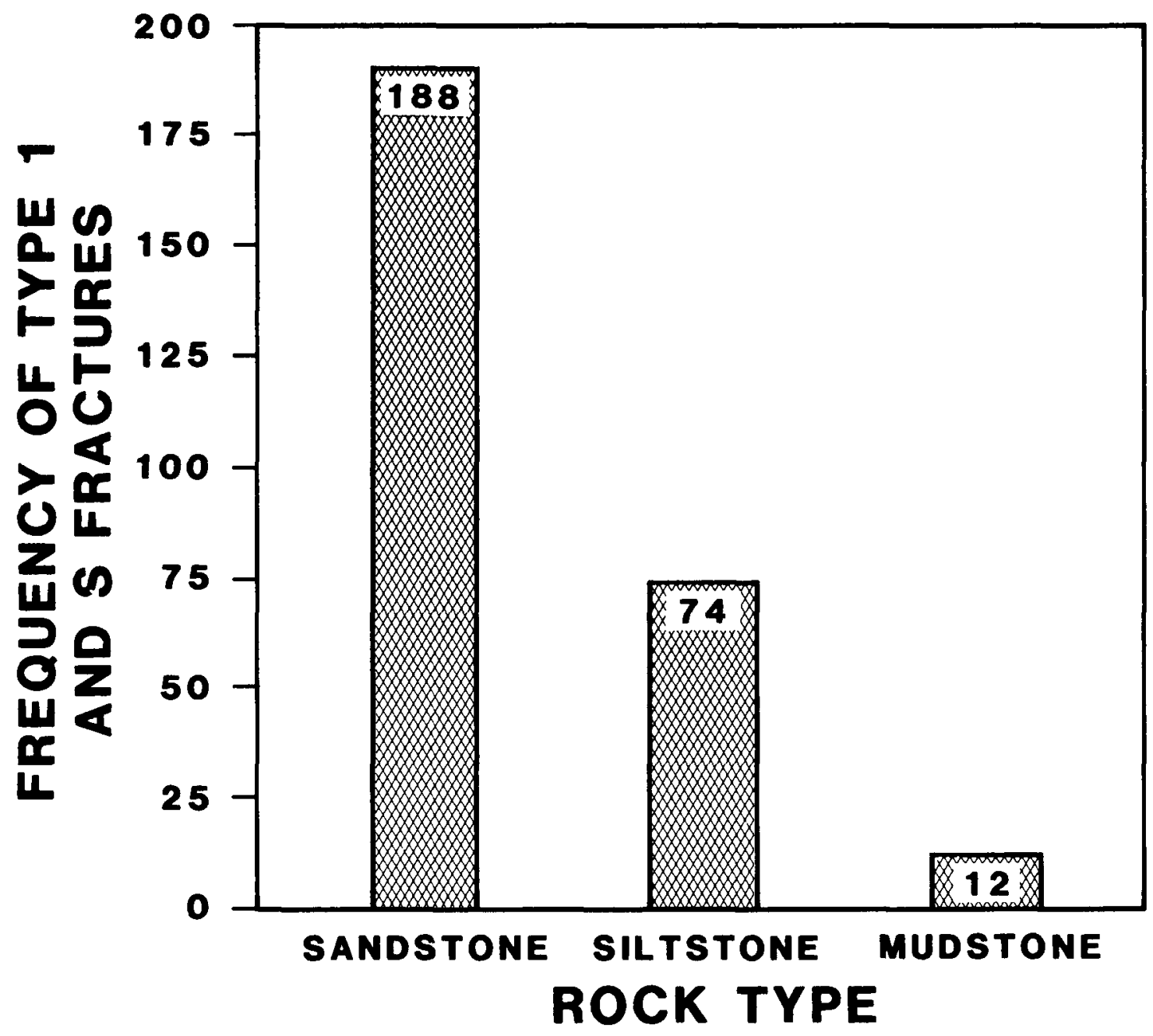

Figure 21. Frequency of Type 1 and Type S Fractures in Three Different Rock Types; Core Data From all Three MWX Wells 
observed in the 4-in.-diameter core or if terminations of only a segment of a much larger fracture are observed in the core. Abrupt terminations of these Type 1 extension fractures at mudstone contacts (as shown in Figure 22), coupled with the very rare occurrence of these fractures in mudstone 1ithologies, suggest that the terminations at mudstone contacts are absolute fracture terminations.

b. "Frac Blast" Fractures (Type 8)

Type 8 or "frac blast" fractures are the second most common subgroup of extension fractures detected in MWX core. Figures 23 and 24 show photographs of typical "frac blast" or Type 8 extension fractures. They appear to have imparted an exploded rock texture to the core, hence the informal name "frac blast." The fracture planes range from undulatory to planar and frequently are coincident with syndepositional sedimentary structures or bedding planes. Measured fracture dips range from horizontal to vertical, and fracture mineralization always includes dickite. In some intervals the Type 8 fractures are parallel to each other, and in other intervals, they are mutually perpendicular to each other. There are no oriented core data available for the interval of core where these "frac blast" fractures were detected.

About 61 "frac blast" fractures were detected; all between $6080 \mathrm{ft}$ and $6315 \mathrm{ft}$ in MWX-1. Figure 25 shows the distribution of these Type 8 extension fractures with depth. The upper coastal interval where Type 8 fractures were detected in MWX-1 was not cored in either of the other two MWX wells. The "frac blast" fractures are highly concentrated between approximately 6129 and $6200 \mathrm{ft}$, and they generally occur in clusters within core intervals 1 to $2 \mathrm{ft}$ in length. It is impossible to determine the relationship of numerous, often undulatory fracture strands, varying widely in length, width, strike, and dip within these clusters. Consequently, an arbitrary maximum fracture number of 6 was assigned when six or more fractures or fracture strands were counted. Forty-eight or 80 percent of the "frac blast" fractures occur in these high-density clusters. 

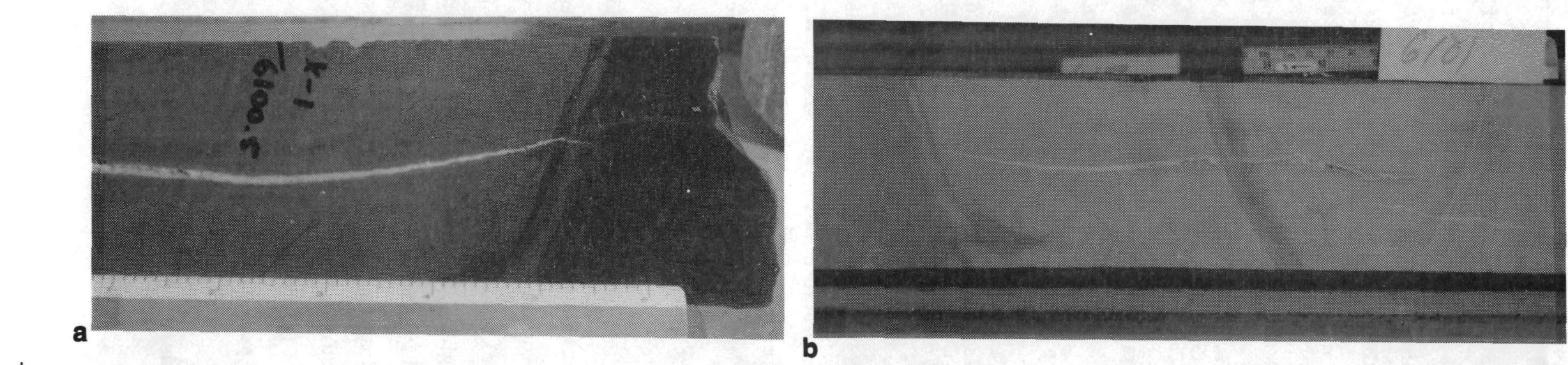

$\stackrel{\dot{w}}{\omega}$
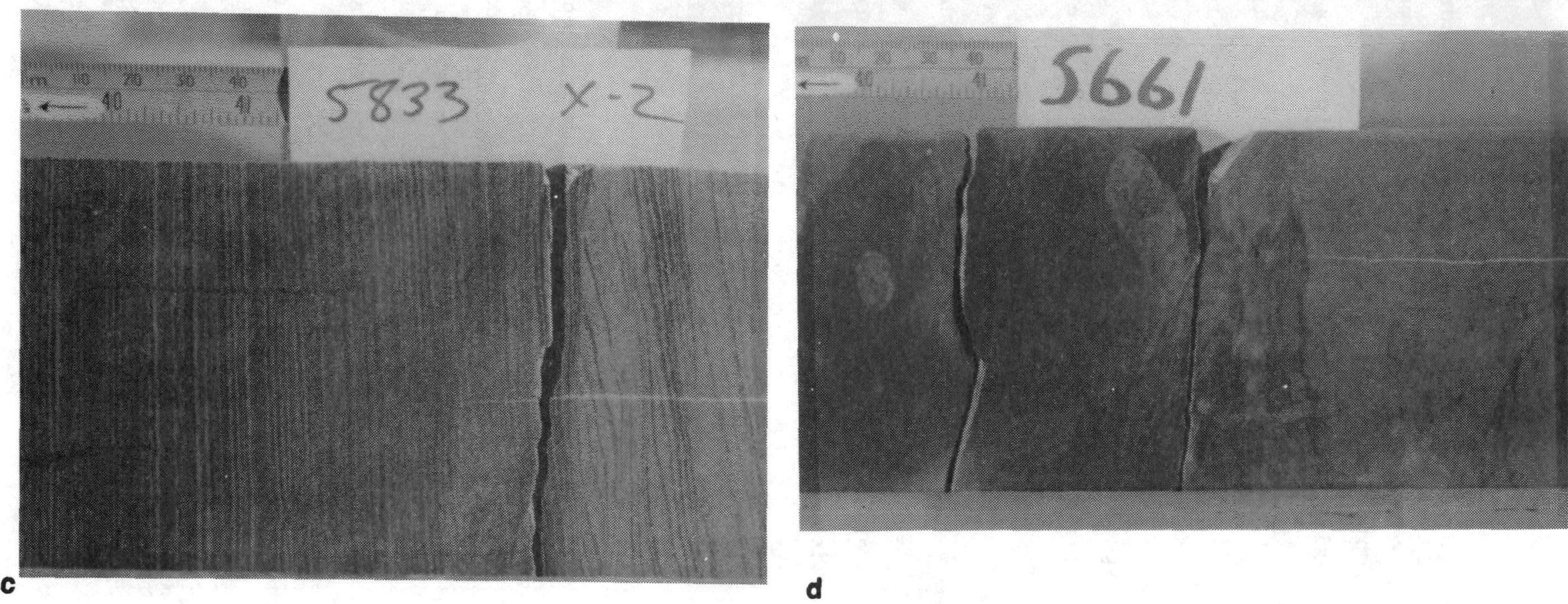

Figure 22. Photographs of Type 1 Fracture Terminations at Mudstone Contacts; (a) $\sim 6100.5 \mathrm{ft}$ in MWX-1; (b) $-6101 \mathrm{ft}$ in MWX-1; (c) $-5833 \mathrm{ft}$ in MWX-2; (d) $25661 \mathrm{ft}$ in MWX-1 

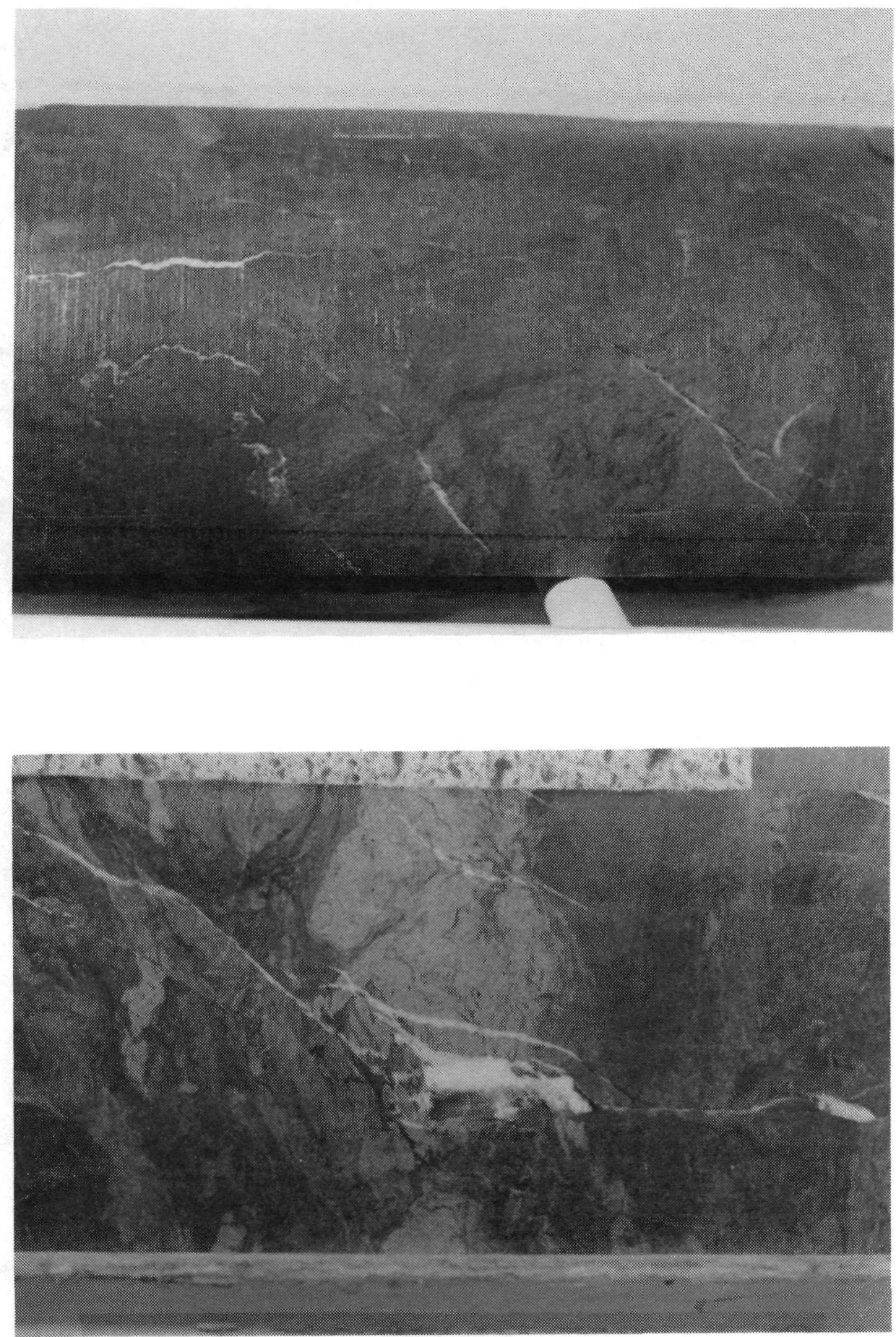

Figure 23. Examples of Type 8 "Frac Blast" Fractures in Core; Both Photos From $-6135 \mathrm{ft}$ in MWX-1 

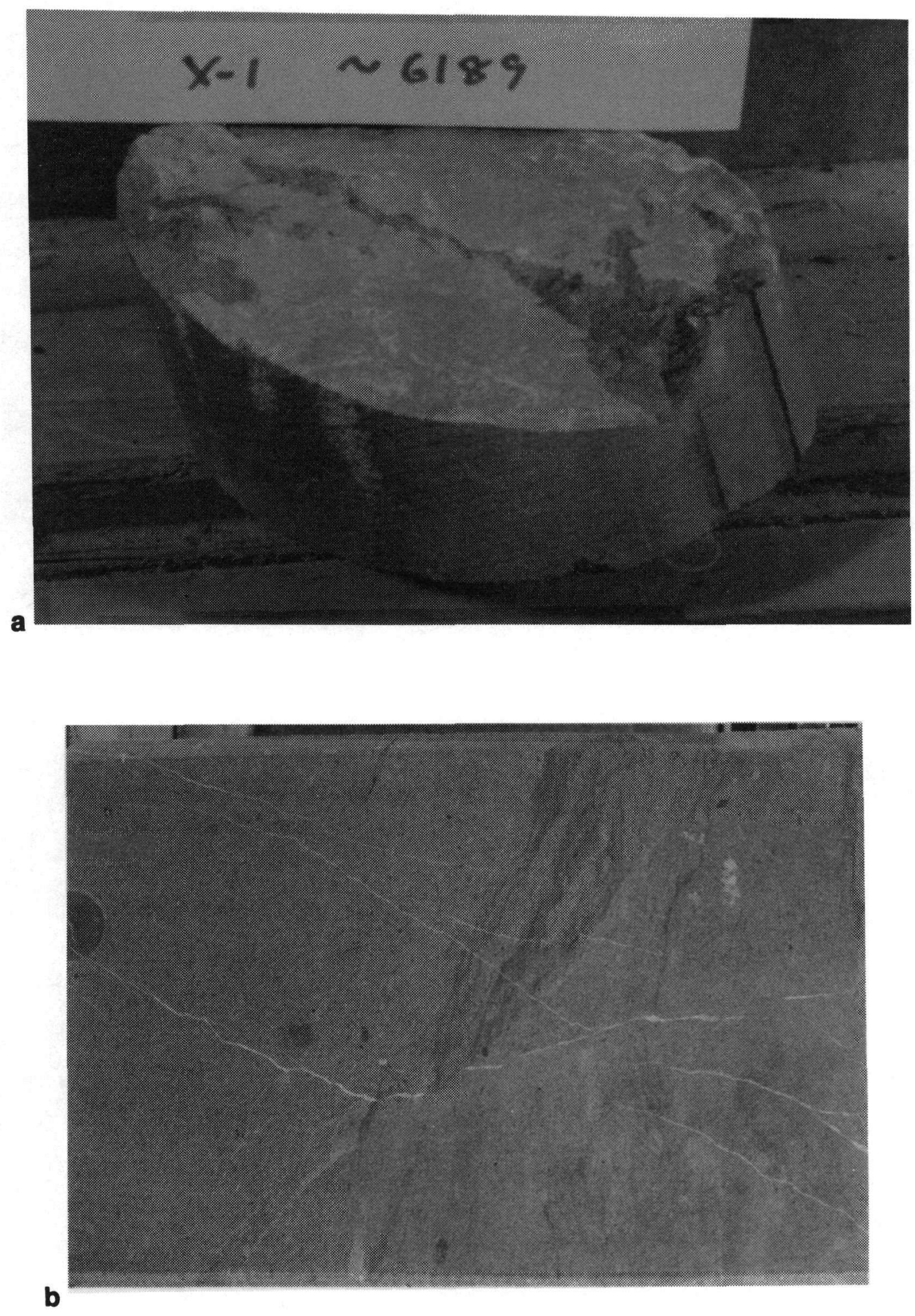

Figure 24. Examples of Type 8 "Frac Blast" Fractures in Core; (a) $\sim 6189 \mathrm{ft}$ in MWX-1; (b) $\sim 6198 \mathrm{ft}$ in MWX-1 
Dickite is the predominant mineralization of the "frac blast" fractures. Dickite has also been detected in other types of fractures within the "frac blast" interval and slightly beyond it. Calcite is also commonly present in Type 8 fractures, and lesser amounts of quartz and barite have been identified microscopically or in $x$-ray. Figure 26 shows photomicrographs of a Type 8 fracture with quartz and calcite mineralization as well as dickite.

The maximum fracture widths of individual "frac blast" fractures are plotted with respect to depth in Figure 27. For "frac blast" clusters, only the maximum width of the widest fracture within the cluster is plotted in Figure 27. The measured fracture width ranges from a small fraction of a millimeter to 6 millimeters in the core. Blue epoxy impregnation of thin sections and SEM analysis reveal the presence of microporosity within dickite mineralization (Figure 28).

Type 8 fractures occur most commonly in muddy siltstone or interlaminated and mixed mudstone, siltstone, and sandstone. In contrast to Type 1 extension fractures, they are infrequently observed in clean sandstones and siltstones. However, clean sandstones and siltstones are less common in the "frac blast" interval than in some other intervals of the core. (Note the gamma log response in the "frac blast" interval marked in Figure 29.) The "frac blast" clusters and individual fractures terminate within the fractured lithology and at mudstone contacts in the core. Since these fractures occur frequently in mudstone lithologies, the occasional termination at a mudstone contact may be coincidental, or represent only an interruption in the fracturing that continues beyond the core diameter.

\section{c. Horizontal Fractures (Type 7)}

This subgroup of extension fractures at MWX is comprised of 27 horizontal to subhorizontal, generally planar, mostly calcite-mineralized fractures. Fractures in this subgroup of extension fractures are indistinguishable from horizontal to subhorizontal "frac blast" fractures 

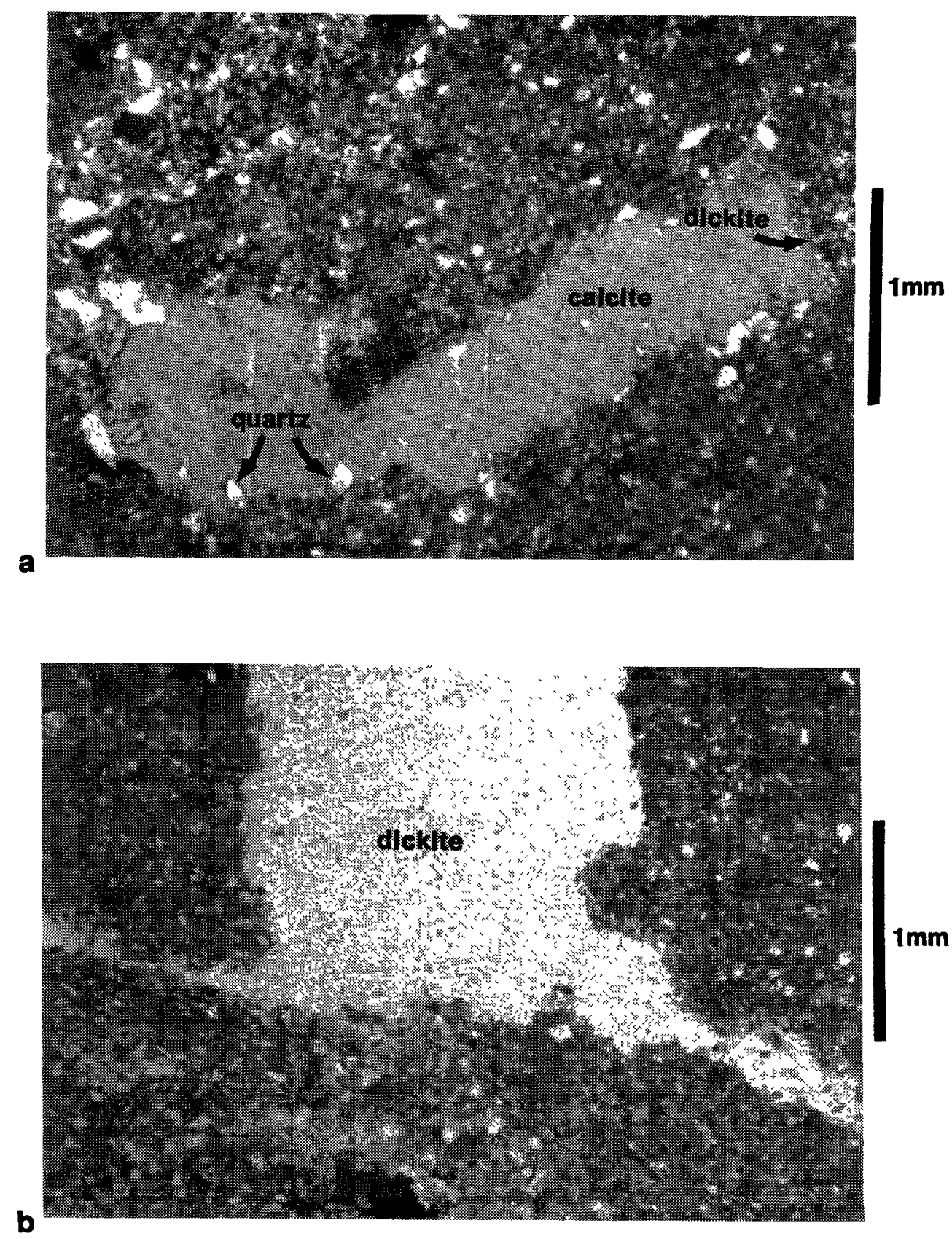

Figure 26. Photomicrographs of Type 8 Fracture Mineralization; (a) Calcite and Quartz in Fracture at $6147.5 \mathrm{ft}$ in MWX-1 (Polarized Light); (b) Dickite in Fracture at $6147.5 \mathrm{ft}$ in MWX-1 (Plane Light); 


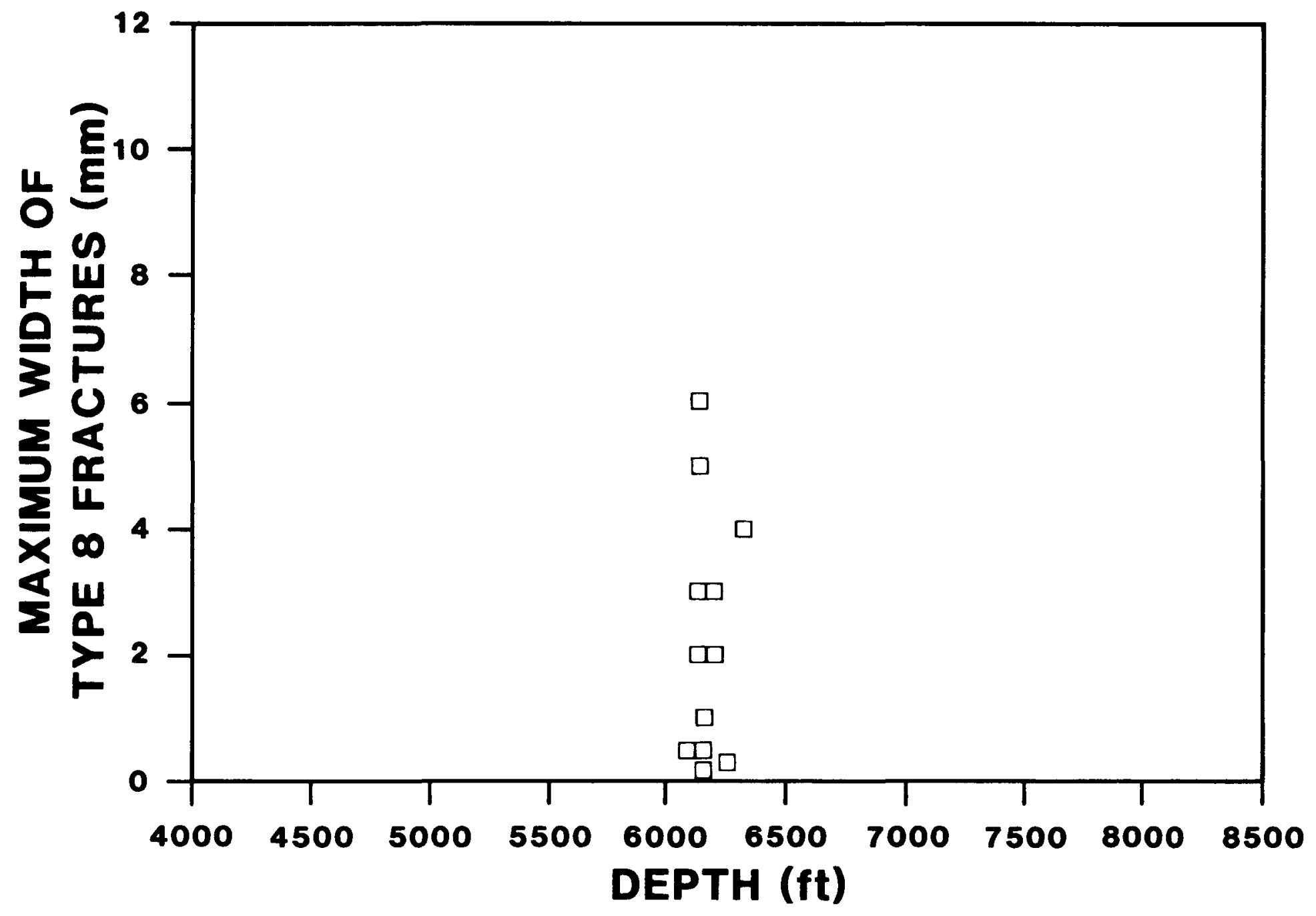

Figure 27. Distribution of Type 8 Fracture Widths With Respect to Depth; Core Data From MWX-1 and MWX-2 

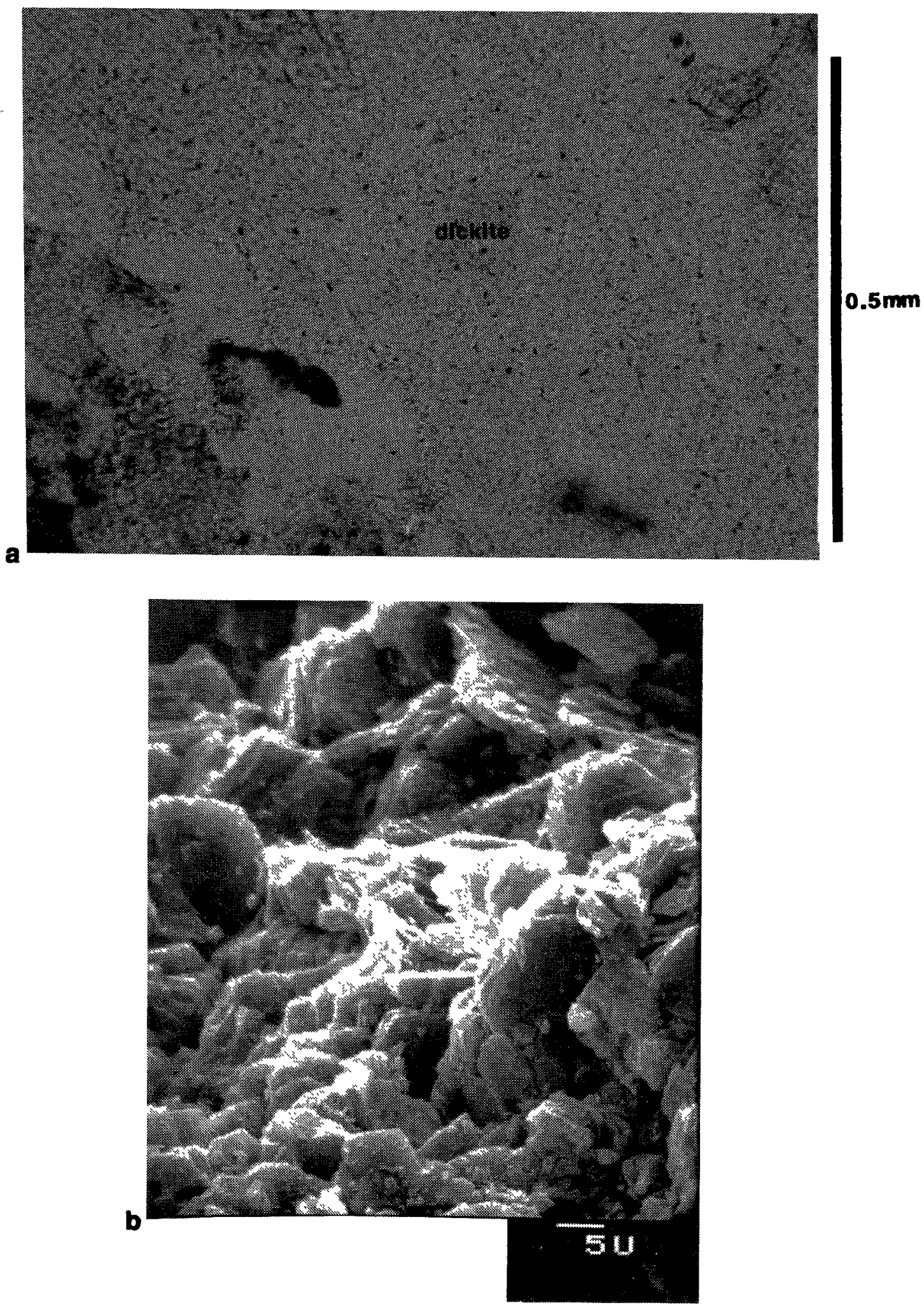

Figure 28. Photomicrographs of Dickite Mineralization

( $6047 \mathrm{ft}, \mathrm{MWX}-1)$; (a) Thinsection of Dickite, MicroPorosity is Darker in Color; (b) SEM Photo of Dickite 


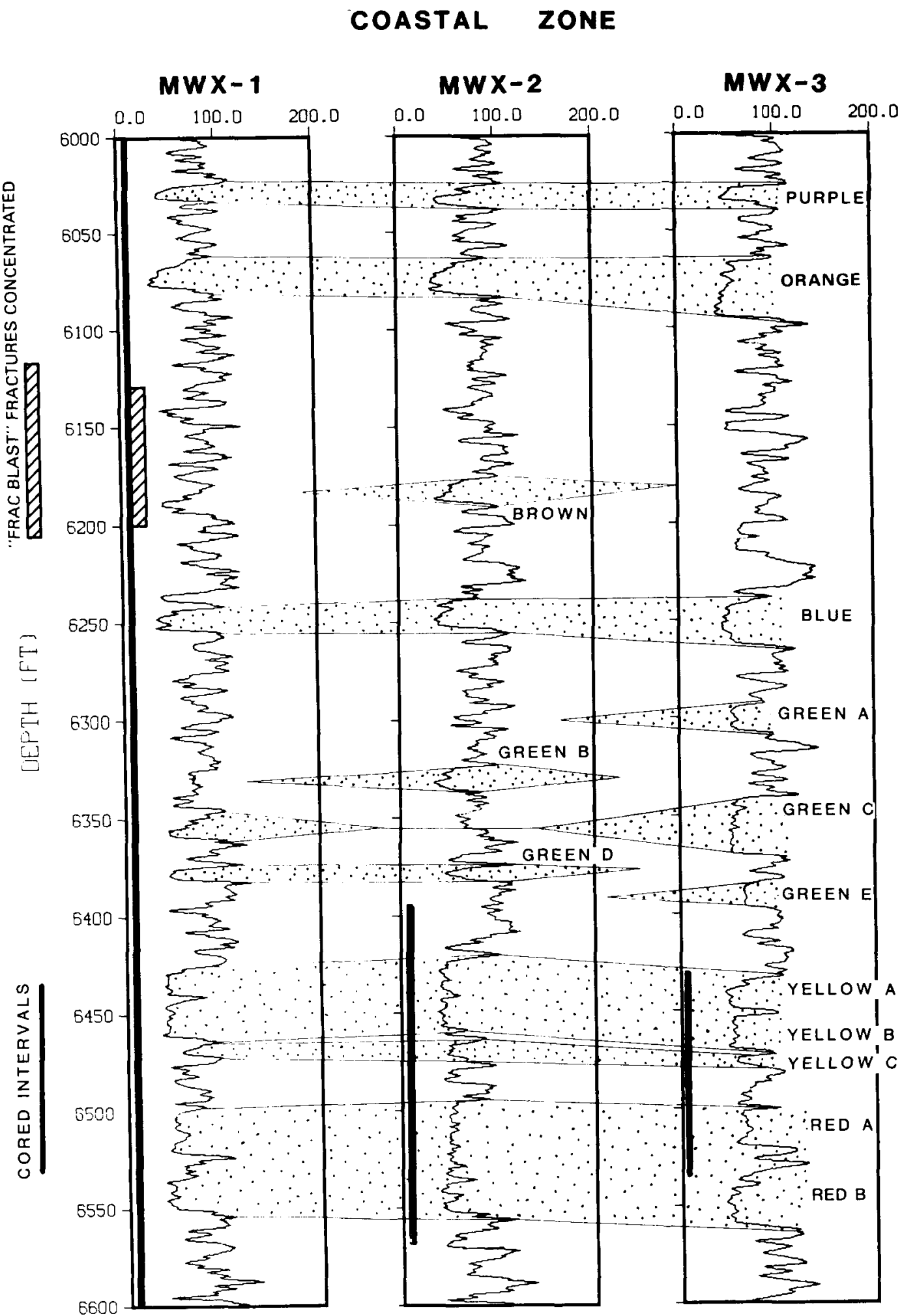

Figure 29. Gamma Log Correlations Through the Coastal Zone at the MWX Site 
based on fracture morphology alone. Therefore, the presence or absence of dickite mineralization was used as a criterion to distinguish between the two groups of fractures. There were no horizontal to subhorizontal extension fractures in the "frac blast" interval ( 6080 to $6315 \mathrm{ft}$ ) without dickite mineralization; therefore, none of the horizontal fractures in this interval were included in the Type 7 subgroup. The frequency distribution of the Type 7 subgroup (shown in Figure 30) appears to show concentrations in the lower fluvial interval and in the lower coastal/upper paludal interval.

The Type 7 subgroup is comprised of fractures that range from horizontal to $40^{\circ}$ in dip (Figure 31). Fracture planes vary from planar to irregular and frequently are coincident with bedding planes and more horizontal reservoir heterogeneities. Although Type 7 fractures occur in all lithologies, 85 percent of those detected are in the MWX sandstones and siltstones.

Like all extension fractures previously discussed, Type 7 fractures often appear stranded or branched (Figure 32). As is the case with any stranded fracture, the relationship between individual fracture strands is often not verifiable in core. If the individual fracture strands were spaced $<0.1 \mathrm{ft}$ apart or within $0.2 \mathrm{ft}$ of a main fracture strand, they were arbitrarily all considered part of the same fracture. Most often one strand appears to be the main fracture strand as it is wider and more continuous through the core. There are no orientation data available for any Type 7 fractures. They either did not occur in oriented core, or were too close to horizontal, or too irregular to make reasonably accurate strike and dip measurements.

As stated earlier, by definition none of the Type 7 fractures were mineralized with dickite. Fracture mineralization includes calcite, quartz, and barite. The most common mineralization is calcite or a combination of calcite and quartz. Quartz alone was detected in one Type 7 fracture in the vicinity of $5567 \mathrm{ft}$ in MWX-2. On1y two Type 7 fractures 

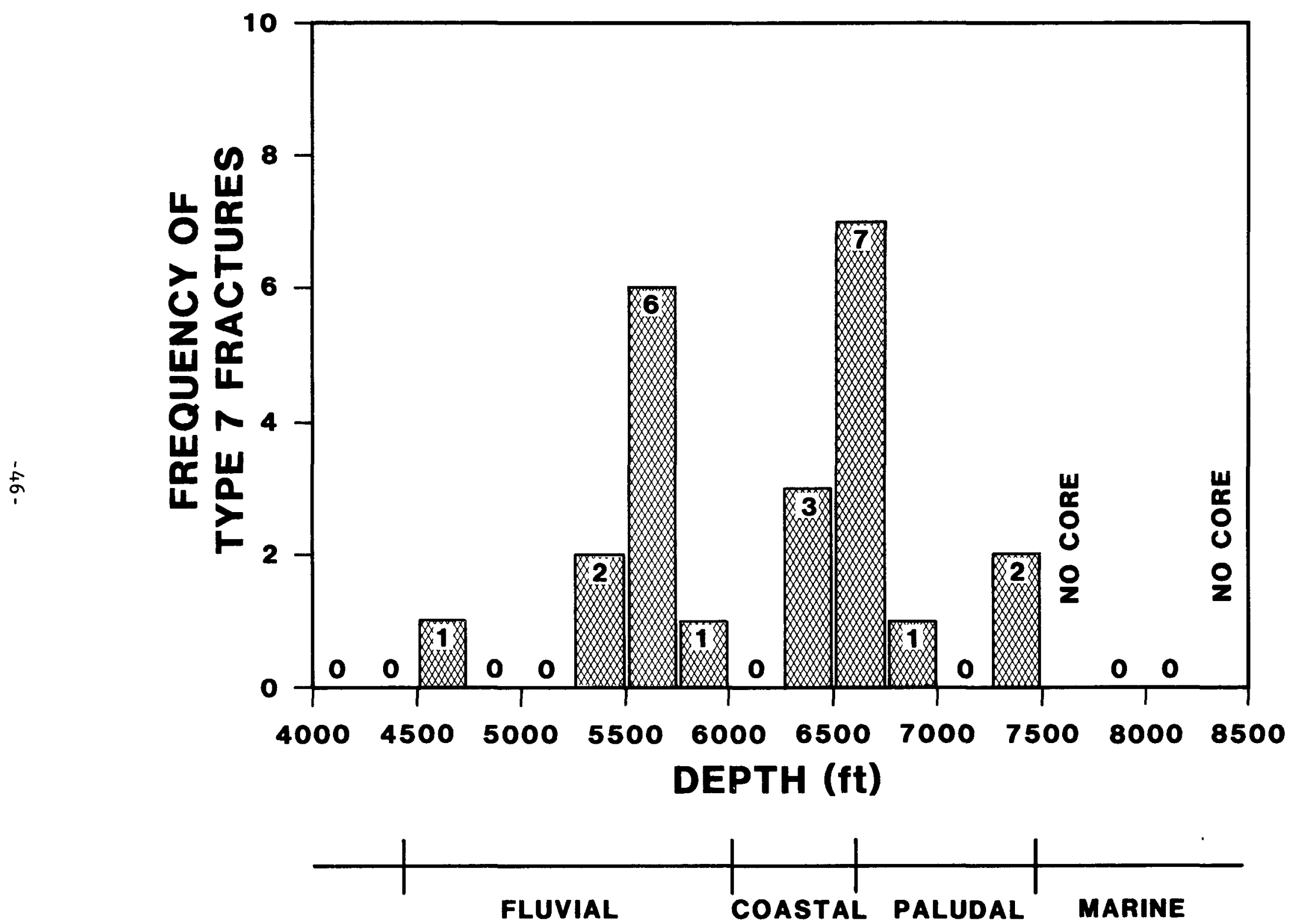

Figure 30. Frequency Distribution of Type 7 Fractures With Respect to Depth; Core Data From MWX-1 and MWX-2 


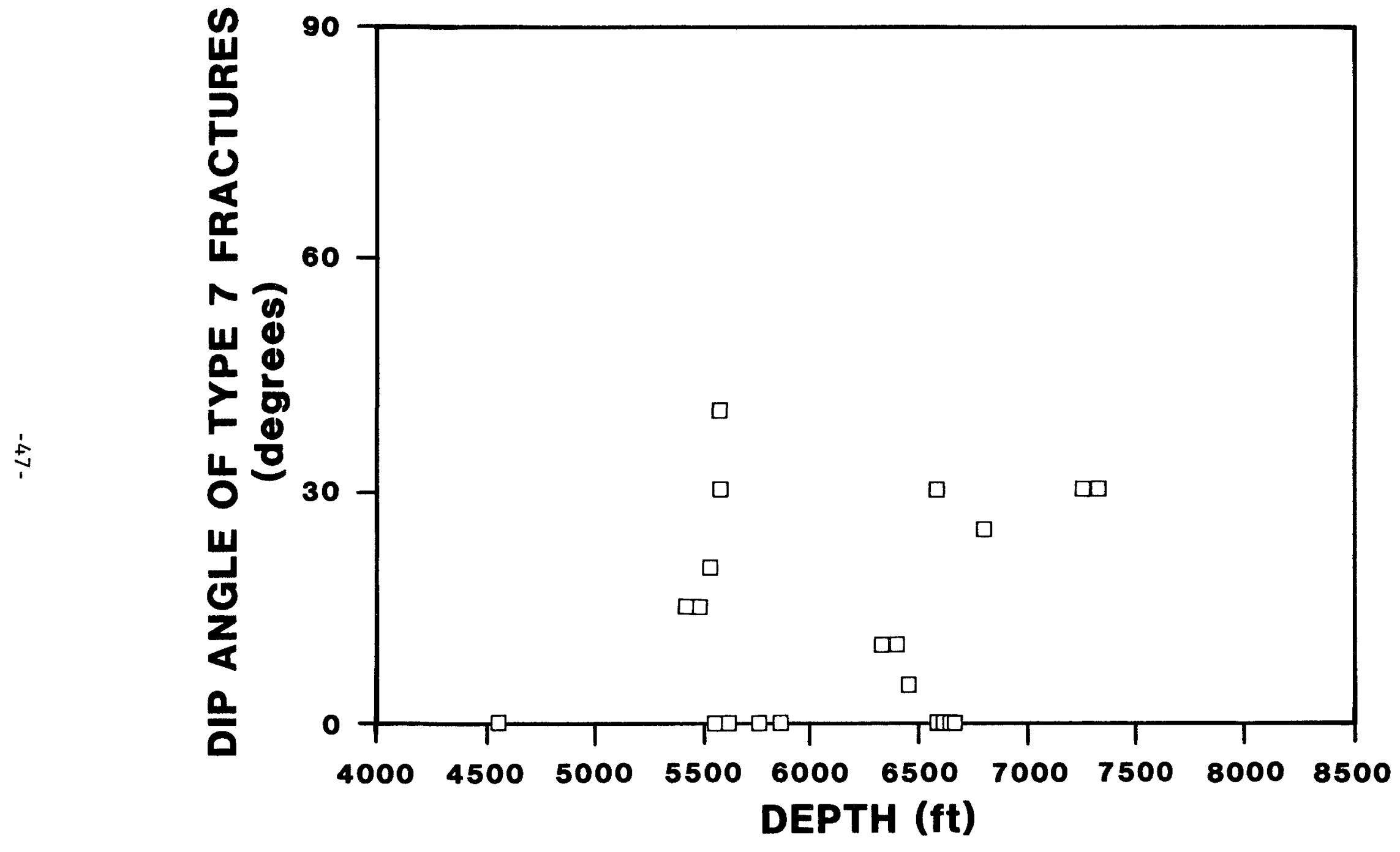

Figure 31. Distribution of Type 7 Fracture Dip Angles With Respect to Depth; Core Data From all Three MWX Wells 


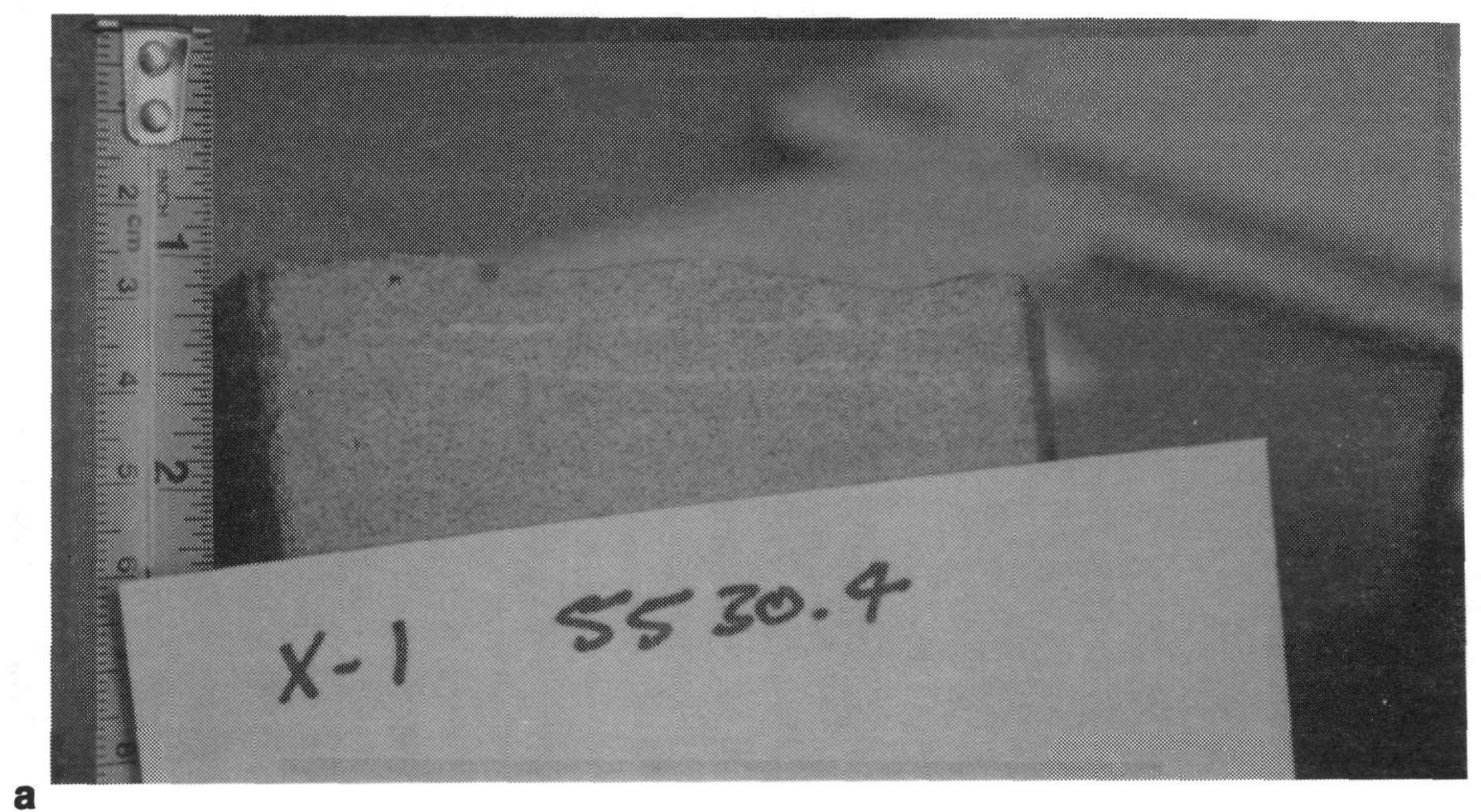

a

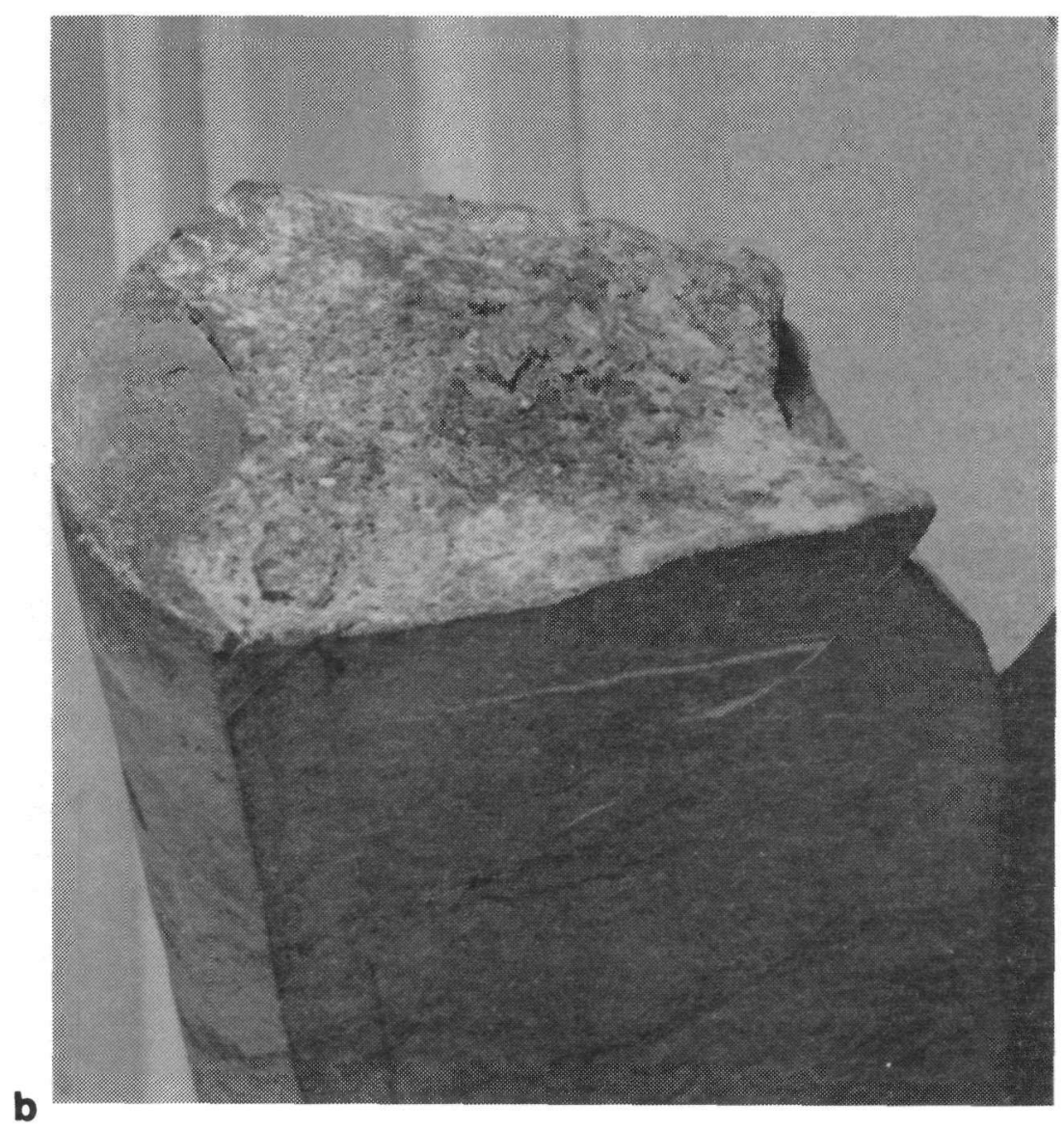

Figure 32. Stranded Type 7 Fractures; (a) $5530.4 \mathrm{ft}$, MWX-1; (b) $6661.9 \mathrm{ft}$, MWX-1 
with barite mineralization were identified; they are both in the coastal interval around $6396 \mathrm{ft}$ in MWX-1. Occasionally mineralization appears subhedral suggesting the fractures are partially open in situ. Measurable fracture width varies from a fraction of a millimeter to 5 millimeters (Figure 33).

\section{d. Other Extension Fractures (Type C and Type N)}

In addition to the three main subgroups of extension fractures, there are two types that occur rarely and may or may not be related to the other subgroups. Type $\mathrm{C}$ extension fractures are mineralized coal cleats. There are roughly four small ( $\leq 0.2 \mathrm{ft}$ in length), vertical, calcite-mineralized coal cleats at $6897.4 \mathrm{ft}$ in $\mathrm{MWX}-3$. They all strike $\mathrm{N} 85 \mathrm{~W}$, parallel to most of the oriented Type 1 extension fractures.

Type $\mathrm{N}$ or "contained fractures" are defined as extension fractures contained in a sandstone or siltstone clast encased in mudstone. In the MWX core there are two occurrences of these Type $N$ fractures. The clasts are small enough to be recognized as clasts in the 4-in. core. At $5388.9 \mathrm{ft}$ in $\mathrm{MWX}-1$, there are roughly 20 horizontal to subhorizontal fractures in a sandstone clast (approximately $0.3 \mathrm{ft}$ by $0.5 \mathrm{ft}$ in core). In thin section, these calcite-mineralized fractures appear to extend slightly into the encasing mudstone lithology (Figure 34). This suggests that the fracturing occurred after the sandstone clast was in place and probably after the mudstone was lithified. What appears to be a smaller sandstone clast (approximately $0.1 \mathrm{ft}$ by $0.2 \mathrm{ft}$ in core) with four horizontal calcite-filled fractures was intersected at $5693.8 \mathrm{ft}$ in MWX-1 (Figure 35).

\section{SHEAR FRACTURES}

Shear fractures involve movement parallel to the fracture plane, and the fracture walls generally exhibit detectable displacement. At MWX this displacement is in the form of slickensides (friction grooves). The shear fractures in the MWX core have been divided up into five different types. 


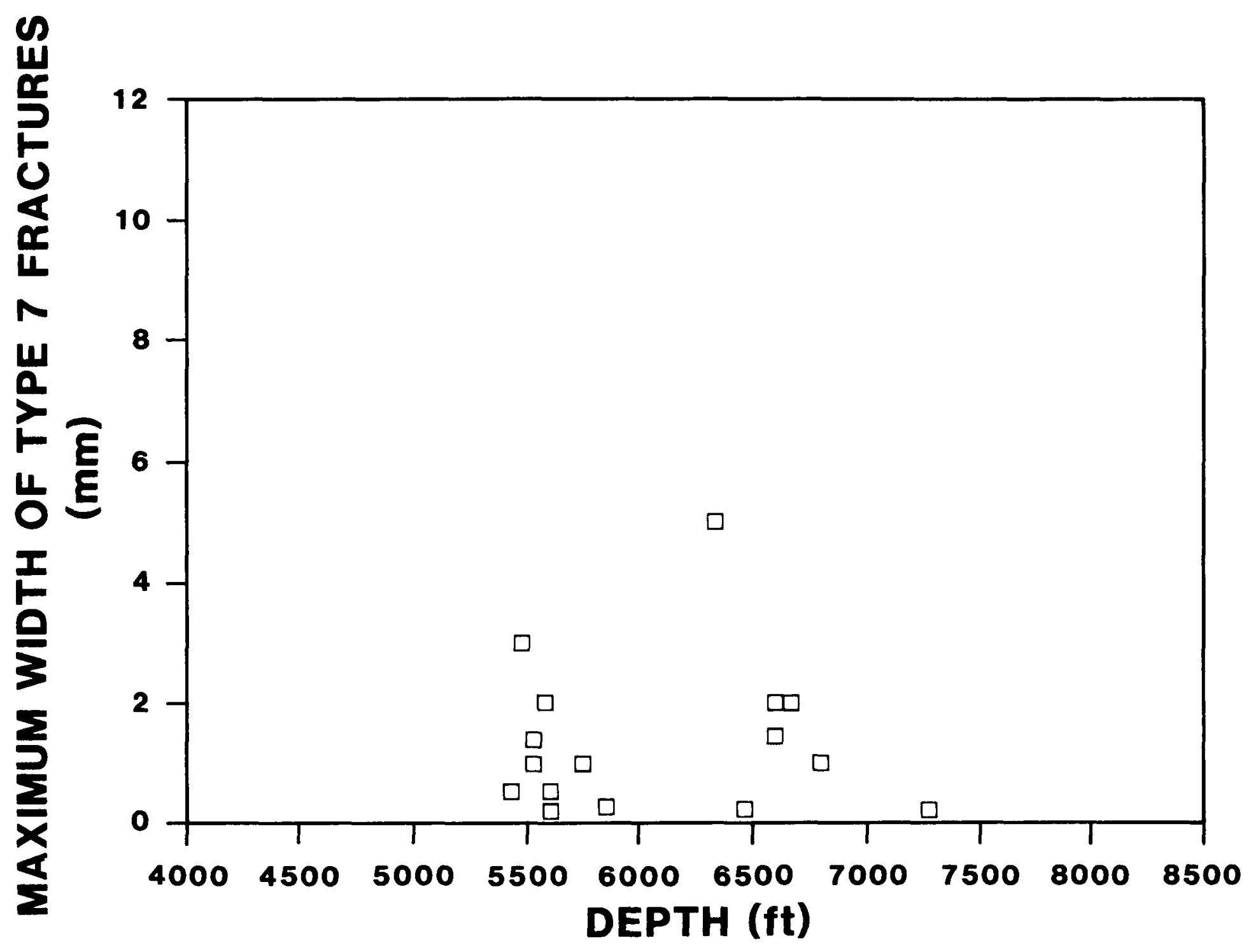

Figure 33. Distribution of Type 7 Fracture Widths With Respect to Depth; Core Data From all Three MWX Wells 

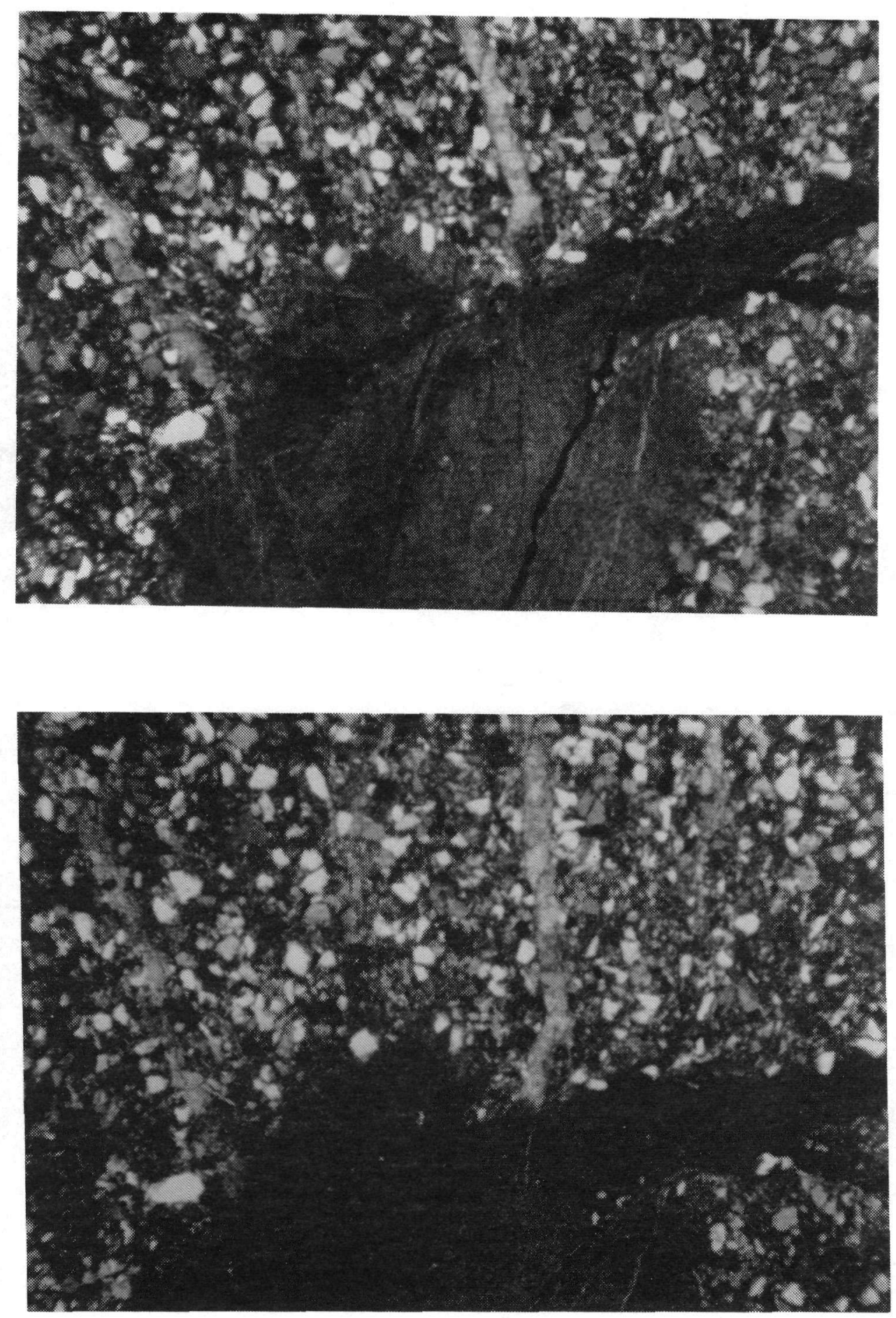

Figure 34. Photomicrographs of Calcite Fractures in a Sandstone Clast Extending into the Encasing Mudstone (5389 ft, MWX-1, polarized light) 


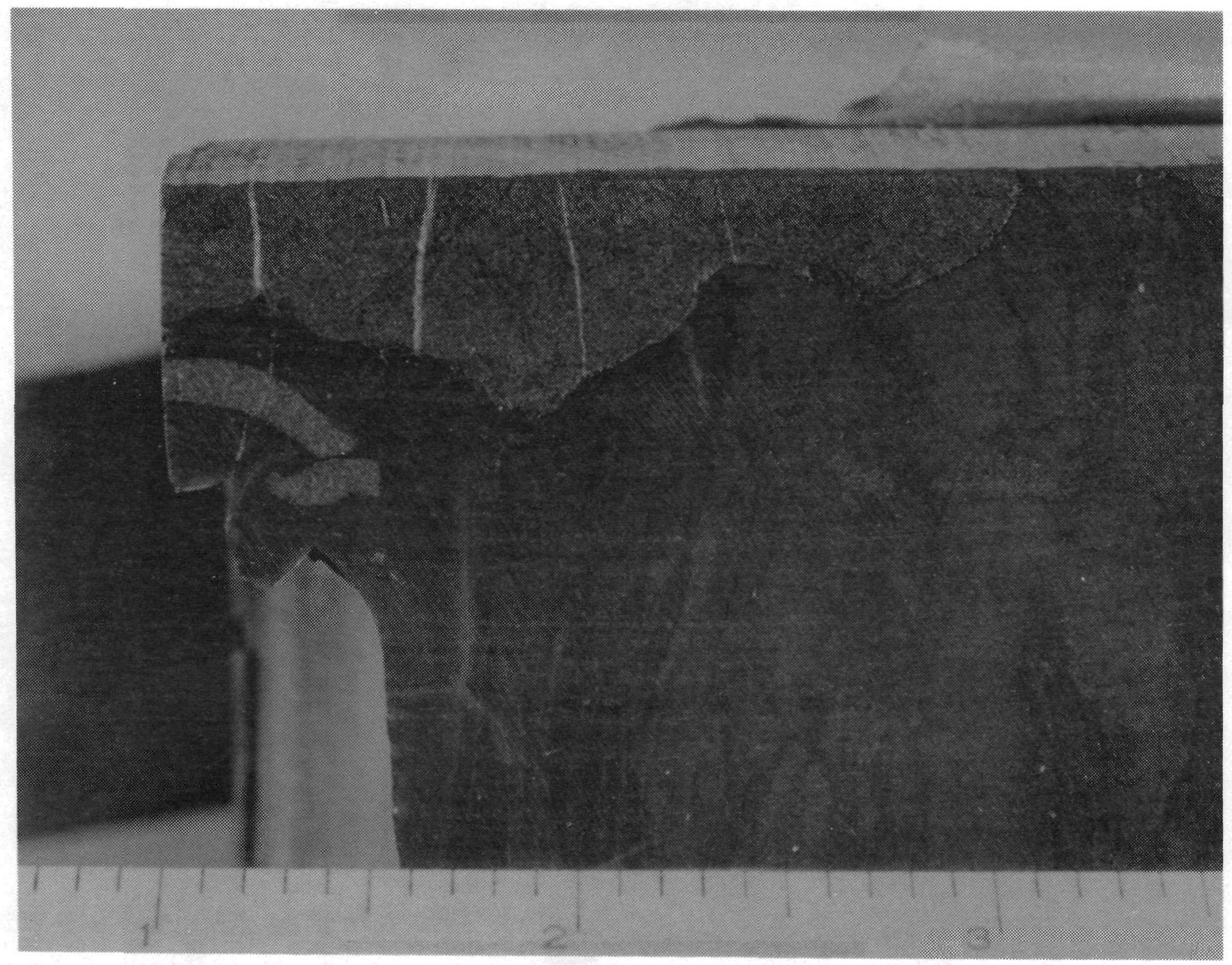

Figure 35. A Fractured Sandstone Clast Encased in Mudstone, Type $\mathrm{N}$; (5693.8 ft, MWX-1) 
Some of these fracture types are distinguished by their host lithology. The shear fractures associated with sandstone and siltstone lithologies include Types 4 and 5. Type 2 fractures are shear fractures confined to carbonaceous mudstone laminations in sandstones and siltstones. Types 3 and 6 fractures are found only in mudstone.

a. Low-Angle Shear Fractures in Sandstone or Siltstone (Type 4)

Al1 low-angle $\left(<50^{\circ}\right)$, slickensided fractures in MWX sandstones and siltstones are included in the Type 4 subgroup. Figure 36 shows photographs of Type 4 fractures detected at MWX. A11 four of the Type 4 fractures were identified at depths in MWX-1 that were not cored in either of the other two MWX wells. Their distribution with depth is shown in Figure 37. Fracture planes range from irregular to planar and from horizontal to $40^{\circ}$ in dip.

The fractures included in this group are mineralized with calcite, quartz, and/or dickite, and mineralization is commonly subhedral in the form of slickencrysts. (Slickencrysts are defined by P. L. Hancock (1985) as mineral fibers or crystals aligned at some small angle to the fracture wall (Figure 38).) Calcite is the predominant mineralization. Quartz and dickite were only detected on one of the four Type 4 fracture planes, where a trace of quartz and an appreciable quantity of dickite showed up in an $x$ ray of the fracture mineralization at $6712.4 \mathrm{ft}$ in MWX-1. Measured fracture width data is not available for these fractures, as all Type 4 fractures separated in the core barrel. Mineralization is a couple of millimeters thick in places, and the presence of subhedral mineralization suggests that in places the fractures may be open at depth.

Slickensides extend across the entire exposed Type 4 fracture plane, and except in one location, the fracture planes extend across the entire core break. At $6712.4 \mathrm{ft}$ the fracture appears to terminate abruptly in one area within the core (Figure 39 ). 

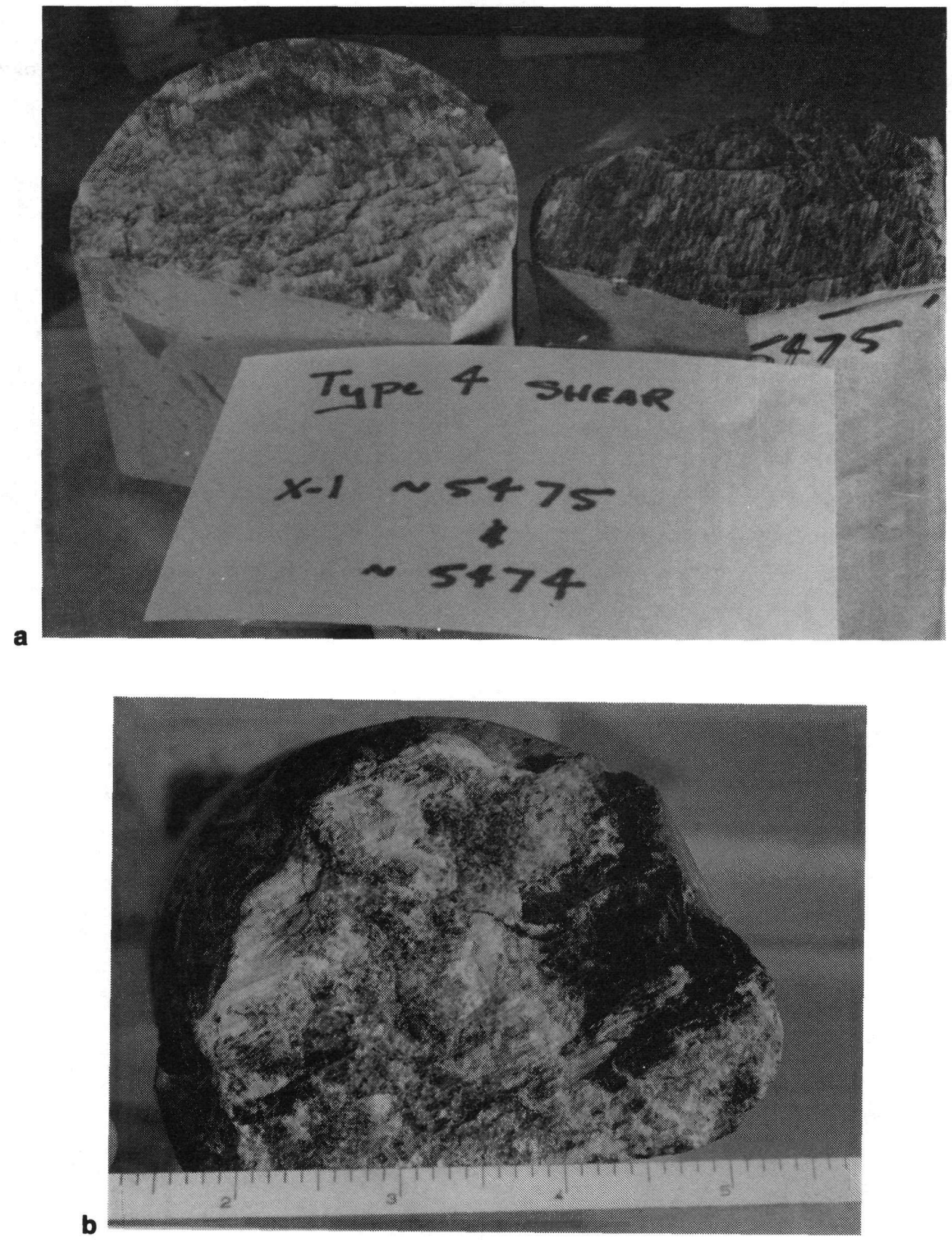

Figure 36. Type 4 Fractures in Core; (a) $5474 \mathrm{ft}$ and $5475 \mathrm{ft}$, MWX-1; (b) $6662.8 \mathrm{ft}, \mathrm{MWX}-1$ 

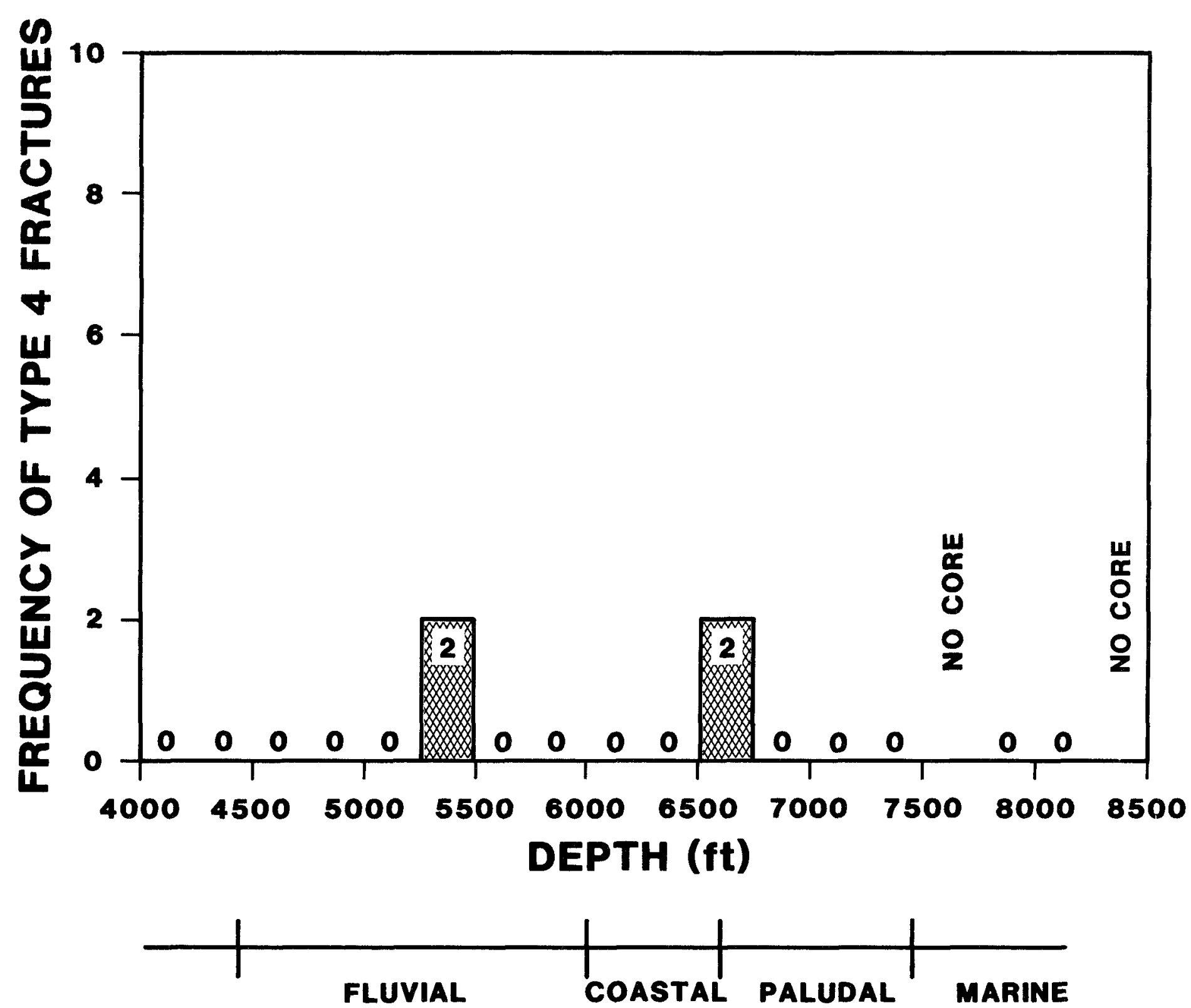

Figure 37. Frequency Distribution of Type 4 Fractures With Respect to Depth; Core Data From MWX-1 and MWX-2 


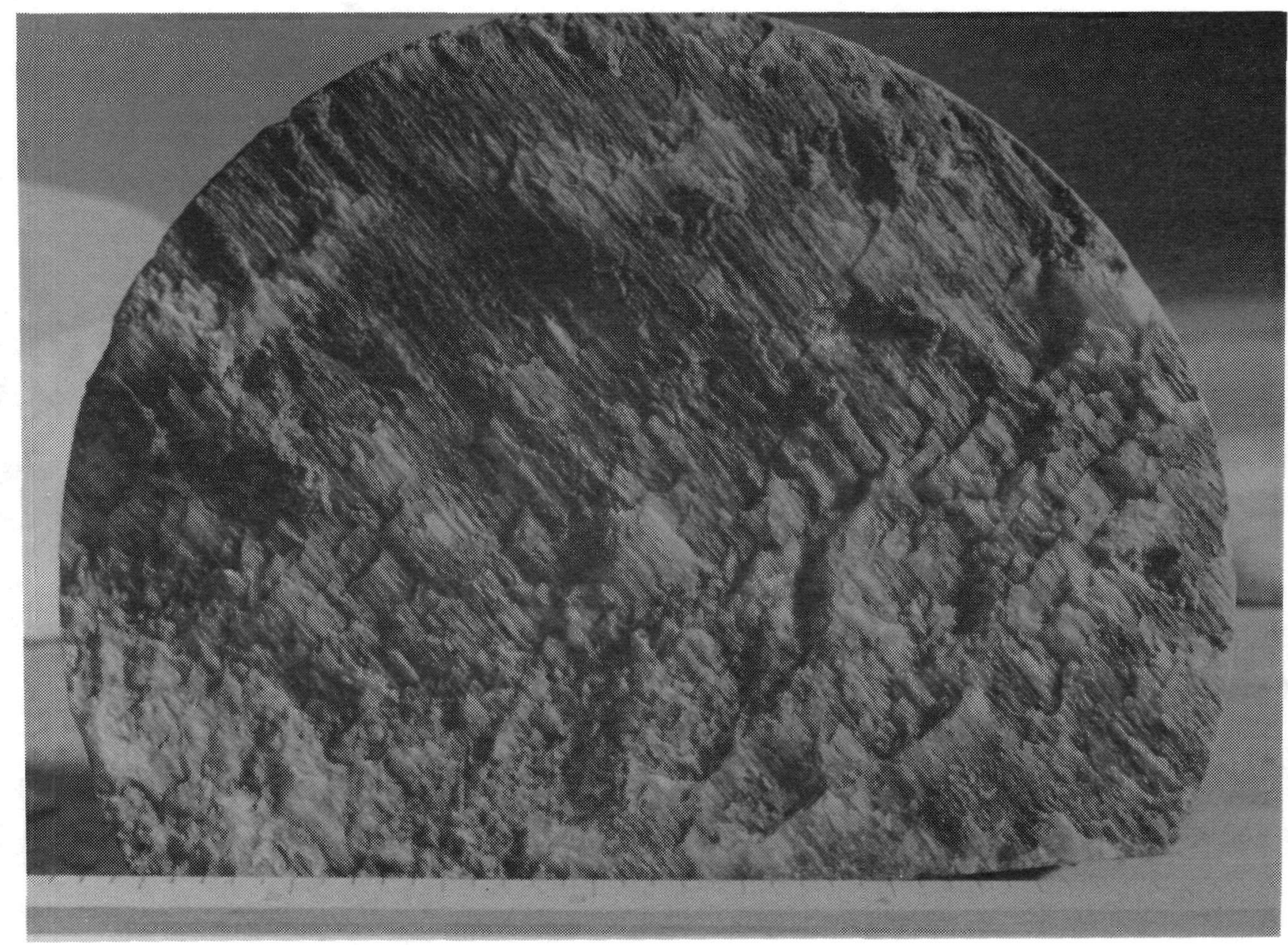

Figure 38. Calcite Slickencrysts on a Type 4 Fracture, $5474 \mathrm{ft}, \mathrm{MWX}-1$ 


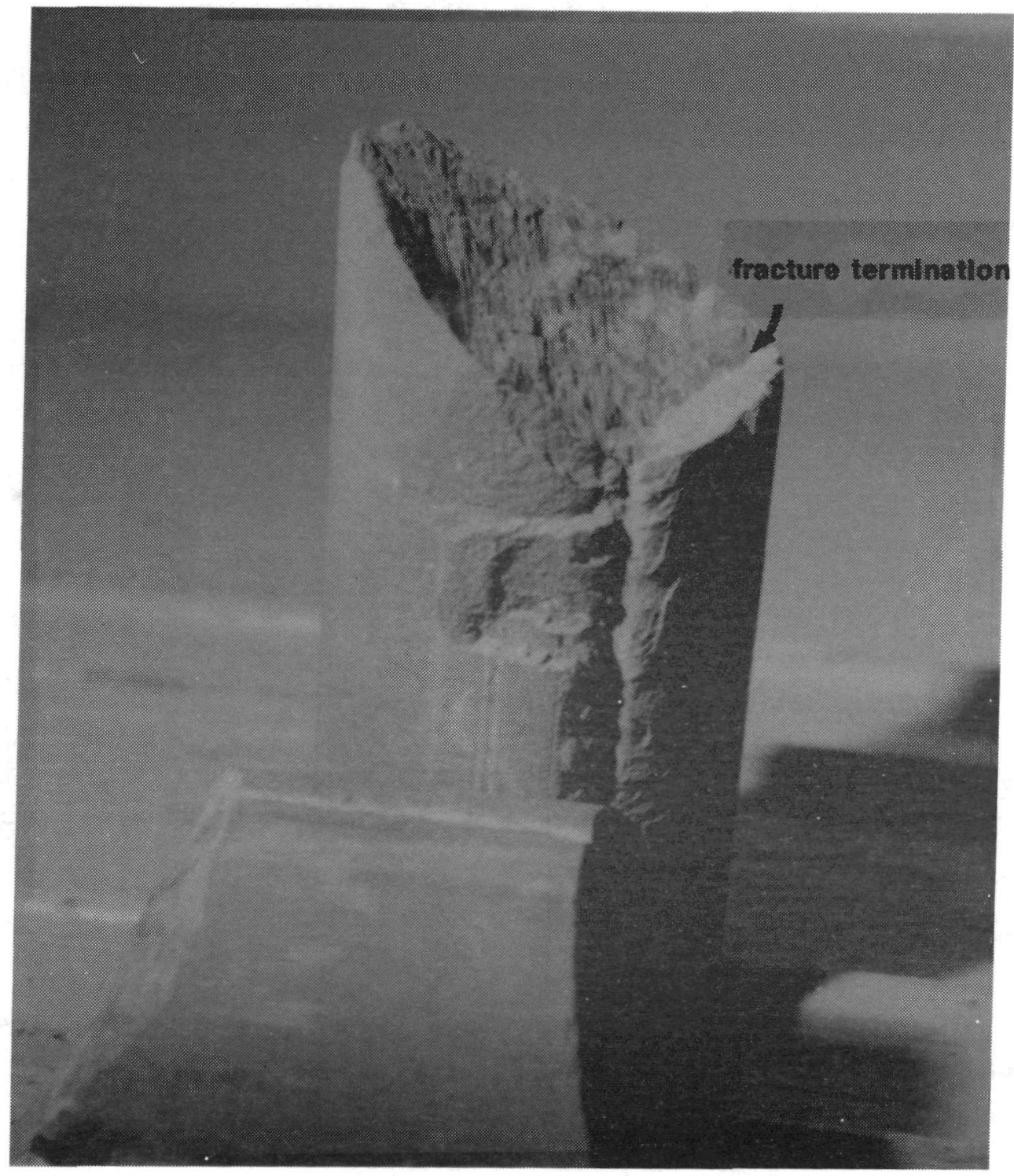

Figure 39. Type 4 Fracture Terminating Within Core Diameter, $6712.4 \mathrm{ft}$, MWX-1 
With the exception of a fracture at $6662.7 \mathrm{ft}$, these fractures occur in predominantly fine-grained sandstone. At $6662.7 \mathrm{ft}$, the host rock is mixed siltstone, fine sandstone, and mudstone, and in the immediate vicinity of the fracture, the rock is predominantly muddy siltstone.

Orientation data is available for three of the four Type 4 fractures. The two Type 4 shear fractures in the fluvial interval look like low-angle thrust faults. Both fractures dip roughly $15^{\circ}$ and are relatively planar. slickensides and slickencrysts suggest that the upper plate at $5474.0 \mathrm{ft}$ and at $5475.0 \mathrm{ft}$ was moved up in the direction of $\mathrm{S} 50 \mathrm{~W}$ and $\mathrm{N60E}$, respectively, as shown in Figure 40. Paleomagnetic data was used to orient the fracture at $6712.4 \mathrm{ft}$. The motion on this fracture appears to be strikeslip, and the slickenside azimuth is roughly N70W. There are no orientation data for the fracture at $6662.7 \mathrm{ft}$; however, the relative motion on this fracture also appears to be strike-slip.

b. High-Angle to Near-Vertical Shear Fractures in Sandstone or Siltstone (Type 5)

Only one fracture in the MWX core fits this category of shear fractures. This unique Type 5 fracture dips roughly $80^{\circ}$. Its undulating fracture walls are lined with carbonaceous mudstone as well as patches of subhedral quartz and calcite. Slickensides also occur in patches and indicate strike-slip motion.

This fracture occurs at 4909.1 ft in MWX-1. It probably intersects or may be part of the Type 1 extension fracture at $4908.0 \mathrm{ft}$. The $0.1 \mathrm{ft}$ of core that contains both the top of the Type 5 fracture and the bottom of the Type 1 fracture has been removed for analysis and is not available for inspection. Both the presence of carbonaceous mudstone and the undulatory nature of this Type 5 fracture suggest this fracture is coincident with a sedimentary feature. 


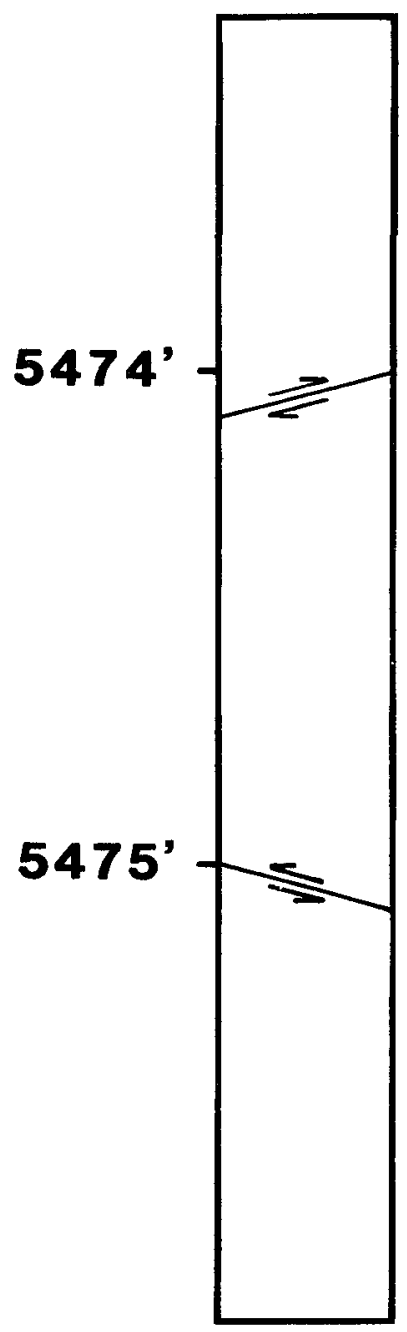

Figure 40. Sketch Showing Configuration of Type 4 Fractures Intersecting MWX-1 in the Fluvial Section 
c. Shear Fractures Within Carbonaceous Mudstone Laminations in Sandstone or Siltstone (Type 2)

Type 2 fractures are defined as shear fractures that are confined to carbonaceous mudstone laminations in sandstones and siltstones. The strike and dip of these fracture planes is probably controlled by bedding. Figure 41 shows photographs of typical Type 2 fractures in MWX core. The thickness of the host mudstone laminations varies from approximately $1 \mathrm{~mm}$ to $2 \mathrm{~cm}$. Slickensides commonly occur in patches, locally interspersed with patches of mineralization. Figure 42 shows the frequency distribution of these shear fractures with depth. All of these fractures separated in the core barrel, so no fracture width data is available. A total of 77 Type 2 fractures were identified in the MWX core from all three wells. Fracture planes range from very planar to very irregular and from horizontal to $50^{\circ}$ in dip (Figure 43).

Mineralization was detected on 22 (308) of the Type 2 fractures. The distribution of these mineralized fractures with depth is shown in Figure 44. Since mineralization is patchy and erratically distributed on the fracture planes, many of the apparently unmineralized Type 2 fractures may be partially mineralized beyond the core diameter. Mineralization is also occasionally microscopic. For example, calcite mineralization was only detected on the fracture at $6523.5 \mathrm{ft}$ in MWX-2 when a microscopic patch of calcite was fortuitously included in a thin section across the fracture plane.

All ten of the mineralized Type 2 fractures in the fluvial interval are partially mineralized with macroscopic calcite that is often subhedral. At $5530.9 \mathrm{ft}$ in MWX-1, sample preparation for fluid inclusion analyses revealed the presence of microscopic quartz crystals, interspersed with the calcite. In the coastal and paludal intervals, calcite is the most commonly observed mineralization on the ten mineralized Type 2 fractures; however, dickite and barite have also been detected. The dickite and 

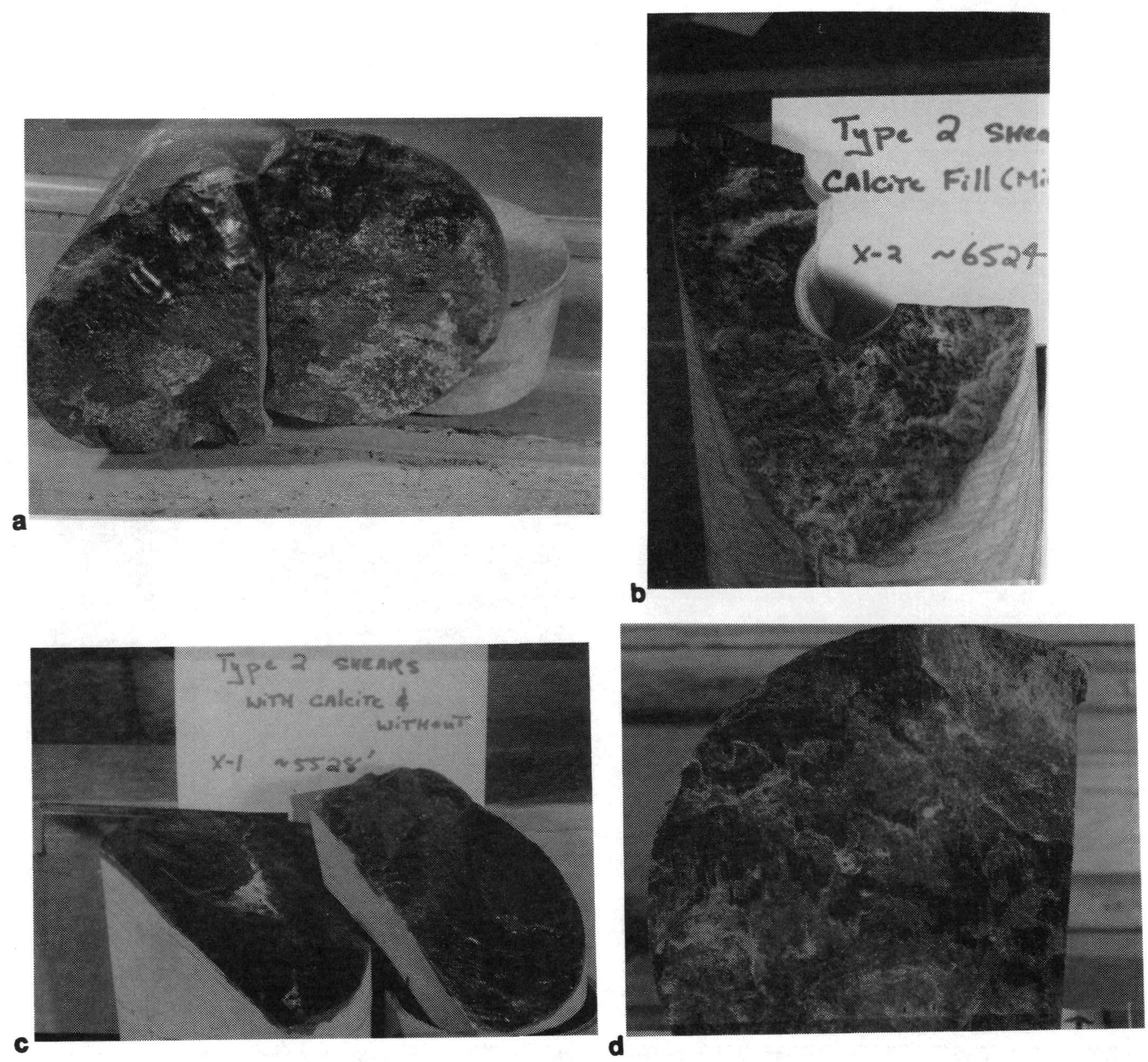

Figure 41. Type 2 Fractures in Core; (a) $7843.9 \mathrm{ft}$, MWX-2;

(b) $6523.5 \mathrm{ft}, \mathrm{MWX}-2$; (c) $5528 \mathrm{ft}, \mathrm{MWX}-1$;

(d) $7838.6 \mathrm{ft}, \mathrm{MWX}-2$ 

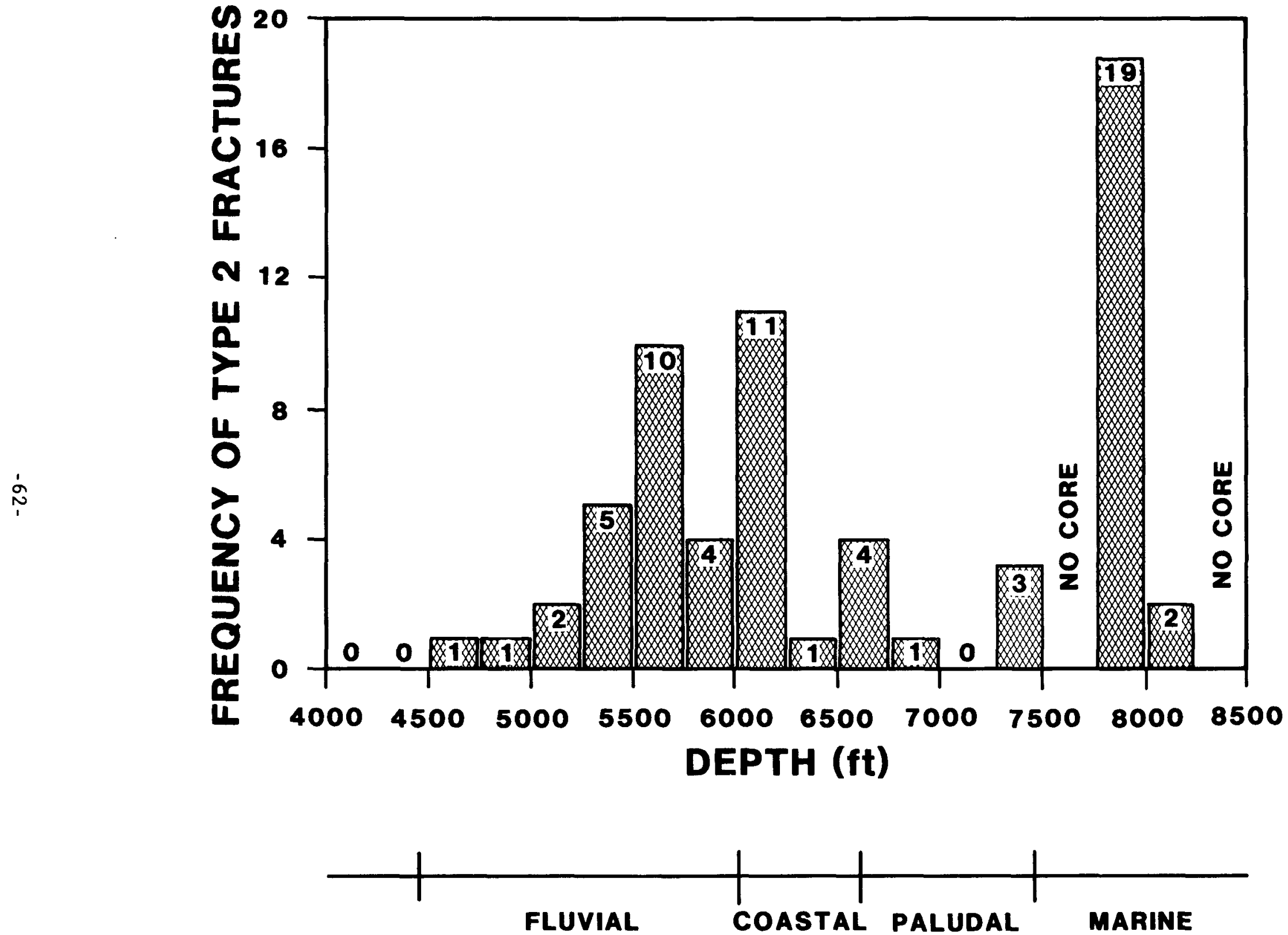

Figure 42. Frequency Distribution of Type 2 Fractures With Respect to Depth; Core Data From MWX-1 and MWX-2 


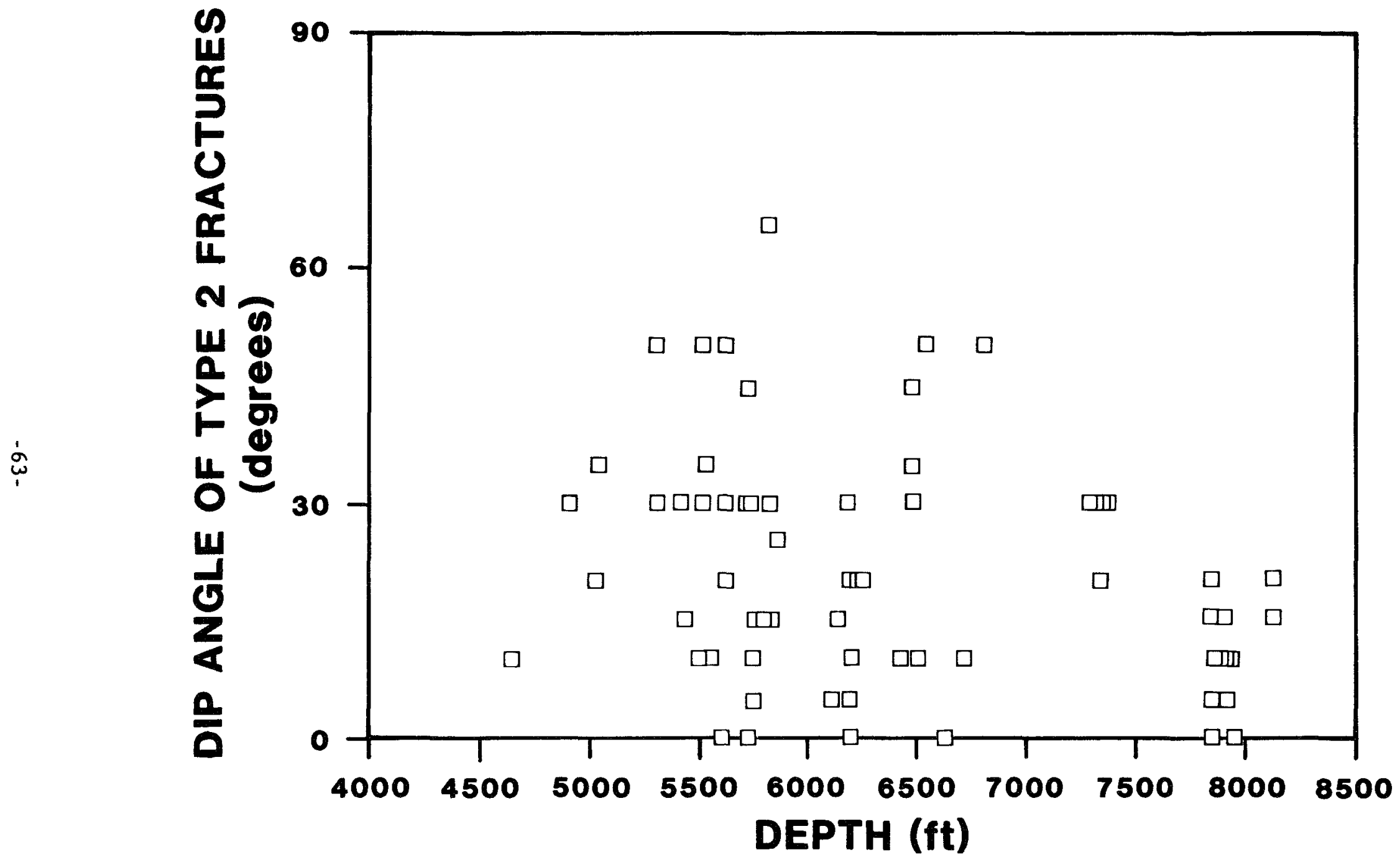

Figure 43. Distribution of Type 2 Fracture Dip Angle With Respect to Depth; Core Data From all Three MWX Wells 


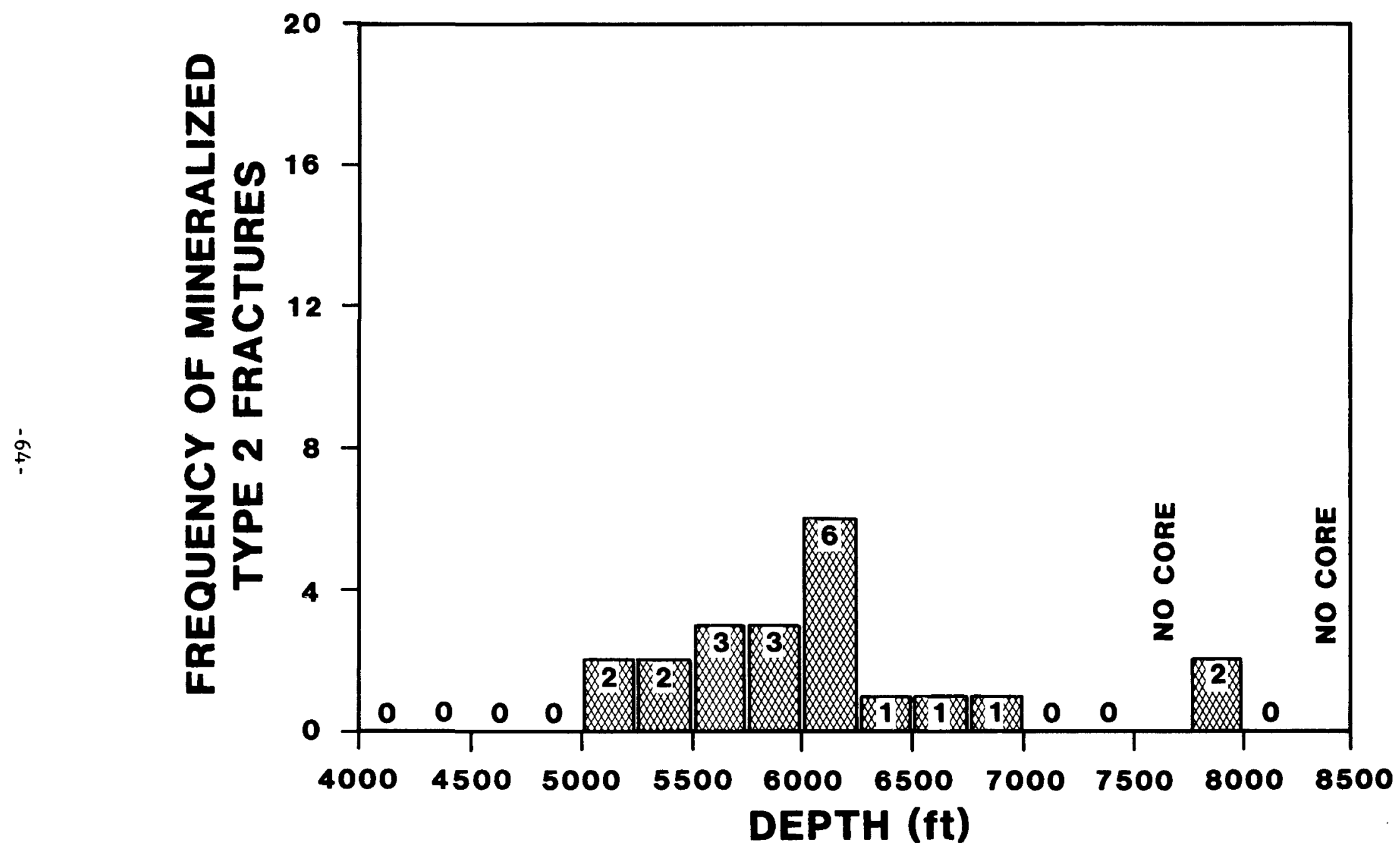

Figure 44. Frequency Distribution of Mineralized Type 2 Fractures With Respect to Depth; Core Data From MWX-1 and MWX-2 
barite are confined to fractures from 6189 to $6197 \mathrm{ft}$ in MWX-1. Patches of subhedral quartz crystals were identified on both of the mineralized Type 2 fractures occurring in marine core.

Occasionally mineral crystals on the Type 2 fractures are aligned as slickencrysts; however, more often the crystals are not aligned and occur in depressions on the fracture walls that are devoid of slickensides. Slickensides on these Type 2 fractures commonly occur in small $(\leq 3 \mathrm{~cm}$ in diameter) patches, but occasionally cover the entire fracture plane exposed in the core. Rarely, slickensides with two distinctly different bearings have been observed on the same fracture plane.

A total of 36 of these fractures have been oriented with respect to true north. Figures 45, 46, and 47 show the distribution of the fracture strikes, dip azimuths, and slickenside bearings with respect to depth. Since we've assumed that strike and dip azimuth are controlled by bedding, only slickenside bearing would be indicative of stress directions. (The angle between slickenside bearing and dip direction ranges from $0^{\circ}$ to $80^{\circ}$.) The slickenside bearings are plotted in a rosette diagram in Figure 48 and show a possible preferred orientation. Relative motion along these fractures is indeterminate for all but two of them: at 5527.8 and 5530.9 ft in MWX-1, slickencrysts imply thrust motion.

One possible explanation for the Type 2 fractures is that they formed along pre-existing bedding planes as minor lateral adjustments within the sandstones, during the different uplift and subsidence stages that the formation was subjected to. This would explain the apparently random dip/azimuths and the nominally aligned slickensides.

\section{d. Dewatering Fractures in Mudstone (Type 3)}

Type 3 fractures in mudstones are randomly oriented, undulating, polished planes with curvilinear slickensides. Opposing fracture walls fit together so tightly that most of these fractures were undetectable until after the core had dried. Others were opened during the coring and handling process. Figures 49 and 50 show photographs of typical Type 3 


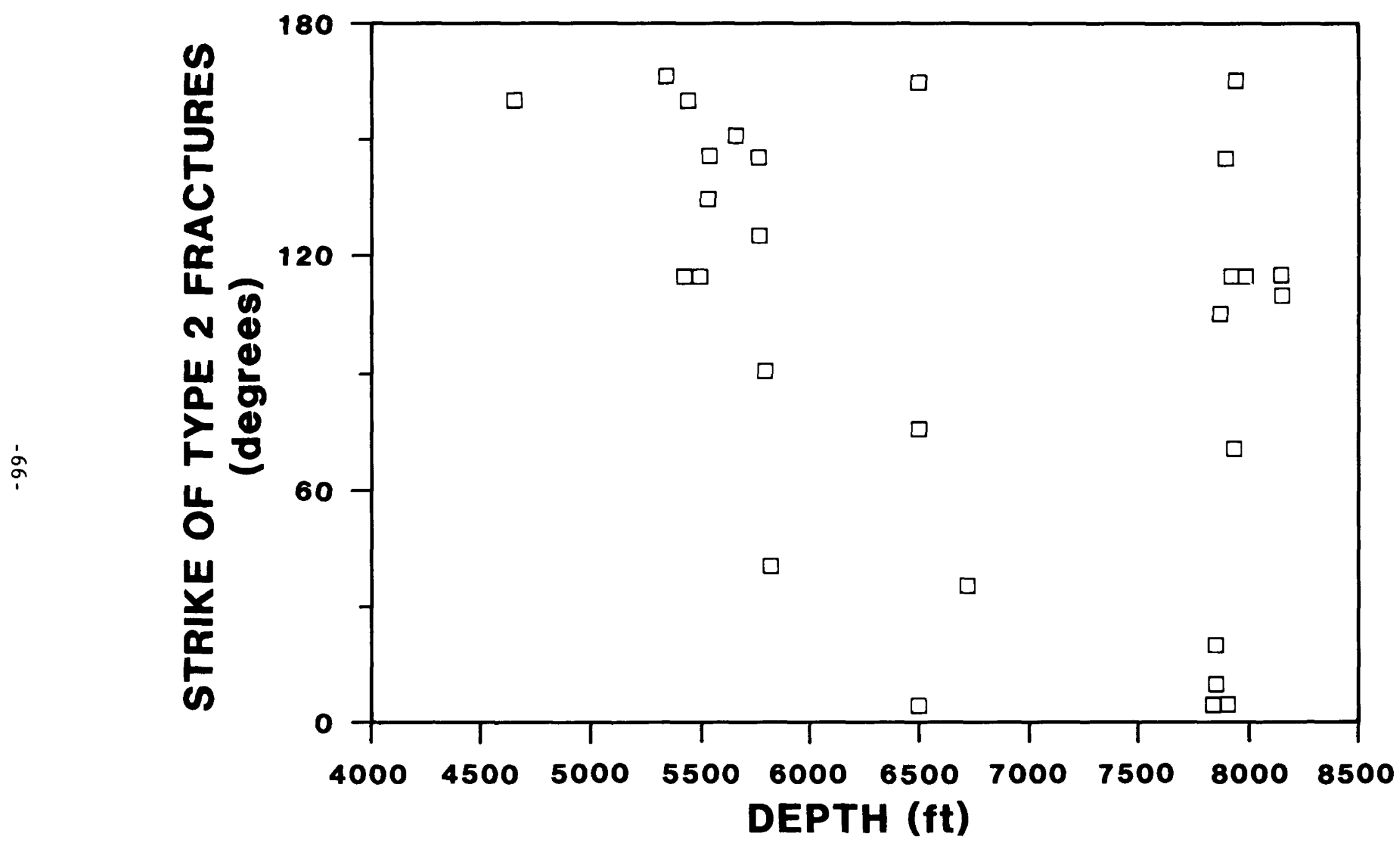

Figure 45. Distribution of Type 2 Fracture Strikes With Respect to Depth; Oriented Core Data From all Three MWX Wells 


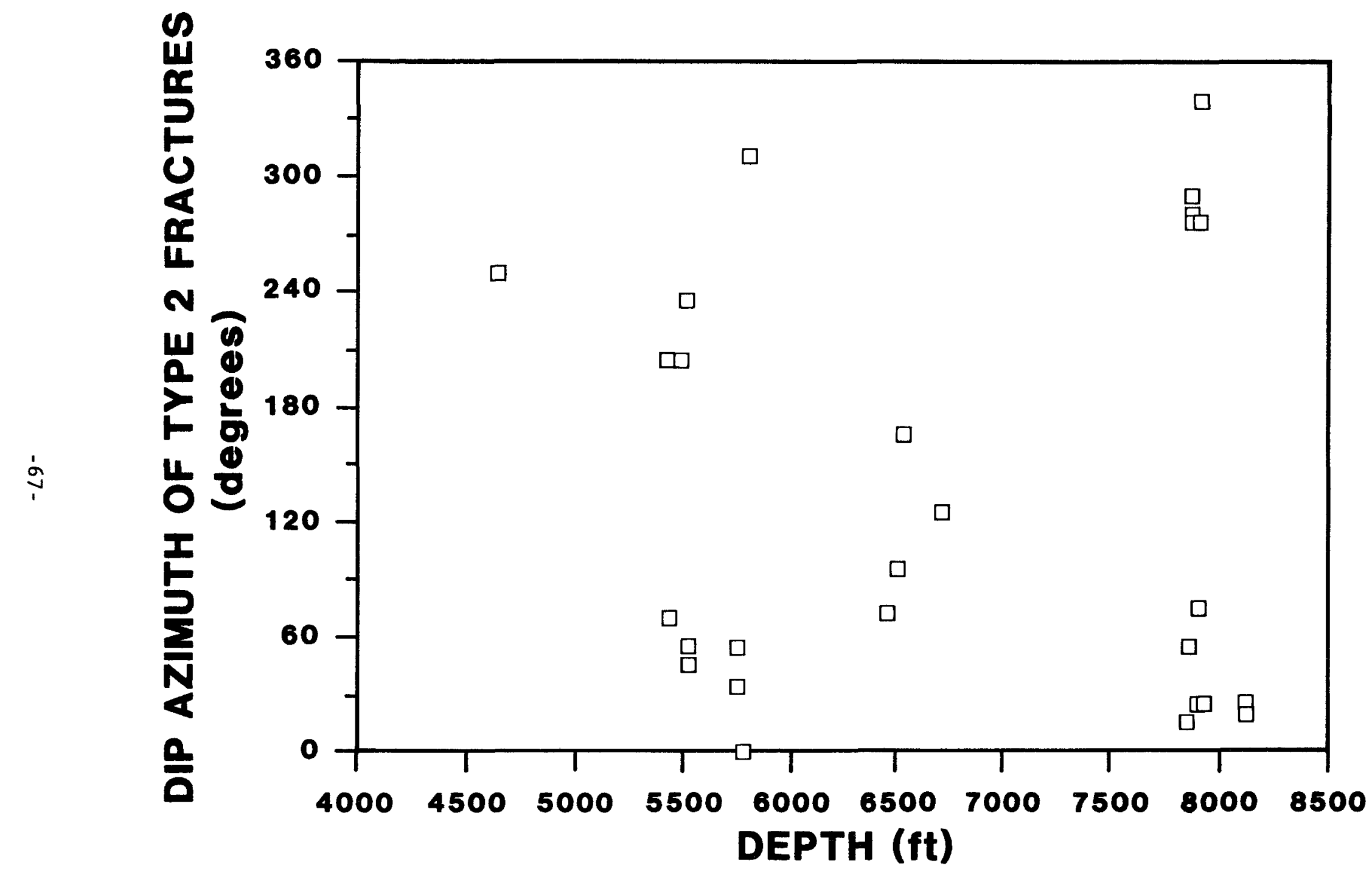

Figure 46. Distribution of Type 2 Dip Azimuths With Respect to Depth; Oriented Core Data From all Three MWX Wells 


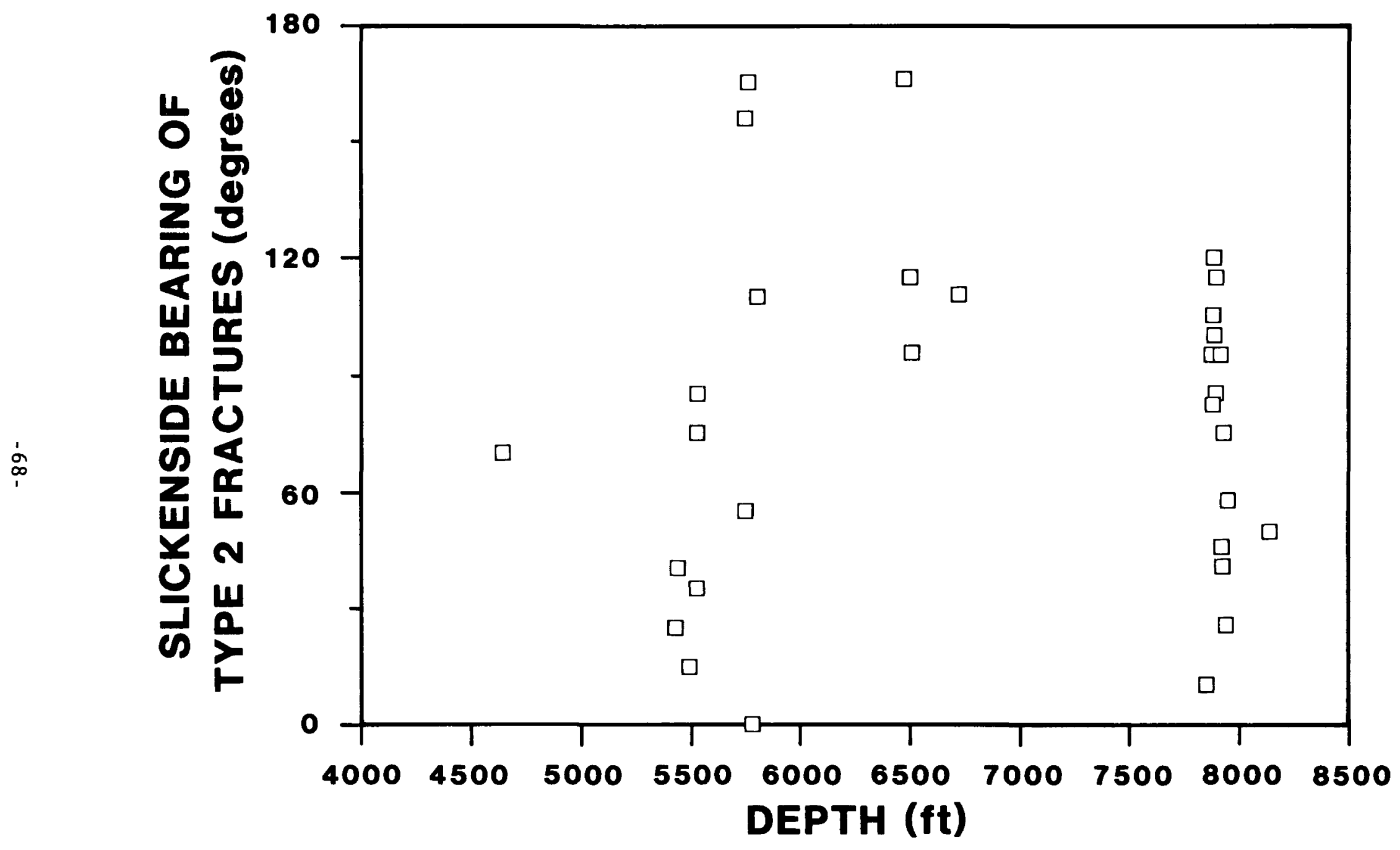

Figure 47. Distribution of Type 2 Slickenside Bearings With Respect to Depth; Oriented Core Data From all Three MWX We1ls 


\section{SLICKENSIDE BEARING OF TYPE 2 FRACTURES}

$n=36$

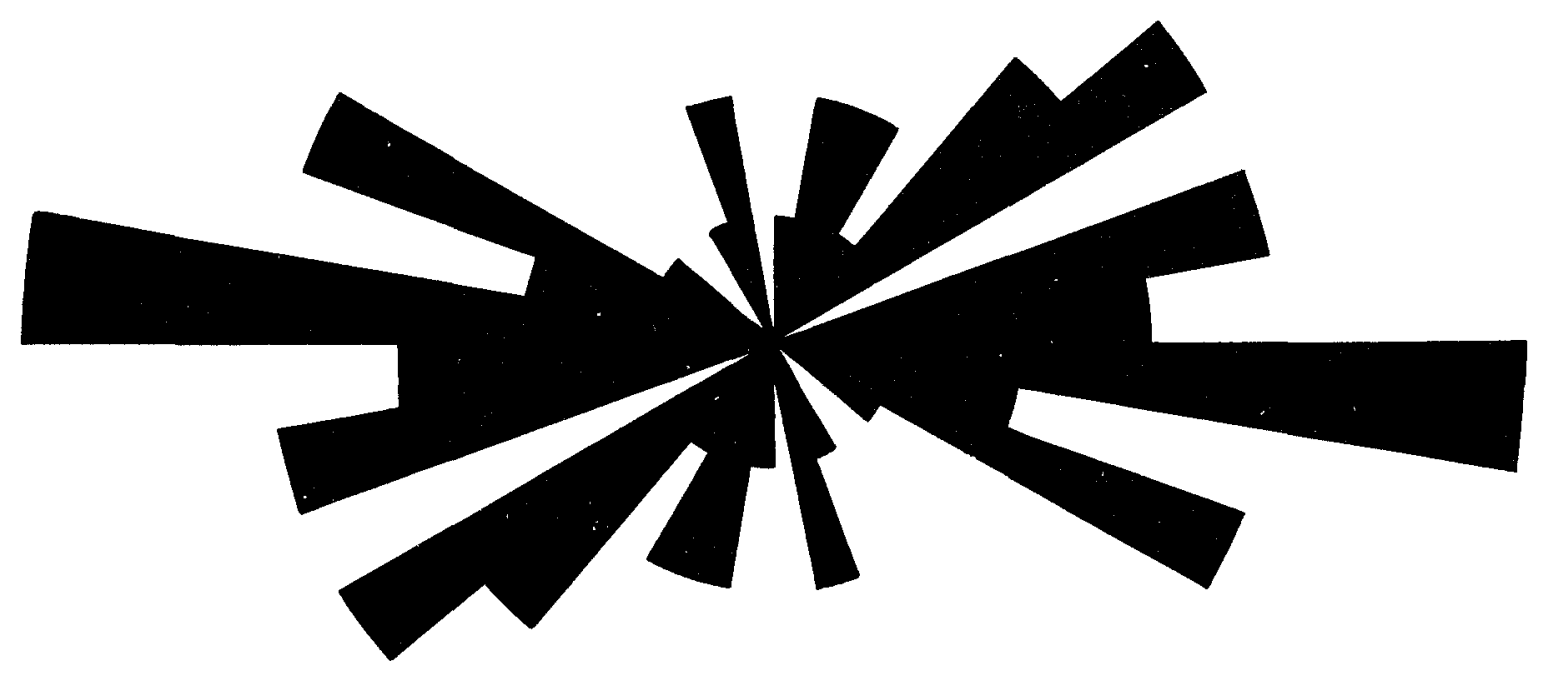

Figure 48. Slickenside Bearings of Type 2 Fractures Plotted in a

Rosette Diagram; Oriented Core Data From all Three MWX Wells 

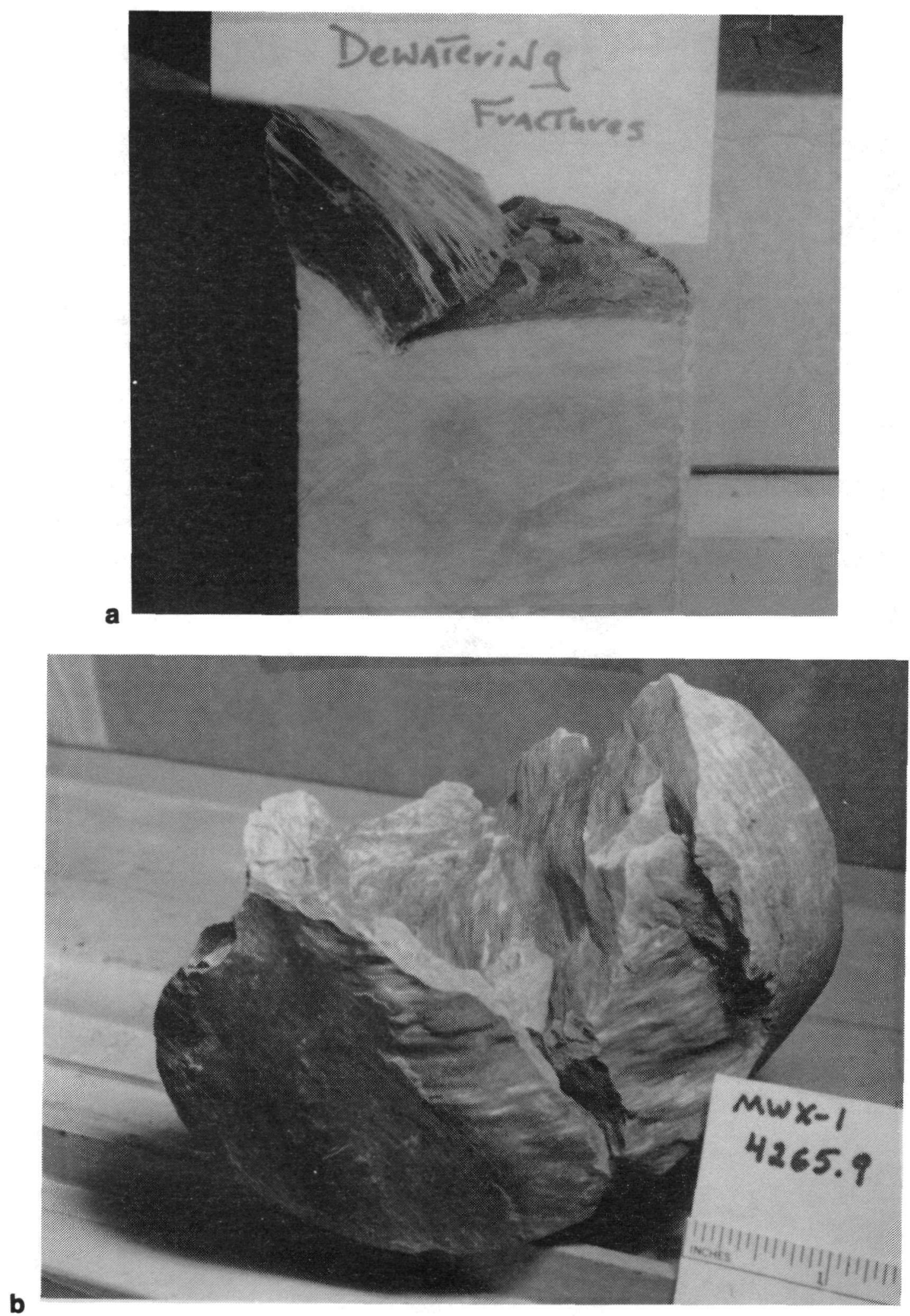

Figure 49. Type 3 Dewatering Fractures; (a) 5737.5 ft MWX-1; (b) $4265.9 \mathrm{ft}, \mathrm{MWX}-1$ 

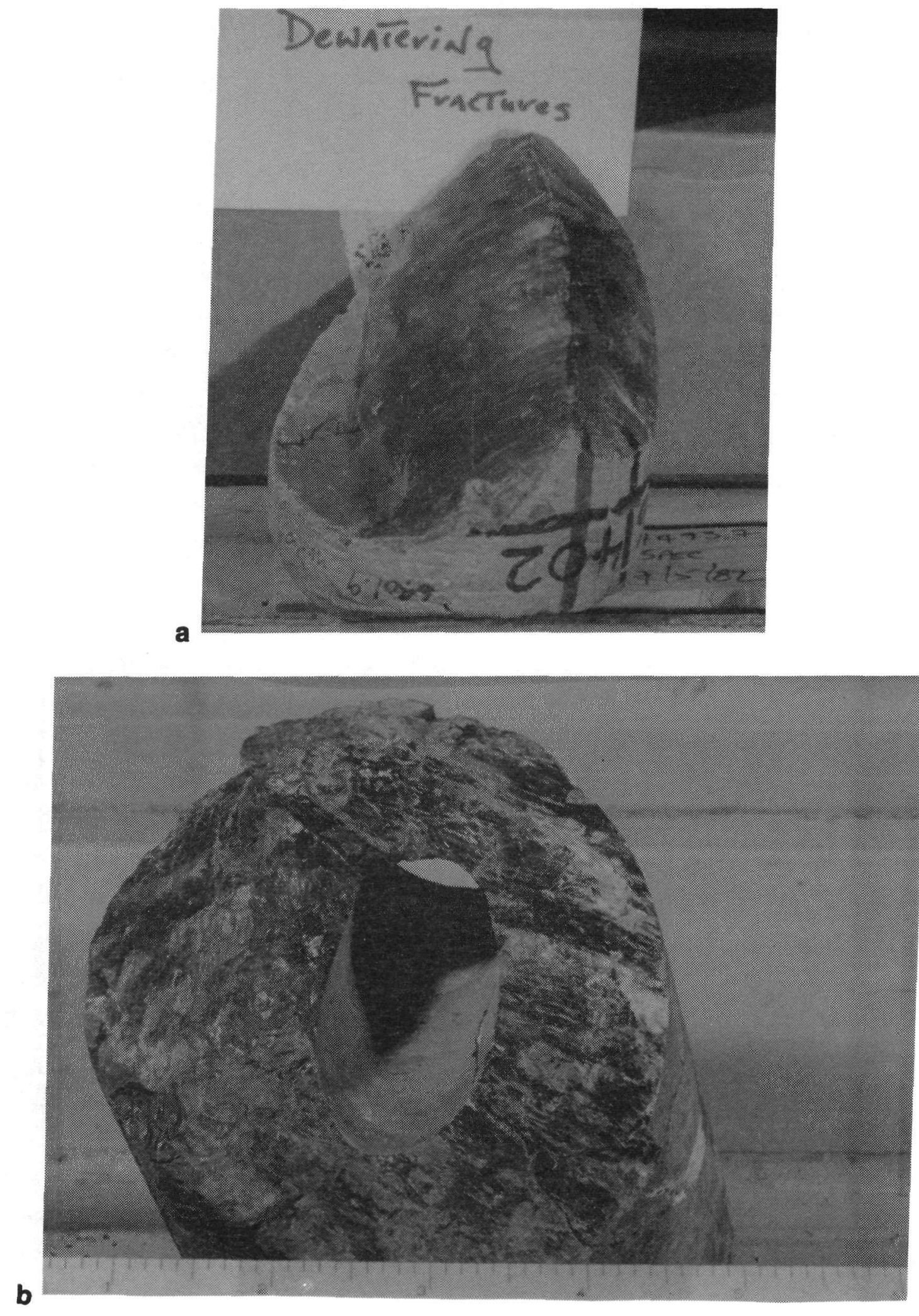

Figure 50. Type 3 Dewatering Fractures; (a) $6402 \mathrm{ft}$, MWX-3;

(b) Mineralized Type 3, $6127 \mathrm{ft}, \mathrm{MWX}-1$ 
fractures. Approximately 1425 Type 3 fractures were identified in the core from the three MWX wells.

The dried MWX mudstone core is incompetent and broken in the intervals where these Type 3 fractures are abundant, making counting and/or describing individual fractures difficult. Except where oriented and where they occurred separately, these fractures were described in groups in Appendix A. A reasonable estimate of the number of fracture planes present was determined by reconstruction of the core from available fragments. Descriptions given for the fracture groups are general descriptions of the entire group. Figure 51 shows the frequency distribution of the Type 3 fractures with depth. Roughly 97 percent of these fractures occur in mudstones in the fluvial and coastal intervals.

Only nine of these fractures are mineralized. Figure 52 shows the distribution of the mineralized Type 3 fractures with respect to depth. Patches of subhedral quartz crystals were detected on one Type 3 fracture at $7913.0 \mathrm{ft}$ in MWX-1, and calcite lines slickenside grooves on a fracture at $5795.5 \mathrm{ft}$ in MWX-3. The seven other mineralized Type 3 fractures all occur roughly between 6125 and $6245 \mathrm{ft}$ in MWX-1. Mineralization on these fractures includes calcite, dickite, and barite. Calcite slickencrysts occur in patches on 2 of these fractures at roughly $6127 \mathrm{ft}$ in MWX-1.

Due to the incompetent condition of the core where these fractures occur, fracture orientations were difficult to measure. In general, Type 3 fractures range from $0^{\circ}$ to $70^{\circ}$ in dip, but most dip between $20^{\circ}$ and $50^{\circ}$. Slickenside bearings are generally parallel to dip direction, and due to the undulating and sometimes conical curvature of the fracture planes, slickensides frequently converge and/or diverge on individual planes. Strike, dip azimuth, and slickenside bearings all appear to be randomly oriented with respect to true north.

Seventy individual Type 3 fractures were oriented with respect to true north between 5690 and $5820 \mathrm{ft}$ in MWX-3. Figures 53, 54, 55, and 56 show the distribution of dip angle, dip direction, strike, and slickenside 

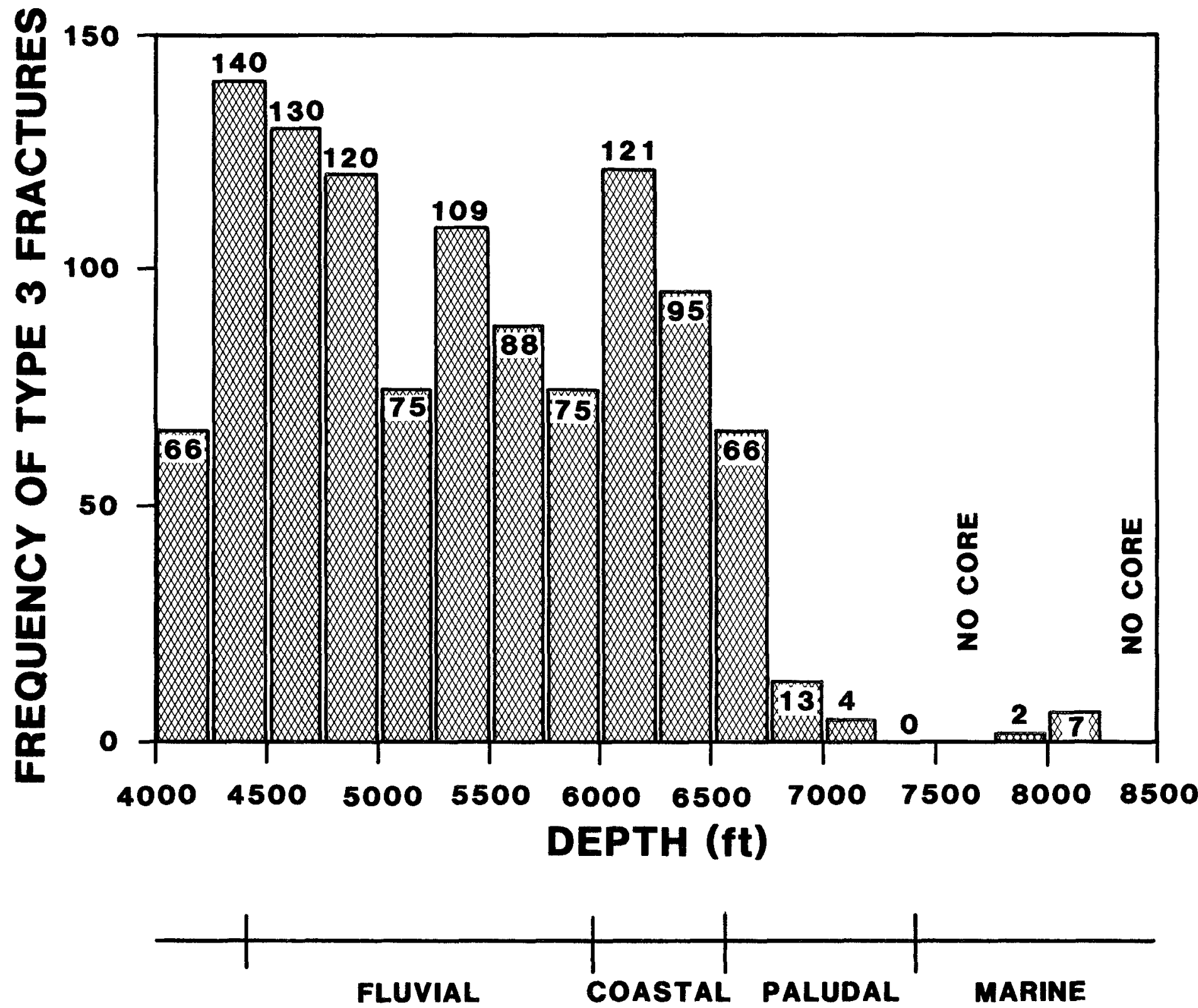

Figure 51. Frequency Distribution of Type 3 Fractures With Respect to Depth; Core Data From MWX-1 and MWX-2 


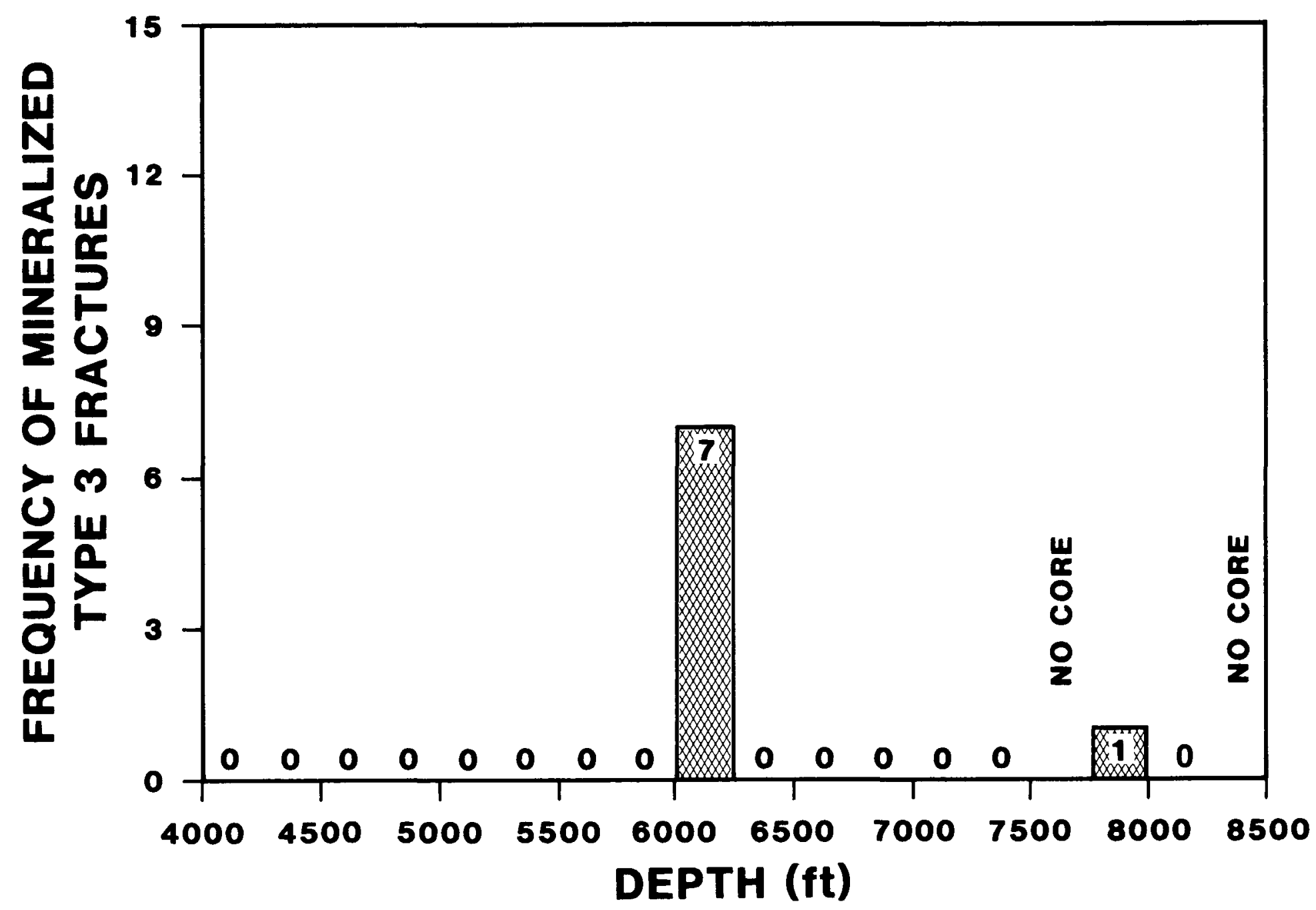

Figure 52. Frequency Distribution of Mineralized Type 3 Fractures

With Respect to Depth; Core Data From MWX-1 and MWX-2 


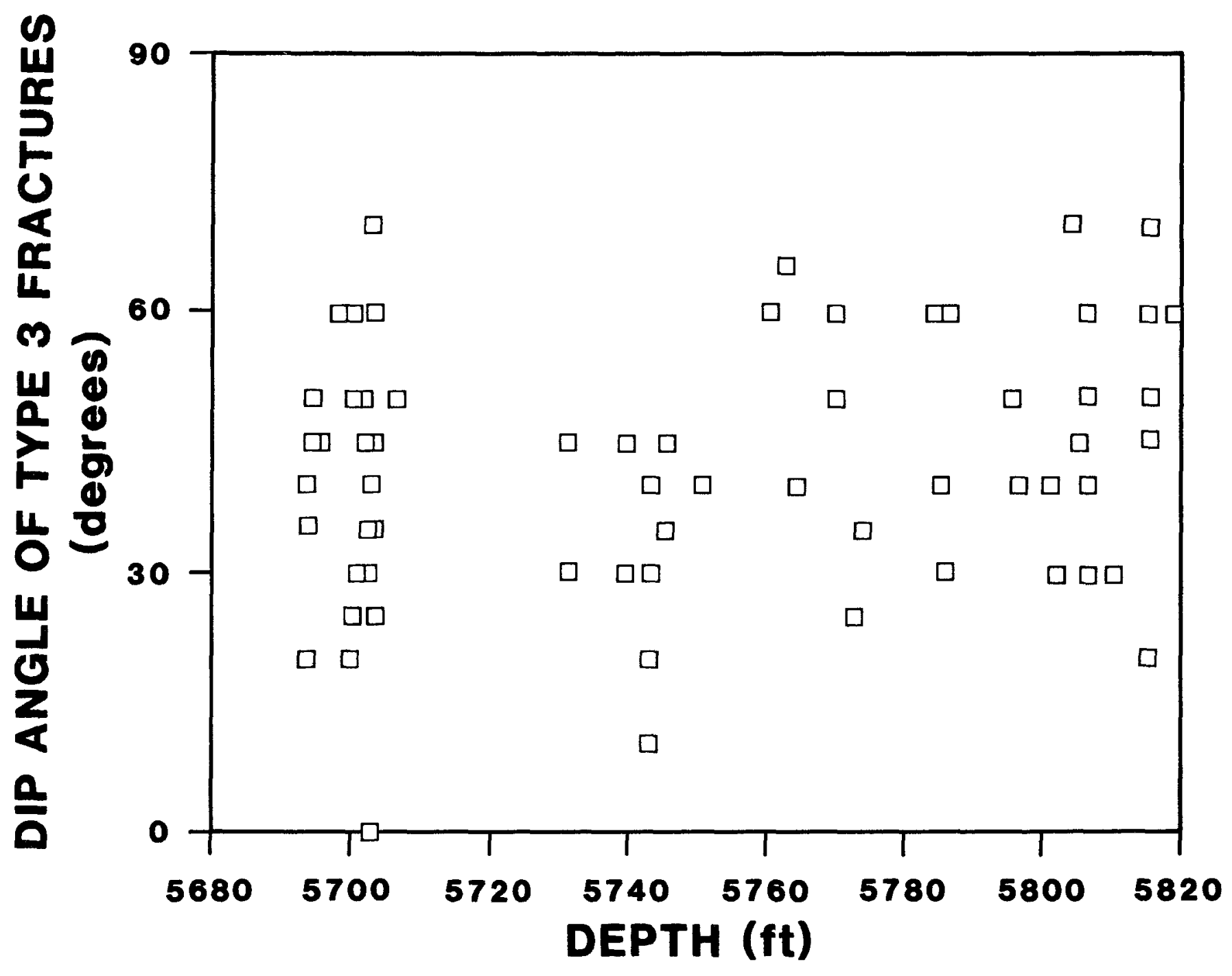

Figure 53. Distribution of Type 3 Fracture Dip Angles With Respect to Depth; Core Data From MWX-3 


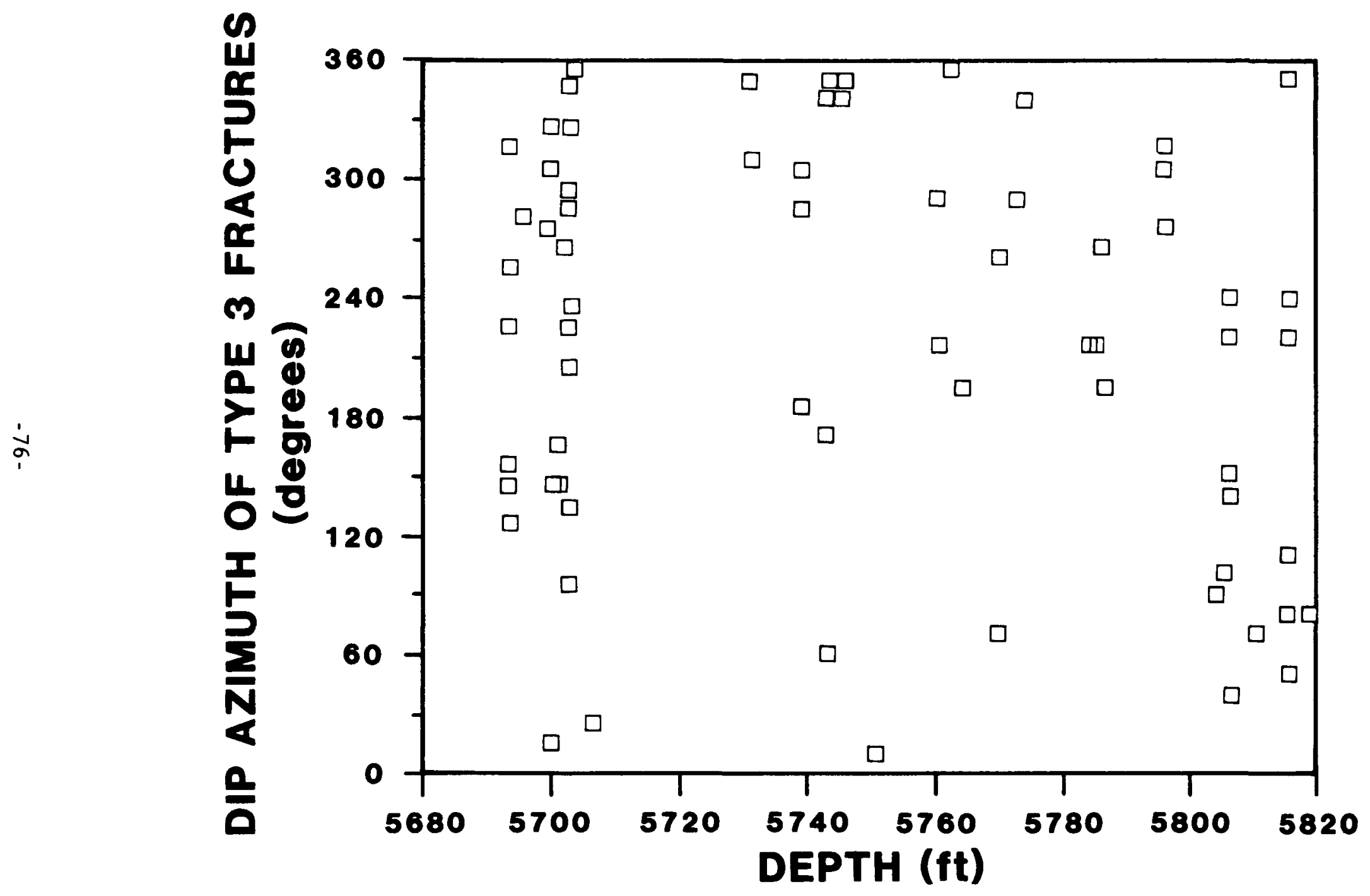

Figure 54. Distribution of Type 3 Fracture Dip Azimuths With Respect to Depth; Oriented Core Data From MWX-3 


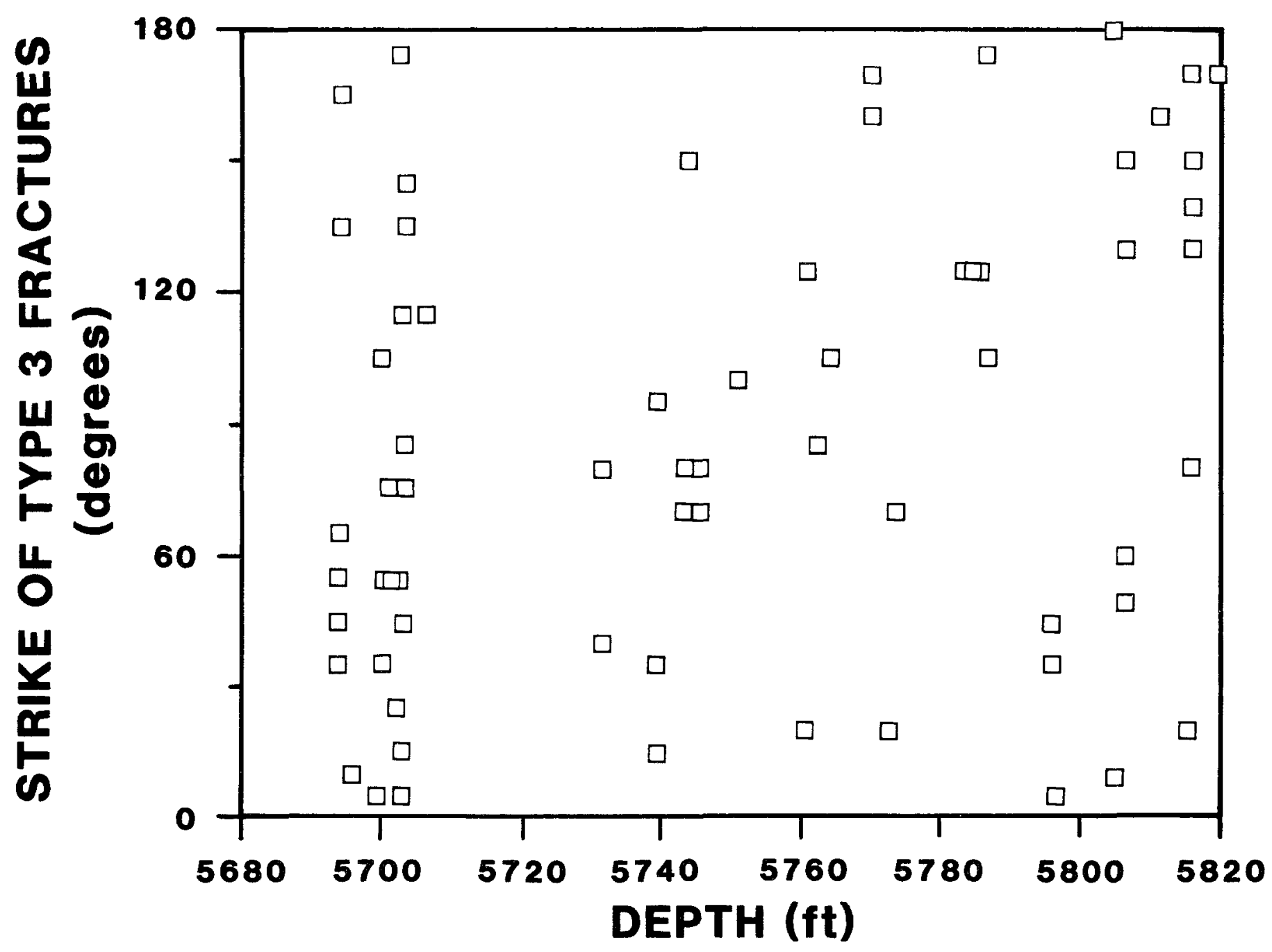

Figure 55. Distribution of Type 3 Fracture Strikes With Respect to Depth; Oriented Core Data From MWX-3 


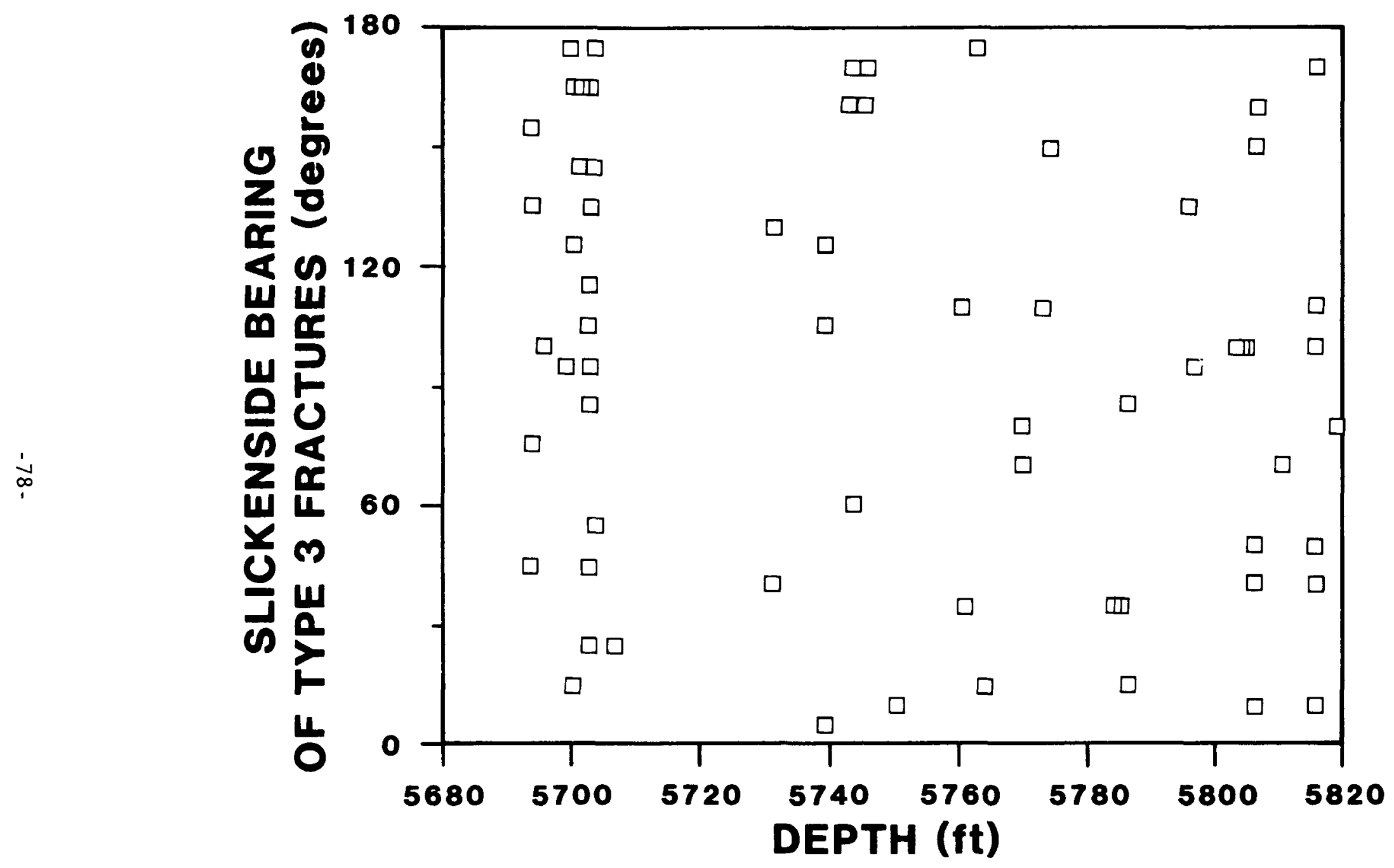

Figure 56. Distribution of Type 3 Fracture Slickenside Bearings With Respect to Depth; Oriented Core Data From MWX-3 
bearing with respect to depth. The distributions shown in Figures 53 through 56 are believed to be typical of all Type 3 fractures in MWX core. Every Type 3 fracture identified in this 130 -ft core interval was carefully oriented in an effort to avoid bias. Other strike, dip, and slickenside bearing measurements made on some of the more competent Type 3 fracture planes throughout the oriented core intervals also suggest these planes are randomly oriented.

Verbeek and Grout (1984) hypothesized that these Type 3 fractures are compaction and dewatering planes with minor slippage (1 to $2 \mathrm{~cm}$ ), that formed early in the depositional history of the rocks while mudstones were still plastic. The undulating to conical surfaces and random orientation support this hypothesis. In outcrop, Verbeek and Grout (1984) recognized that this type of fracturing in mudstone is associated with discrete dewatering conduits in overlying sandstones. Three such dewatering pipes were identified in the core (e.g. Figure 57) and are included in the fracture database as Type D. These dewatering fractures or planes in mudstones probably act as planes of weakness, but only rarely as planes of permeability at depth as evidenced by the scarcity of mineralization.

The higher frequency of dewatering fractures in the core above $6750 \mathrm{ft}$ (Figure 51) may be due to increased rates of deposition of these strata. More rapid deposition would encourage the entrapment of water in undercompacted sediments, and thus the formation of dewatering structures as the dewatering took place at greater than usual depths.

\section{e. Shears in Mudstones (Type 6)}

It is difficult to distinguish Type 6 from Type 3 shear fractures in mudstones. However, it is important to do so since Type 3 fractures have a distinct prelithification origin, whereas Type 6 fractures were most likely formed after lithification of the mudstones. Shear fractures in sandstones and siltstones were distinguished by dip angle, and in the case of Type 2 by host 1ithology, whereas Type 3 and Type 6 fractures occur in the same lithologies and have comparable dip angles. Type 6 shear fractures, by 

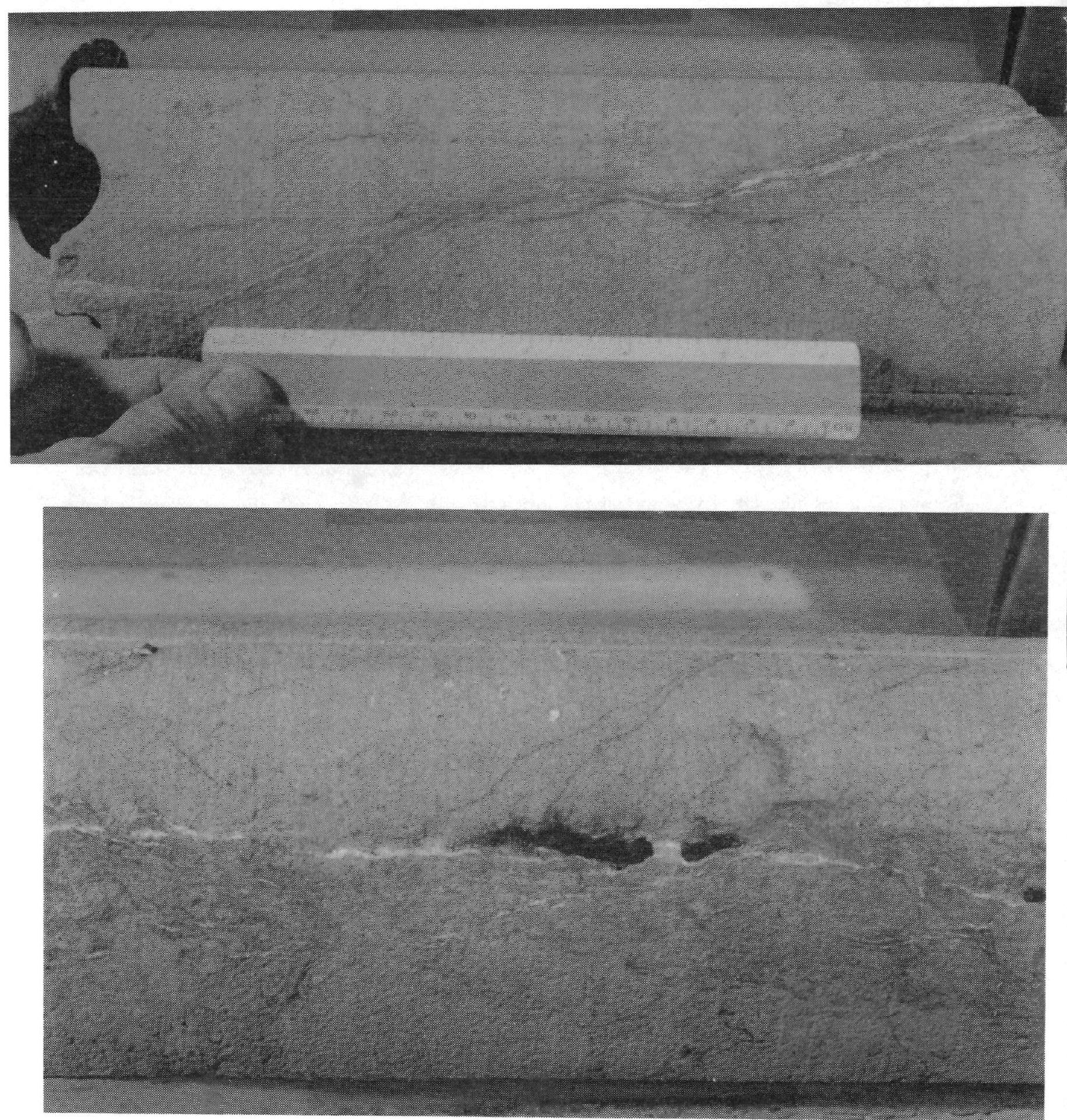

Figure 57. Dewatering Pipe in Sandstone at $5798 \mathrm{ft}$ in MWX-1 
definition, occur in predominantly mudstone lithology, are relatively planar, and are covered with linear slickensides that are continuous across the entire fracture plane exposed in the core. Eight Type 6 fractures have been identified in MWX core and are described in Appendix $A$. These fractures range from horizontal to $50^{\circ}$ in dip, and most of the fracture planes appear to be polished. Figure 58 shows the distribution of these Type 6 fractures with depth, and Figure 59 is comprised of photographs of Type 6 fractures.

Al1 of these Type 6 fractures have a slickenside bearing that is within $10^{\circ}$ of the dip azimuth except the fracture at $6060.0 \mathrm{ft}$ in MWX-1. The angle between the dip direction and the slickenside bearing is closer to $50^{\circ}$ at this location. Only three of these fractures occur in oriented core. At $8123.9 \mathrm{ft}$ in MWX-2, the dip azimuth is $\mathrm{N} 68 \mathrm{E}$ and the slickenside bearing is N58E, whereas at $6884.9 \mathrm{ft}$ in MWX-3, both the dip direction and slickenside bearing are N65E. At 8101.4 ft in MWX-2, the slickenside bearing is $\mathrm{N} 10 \mathrm{E}$ on this horizontal Type 6 fracture.

A11 of these fractures separated along the fracture plane in the core barrel, so no fracture width data is available. Three of the fractures are partially mineralized. Calcite was identified on two Type 6 fractures and dickite was detected on one fracture. The calcite is subhedral at 6060.0 ft in MWX-1, but not at $6884.9 \mathrm{ft}$ in MWX-3. "Frac blast" fractures are associated with the dickite-mineralized Type 6 fracture at $6151.1 \mathrm{ft}$ in MWX-1 (Figure 60).

With the exception of the Type 6 at $8123.9 \mathrm{ft}$ in MWX-2, all of these fractures occur in fairly homogeneous mudstone lithologies. At $8123.9 \mathrm{ft}$, the host rock is finely interlaminated siltstone and mudstone, and this Type 6 fracture crosscuts bedding.

\section{SUMMARY AND CONCLUSIONS}

A comprehensive natural fracture database for the Department of 


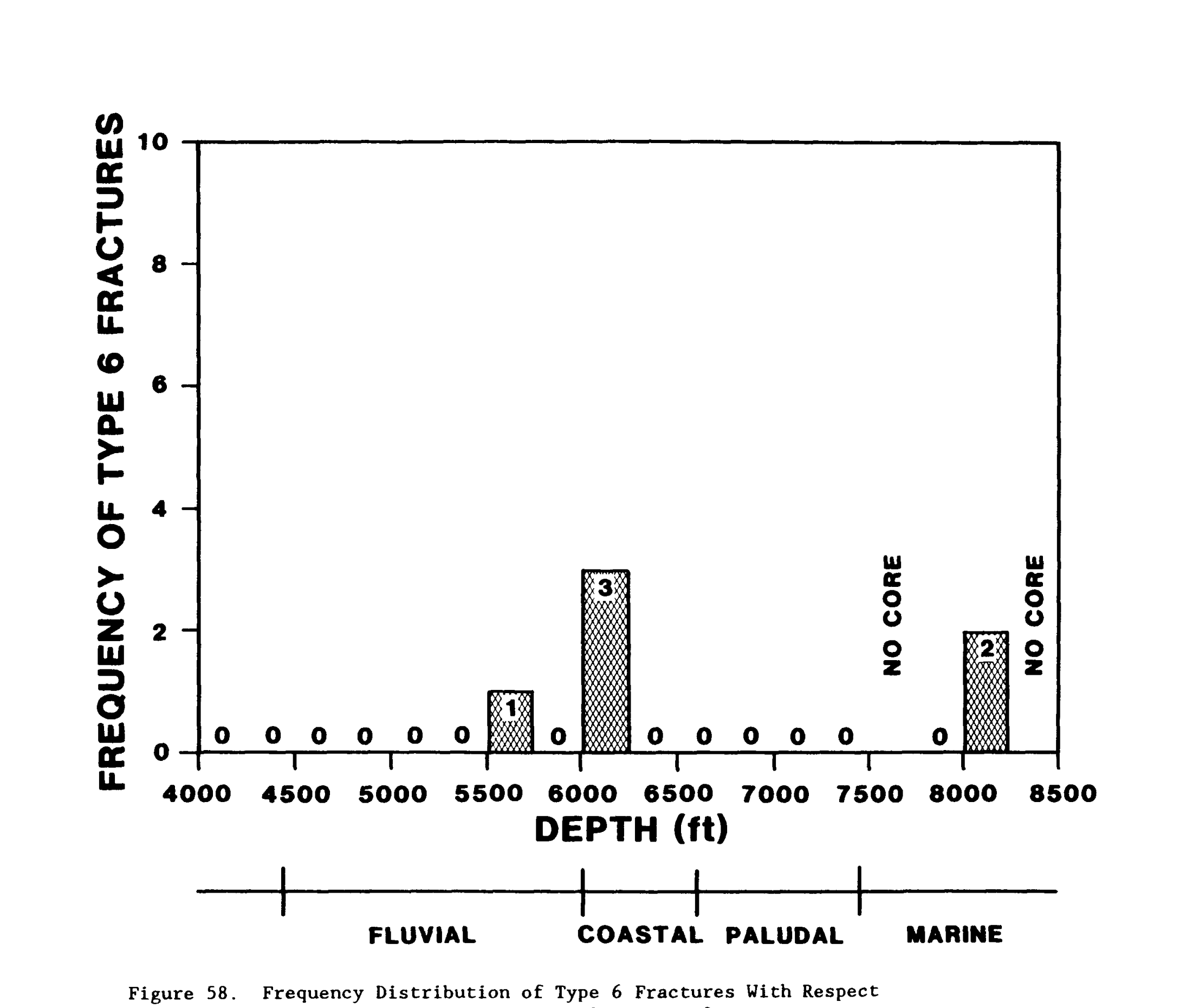



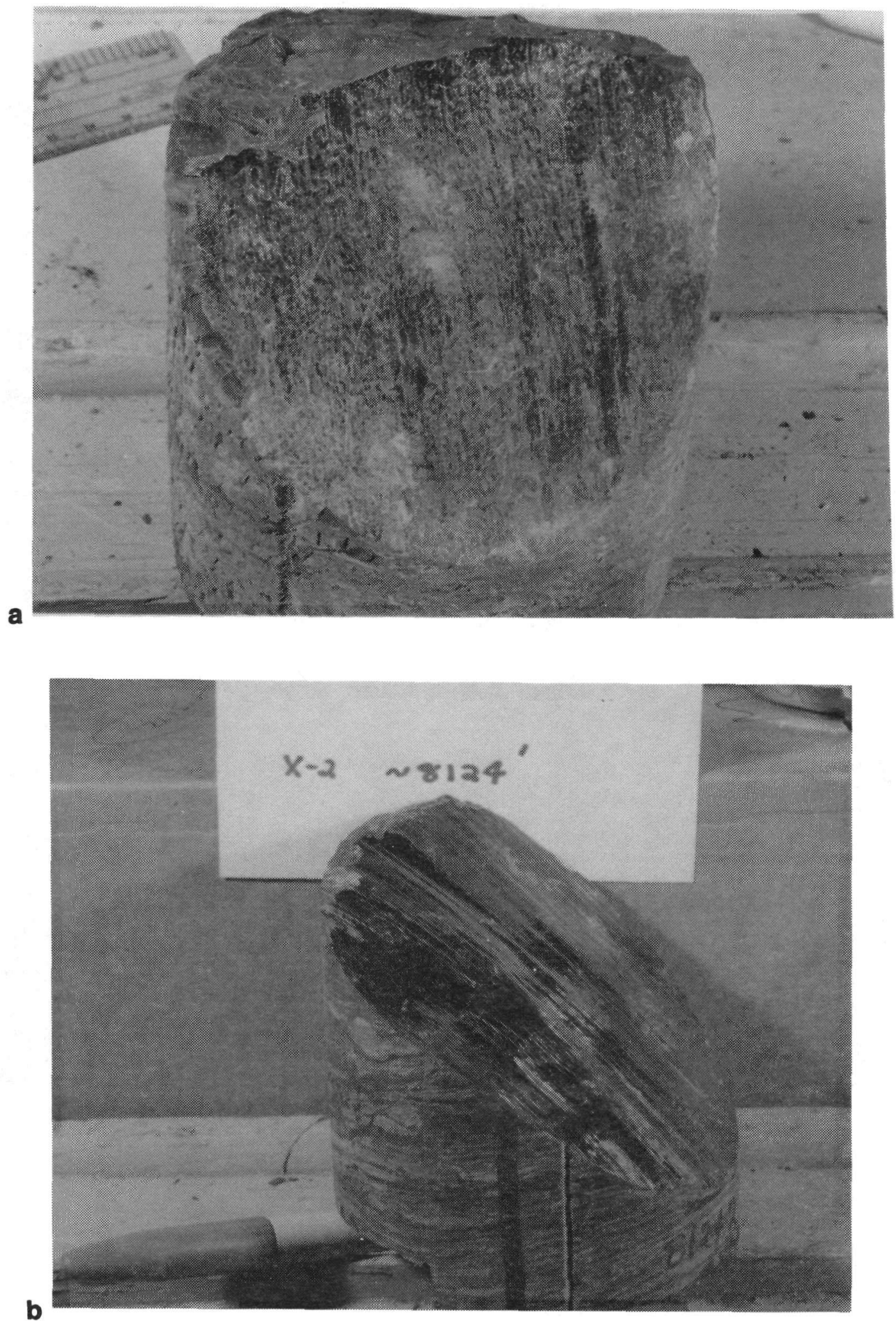

Figure 59. Type 6 Fractures in Core; (a) $5848.5 \mathrm{ft}, \mathrm{MWX}-2$;

(b) $8123.9 \mathrm{ft}, \mathrm{MWX}-2$ 


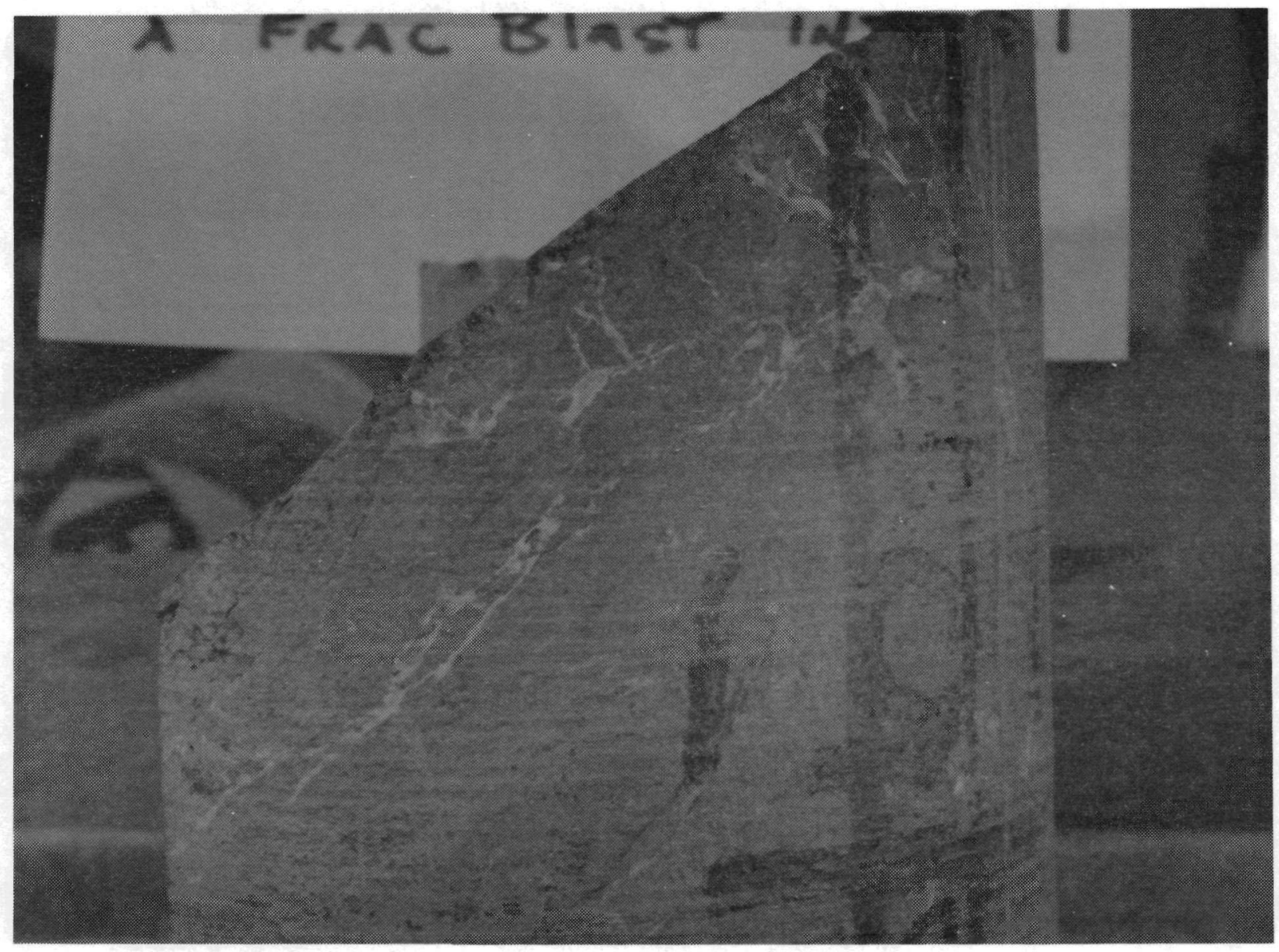

Figure 60. Type 6 Fracture With Associated "Frac Blast" Fractures, $6151.1 \mathrm{ft}, \mathrm{MWX}-1$ 
Energy's $4200 \mathrm{ft}$ of MWX core is presented and described in this report. Approximately 1880 natural fractures and 117 mechanically induced fractures are included. This database is presented in Appendix A. (It is also available on floppy disc upon request; see page iii for details.)

Approximately 1425 or 75 percent of the MWX fractures are interpreted as early-formed dewatering and compaction planes. They are randomly oriented, undulating, polished planes generally inclined from $20^{\circ}$ to $50^{\circ}$. Type 3 fractures are rarely mineralized, and slickensides on these fracture planes are curvilinear.

Extension fractures (Types $1, S, 7$ and 8) make up 20 percent of the MWX natural fracture database. These include approximately 275 vertical to subvertical, planar, mostly calcite-mineralized Type 1 and $\mathrm{S}$ fractures, as well as 27 horizontal to subhorizontal, planar, mostly calcite-mineralized Type 7 fractures. Types $1, \mathrm{~S}$ and 7 are frequently stranded or branched. Approximately 25 percent of the Type and $S$ fractures have been oriented with respect to true north. The orientation data indicate that the predominant fracture strike is west-northwest parallel to the present-day maximum compressive stress direction, independently measured at the MWX site. A few Type 1 and $S$ fractures with strike azimuths north-northwest and northeast were also identified in some core intervals.

In addition, there are roughly 61 "frac blast" type extension fractures, densely concentrated between 6100 and $6200 \mathrm{ft}$ in MWX-1. The "frac blast" or Type 8 fractures have imparted an exploded rock texture to the host rock and are frequently coincident with sedimentary structures and bedding planes. These Type 8 fractures range from undulatory to planar and from horizontal to vertical. Dickite is the predominant fracture mineralization.

The remaining 5 percent of the natural fractures in MWX core are shear fractures that are probably not related to mudstone dewatering. These are the Type 4, 5, 2, and 6 fractures discussed in this paper. There were four 
low-angle, slickensided Type 4 fractures identified in MWX sandstones and siltstones. Type 4 fracture planes range from horizontal to $40^{\circ}$ in dip and calcite is the predominant mineralization. With the exception of Type 4 and 5 shears, the relative motion along the MWX shear fractures is generally indeterminate. Two Type 4 fractures are thrust faults and two are strike-slip faults. The database includes only one vertical to subvertical, slickensided, calcite-mineralized Type 5 fracture in a sandstone lithology. Relative motion on this fracture also is apparently strike-slip.

A total of 77 slickensided Type 2 fractures, confined to carbonaceous mudstone laminations in sandstone and siltstone, have been identified in MWX core. Type 2 fractures range from horizontal to $50^{\circ}$ in dip, and onethird of these fractures are mineralized, predominantly with calcite.

There are eight Type 6 fractures described in the MWX fracture database. The Type 6 fractures in mudstone are planar, occasionally mineralized fractures with continuous linear slickensides.

Changes in fracturing characteristics at MWX are in places coincident with changes in depositional environment and in other places with lithologic boundaries. For example, Type 1 and $\mathbf{S}$ fractures are confined to sandstone and siltstone lithologies and are densely concentrated in the lower fluvial and upper coastal environments. Present-day stress changes are also coincident with lithologic boundaries (Warpinski et a1., 1985; Warpinski and Teufel, 1987) and possibly coincident with depositional boundaries (Warpinski, 1988).

Branagan et a1. (1984) established that natural fractures make a substantial contribution to reservoir production at the MWX site. Results of laboratory permeability tests of matrix rock indicate permeabilities that are one to three orders of magnitude lower than those calculated from well test results at MWX. Lorenz and Finley (1987) discussed fracture characteristics and related production for Mesaverde intervals tested at 
MWX, but additional work needs to be done. Although the majority of fractures are Type 3 dewatering fractures that are probably unimportant to reservoir productivity, there are more than 400 fractures whose significance to reservoir productivity needs to be completely evaluated.

It is reasonable to assume that all mineralized fractures, both shear and extension fractures, were open to the movement of fluids at some time in the depositional and burial history of the rocks, and they are most likely still open at depth. Figure 61 shows the distribution of these potentially permeable paths with respect to depth at MWX. Patchy and incomplete mineralization may act as a natural proppant, and laboratory tests suggest that even the most completely calcite-mineralized fractures enhance permeability of sandstone cores one to two orders of magnitude (Lorenz et al., 1986). Moreover, subhedral mineralization on some of the fracture walls is direct evidence for an opening along the fracture at depth. Apparently unmineralized shear fractures may also be propped and permeable as shearing may create asperities on fracture walls.

Natural fractures are the dominant control on in situ reservoir permeability at the MWX site (Lorenz and Finley, 1987; Lorenz et al., 1986). This report is a detailed catalog of the natural fractures encountered in core from the MWX wells. Its purpose has been to present a quantitative fracture database to be used for future studies in fracture distribution and its effect on reservoir production. 

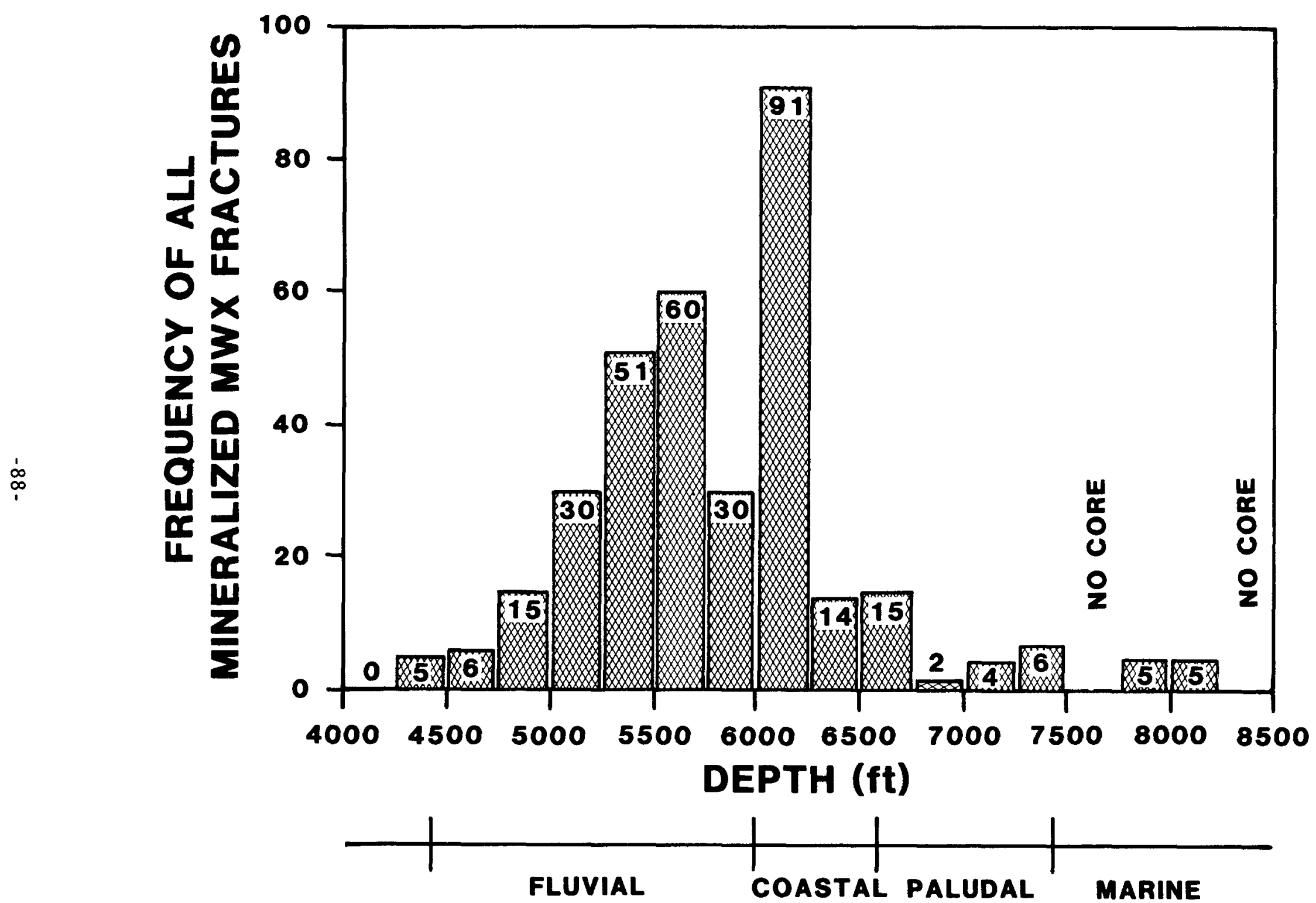

Figure 61. Frequency Distribution of all Mineralized Fractures

With Respect to Depth; Core Data From MWX-1 and MWX-2 


\section{REFERENCES}

1. Branagan, P. T., G. Cotner, S. J. Lee, R. Wilmer, "Interference Testing of the Naturally Fractured Cozzette: A Case Study at the DOE MWX Site," SPE 12869, Proceedings of the SPE/DOE/GRI Unconventional Gas Recovery Symposium, Pittsburgh, PA, May 1984, pp 359-366.

2. Clark, J. A., "Descriptive Statistics--MWX Core Fractures Described by D. D. Madsen" memorandum of record in MWX database, 1.4.4.009, August 1983 .

3. Geissman, J., Personal Communication on Paleomagnetic Techniques, 1988 .

4. Hancock, P. L., "Brittle Microtectonics: Principles and Practice," Journal of Structural Geology, 1985, Vol. 7, Nos. 3/4 pp 347-457.

5. Lorenz, J. C., "Reservoir Sedimentology of Mesaverde Rocks at the Multiwell Experiment Site and East Central Piceance Creek Basin," Sandia National Laboratories Report, SAND87-0040, January 1987.

6. Lorenz, J. C., P. T. Branagan, N. R. Warpinski, A. R. Sattler, "Fracture Characteristics and Reservoir Behavior of Stress-Sensitive Fracture Systems in Flat-Lying, Lenticular Formations," SPE-15244, Proceedings SPE Unconventional Gas Technology Symposium, Louisville, Kentucky, May 1986, pp 423-436.

7. Lorenz, J. C. and S. J. Finley, "Differences in Fracture Characteristics and Related Production of Natural Gas in Different Zones of the Mesaverde Formation, Northwestern Colorado," SPE 16809, 62nd Annual Technical Conference and Exhibition of the Society of Petroleum Engineers of AIME/Formation Evaluation and Reservoir Geology Proceedings, Dallas, TX, September 1987, pp. 589-593.

8. Lorenz, J. G. and S. J. Finley, "Significance of Drilling and CoringInduced Fractures in Mesaverde Core, Northwestern Colorado," Sandia National Laboratories Report, SAND88-1623, June 1988.

9. Maynard, B. J., "Geochemistry of Dolitic Iron Ores, and Electron Microprobe Study," Economic Geology, Vol. 81, 1986, pp 1473-1483.

10. Sattler, A. R., 1984, "The Multiwell Experiment Core Program II," SPE/DOE/GRI 12584, Proceedings of the SPE/DOE/GRI Unconventional Gas Recovery Symposium, Pittsburgh, PA, May, 1984.

11. Verbeek, E. R. and M. A. Grout, "Fracture Studies in Cretaceous and Paleocene Strata in and around the Piceance Basin, Colorado: Preliminary Results and Their Bearing on a Fracture-Controlled, Natural Gas Reservoir at the MWX Site," USGS Open File Report 84-156, 1984.

12. Warpinski, N. R., Personal Communications, 1988. 
13. Warpinski, N. R. and L. W. Teufel, "In Situ Stresses in LowPermeability, Nonmarine Rocks," SPE/DOE 16402, Proceedings 1987 SPE/DOE Joint Symposium on Low Permeability Reservoirs, Denver, CO, May 1987, pp 165-172. 


\section{LEGEND FOR APPENDIX A}

We11 Number: MWX-1, MWX-2, or MWX-3

Core Depth and Log Depth: Depth of the top of the fracture or fracture group in feet.

Frac Type: Fracture type as defined in text.

1 - vertical to subvertical extension fracture

2 - shear fracture confined to carbonaceous lamination in sandstone or siltstone

3 - dewatering fracture

4 - low angle shear fracture in sandstone or siltstone

5 - high angle shear fracture in sandstone or siltstone

6 - shear fracture in mudstone

7 - horizontal to subhorizontal extension fracture

8 - "frac blast" fracture

S - fracture swarm of type 1 extension fractures; fracture number is denoted as $\underline{03}$

C - mineralized coal cleat

$\mathrm{N}$ - fractured sandstone clast encased in mudstone

$D$ - dewatering pipe or conduit

$P$ - drilling-induced petal fracture

$B$ - coring-induced scribe-line fracture

\# of Fracs: Number of fractures that fit the description.

Frac Height: Core height of a fracture or fracture group in feet. 9999-information not available.

Frac Width: Maximum fracture width in $\mathrm{mm}$; this width is always the maximum width of a single strand of the fracture or fracture group. 9999-information not available.

Frac Strike*: True strike. 999--information not available.

Dip Angle: Dip inclination in degrees; angle measured relative to horizontal. 99--information not available.

Dip Azimuth*: True direction of down dip. 999--information not available.

Slick Bearing*: True bearing of the slickensides. 999--information is not available.

* The true orientations have been determined using multishot oriented core data unless they are followed by a P. True orientations followed by a (P) were determined using paleomagnetic techniques. 
Type Motion: Type of motion with reference to shear fractures

R - reverse

$N$ - normal

S - strike slip

9 - information not available

Slick Extent: Extent of slickensides

+ - slickensides across core break

- slickensides in patches

9 - information not available

Fill Type: Type of mineralization

C - calcite

Q - quartz

D - dickite

B - barite

H - chamosite

999 - no mineralization detected

Fil1 Amount: Amount of mineralization

P - partial fill

C - complete fill

9 - no mineralization

Crystal Type:

S - macroscopic subhedral crystals present

9 - no mineralization

blank - no macroscopic subhedral crystals detected.

Top Term: Upper termination of fracture or fracture group

1 - at mudstone contact

2 - out of core

3 - within lithology

4 - at gradational mudstone contact

5 - at mudstone lamination in sandstone or siltstone

6 - at grainsize change other than mudstone

7 - termination sampled (information unavailable)

8 - at rubble zone

9 - information not available

Bot Term: Bottom termination of fracture or fracture group. Same legend as Top Term above 
Lith: Predominant 1ithology

0 - finely interlaminated mudstone and siltstone

1 - coarse sandstone

2 - medium-grained sandstone

3 - fine grained sandstone

4 - fine grained sandstone with mudstone laminations

5 - sandstone, siltstone, and mudstone intermixed with soft sediment swirls

6 - siltstone

7 - mudstone

8 - coal

9 - information not available

Lab Analyses: Laboratory analyses completed

$\mathrm{T}$ - petrographic analysis

$S$ - SEM analysis

$X$ - $x$-ray diffraction analysis

$F$ - fluid inclusion analysis

blank - no lab analysis conducted

Second Line: Additional comments 
APPENDIX A

$-\mathrm{A} 4-$ 


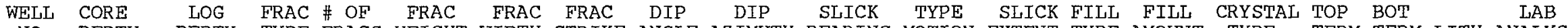

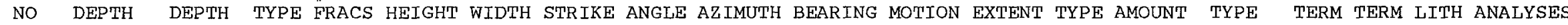

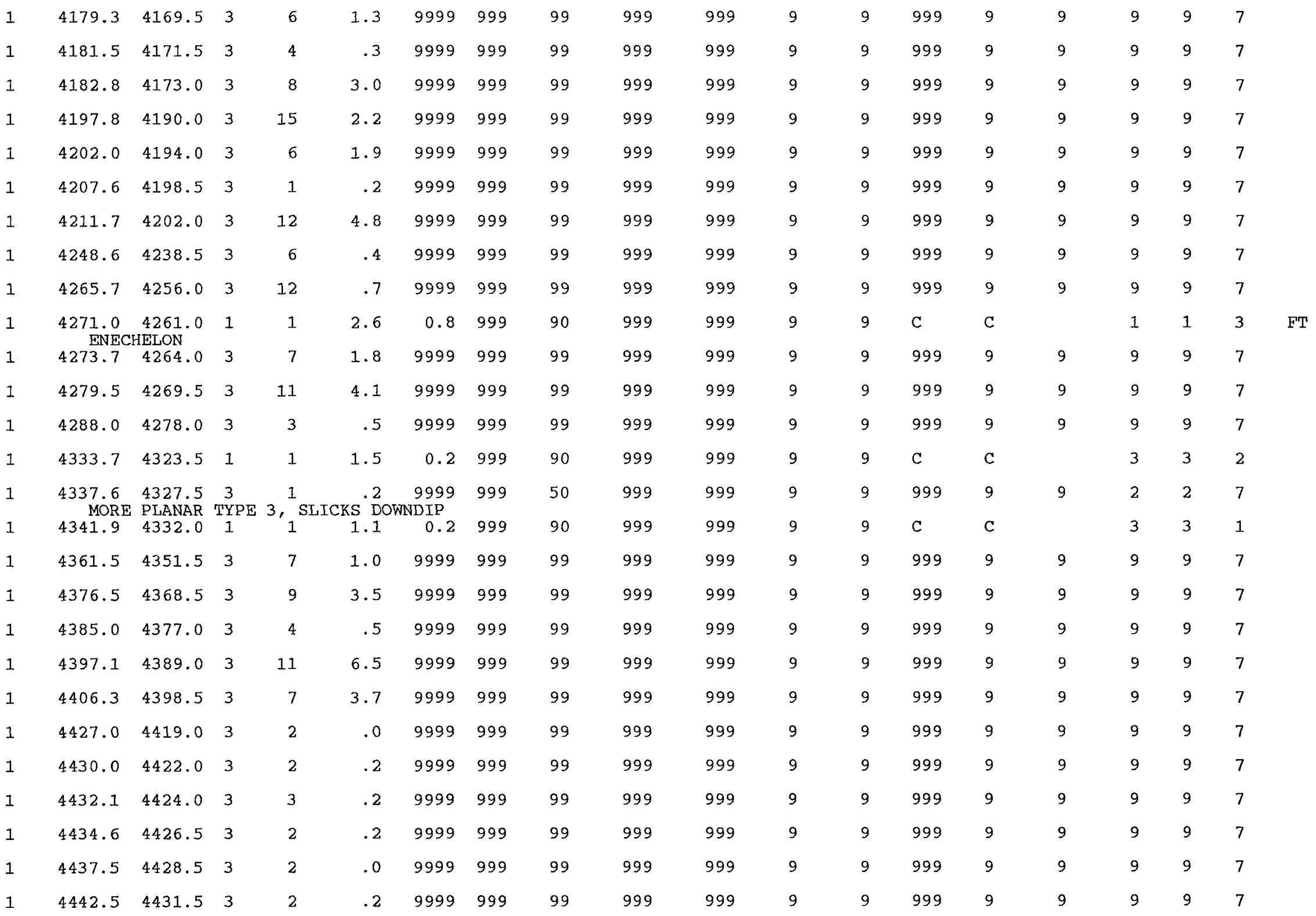




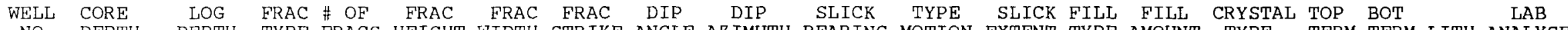

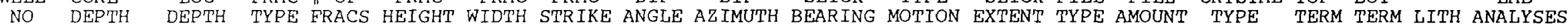

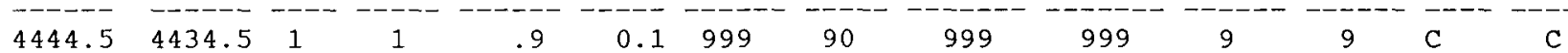
MULTIPLE SMALT ENECHELON FRACS, ORGANICS WITH CALCTTE
4452.04442 .0
999

$4454.4 \quad 4444.5 \quad 3 \quad 7$

$4460.9 \quad 4451.0 \quad 3$

$2.19999 \quad 999 \quad 99$

999

9

9999

$1.99999999 \quad 99$

999

999

$4465.0 \quad 4455.0 \quad 3 \quad 10$

$\begin{array}{llll}3.0 & 9999 \quad 999 \quad 99 \quad 999\end{array}$

$4474.0 \quad 4464.0 \quad 3 \quad 10$

$\begin{array}{llll}4.0 & 9999 & 999 & 99\end{array} 999$

$4481.2 \quad 4471.0 \quad 3$

$4491.9 \quad 4480.0 \quad 1$

$4493.6 \quad 4482.5 \quad 3 \quad 16$

$\begin{array}{llll}1.5 & 9999 & 999 & 99\end{array} 999$

$\begin{array}{lllll}1.7 & 0.4 & 999 & 90 & 999\end{array}$

$\begin{array}{lllll}5.9 & 9999 & 999 & 99 & 999\end{array}$

$4505.7 \quad 4493.5 \quad 3 \quad 4$

$\begin{array}{llll}.0 & 9999 & 999 & 99\end{array}$

$4509.9 \quad 4498.0 \quad 3 \quad 7$

$\begin{array}{lllll}6.6 & 9999 & 999 & 99 & 999\end{array}$

999

999

999

999

999

999

999

$4529.1 \quad 4517.0 \quad \mathrm{P} \quad 1$ $.2 \quad 9999 \quad 999 \quad 70$

999 INIATTON ANGLE 40 DEG., CONCAVE UP

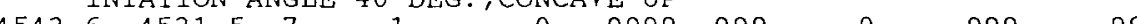

457MPLED BY PITTMAN AND SPRUNT, FILL?, NO DATA AVAILABLE

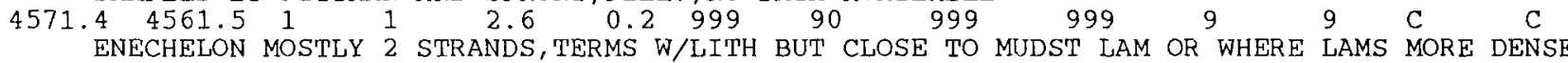

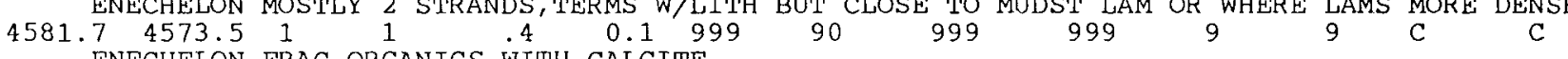

4585.524576 .5 TRAC ORGANICS WITH CALCITE

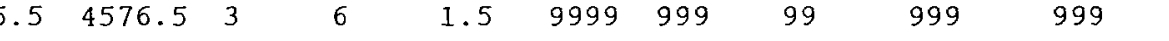

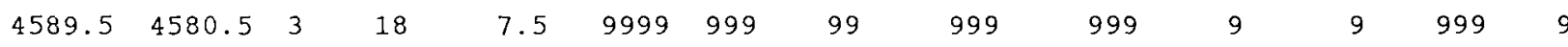

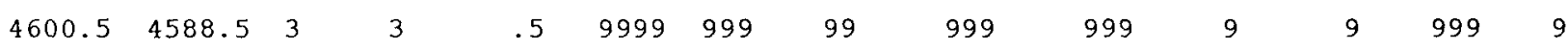

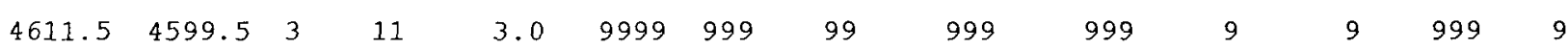

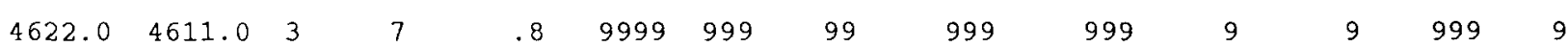

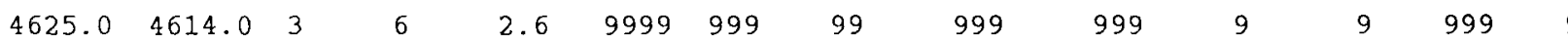

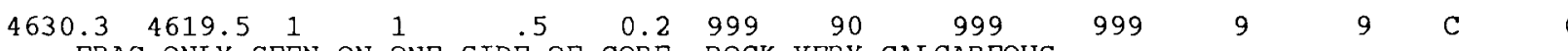

4645.3 .

BUMPY IRREGULAR PLANE WITH PATCHES OF SLICKS

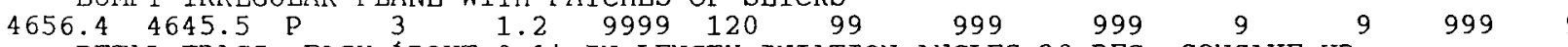

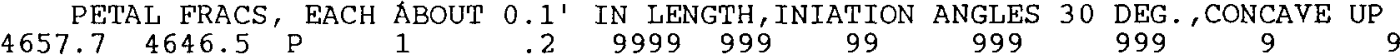

INIATION ANGLE 35 DEG.-CONCAVE UP

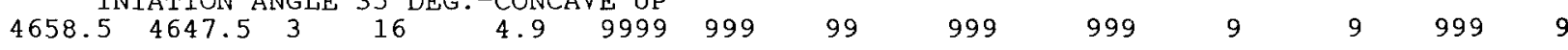

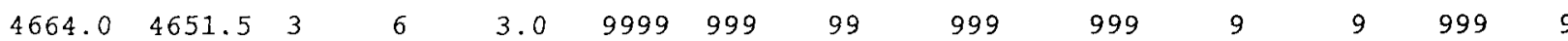

$4705.6 \quad 4692.5$

FRAC JUST BARELY SKIMMED CORE, 2 ILL LOOKS PATCHY ON EXPOSED PLANE 


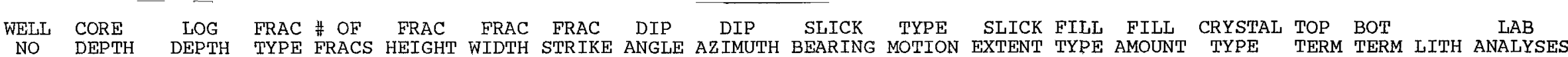

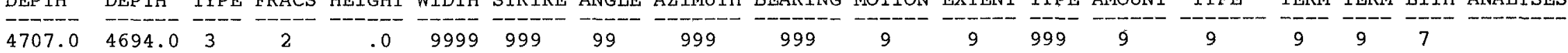

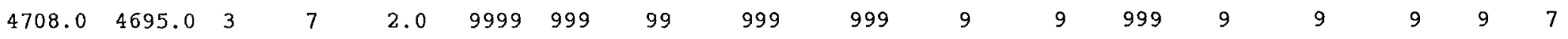

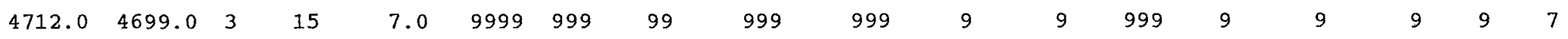

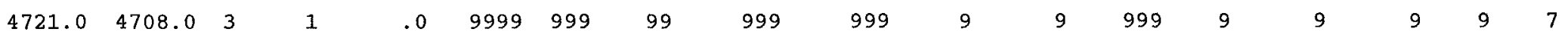

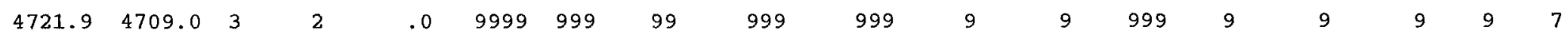

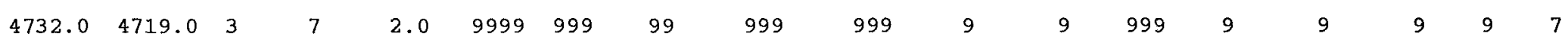

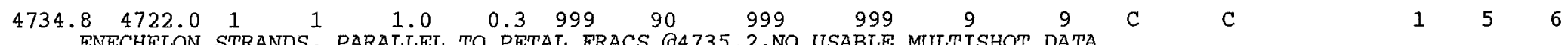

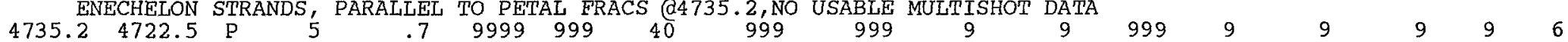
APPROX $0.1^{\prime}$ IN LENGTH, INIATION ANGLE 50 DEG., CONCAYE UP $\begin{array}{lllllllll}4736.3 & 4723.5 & P & 2 & .3 & 9999 & 999 & 99 & 999\end{array}$ APPROX 0.1'IN LENGTH INIATION ANGLE 33 DEG., CONCAVE UP $\begin{array}{llllllllll}4736.6 & 4724.0 & 1 & 1 & .5 & 0.1 & 999 & 90 & 999 & 999\end{array}$

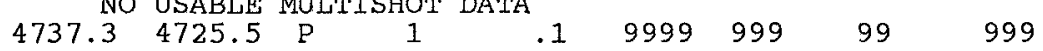
4739.6 $4727.5 \quad 3 \quad 1 \quad$. 3999999999

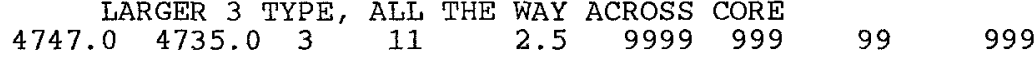

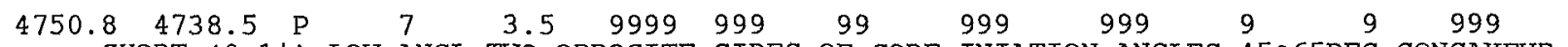

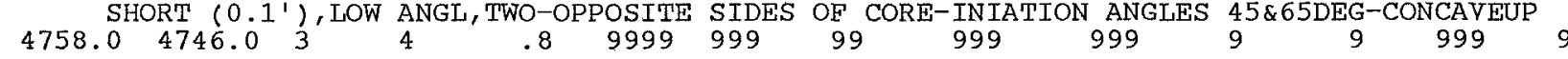

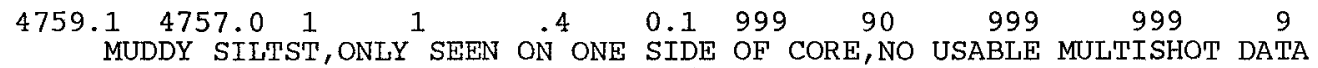

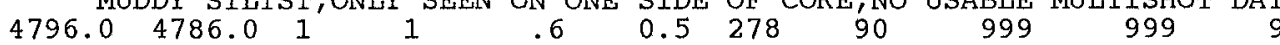
STRANDED, TOPTERM @ INTERLAMINATED MUDST AND SS

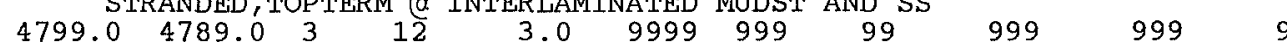
$\begin{array}{lllllllll}4803.0 & 4793.0 & 3 & 4 & 3.0 & 9999 & 999 & 99 & 999\end{array}$ $\begin{array}{llllllll}4812.0 & 4802.0 & 3 & 4 & 2.0 & 9999 & 999 & 99\end{array}$

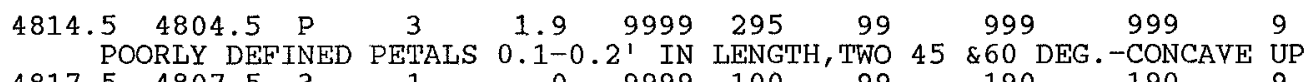

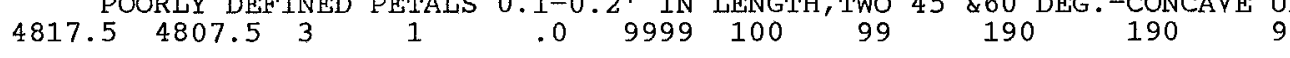




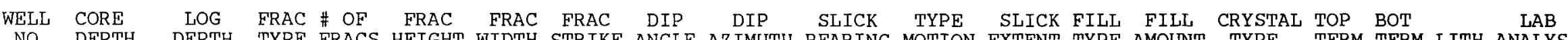

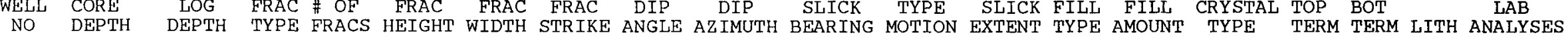

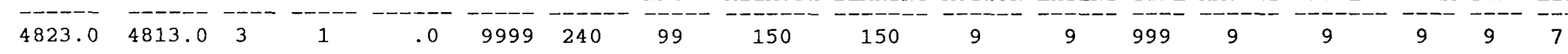

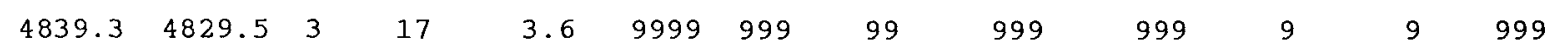
$\begin{array}{llllllll}4843.8 & 4834.0 & 1 & 1 & .9 & 0.2 & 999 & 90\end{array}$ $\begin{array}{llllllll}4846.4 & 4837.0 & 1 & 1 & 1.2 & 1.0 & 999 & 90\end{array}$ 999999 $4846.4 \quad 4837.0 \quad 1 \quad \frac{1}{1} \quad \begin{array}{lll}1.2 & 1.0 & 999\end{array}$ $\begin{array}{cccccccc}4853.6 & 4843.5 & 1 & 1 & 1.0 & 0.3 & 999 & 90\end{array}$

999

\section{9}

$4858.5 \quad 4848.5 \quad 3 \quad 1$

$.29999 \quad 999 \quad 99$

$\begin{array}{llll}4864.5 & 4854.5 & 3 & 13\end{array}$

$11.59999 \quad 999 \quad 99$

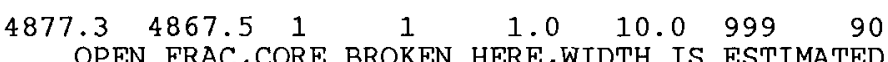

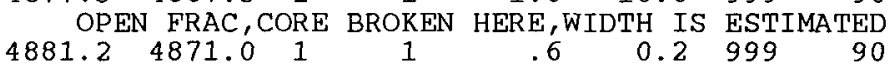

999

$\begin{array}{llllllll}4889.7 & 4879.5 & 3 & 4 & 2.6 & 9999 & 999 & 60\end{array}$ ALL PARALLEL, POLISHED SURFACES THROUGH CORE

MOSTLY COMPLETE BUT SOME GAPS IN FILL,POSSIBLY SOME QTZ TOO

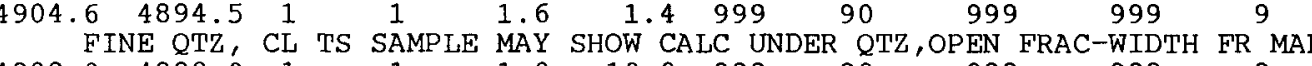

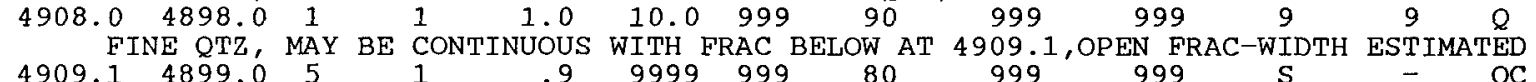

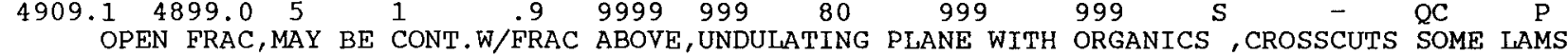

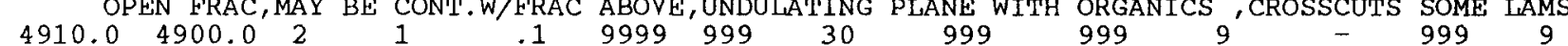
FRAC ABOVE TERMS HERE

$\begin{array}{ccccccccc}4919.7 \quad 4909.5 & 1 & 1 & .5 & 0.2 & 999 & 90 & 999 & 999\end{array}$

4TL LOKS PARTIAI ON EXPOSED PIANE

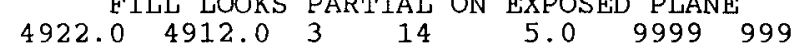

$\begin{array}{llllllll}4952.7 & 4950.5 & 3 & 1 & .2 & 9999 & 999 & 99\end{array}$

LARGER 3 TYPE
$4959.0 \quad 4947.0 \quad 3$

99999

999

9

$4964.4 \quad 4952.53$

$9999 \quad 999-99$
999

999

999

IJARGER 3 TYPES

$2.9 \quad 9999 \quad 999 \quad 99$

$3.0 \quad 9999 \quad 999 \quad 99$

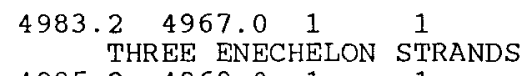

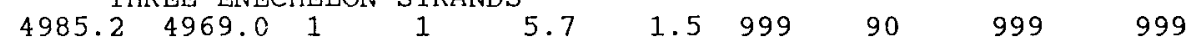

STRANDED, SEVERAL MISSING CORE INTERVALS IN THE MIDDLE

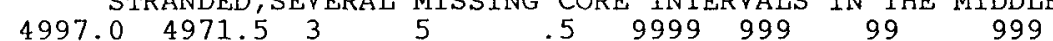

$\begin{array}{llllllll}4999.1 & 4973.5 & 1 & 1 & .1 & 0.1 & 999 & 90\end{array}$

999

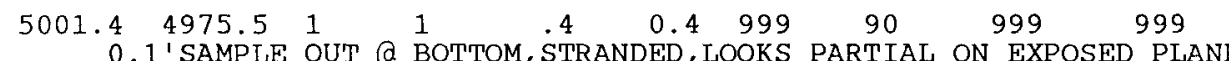

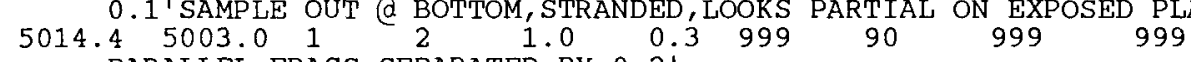

5016.4 5ARALLEL FRACS SEPARATED BY 0.2

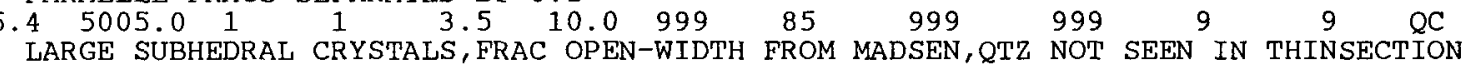




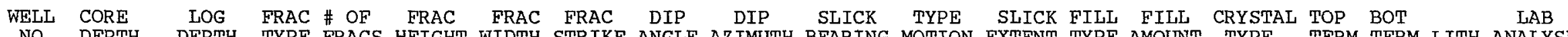

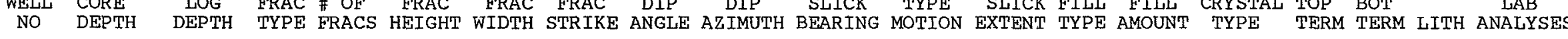

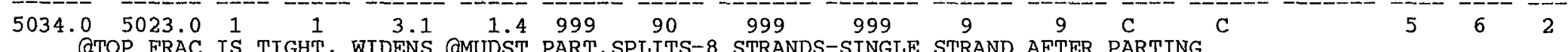
5035. 6 TOP FRAC IS TIGHT, WIDENS QMUDST PART.SPLITS-8 STRANDS-SINGLE STRAND AFTER PARTING DOWN DIP SLKS PARALLEL TO FRAC STRIKE Q5034.0-CM GAP IN EXT FRAC-?OFFSET

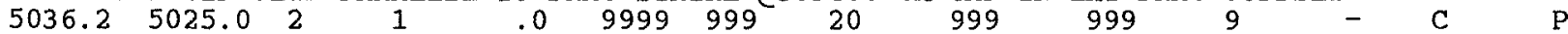
POLISHED, SLKS NORMAL TO FRAC STRIKE @5034.0, OCCURS@GAP IN FRACD5034.0, IRREG PL SINGLE STRAND

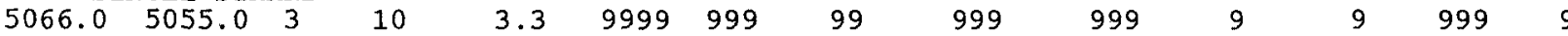

$\begin{array}{lllllllllllllll}5067.1 & 5055.5 & 1 & 1 & .3 & 0.3 & 999 & 50 & 999 & 999 & 9 & 9 & \mathrm{C} & \mathrm{C}\end{array}$

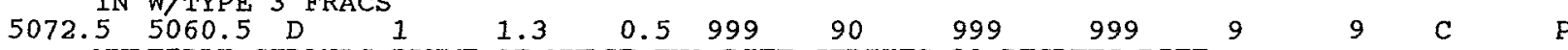

5074.9 MUTIPLE STRANDS PLUME OF MUDST, TWO DIFF STRIKES-30 DEGREES DIFF

MOSTLY COMPLETE FILL-SOME GAPS

$\begin{array}{llllllllllllll}5078.5 & 5067.5 & 1 & 1 & .4 & 1.0 & 999 & 80 & 999 & 999 & 9 & 9 & \mathrm{C} & \mathrm{C}\end{array}$

$\begin{array}{llllllllllllll}5080.8 & 5069.5 & 1 & 1 & 1.0 & 0.1 & 999 & 90 & 999 & 999 & 9 & 9 & \mathrm{C} & \mathrm{C}\end{array}$

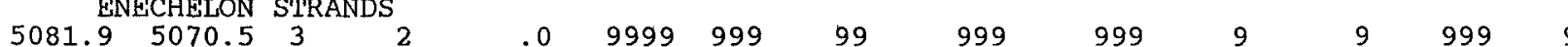

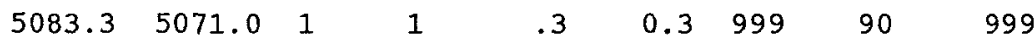

$5094.2 \quad 5083.0 \quad 1 \quad 1$

$.3 \quad 0.2 \quad 999 \quad 90$

$5113.1 \quad 5102.0 \quad 3 \quad 7$

$2.99999 \quad 999 \quad 99$

6 - 9999099

$5122.0 \quad 5111.0 \quad 3 \quad 3$

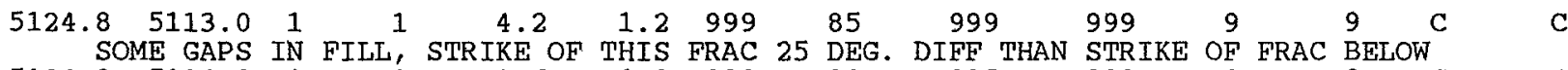

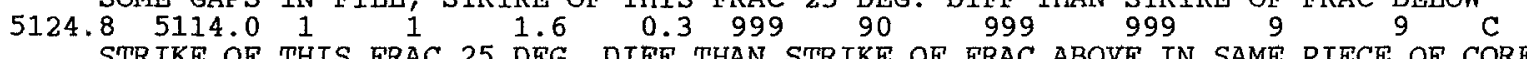

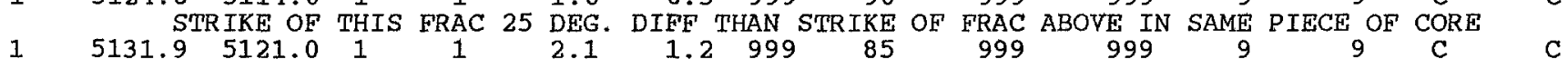

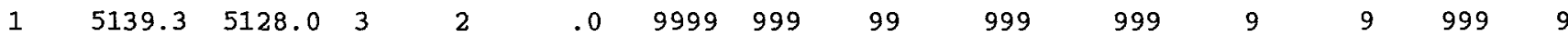

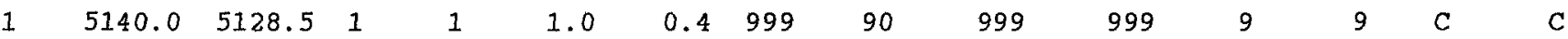

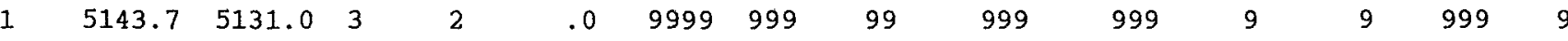

$\begin{array}{lllllllllllllll}5144.4 & 5131.5 & 1 & 1 & 2.0 & 0.2 & 999 & 90 & 999 & 999 & 9 & 9 & \mathrm{C} & \mathrm{C}\end{array}$

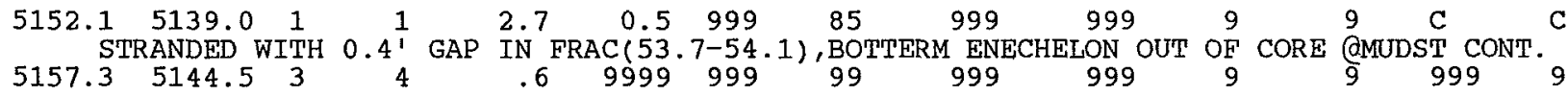

$\begin{array}{llllllllllllll}5157.9 & 5145.0 & 1 & 1 & .5 & 0.3 & 999 & 90 & 999 & 999 & 9 & 9 & \mathrm{C} & \mathrm{C}\end{array}$

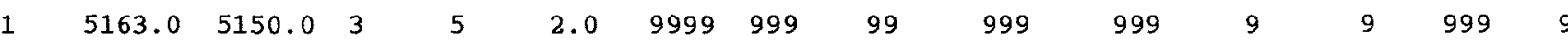

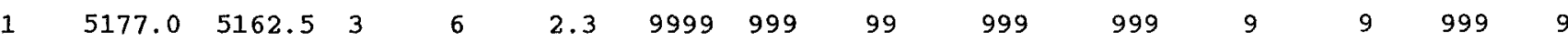

$\begin{array}{lllllllllllll}1 & 5183.0 & 5168.0 & 3 & 8 & 1.3 & 9999 & 999 & 99 & 999 & 999 & 9 & 9\end{array}$ 
CORE LOG FRAC \# OF FRAC FRAC FRAC DIP DIP SLICK TYPE SLICK FILL FILL

CRYSTAL TOP BOT LAB LAB
AALYSES 
WELL CORE LOG FRAC \# OF FRAC FRAC FRAC DIP DIP SLICK TYPE SLICK FILL FILL CRYSTAL TOP BOT

LAB

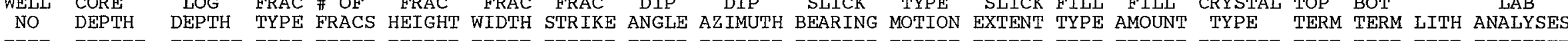

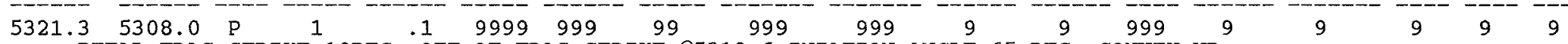

PETAL FRAC STRIKE 10DEG. OFF OF FRAC STRIKE @5319.6-INIATION ANGLE 65 DEG.-CONVEX UP

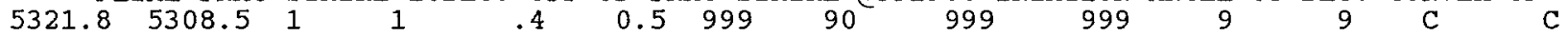

ROCK TYPE-INTERBED MUDST \& SANDST

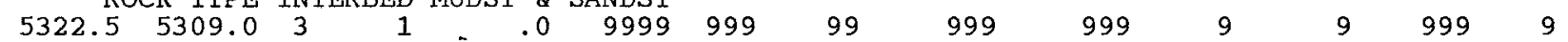

$\begin{array}{llllllllllllll}5324.6 & 5311.0 & 1 & 1 & .3 & 0.1 & 999 & 90 & 999 & 999 & 9 & 9 & \mathrm{C} & \mathrm{C}\end{array}$

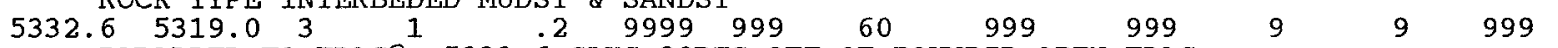

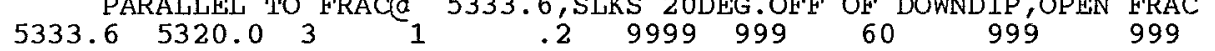

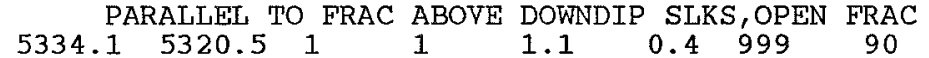

FILL LOOKS PARTIAL ON EXPOSED PLANE

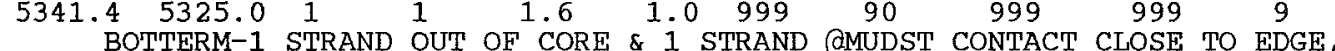

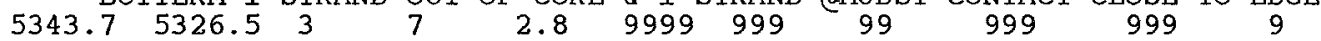

$\begin{array}{lllllllll}5347.4 & 5330.5 & 1 & 1 & .3 & 0.1 & 999 & 90 & 999\end{array}$

$\begin{array}{lllllllll}5358.6 & 5343.0 & 1 & 1 & 1.4 & 0.5 & 999 & 90 & 999\end{array}$

ENECHELON STRANDS, WAVY \& CLOSE TO EDGE OF CORE

$\begin{array}{lllllllll}5360.9 & 5345.5 & 1 & 1 & .8 & 0.4 & 999 & 90 & 999\end{array}$

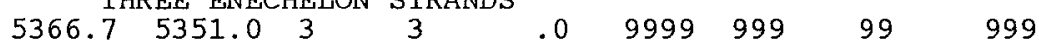

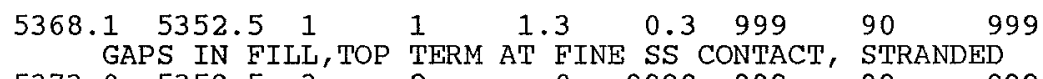

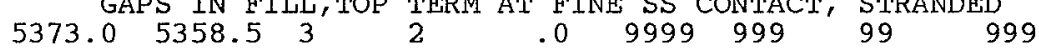

999

9

$\begin{array}{lllllllll}5373.4 & 5359.0 & 1 & 1 & .7 & 0.2 & 999 & 90 & 999\end{array}$

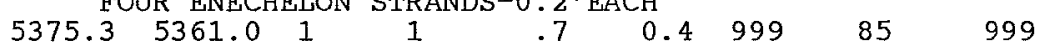

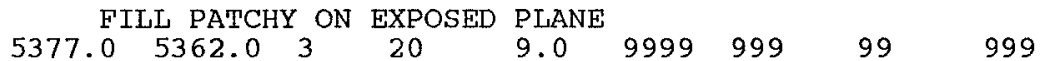

$\begin{array}{lllllllll}5388.3 & 5377.5 & 1 & 1 & .1 & 9999 & 999 & 90 & 999\end{array}$

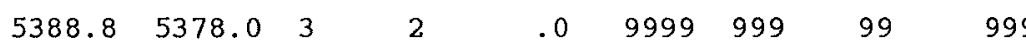

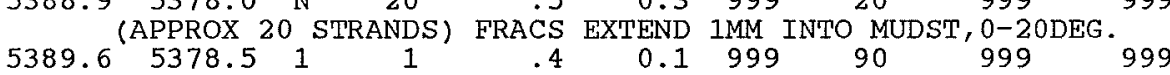

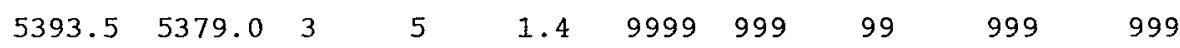

$\begin{array}{llllllllll}5398.6 & 5383.5 & 1 & 1 & .5 & 0.1 & 999 & 90 & 999 & 999\end{array}$

$\begin{array}{llllllllll}5399.3 & 5384.5 & 1 & 1 & .4 & 0.2 & 999 & 90 & 999 & 999\end{array}$

FRAC MAY BE RELATED TO FRAC @5398.6-GAP @ 2 "MUDST PARTING

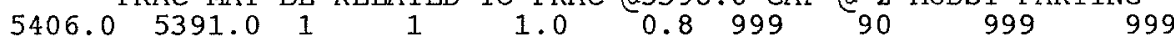

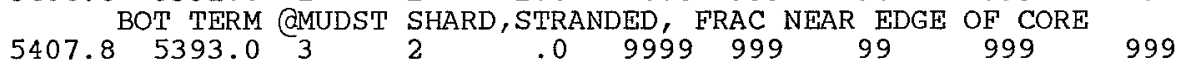

$5409.2 \quad 5394.0 \quad 1$

$\begin{array}{clcc}5394.0 & 1 & 1 & 1.1 \\ \text { STRANDED, } & \text { WIDER AT } & \text { BOTTOM }\end{array}$

0.8999

90

999

999

\section{9}

9

99

99


WELL CORE LOG FRAC \# OF FRAC FRAC FRAC DIP DIP SLICK TYPE SLICK FILL FILL CRYSTAL TOP BOT

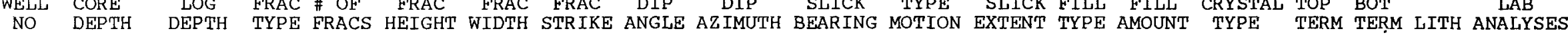

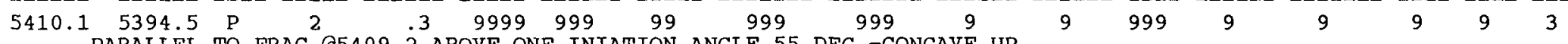

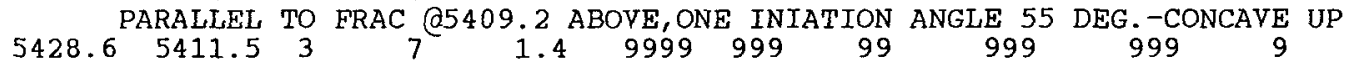

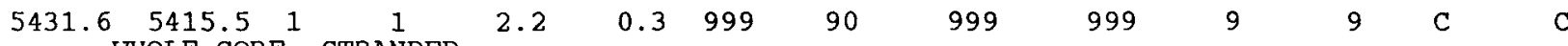

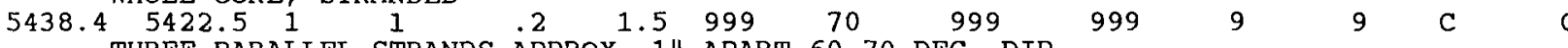

5439 THREE PARALLEL STRANDS APPROX. 1" APART, $60-70$ DEG. DIP

I LAMS MORE 1 .

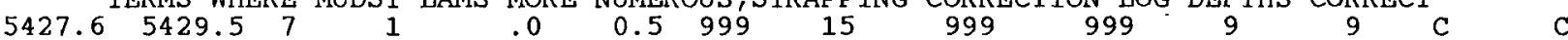

5429.9 FRAC ONLY PART WAY THRU CORE, FRAC APPEARS TO BE WITHIN ORGA MUDST LAM.

. 5432.00

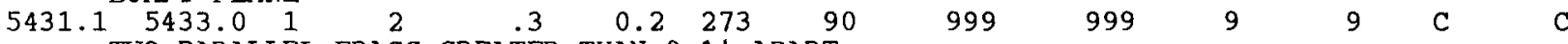

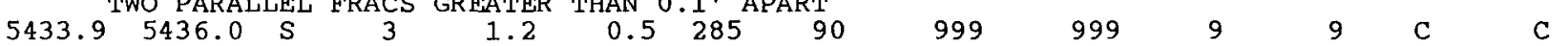

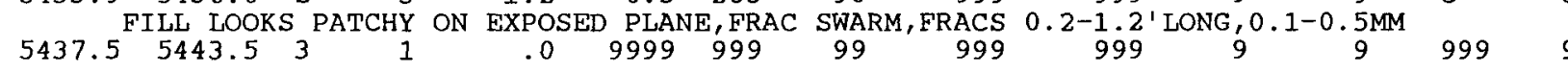

$\begin{array}{llllllllllll}5438.5 & 5444.5 & 2 & 1 & .0 & 9999 & 340 & 15 & 70 & 220 & 9 & -\end{array}$

5440.6 PATCHES OF CALCITE OPEN FRAC, BUMPY IRREG BREAK, FLAT XSTALS, FAINT SLKS

FRAC IS CLOSE TO EDGE OF CORE, OPEN FRAC, FILL PATCHY ON EXPOSED PLANE

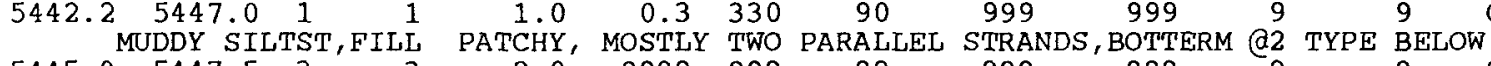

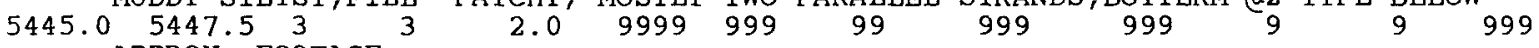

APPROX. FOOTAGE

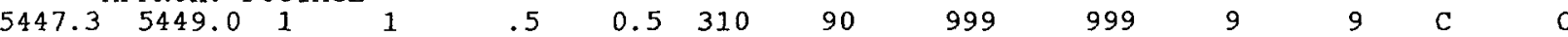

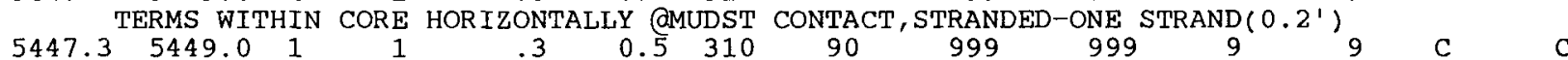

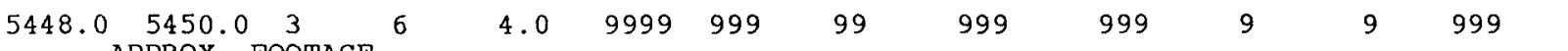

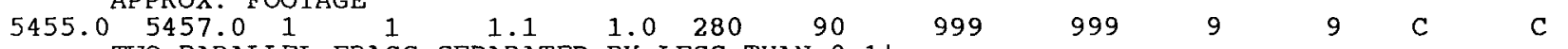

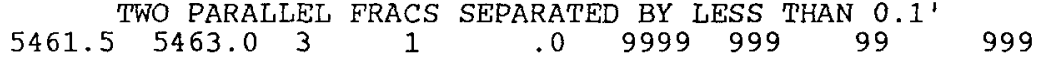

$\begin{array}{lllllllllllllllllll}5474.0 & 5475.0 & 4 & 1 & .0 & 9999 & 290 & 15 & 20 & 230 & \mathrm{R} & +\mathrm{C}\end{array}$

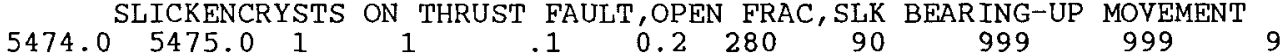

TOP TERM @THRUST FAULT ABOVE, BOT TERM CLOSE TO MUDST CONTACT

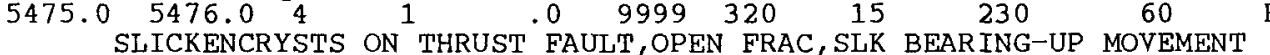

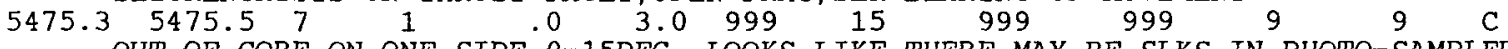

5488.054900 1 11 SIDE, 0 -15DEG., LOOKS LIKE THERE MAY BE SLKS IN PHOTO-SAMPLED

ONLY SEEN ON ONE SIDE OF CORE

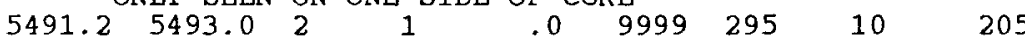

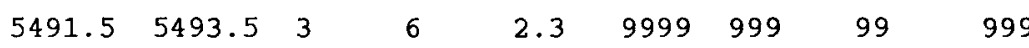

9999

$5-9-999$

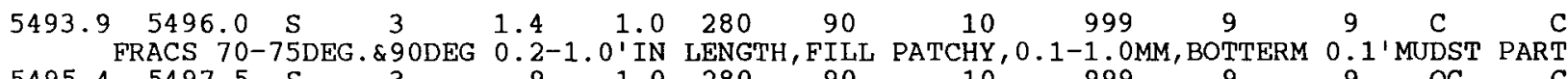

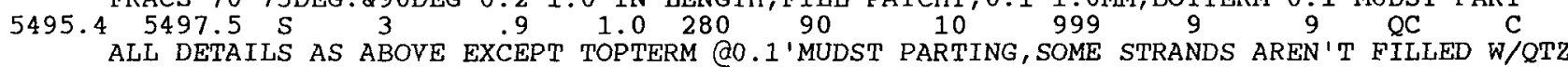




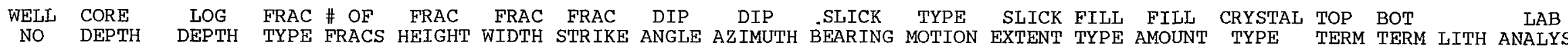

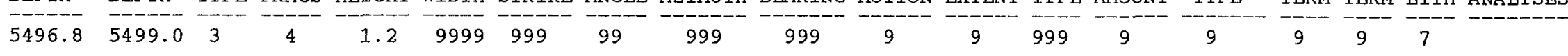
$\begin{array}{llllllllll}5498.4 & 5500.5 & 1 & 1 & .5 & 0.5 & 290 & 70 & 20 & 999\end{array}$

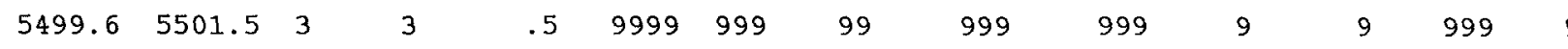

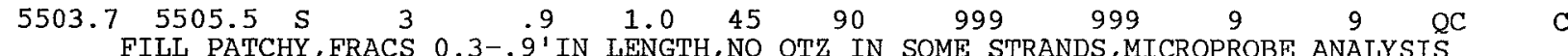

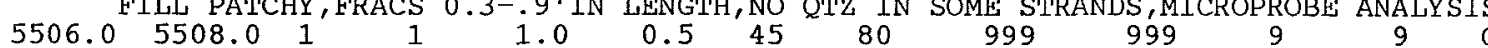
FILI PATCHY, FRAC SKIMS CORE CLOSE TO EDGE

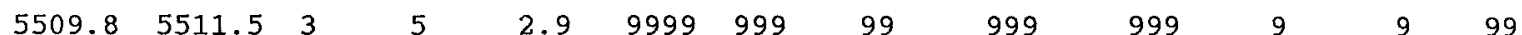

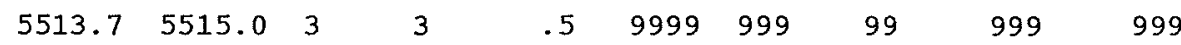

$5520.6 \quad 5522.0 \quad 1$

$5523.0 \quad 5525.0 \quad 3$

0.5295

$\begin{array}{llll}5523.4 & 5525.5 & 3 & 1\end{array}$

$.09999999 \quad 99$

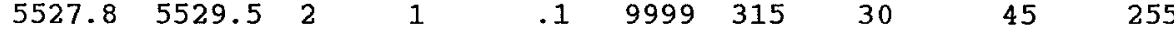
5528.0 SLK BEARING-UP DIR. CARB; MAT'L CONCENTRATED ON THRUST FAULT PLANE, SUBTLE SLICKS SLKS IN PATCHES ASSOC W/ORGA MAT'

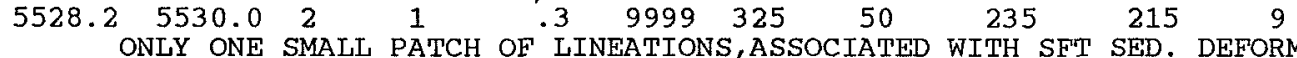

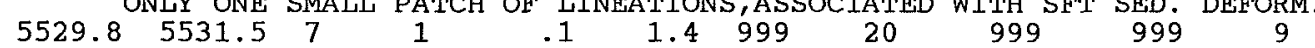
ONF FND OF FRAC IN LTTH, $0-20 D E G$. DIP $5530.4 \quad 5532.5 \quad 7 \quad 1 \quad 1101.0 \quad 230$

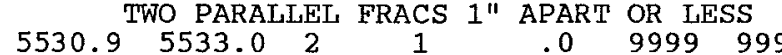

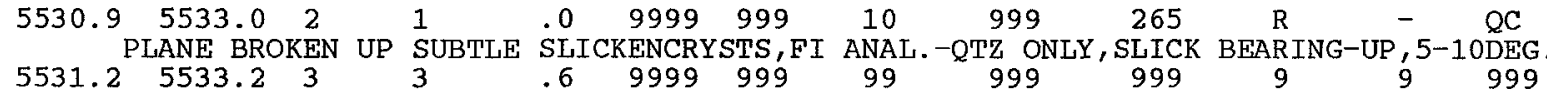

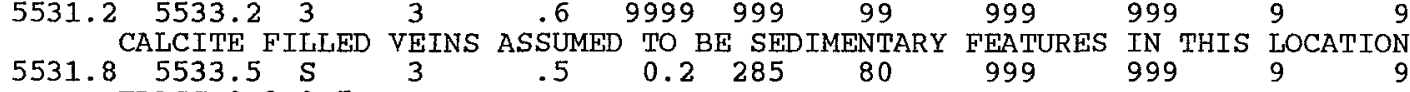

$5531.85533 .5 \mathrm{~S}$ FRACS $0.2-0$.

$5532.1 \quad 5533.7 \quad 1$

$1 \quad \begin{array}{lllll}2 & 0.2 & 325 & 80 & 999\end{array}$ 999 5536.95385 P 5536.9 . 15 DEG - 0 CONCAVE UP

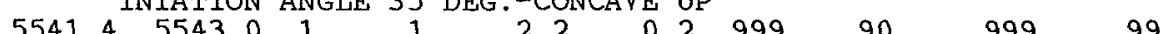
OFFSET Q TYPE 2 5543.2, PARALLEL TO PETAL ABOVE

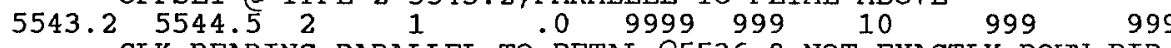

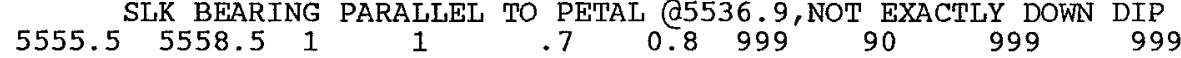
ALI DATA FROM MADSEN'S NOTES, STRANDED $\begin{array}{llllllllll}5557.9 & 5561.0 & 1 & 1 & 4.0 & 1.0 & 999 & 90 & 999 & 999\end{array}$ 5562.6 SOME CORE MISSING HERE

OCCURS IN ORGA LAM IN SS,SUBHEDRAL?, OPEN FRAC

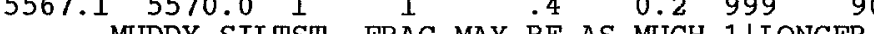

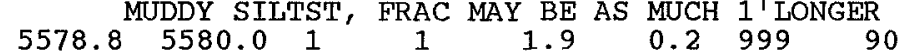


DI

SLICK TYPE SLICK FILL FILI CRYSTAL TOP BOT

$5583.6 \quad 5584.5 \quad 3 \quad 10$

\begin{abstract}
6.49999999
\end{abstract}
DLE AZ IMUTH BEARING MOTION EXTENT TYPE AMOUNT TYPE

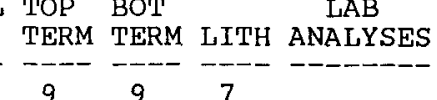

$5587.0 \quad 5590.0 \quad 3$

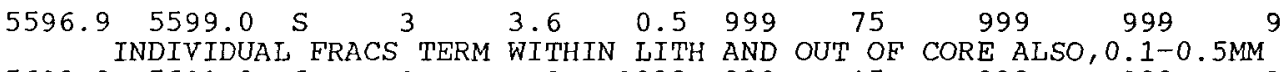

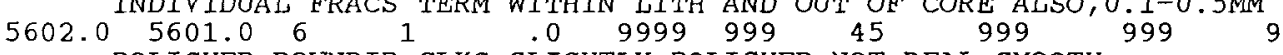

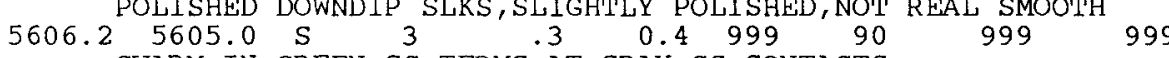

5607 SWARM IN GREEN SS, TERMS AT GRAY SS CONTACTS

CROSSES HORIZ. FRAC BELOW, HORIZ FRAC APPEARS OLDER

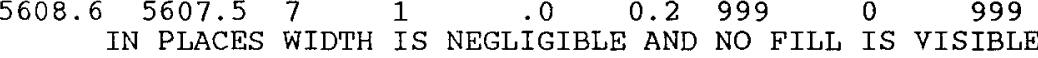

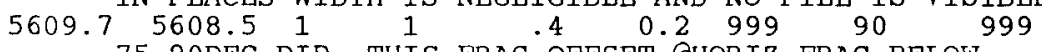

$5610.075-900$ G. DIP, THIS FRAC OFFSET QHORIZ FRAC BELOW 999

$\begin{array}{llllll}999 & 0 & 999 & 999 & 9 & 9\end{array}$

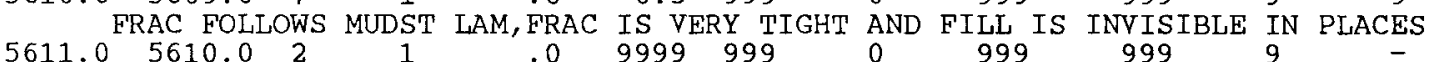

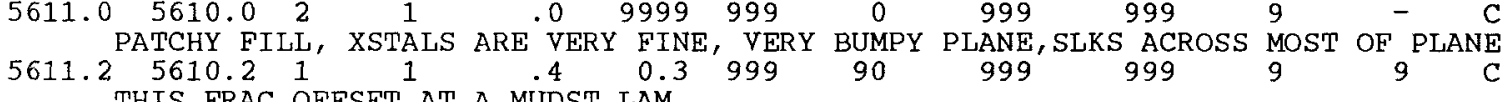

5611.75610 .5771 A 7 A

FOLLOWS IRREG. BEDDING PLANE, IN PLACES FILL IS INVISIBLE

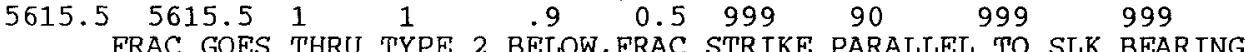

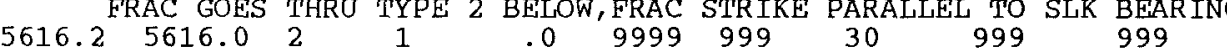

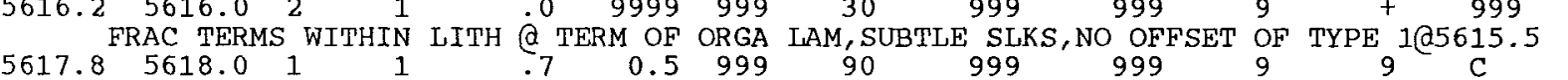

FRAC JUST BARELY SKTMS CORE-QUESTIONABLE WIDTH

$\begin{array}{llllllllll}5623.7 & 5623.5 & 2 & 1 & .0 & 9999 & 999 & 20 & 999 & 999\end{array}$

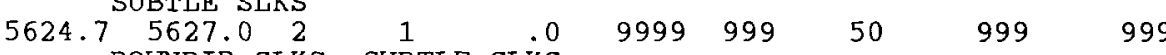

DOWNDIP SLKS, SUBTLE SLKS

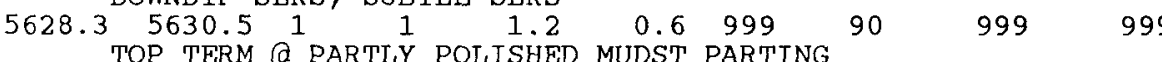

5633.0 5635.0

PROBABLY ONLY A FEW TENTHS LONGER, SEPARATED FROM FRAC BELOW BY SED. SWIRL C C

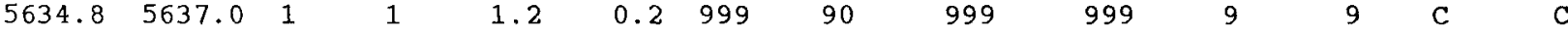

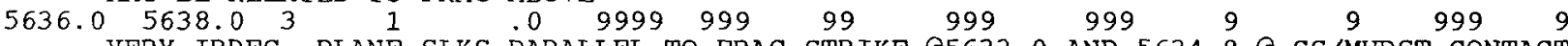

VERY IRREG. PLANE SLKS PARALLEL TO FRAC STRIKE @5633.0 AND 5634.8,@ SS/MUDST CONTACT

$\begin{array}{llllllll}5639.3 & 5641.5 & 3 & 1 & .0 & 9999 & 999 & 99\end{array}$

999999

$5644.8 \quad 5646.5 \mathrm{~S} \quad 3$

$5646.5 \quad 5647.0 \quad 3$

$\begin{array}{llll}.5 & 0.1 & 999 & 80\end{array}$

999

999

5647.95648 .0

1.09999999

99

999

999

$5648.3 \quad 5648.5 \quad 1$

$.0 \quad 9999 \quad 999 \quad 99$

999

999

ALL FROM MADSEN'S NOTES

999

$\begin{array}{llll}9 & 9 & 999 & 9 \\ 9 & 9 & \mathrm{C} & \mathrm{C} \\ 9 & 9 & 999 & 9 \\ 9 & 9 & 999 & 9 \\ 9 & 9 & \mathrm{C} & \mathrm{C}\end{array}$

\begin{tabular}{|c|c|c|}
\hline 9 & $y$ & \\
\hline \multirow[t]{2}{*}{9} & 9 & 9 \\
\hline & 1 & 1 \\
\hline \multirow[t]{6}{*}{9} & 2 & 2 \\
\hline & 6 & 6 \\
\hline & 1 & 1 \\
\hline & 2 & 2 \\
\hline & 1 & 1 \\
\hline & 2 & 2 \\
\hline \multirow[t]{4}{*}{$S$} & 2 & 2 \\
\hline & 1 & 1 \\
\hline & 2 & 2 \\
\hline & 3 & 2 \\
\hline \multirow[t]{2}{*}{9} & 2 & 3 \\
\hline & 2 & 2 \\
\hline 9 & 9 & 9 \\
\hline 9 & 2 & 2 \\
\hline \multirow[t]{4}{*}{9} & 2 & 2 \\
\hline & 5 & 3 \\
\hline & 7 & 3 \\
\hline & 3 & 1 \\
\hline 9 & 2 & 2 \\
\hline 9 & 9 & 9 \\
\hline \multirow[t]{2}{*}{9} & 9 & 9 \\
\hline & 1 & 1 \\
\hline 9 & 9 & 9 \\
\hline \multirow[t]{2}{*}{9} & 9 & 9 \\
\hline & 3 & 3 \\
\hline
\end{tabular}




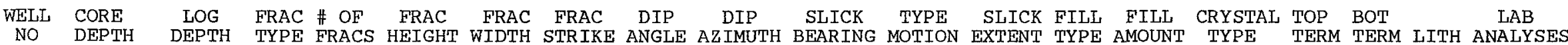
DEPTH DEPTH TYPE FRACS HEIGHT WIDTH STRIKE ANGLE AZIMUTH BEARING MOTION EXTENT TYPE AMOUNT TYPE TERM TERM LITH ANALYSES

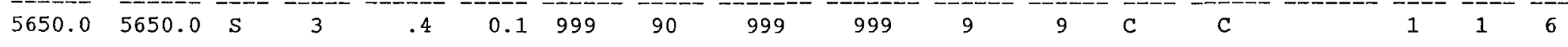

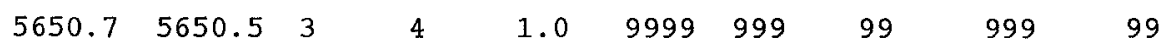
$\begin{array}{lllllllll}5652.1 & 5652.0 & S & 3 & .6 & 0.1 & 999 & 90 & 999\end{array}$ $\begin{array}{lllllllll}5653.5 & 5653.5 & 3 & 1 & .0 & 9999 & 999 & 99 & 999\end{array}$ $\begin{array}{lllllllll}5655.8 & 5657.0 & 1 & 1 & .1 & 0.1 & 999 & 90 & 999\end{array}$ $\begin{array}{lllllllll}5658.5 & 5659.5 & 3 & 4 & .0 & 9999 & 999 & 99 & 999\end{array}$ $\begin{array}{lllllllll}5661.0 & 5662.0 & 1 & 1 & .6 & 0.4 & 999 & 90 & 999\end{array}$

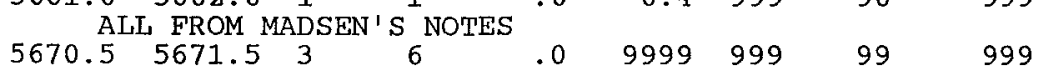


SLICK TYPE

SLICK FILL FILL
EXTENT TYPE AMOUNT

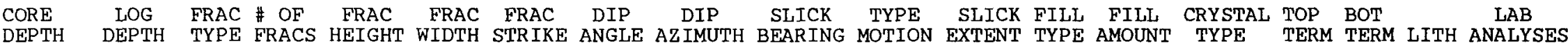

TOP BOT

LAB

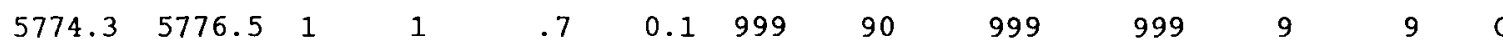

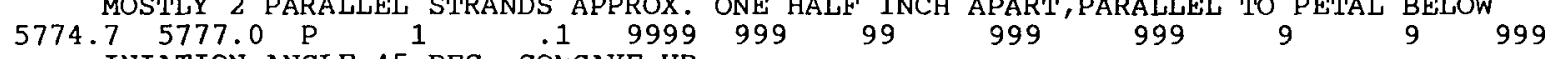

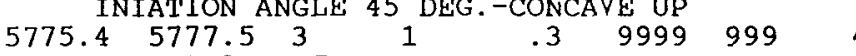

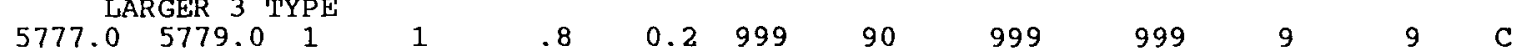

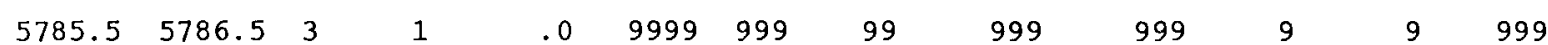

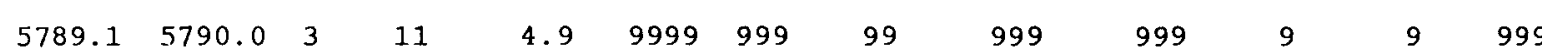

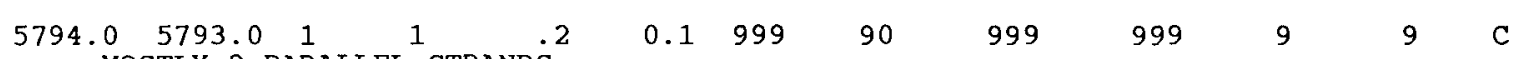

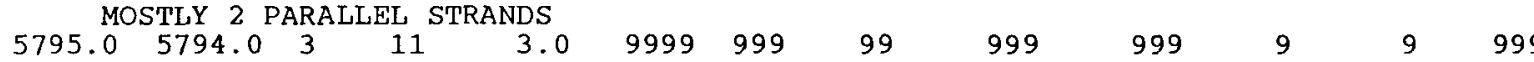

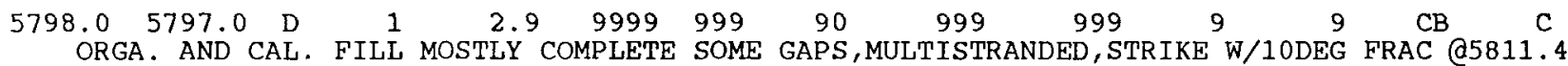

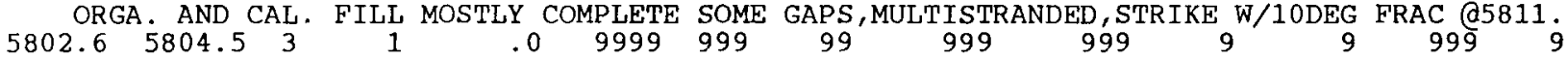

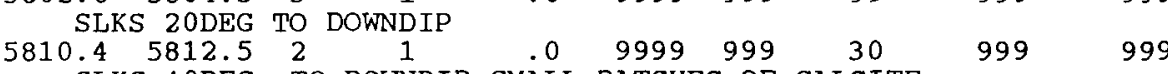

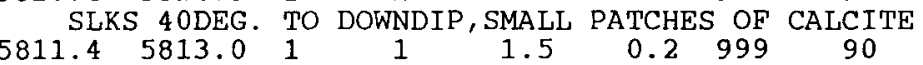

999999

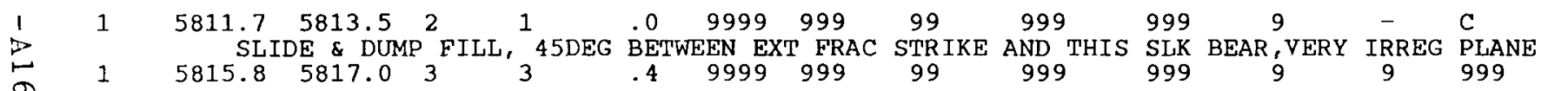

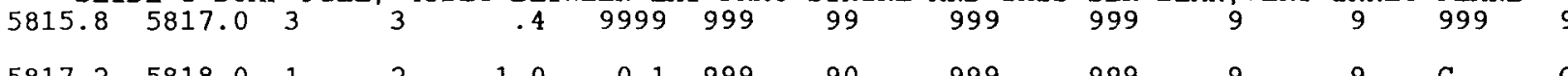

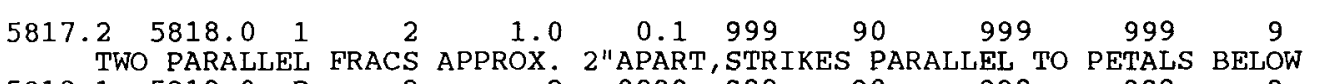

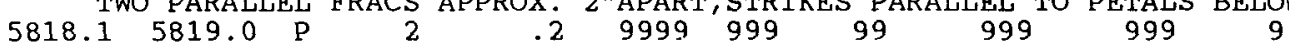

INIATION ANGLES 50 DEG. - CONVEX UP

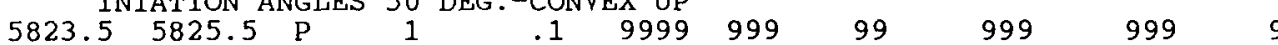

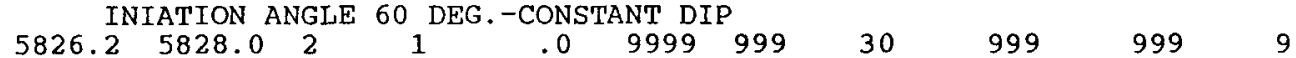

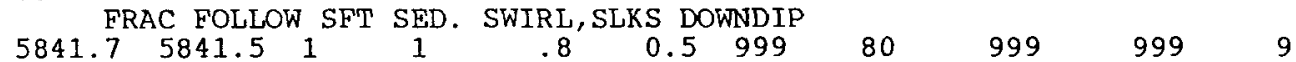

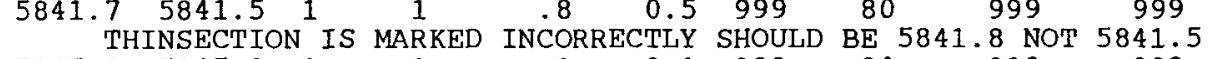

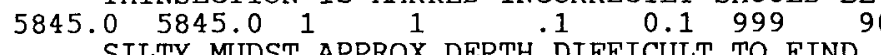

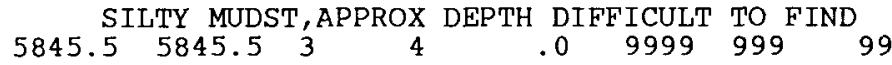

$999 \quad 999$

$\begin{array}{llllllll}5848.7 & 5848.5 & 3 & 3 & .3 & 9999 & 999 & 99\end{array}$

999

999

$\begin{array}{llllllll}5850.6 & 5850.5 & 3 & 3 & .0 & 9999 & 999 & 99\end{array}$

$999 \quad 999$

$\begin{array}{llllllll}5852.0 & 5852.0 & 3 & 4 & .0 & 9999 & 999 & 99\end{array}$

999

999

$\begin{array}{llllllll}5862.5 & 5861.5 & 3 & 4 & .0 & 9999 & 999 & 99\end{array}$

999

999

$5863.9 \quad 5863.0 \quad 1 \quad 1 \quad 1.8 \quad 7.0 \quad 999 \quad 90$

$999 \quad 999$

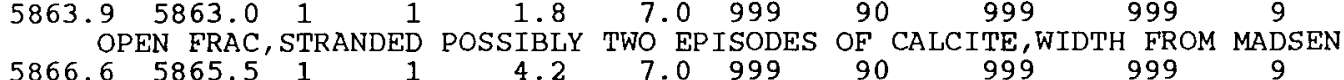

OPEN-WIDTH FR MADSEN SAMPLE OUT ONLY 4 'LONG, FILL AS ABOVE, MAY BE RELATED TO FRAC ABOYE?

$5871.75870 .5 \stackrel{S}{S}{ }^{3} \quad .2$
FRACS PARALLEL TO FRAC@5 866.6 


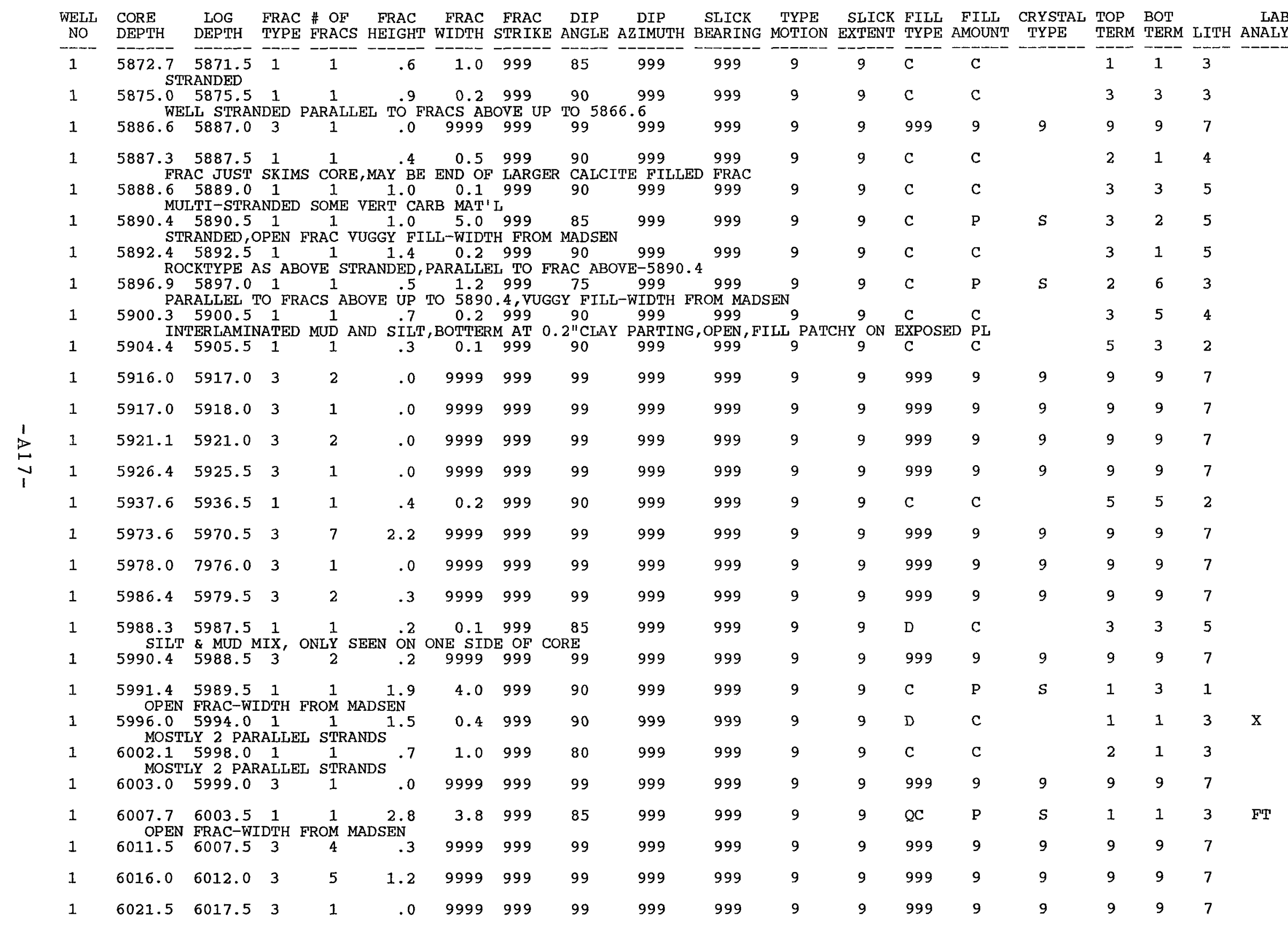




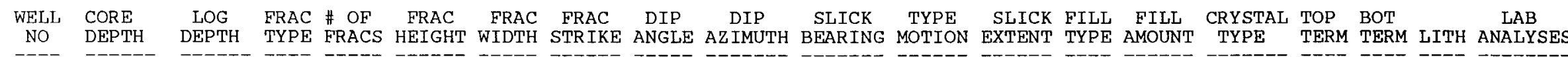

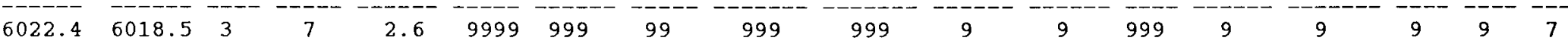

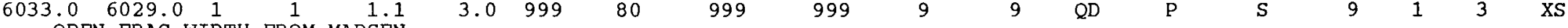

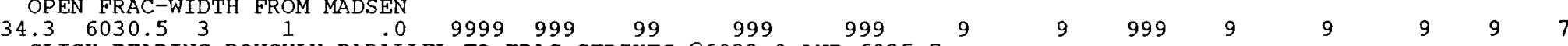

SLICK BEARING ROUGHLY PARALLEL TO FRAC STRIKES @6033.0 AND 6035.7

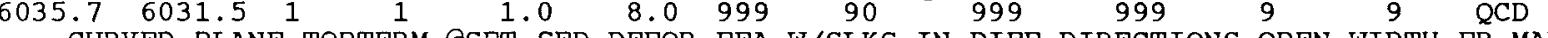

CURVED PLANE, TOPTERM QSFT SED DEFOR FEA W/SLKS IN DIFF DIRECTIONS, OPEN-WIDTH FR MAD

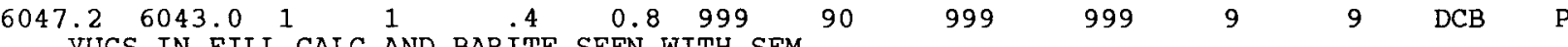

$\begin{array}{lllllllllllllll}6048.4 & 6044.5 & 1 & 1 & .9 & 1.0 & 999 & 80 & 999 & 999 & 9 & 9 & \text { DC } & \text { P }\end{array}$

$6050.7 \begin{array}{cccccccc}6046.5 & 1 & 1 & .3 & 2.0 & 999 & 90 & 999\end{array}$

6054.96 FILL

$\begin{array}{lllllll}6051.0 & 3 & 2 & .0 & 9999 & 999\end{array}$

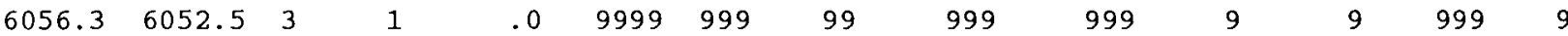

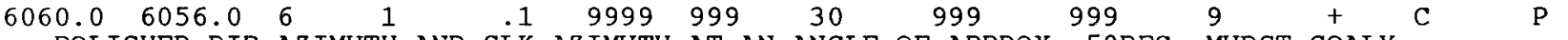

POLISHED, DIP AZIMUTH AND SLK AZIMUTH AT AN ANGLE OF APPROX. 5ODEG., MUDST-COALY

$\begin{array}{lllll}6071.5 & 1 & 1 & 1.4\end{array}$

6081.56077 .511

$6082.56078 .5 \& 8$

$\begin{array}{lllllll}2 & 1 & 0.5 & 999 & 10 & 999\end{array}$

$\begin{array}{lcccc}1 & 0.5 & 999 & 10 & 99 \\ . & 99 & \end{array}$

DEWATERING PIPE ABOVE

$6084.46081 .0 \quad 1.1$

$\begin{array}{lllllllll}6086.1 & 6082.5 & 3 & 1 & .0 & 9999 & 999 & 99 & 999\end{array}$

$\begin{array}{lllllllll}6088.7 & 6085.0 & 1 & 1 & .4 & 0.2 & 999 & 90 & 999\end{array}$

$\begin{array}{lllllllll}6100.2 & 6096.0 & 1 & 1 & .9 & 2.0 & 999 & 90 & 999\end{array}$

VUGGY FILL

$\begin{array}{lllllllll}6106.9 & 6103.0 & 1 & 1 & 1.1 & 0.4 & 999 & 90 & 999\end{array}$

$\begin{array}{lllllllll}6111.5 & 6107.5 & 3 & 7 & 1.0 & 9999 & 999 & 99 & 999\end{array}$

$\begin{array}{lcccccccc}\text { DEWATER ING } & \text { PIPE } & \text { ABOVE } & & & & & \\ 16.1 & 6112.0 & 3 & 2 & .0 & 9999 & 999 & 99 & 999\end{array}$

$\begin{array}{lllllllll}6117.9 & 6114.0 & 1 & 1 & .6 & 0.4 & 999 & 90 & 999\end{array}$

MUDDY SS

$\begin{array}{lllllllll}6119.1 & 6115.0 & 2 & 1 & .0 & 9999 & 999 & 5 & 999\end{array}$

$\begin{array}{ccccccccc}\text { OCCURS AT MUDST LAM } & & & & & \\ 23.3 & 6119.0 & 3 & 2 & .1 & 9999 & 999 & 99 & 999\end{array}$

$\begin{array}{lllllllll}6124.3 & 6120.0 & 1 & 1 & .4 & 0.8 & 999 & 90 & 999\end{array}$

$999 \quad 999$

VUGGY FILL, ONLY SEEN ON ONE SIDE OF CORE

$\begin{array}{llllllll}6124.4 & 6120.5 & 1 & 1 & 1 & 0.3 & 999 & 99\end{array}$

JUST BARELY SKIMMED CORE

$99 \quad 999$

999

$\begin{array}{llllllll}6125.3 & 6121.5 & 3 & 1 & 0 & 9999 & 999 & 99\end{array}$ 
WELL CORE LOG FRAC \# OF FRAC FRAC FRAC DIP DIP SLICK TYPE SLICK FILL FILL CRYSTAL TOP BOT

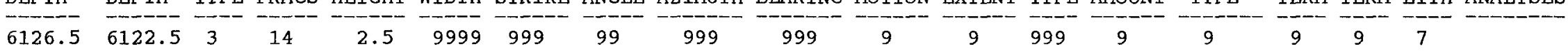

$\begin{array}{llllllllllllllllll}6127.1 & 6123.0 & 3 & 2 & .1 & 9999 & 999 & 30 & 999 & 999 & 9 & 9 & \mathrm{C} & \mathrm{P} & \mathrm{S} & 9 & 9 & 7\end{array}$

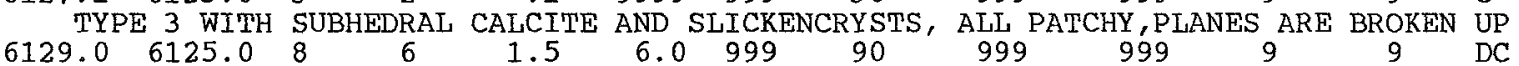
BREC SS, SS \& MUD MIX 0.1-6MM, SED FEATURES W/CAL\&DIC, HORI TO VERTI,PART-COMP

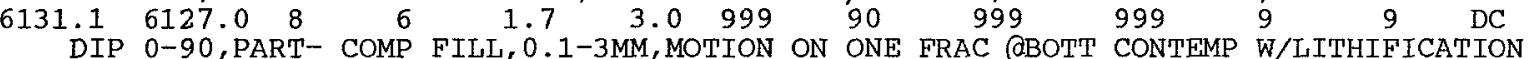

DIP 0-90,PART- COMP FILL, 1 -3MM,MOTION ON ONE FRAC OBOTT CONTEMP W/LITHIFICATION

DOWNDIP SLKS, PLANAR, POLISHED

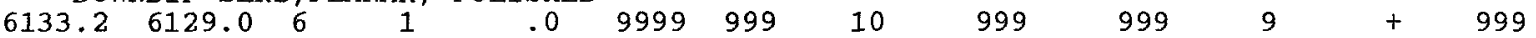

DOWNDIP SLKS, POLISHED VERY PLANAR

134.9 6131.0
MIXED SILT/MUD, $0.1-5 \mathrm{MM}, \mathrm{DIP} 40-90$

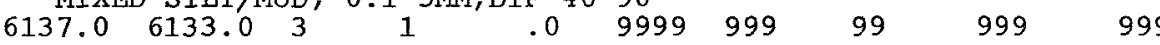

$\begin{array}{lllllllllllll}6143.6 & 6140.5 & 8 & 1 & .0 & 2.0 & 999 & 10 & 999 & 999 & 9 & 9 & \text { DC }\end{array}$

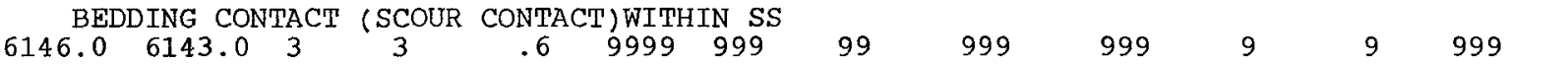

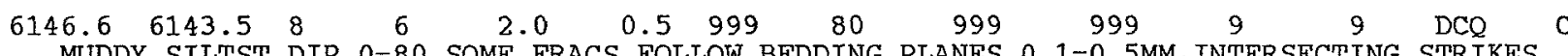

MUDDY SILTST, DIP $0-80$ SOME FRACS FOLLOW BEDDING PLANES, $0.1-0.5 \mathrm{MM}$, INTERSECTING STRIKES

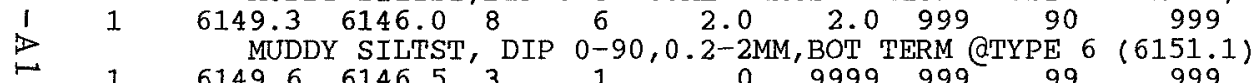

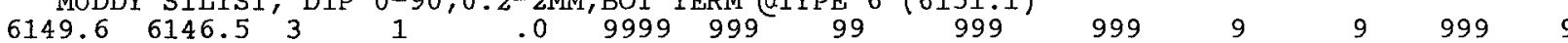

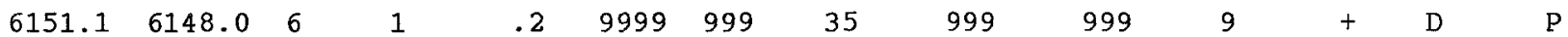

WEB TYPE FRACS CONC 1 "ABOVE THIS FRAC, OPEN FRAC, DOWNDIP SLKS, POLISHED

9999

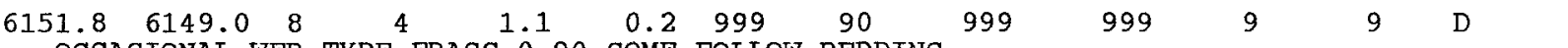

OCCASIONAL WEB TYPE FRACS, 0-90, SOME FOLLOW BEDDING

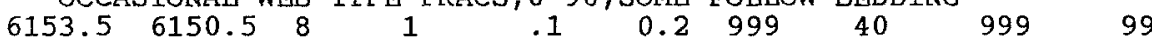

$\begin{array}{lllllllllllllll}6154.2 & 6151.0 & 8 & 1 & .0 & 1.0 & 999 & 10 & 999 & 999 & 9 & 9 & \mathrm{D} & \mathrm{C}\end{array}$

$\begin{array}{ccccccccccc}\text { MUDDY } & \text { SILTST } & & & & & & & \end{array}$

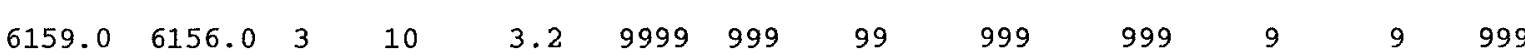

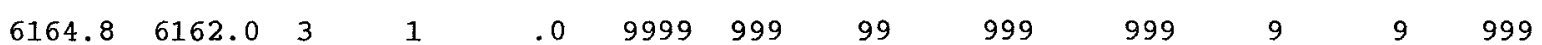

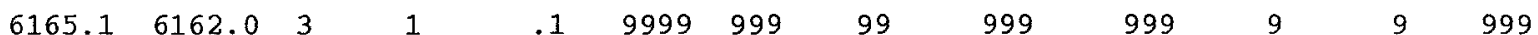

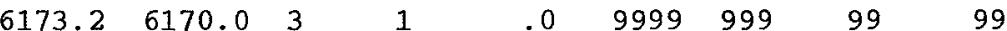

$\begin{array}{lllllllll}6174.5 & 6171.5 & 3 & 2 & .0 & 9999 & 999 & 99 & 999\end{array}$

$\begin{array}{lllllllll}6178.9 & 6176.0 & 2 & 1 & .0 & 9999 & 999 & 30 & 999\end{array}$

$6187.0 \quad 6184.0 \quad 3 \quad 4$

$.29999 \quad 999 \quad 99 \quad 999$

6188.36185 .5

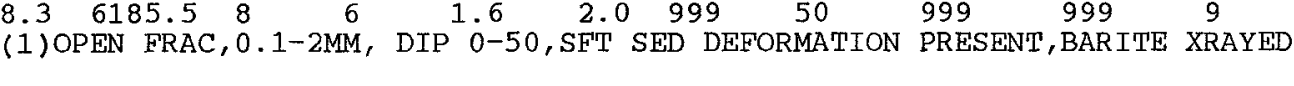

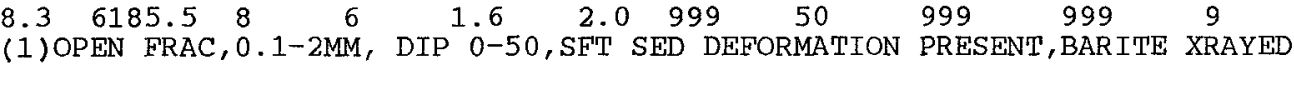

9999999

999

999

999

999

999

999

BD

115$$
\text { (3) }
$$

2

(a)

(1)

(a)

(a)

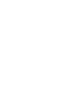

9

9


SLICK TYPE SLICK FILL FILL CRYSTAL TOP BOT

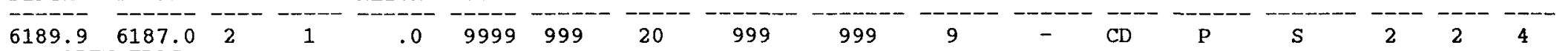

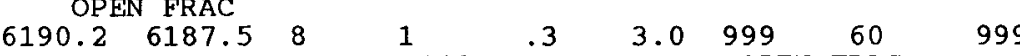

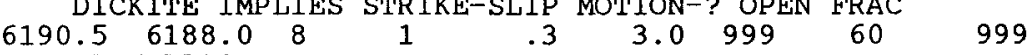
OPEN FRAC

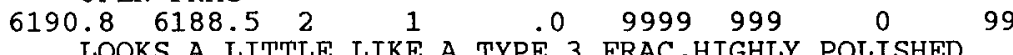

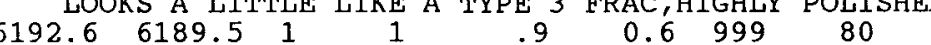
\begin{tabular}{cccccccccccc}
6193.0 & 6190.0 & 2 & 1 & .0 & 9999 & 999 & 0 & 999 & 999 & 9 & - \\
\hline
\end{tabular}

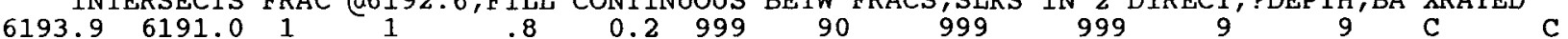
MOSTLY COMP FILL, MAYBE SOME DICKITE TOO

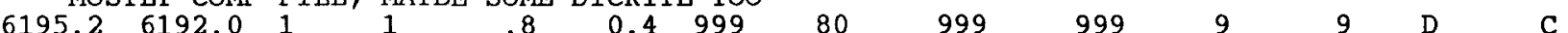

DIP 60-80, OFFSET @TYPE 2 BELOW, INTERSECTS FRAC TYPE 1@6195.4

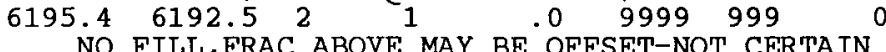

$6195.46192 .511 \quad 1 \quad 1.5 \quad 0.3999 \quad 80$

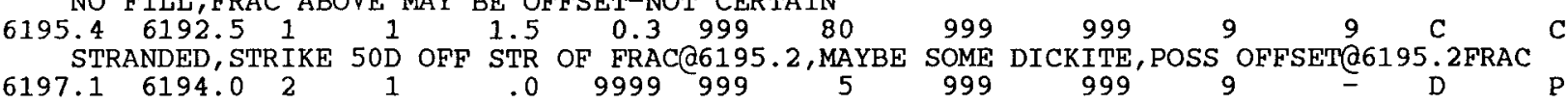
OPEN FRAC

$\begin{array}{lllllllllllll}6197.7 & 6194.5 & 2 & 1 & .0 & 9999 & 999 & 10 & 999 & 999 & 9 & - & 999\end{array}$

$\begin{array}{lllllllll}6197.7 & 6194.5 & 8 & 6 & .9 & 2.0 & 999 & 75 & 999\end{array}$

TOP Q6197.7 SHEAR, DIP 50-75,0.1-2MM

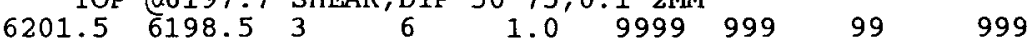

$\begin{array}{lllllllll}6203.5 & 6200.5 & 2 & 1 & .1 & 9999 & 999 & 20 & 999\end{array}$

VERY PLANAR, OPEN FRAC, SLKS IN 2 DIFFERENT DIRECTIONS

$\begin{array}{lllllllll}6206.9 & 6204.0 & 3 & 1 & .0 & 9999 & 999 & 30 & 999\end{array}$

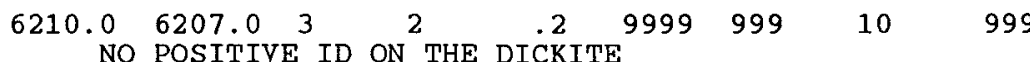

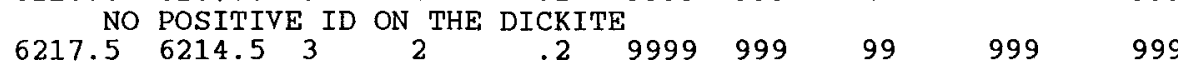

999

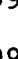

999

999

999

999

$\begin{array}{lllllllll}6219.8 & 6217.0 & 3 & 1 & .0 & 9999 & 999 & 5 & 999\end{array}$

$\begin{array}{lllllllll}6225.0 & 6221.5 & 3 & 4 & .6 & 9999 & 999 & 99 & 999\end{array}$

$\begin{array}{lllllllll}6233.8 & 6230.0 & 3 & 6 & .7 & 9999 & 999 & 99 & 999\end{array}$

$\begin{array}{lllllllll}6242.0 & 6238.0 & 3 & 2 & .0 & 9999 & 999 & 99 & 999\end{array}$

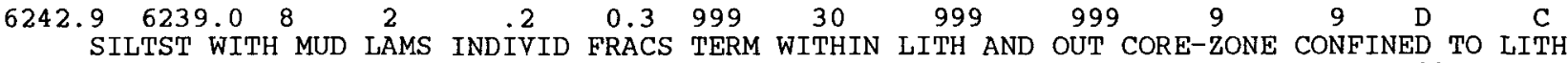

6243.26239 .5

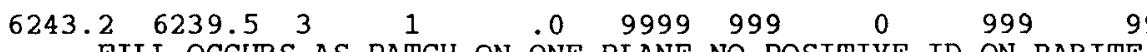

FILL OCCURS AS PATCH ON ONE PLANE, NO POSITIVE ID ON BARITE

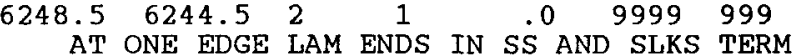

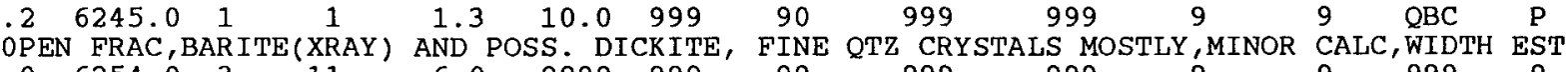

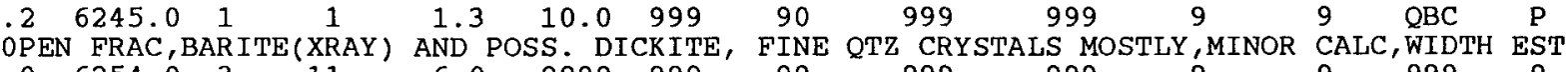

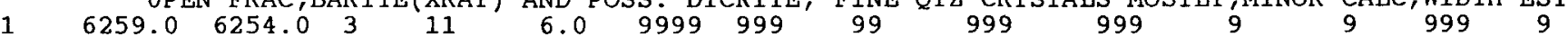

\begin{tabular}{|c|c|c|}
\hline 2 & 2 & 3 \\
\hline 2 & 2 & 3 \\
\hline 2 & 2 & 4 \\
\hline 3 & 5 & 3 \\
\hline 2 & 2 & 4 \\
\hline 5 & 3 & 4 \\
\hline 2 & 2 & 0 \\
\hline 2 & 2 & 0 \\
\hline 5 & 5 & 3 \\
\hline 2 & 2 & 4 \\
\hline 2 & 2 & 4 \\
\hline 5 & 3 & 6 \\
\hline 9 & 9 & 7 \\
\hline 2 & 2 & 4 \\
\hline 9 & 9 & 7 \\
\hline 9 & 9 & 7 \\
\hline 9 & 9 & 7 \\
\hline 2 & 3 & 7 \\
\hline 9 & 9 & 7 \\
\hline 9 & 9 & 7 \\
\hline 9 & 9 & 7 \\
\hline 3 & 3 & 6 \\
\hline 9 & 9 & 7 \\
\hline 9 & 9 & 7 \\
\hline 2 & 3 & 4 \\
\hline 5 & 2 & 3 \\
\hline 9 & 9 & 7 \\
\hline
\end{tabular}




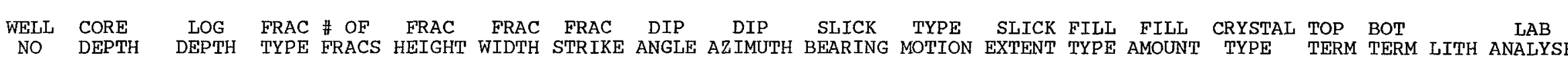

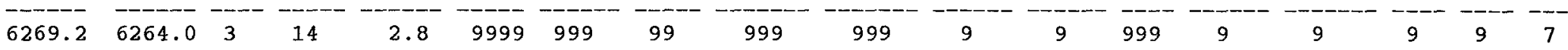

$\begin{array}{rlllllllllllllllll}6274.7 & 6269.5 & 3 & 4 & .0 & 9999 & 999 & 99 & 999 & 999 & 9 & 9 & 999 & 9 & 9 & 9 & 9 & 7\end{array}$

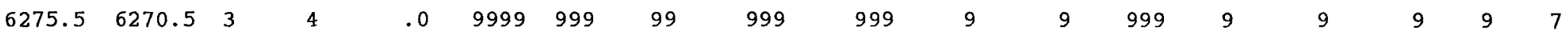

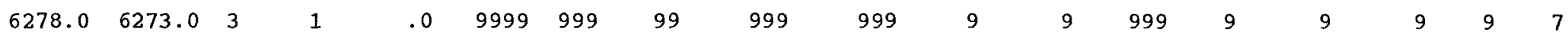

$\begin{array}{rlllllllllllllllll}6279.4 & 6274.5 & 3 & 3 & .2 & 9999 & 999 & 99 & 999 & 999 & 9 & 9 & 999 & 9 & 9 & 9 & 9 & 7\end{array}$

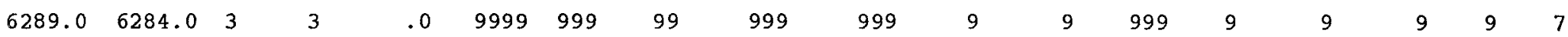

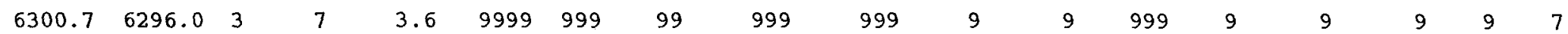

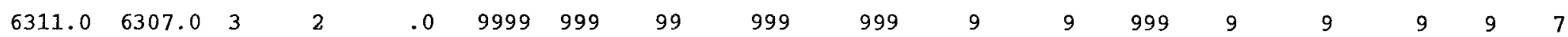

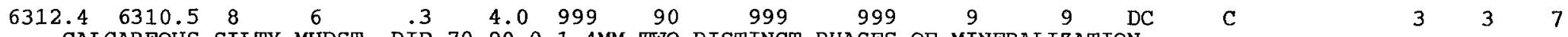

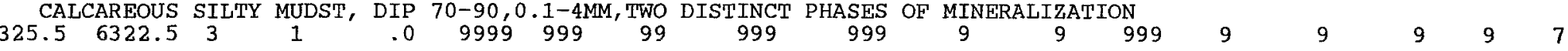

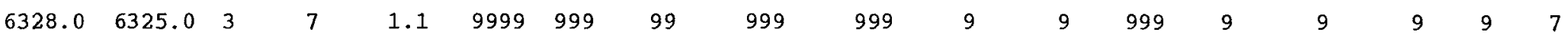

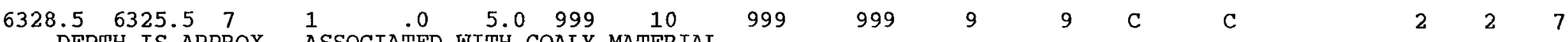

6358.7 6353.5 1 . 1 . 1 .

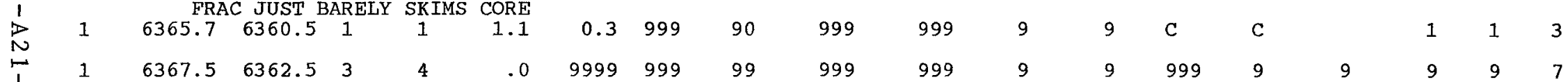

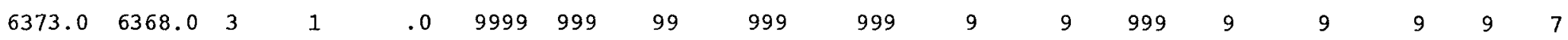

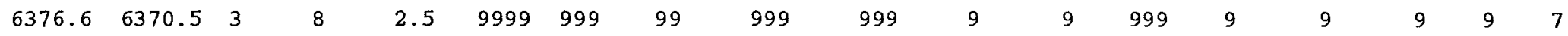

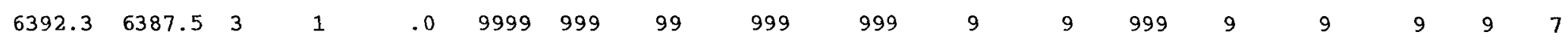

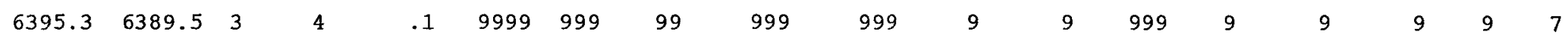

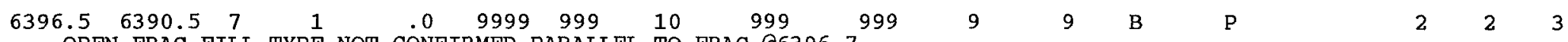

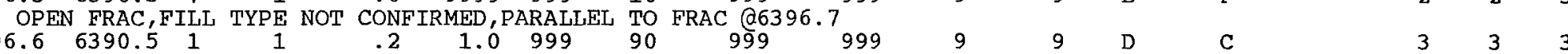

BOTHOM TERM @ FRAC AT 6396.8 BELOW

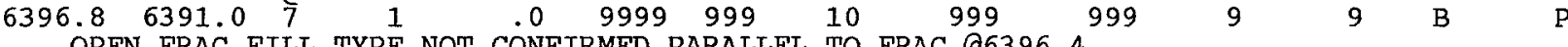

OPEN FRAC, FILL TYPE NOT CONFIRMED, PARALLEL TO FRAC @6396.4

$\begin{array}{llllllllll}6399.0 & 6394.0 & 1 & 1 & 2.9 & 0.2 & 999 & 90 & 999 & 999\end{array}$

$\begin{array}{lllllllll}6406.6 & 6403.0 & 3 & 5 & 1.8 & 9999 & 999 & 99 & 999\end{array}$

$\begin{array}{lllllllll}6410.7 & 6406.5 & 3 & 3 & .2 & 9999 & 999 & 99 & 999\end{array}$

$\begin{array}{lllllllll}6414.1 & 6410.5 & 3 & 1 & .0 & 9999 & 999 & 99 & 999\end{array}$

$6418.0 \quad 6414.0 \quad 3 \quad 5$

$.0 \quad 9999 \quad 999 \quad 99$

999

99 


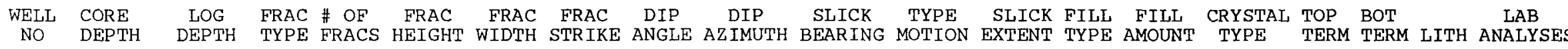

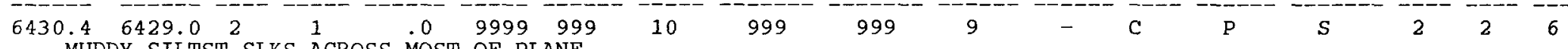

MUDDY SILTST SLKS ACROSS MOST OF PLANE

$\begin{array}{lllllllllllllllll}6465.0 & 6462.0 & 3 & 1 & .0 & 9999 & 999 & 99 & 999 & 999 & 9 & 9 & 999 & 9 & 9 & 9 & 9\end{array}$

$\begin{array}{llllllllllllllll}6490.6 & 6487.5 & 3 & 1 & .0 & 9999 & 999 & 99 & 999 & 999 & 9 & 9 & 999 & 9 & 9 & 9\end{array}$

$\begin{array}{llllllllllllllll}6501.4 & 6499.5 & 2 & 1 & .0 & 9999 & 5 & 10 & 95 & 95 & 9 & - & 999 & 9 & 9 & 2\end{array}$

$\begin{array}{lllllllllllllllll}525.1 & 6523.0 & 1 & 1 & .7 & 0.2 & 290 & 90 & 999 & 999 & 9 & 9 & \mathrm{C} & \mathrm{C} & & 2\end{array}$

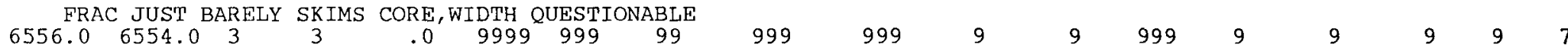

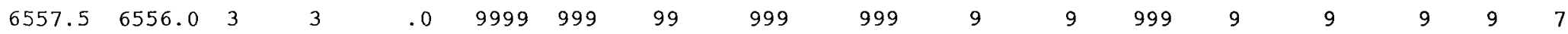

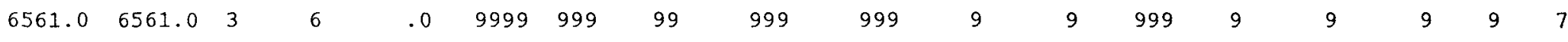

$\begin{array}{llllllllllllllll}6584.3 & 6588.0 & 7 & 1 & .0 & 9999 & 999 & 0 & 999 & 999 & 9 & 9 & \mathrm{C} & \mathrm{P} & & 2\end{array}$

$\begin{array}{llllllllllllllll}6584.7 & 6588.5 & 7 & 1 & .2 & 1.4 & 999 & 30 & 999 & 999 & 9 & 9 & \mathrm{C} & \mathrm{P} & 4\end{array}$

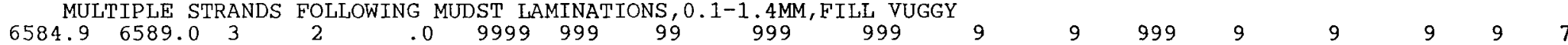

$\begin{array}{llllllllllllllll}6588.5 & 6592.5 & 3 & 5 & .4 & 9999 & 999 & 99 & 999 & 999 & 9 & 9 & 999 & 9 & 9 & 9\end{array}$

$\begin{array}{llllllllllllllll}6593.0 & 6597.0 & 3 & 4 & .2 & 9999 & 999 & 99 & 999 & 999 & 9 & 9 & 999 & 9 & 9\end{array}$

$\begin{array}{lllllllllllllll}6594.0 & 6598.0 & 3 & 2 & .0 & 9999 & 999 & 99 & 999 & 999 & 9 & 9 & 999 & 9 & 9\end{array}$

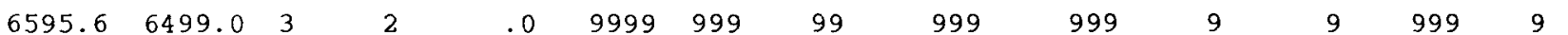

$\begin{array}{llllllllllllll}6597.5 & 6600.5 & 3 & 1 & .0 & 9999 & 999 & 99 & 999 & 999 & 9 & 9 & 999 & 9\end{array}$

$\begin{array}{rrrrrrrrrrrrrrrr}6603.4 & 6606.0 & 7 & 1 & .0 & 2.0 & 999 & 0 & 999 & 999 & 9 & 9 & \mathrm{C} & \mathrm{C} & 2\end{array}$

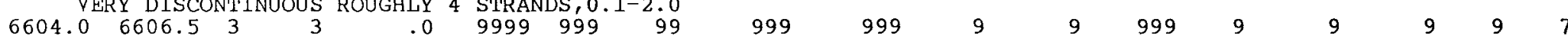

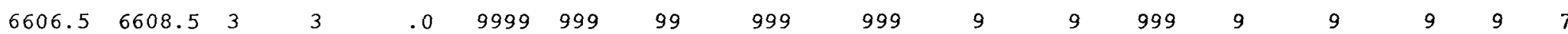

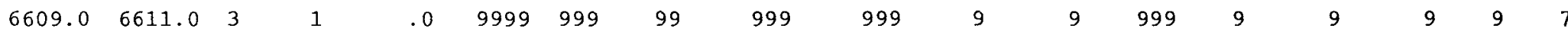

$\begin{array}{lllllllllllllllll}6613.7 & 6614.5 & 3 & 2 & .1 & 2.0 & 999 & 0 & 999 & 999 & 9 & 9 & 999 & 9 & 9 & 9 & 9\end{array}$

\begin{tabular}{lllllllllllllll}
6613.7 & 6614.5 & 7 & 1 & .1 & 2.0 & 999 & 0 & 999 & 999 & 9 & 9 & $\mathrm{C}$ & $\mathrm{C}$ & 3 \\
\hline
\end{tabular}

COALY MUDST, FRAC ZONE IS CONFINED TO LITH, (3) STRANDS DISCONTINUOUS, ONE END-OUTCORE?

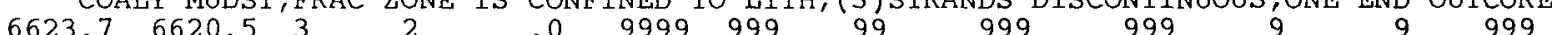

$\begin{array}{lllllllll}6630.2 & 6627.0 & 2 & 1 & .0 & 9999 & 999 & 0 & 999\end{array}$

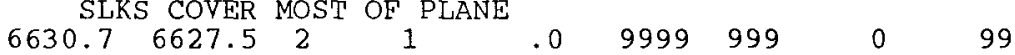

$\begin{array}{lllllllll}6633.9 & 6631.0 & 3 & 1 & .0 & 9999 & 999 & 99 & 999\end{array}$

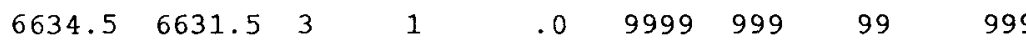

999

$\begin{array}{llllllll}6634.6 & 6631.6 & 3 & 1 & .0 & 9999 & 999 & 99\end{array}$ 


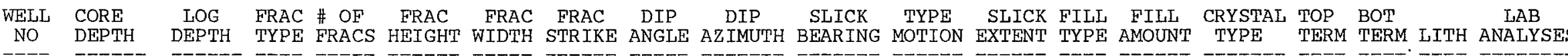

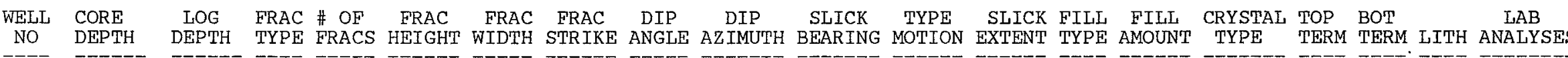

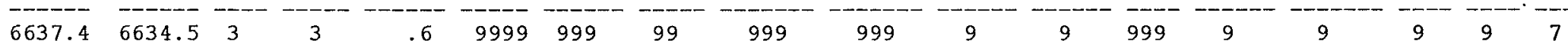
\begin{tabular}{lllllllllllllllll}
6661.5 & 6658.5 & 7 & 3 & .6 & 2.0 & 999 & 0 & 999 & 999 & 9 & 9 & $\mathrm{CQ}$ & $\mathrm{P}$ & $\mathrm{S}$ & 2 & 2 \\
\hline
\end{tabular}

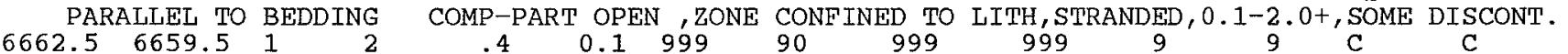

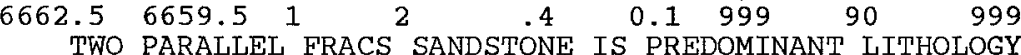

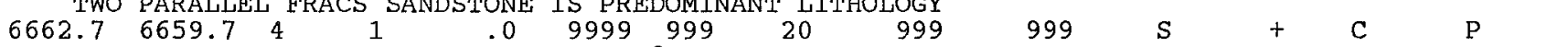

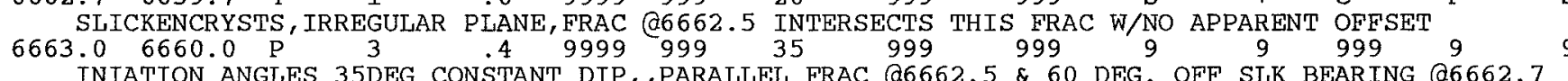

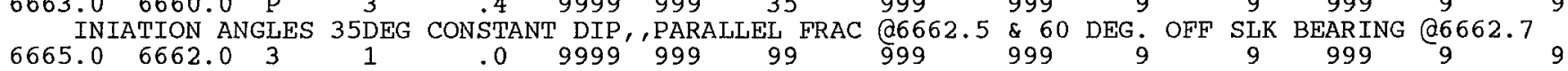

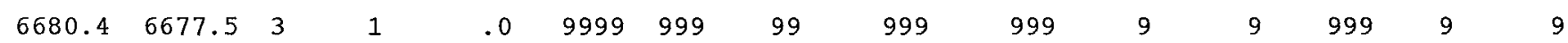

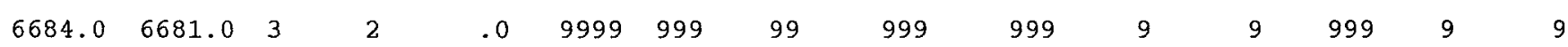

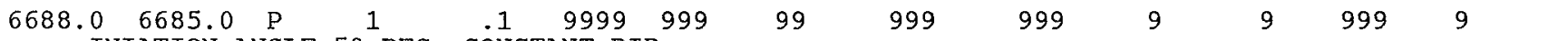

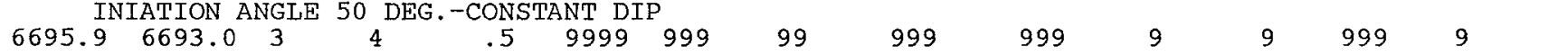
$\begin{array}{rrrrrrrrrrr}6710.9 & 6709.0 & 1 \\ \text { FRAC CROSSES THE TWO SHEAR FRACS DESCRIBED BELOW, ORIENTATION FROM PALEOMAG } & 1 & 2.7 & 0.5 & 330 \mathrm{P} & 90 & 999 \mathrm{P} & 999 \mathrm{P} & 9\end{array}$

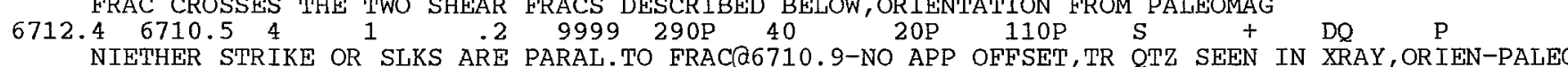

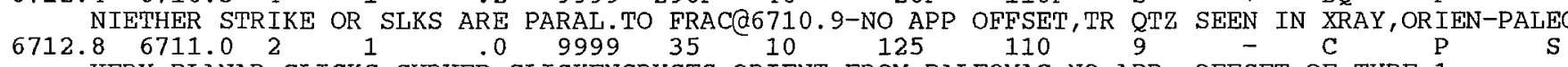

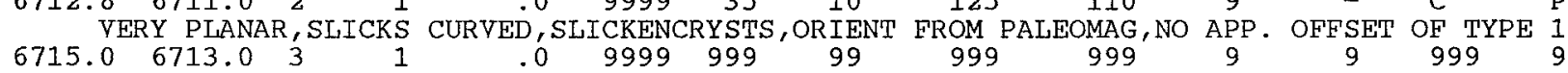

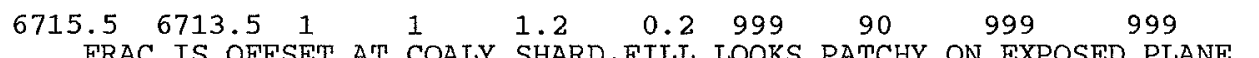

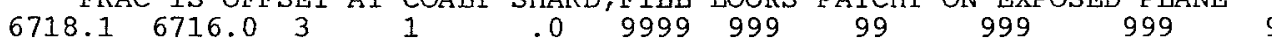
$\begin{array}{llllllllll}6718.3 & 6716.5 & 3 & 1 & .0 & 9999 & 999 & 99 & 999 & 999\end{array}$ $\begin{array}{lllllllll}6719.0 & 6717.0 & 3 & 2 & .0 & 9999 & 999 & 99 & 999\end{array}$ $\begin{array}{lllllllll}6743.0 & 6741.0 & 3 & 2 & .0 & 9999 & 999 & 99 & 999\end{array}$ $\begin{array}{lllllllll}6748.0 & 6746.0 & 3 & 3 & .0 & 9999 & 999 & 99 & 999\end{array}$ $\begin{array}{lllllllll}6749.3 & 6747.5 & 3 & 3 & .0 & 9999 & 999 & 99 & 999\end{array}$ $\begin{array}{lllllllll}6759.7 & 6757.5 & \mathrm{D} & 1 & 2.0 & 9999 & 999 & 99 & 999\end{array}$ SOME APPARENT STRIKE/SLIP MOTION

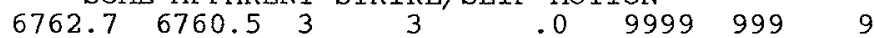

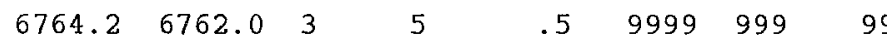
$\begin{array}{llllllll}6776.7 & 6774.5 & 3 & 1 & .0 & 9999 & 999 & 99\end{array}$

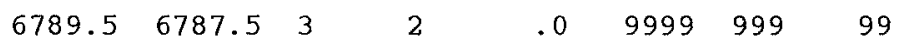
$\begin{array}{llllllll}6790.2 & 6788.0 & 3 & 2 & .0 & 9999 & 999 & 99\end{array}$ $\begin{array}{llllllll}6797.7 & 6795.5 & 7 & 1 & .1 & 1.0 & 999 & 25\end{array}$ MUDDY SILTST, DIP $0-25$ 
SLICK TYPE SLICK FILL FILL CRYSTAL TOP BOT

DEPTH DEPTH TYPE FRACS HEIGHT WIDTH STRIKE ANGLE AZIMUTH BEARING MOTION EXTENT TYPE AMOUNT TYPE TERM TERM LITH ANALYSES

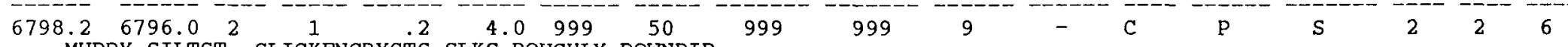
MUDDY SILTST, SLICKENCRYSTS, SLKS ROUGHLY DOWNDIP

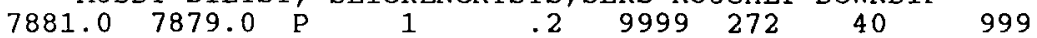
INIATION ANGLE 30 DEG.-CONVEX UP

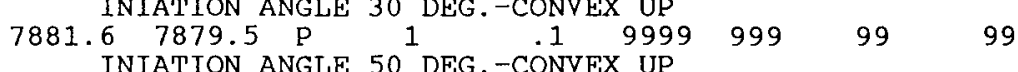

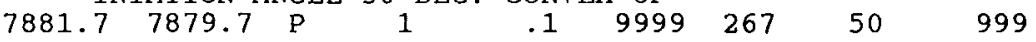

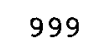

999

9999

200

999

7882.87880 .5 $\begin{array}{llll}1 & .1 & 9999 & 274\end{array}$ INIATION ANGLE 45 DEG. -CONVEX UP

7884.0 7882.0 P 9990 INTATION ANGLE 25 DEG.-CONYEX UP

7884.17882 P 999

7884.

7884.7883 .0 P INIATION ANGLE 15 DEG. -CONVEX UP

7886 . 7884 ANGE 15 DEG. -CONVEX UP INIATION ANGLE $20{ }^{1}$ DEG. - CONYEX UP

$7886.37884 .5 \quad \mathrm{P} \quad \mathrm{l} \quad .0 \quad 9999$

7886.6 TATON ANGLE 40 DEG. -CONVEX UP INIATION ANGLE $35^{1}$ DEG.-IRREGULAR

$7892.1 \quad 7890.0 \quad \mathrm{P} \quad 110.1999$

INIATION ANGLE 65 DEG. -??

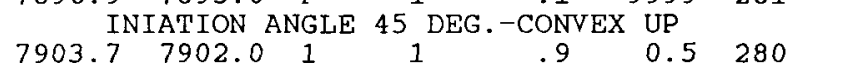

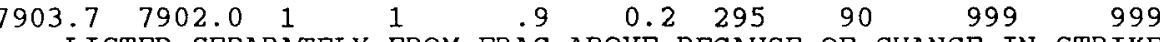

L904 LISTED SEPARATELY FROM FRAC ABOVE BECAUSE OF CHANGE IN STRIKE, FILL PATCHY ON EXPOSED PL.

7904.17902 .0 P 50 - 5 . 5999

$7913.0 \quad 7910.0 \quad 3 \quad 130.0$. $3999 \quad 999$

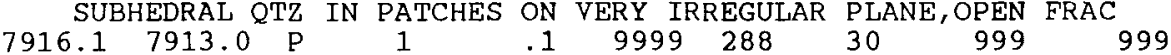
INIATION ANGLE 40 DEG.-CONCAVE UP

$\begin{array}{llllllllll}7916.5 & 7913.5 & P & 1 & .1 & 9999 & 288 & 30 & 999 & 999\end{array}$ INIATION ANGLE 35 DEG.-CONCAVE UP

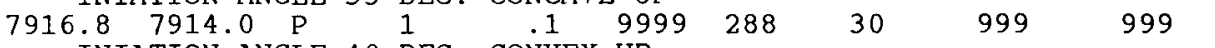
INIATION ANGLE 40 DEG.-CONVEX UP

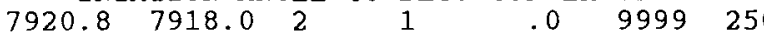
SLKS COVER MOST OF PLANE

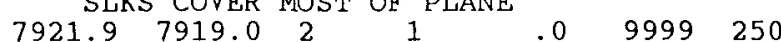

$\begin{array}{lllllll}7942.1 & 7939.0 & 2 & 1 & .0 & 9999 & 295\end{array}$

$\begin{array}{lllllll}7948.3 & 7945.5 & 2 & 1 & .0 & 9999 & 999\end{array}$

$\begin{array}{lllllll}7949.7 & 7946.5 & 3 & 1 & .0 & 9999 & 58\end{array}$ $\begin{array}{ccccccc}\text { REALLY AT CONTACT } & \text { BETWEEN } & \text { SS } & \text { AND MUDST } \\ 873.0 & 4863.0 & 3 & 6 & 4.0 & 9999 & 999\end{array}$

$5 \quad 340$

45

$10 \quad 340$

40

$4877.0 \quad 4867.0 \quad 3$

$2.29999999 \quad 99$

25

25

$0 \quad 999$

57

$5 \quad 310$

50

$4917.4 \quad 4906.5$

999

BOTTERM AT SED FEAT WITH BLK ORGA MAT'L AND PATCHES 
WELL CORE LOG FRAC \# OF FRAC FRAC FRAC DIP DIP SLICK TYPE SLICK FILL FILL CRYSTAL TOP BOT

NO DEPTH DEPTH TYPE FRACS HEIGHT WIDTH STRIKE ANGLE AZIMUTH BEARING MOTION EXINNT

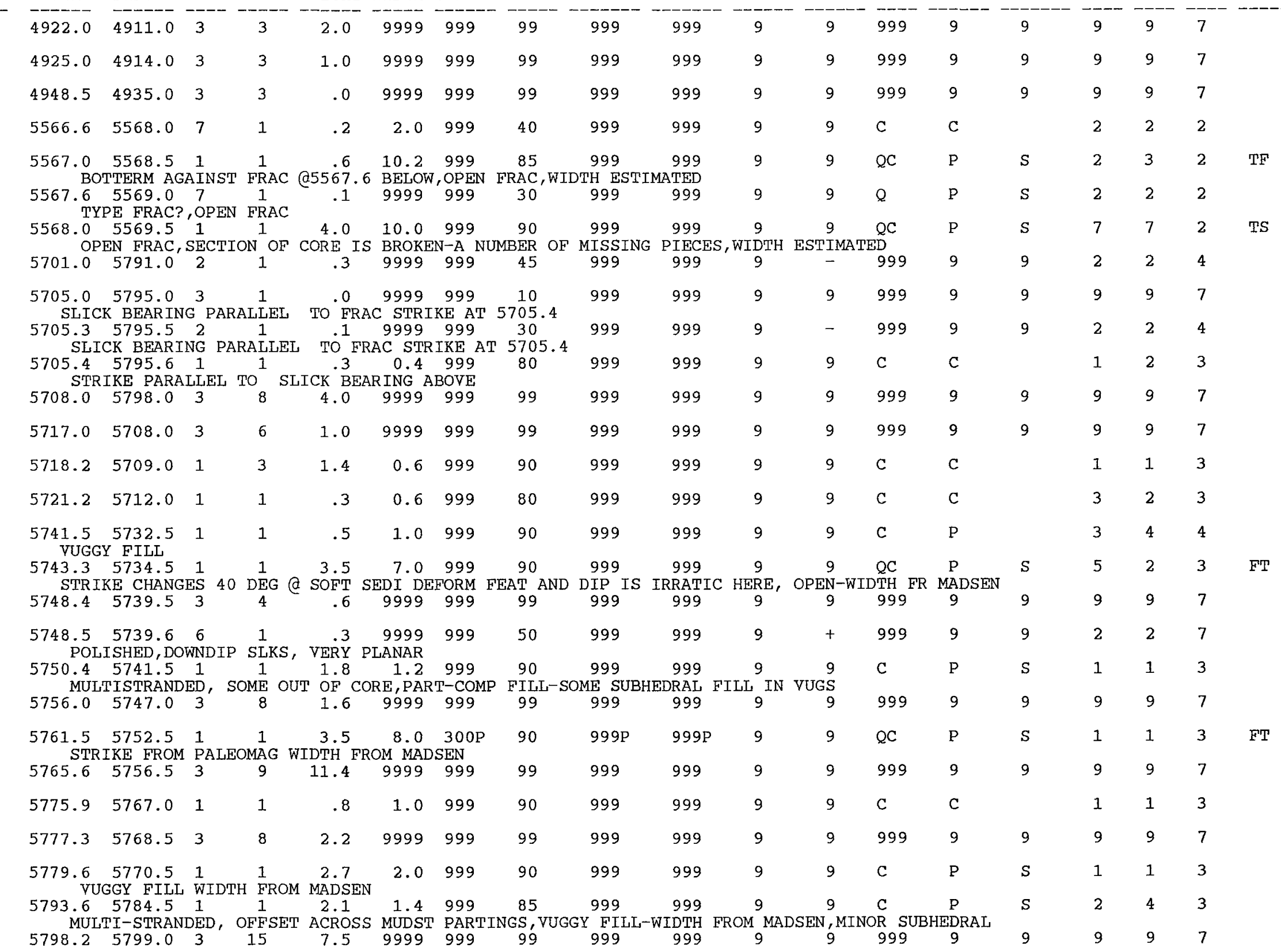




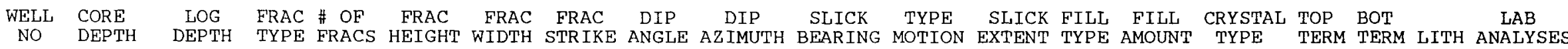

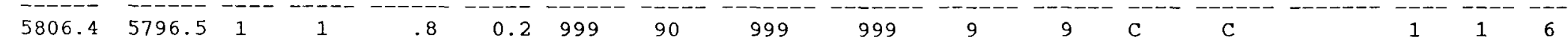

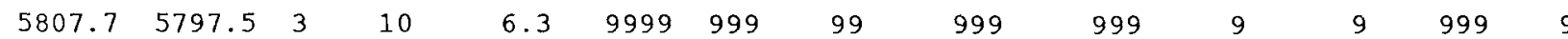

$\begin{array}{lllllllllllll}5814.1 & 5803.0 & 1 & 1 & .5 & 0.4 & 999 & 90 & 999 & 999 & 9 & 9 & \mathrm{C}\end{array}$

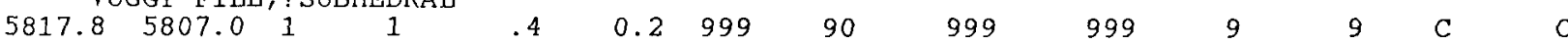

5825 ONLY SEEN ON ONE SIDE OF WHOLE CORE

$\begin{array}{llllllllllllll}5826.2 & 5815.0 & 1 & 1 & 2.7 & 1.5 & 999 & 85 & 999 & 999 & 9 & 9 & \mathrm{C} & \mathrm{P}\end{array}$

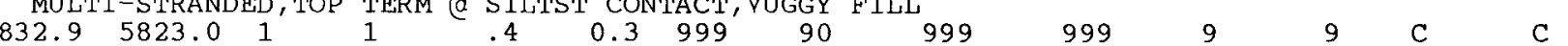

WORM BURROW AT TERM OF FRAC, FRAC THINS \& TERMS AS MUDST LAMS MORE NUMEROUS

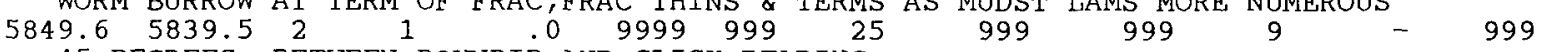

45 DEGREES BETWEEN DOWNDIP AND SLICK BEARING

$\begin{array}{llllllll}5850.3 & 5840.5 & 2 & 1 & .0 & 9999 & 999 & 15\end{array}$

850.8 SUBTLE SLKS

$\begin{array}{llll}0 & 9999 & 999 \quad 15\end{array}$

999999

$999 \quad 999$

VERY IRREG PLANE OMUDST-SS CONTACT

$\begin{array}{llllllllll}5852.5 & 5842.5 & 1 & 1 & .4 & 0.2 & 999 & 90 & 999 & 999\end{array}$

ONLY SEEN ON ONE SIDE OF CORE

$\begin{array}{lllllll}5853.0 & 5843.0 & 3 & 6 & 3.0 & 9999 & 999\end{array}$

$\begin{array}{llllllll}5858.4 & 5848.5 & 3 & 4 & .1 & 9999 & 999 & 99\end{array}$

$999 \quad 999$

1
$n$
0
1

$\begin{array}{llllllll}5858.8 & 5849.0 & 1 & 1 & .8 & 0.2 & 999 & 90\end{array}$

$\begin{array}{llllllll}5864.8 & 5855.0 & 3 & 8 & .7 & 9999 & 999 & 99\end{array}$

$\begin{array}{llllllll}6401.9 & 6398.0 & 3 & 13 & 6.0 & 9999 & 999 & 9\end{array}$

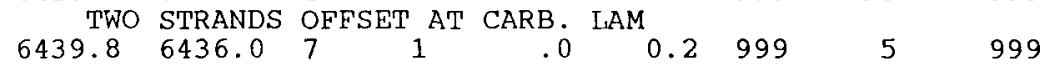

$\begin{array}{lllllllll}6461.6 & 6457.5 & 2 & 1 & .0 & 9999 & 999 & 30 & 999\end{array}$

SLKS DOWNDIP

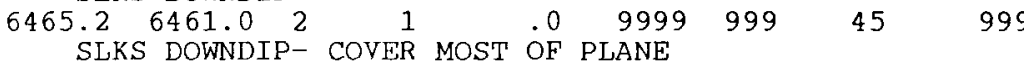

$999 \quad 999$

$\begin{array}{llllllll}6496.3 & 6490.0 & 3 & 3 & .0 & 9999 & 999 & 99\end{array}$

$\begin{array}{llllllll}6496.4 & 6490.5 & 3 & 1 & .0 & 9999 & 348 & 40\end{array}$

IRREGUIAR PIANE

6496.56490 .63

IRREGULAR PLANE

$1 \quad .0 \quad 9999 \quad 358 \quad 40$

999

258

6523.56516 .0

$\begin{array}{cccc}1 & \cdot 3 & 9999 & 75 \\ \text { SEEN ONLY } & \text { IN } & \text { THINSECTION }\end{array}$

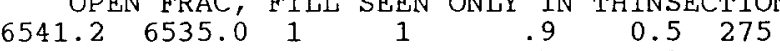
BOT TERM WITHIN SS WITH ABUND ORGA LAMS

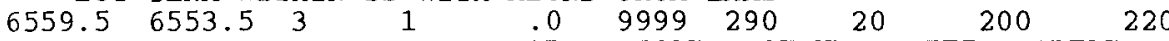

ORIENTATION DATA QUESTIONABLE BECAUSE OF UNSPECIFIED BREAK

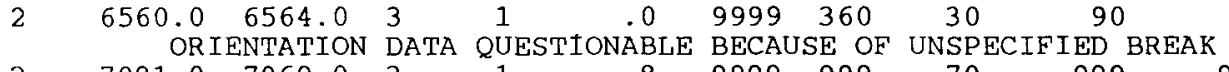

$\begin{array}{llllllllll}2 & 7081.0 & 7069.0 & 3 & 1 & .8 & 9999 & 999 & 70 & 999\end{array}$ 


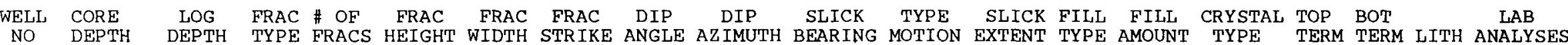

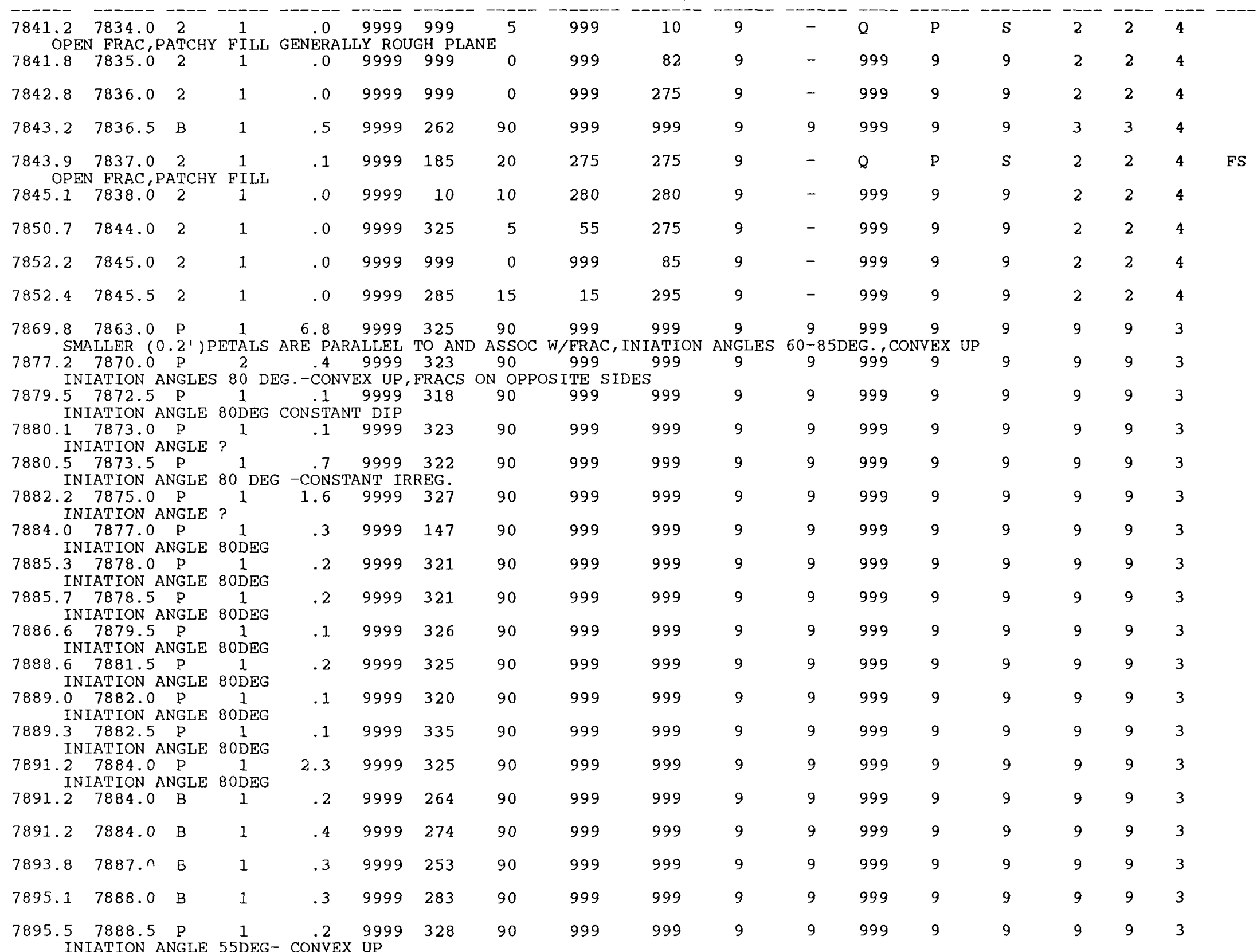


WELL CORE

LOG

SLICK TYPE SLICK FILI FILL CRYSTAL TOP BOT

LAB

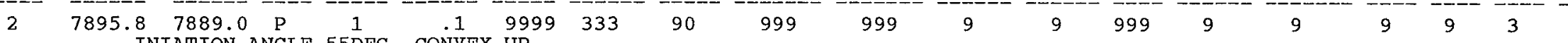

7896.2
2

$\begin{array}{llllllll}7896.4 & 7889.5 & 2 & 1 & .0 & 9999 & 295 & 10\end{array}$

$\begin{array}{lllllllll}7897.9 & 7891.0 & 2 & 1 & .0 & 9999 & 999 & 5 & 999\end{array}$

$\begin{array}{lllllllll}7898.1 & 7891.2 & 2 & 1 & .0 & 9999 & 999 & 15 & 999\end{array}$

$7903.2 \quad 7896.0 \quad 2 \quad 1$

$.0 \quad 9999 \quad 345 \quad 10$

$\begin{array}{lllllllll}7903.4 & 7896.5 & \mathrm{P} & 1 & .9 & 9999 & 343 & 90 & 999\end{array}$

7903.7 INIATION ANGLE 65DEG CONSTANT DIP

INIATION ANGLE 65 DEG CONSTANT DIP

$\begin{array}{lllllll}7903.9 & 7897.0 & P & 1 & .1 & 9999 & 3\end{array}$

$7904.2 \quad 7897.2$ INIATION ANGLE 65DEG CONSTANT DIP

INIATION ANGLE 65 DEG CONSTANT DIP

$8101.48094 .5 \quad 6 \quad 100.099999$

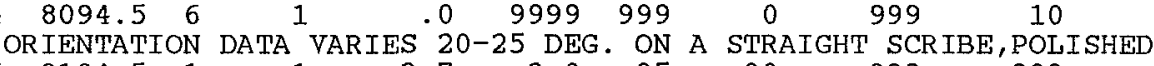

$8121.6 \quad 8113.5 \quad 2$

VERY FAINT SLKS
8122.88114 .53

$.0 \quad 9999 \quad 295 \quad 20$

99

$8122.9 \quad 8115.0 \quad 3 \quad 1$

$8123.1 \quad 8115.5 \quad 3 \quad 1$

$.0 \quad 9999 \quad 290 \quad 15$

25

$.0 \quad 9999 \quad 270 \quad 30$

20

50

$8123.2 \quad 8115.6 \quad 3 \quad 1$

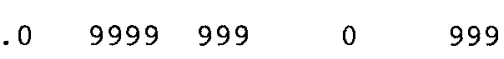

$\begin{array}{llllll}1 & .0 & 9999 & 10 & 10 & 280\end{array}$

$\begin{array}{lllllllll}8123.3 & 8115.7 & 3 & 1 & .0 & 9999 & 80 & 5 & 350\end{array}$

$8123.3 \quad 8115.7 \quad 3 \quad 1$

$.0 \quad 9999 \quad 310 \quad 30$

40

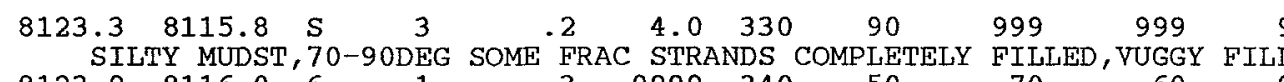

8123.98116 .0

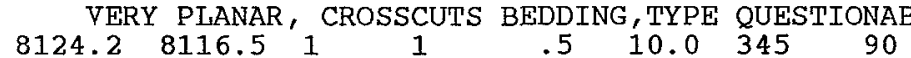

999

SKIMS EDGE OF CORE, OPEN FRAC-WIDTH ESTIMATED

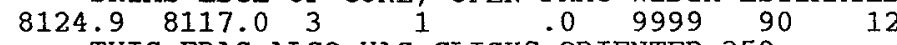

THIS FRAC ALSO HAS SLICKS ORIENTED 358

$\begin{array}{llllllll}4887.1 & 4887.0 & \mathrm{P} & 2 & .3 & 9999 & 277 & 90\end{array}$ INIATION ANGLE 65DEG CONCAYE UP

4903.7 . 4903.5 I

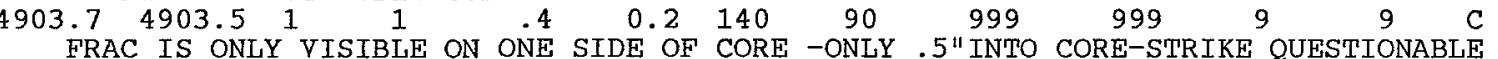

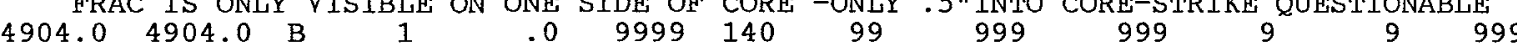

SCRIBELINE FRAC PARALLEL TO EXT. FRAC ABOVE

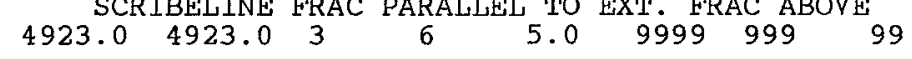

999

999

$99 \begin{array}{cc}+ \\ 9 & 9\end{array}$

CK 999

$999 \quad 9$

99

99

999

999

999

99

999

$\mathrm{QC}$

$\mathrm{TF}$

999

999

999

999

999

99

99

TFS

TXS 


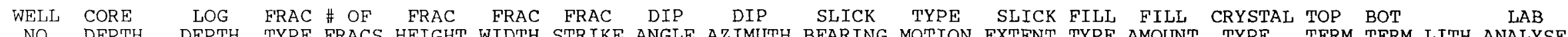

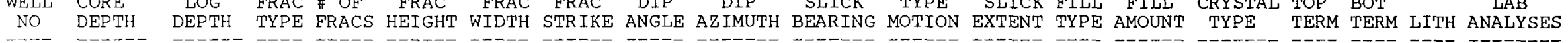

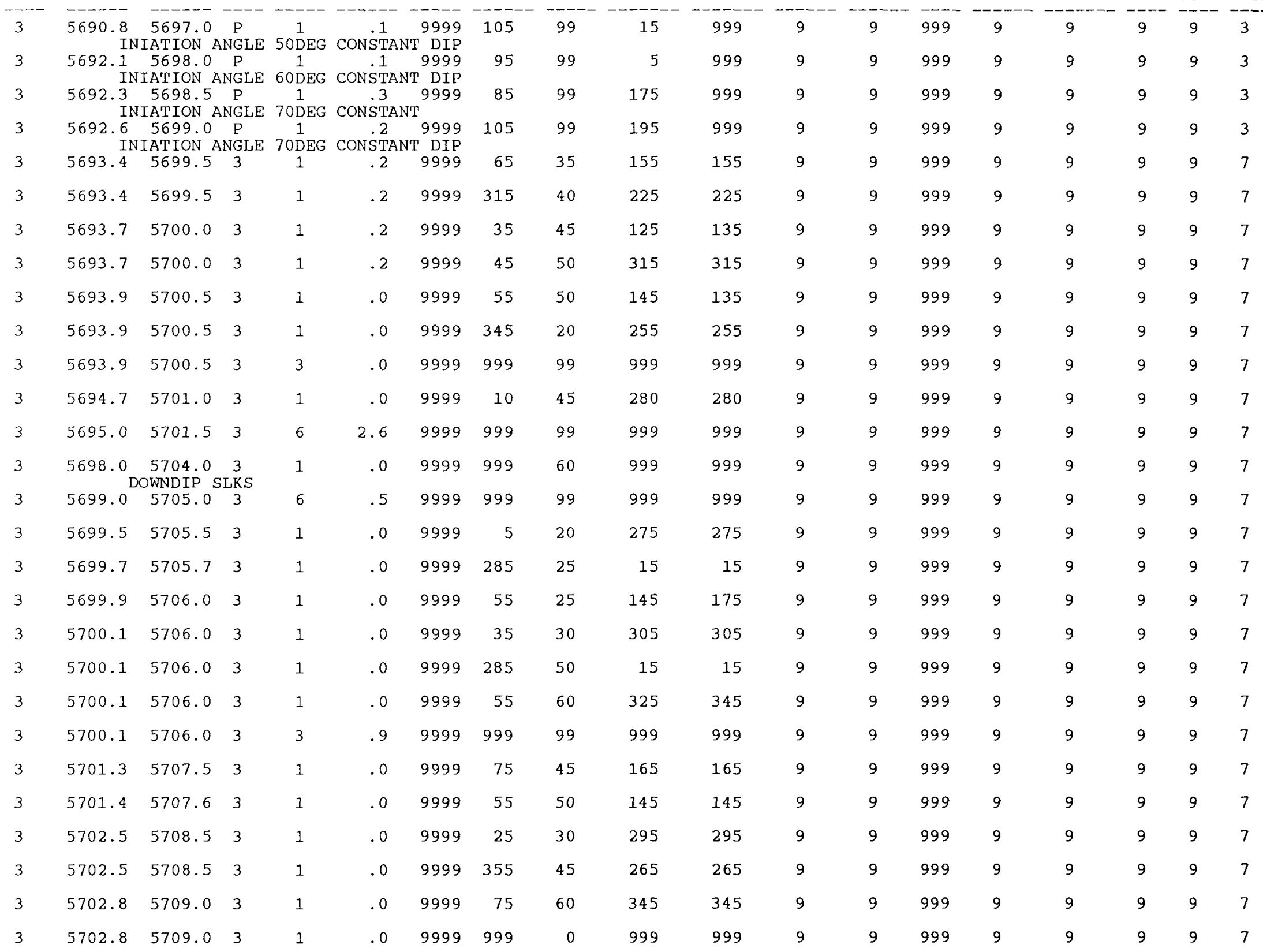




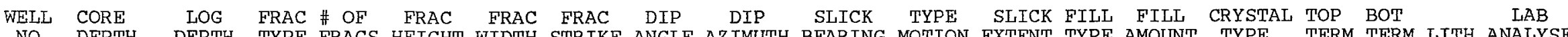

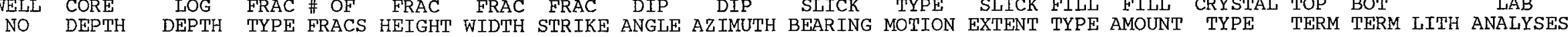

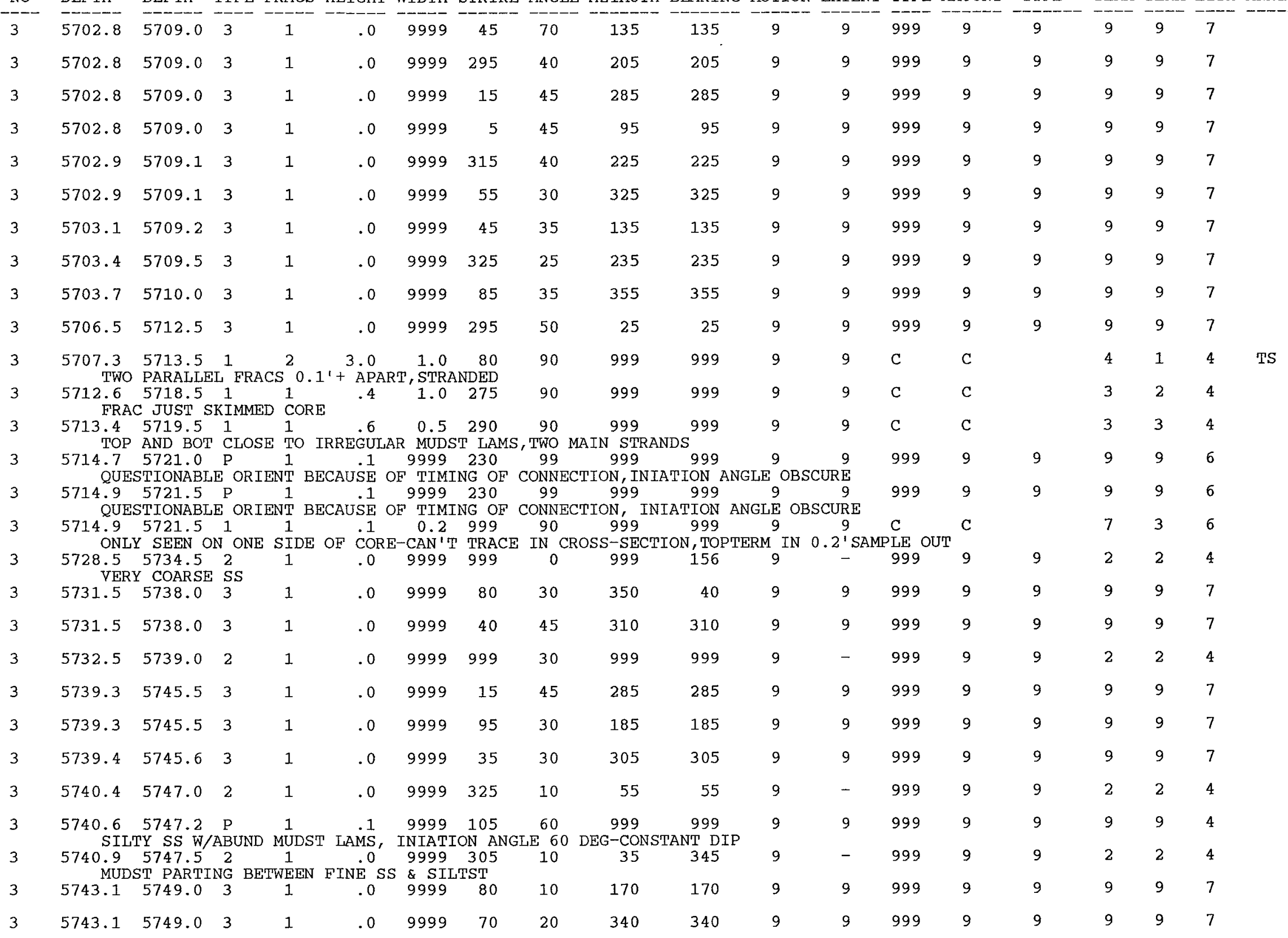




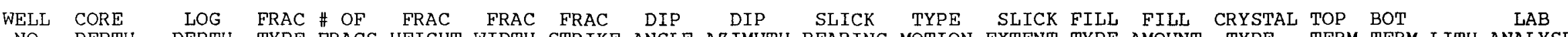
DEPTH DEPTH TYPE FRACS HEIGHT WIDTH STRIKE ANGLE AZIMUTH BEARING MOTION EXTENT TYPE AMOUNT TYPE TERM TERM LITH ANALYSES

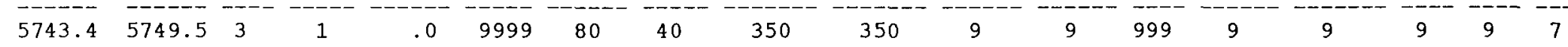

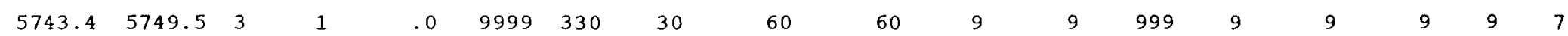

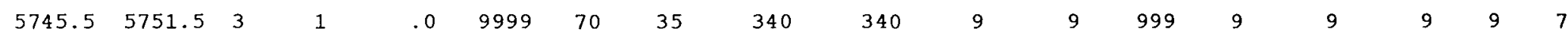

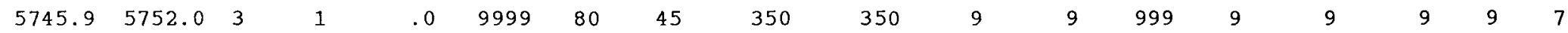

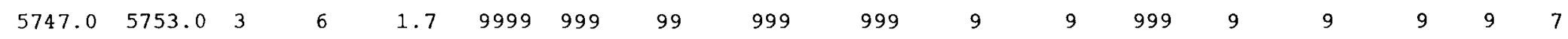
$\begin{array}{cccccccccccccccc}5749.4 & 5755.5 & 1 & 1 & .8 & 0.5 & 280 & 90 & 999 & 999 & 9 & 9 & \mathrm{C} & \mathrm{C} & & 1\end{array}$

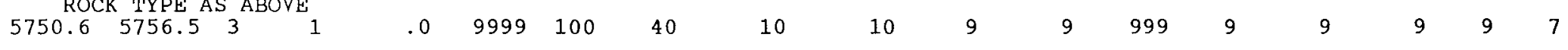
$\begin{array}{cccccccccccccccc}5752.9 & 5759.0 & P & 1 & .1 & 9999 & 120 & 60 & 999 & 999 & 9 & 9 & 999 & 9 & 9 & 9\end{array}$

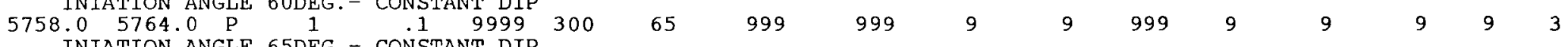
$\begin{array}{lllllllllllllll}5760.3 & 5766.5 & 1 & 1 & .5 & 0.5 & 80 & 90 & 999 & 999 & 9 & 9 & \mathrm{C} & \mathrm{C} & \mathbf{3}\end{array}$ $\begin{array}{lllllllllllllllll}5760.5 & 5766.5 & 3 & 1 & .0 & 9999 & 20 & 60 & 290 & 290 & 9 & 9 & 999 & 9 & 9 & 9 & 9\end{array}$

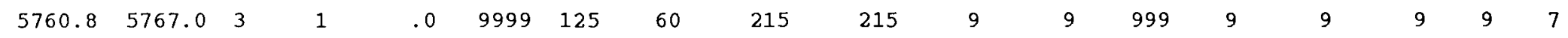
$\begin{array}{llllllllllllllllll}5762.6 & 5768.5 & 3 & 1 & .0 & 9999 & 85 & 65 & 355 & 355 & 9 & 9 & 999 & 9 & 9 & 9 & 9 & 7\end{array}$

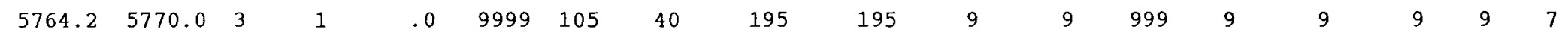

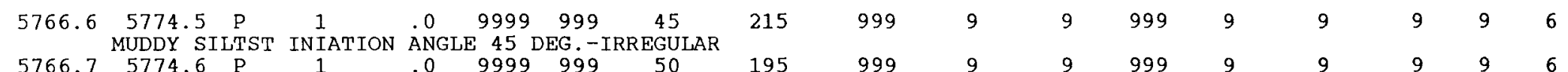

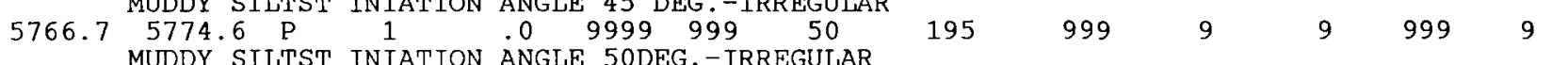

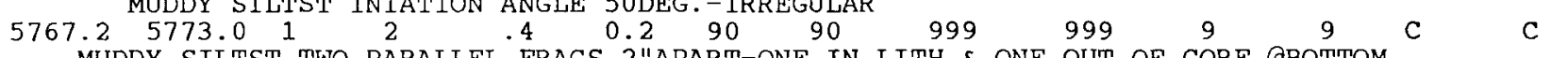

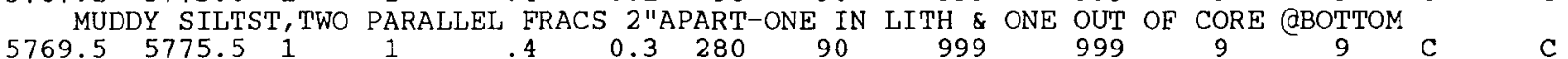

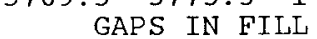


WELL CORE LOG FRAC \# OF FRAC FRAC FRAC DIP DIP SLICK TYPE SLICK FILL FILL CRYSTAL TOP BOT DEPTH DEPTH TYPE FRACS HEIGHT WIDTH STRIKE ANGLE AZIMUTH BEARING MOTION EXTENT TYPE AMOUNT TYPE TERM TERM LITH ANALYSES

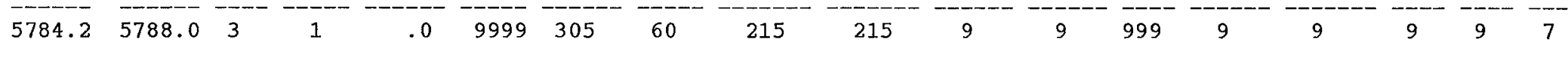

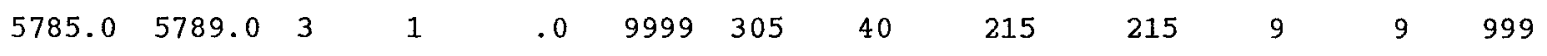

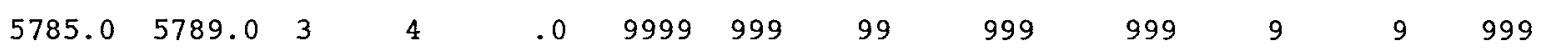

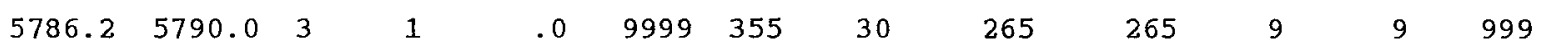

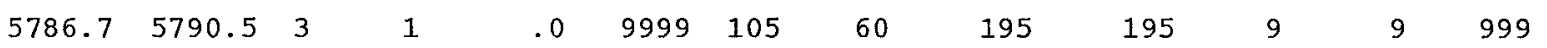

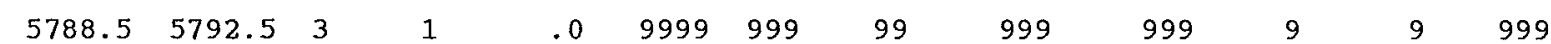

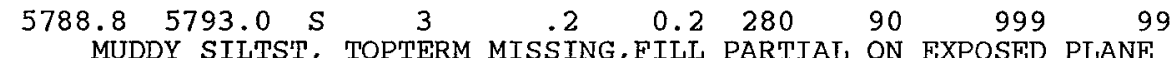

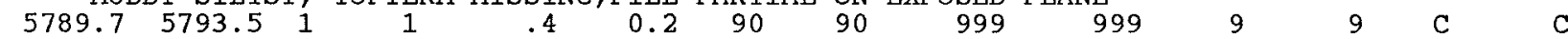

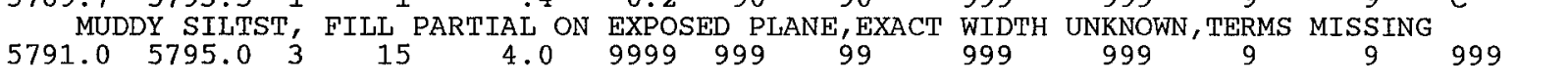
$\begin{array}{lllllllllllll}5795.5 & 5799.5 & 3 & 1 & .0 & 9999 & 45 & 50 & 315 & 315 & 9 & 9 & \mathrm{C}\end{array}$

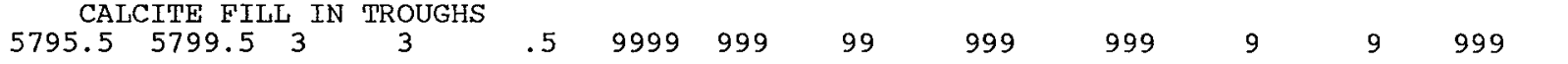

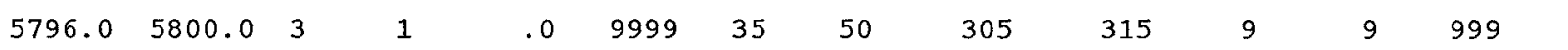
$\begin{array}{llllllllllllll}5796.5 & 5800.5 & 3 & 1 & .0 & 9999 & 5 & 40 & 275 & 275 & 9 & 9 & 999 & 9\end{array}$

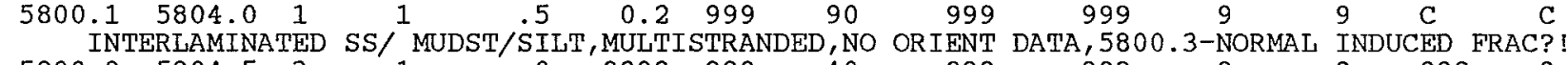

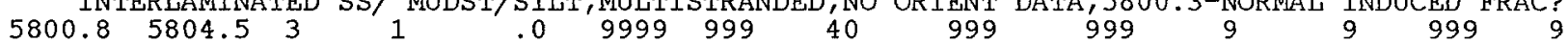

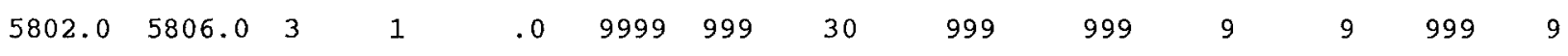

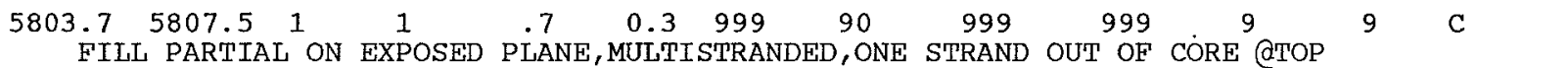
$\begin{array}{cccccccccc}5804.4 & 5808.5 & 3 & 1 & .0 & 9999 & 360 & 70 & 90 & 100\end{array}$ $\begin{array}{llllllllllll}5805.0 & 5809.0 & 2 & 1 & .0 & 9999 & 40 & 65 & 310 & 290 & 9 & -\end{array}$

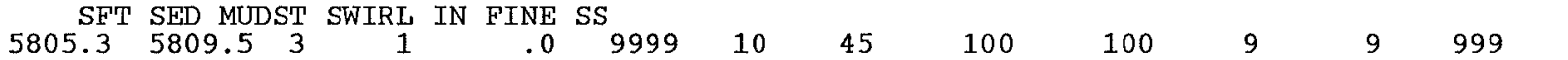

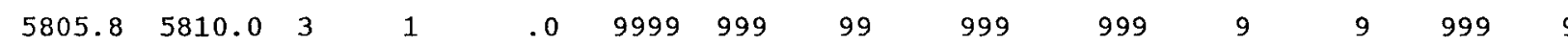
$\begin{array}{llllllll}5806.3 & 5810.5 & 3 & 1 & .0 & 9999 & 310 & 50\end{array}$ 


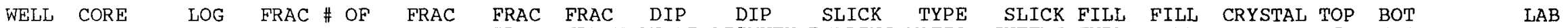

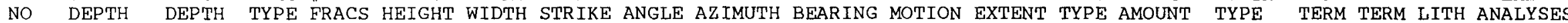

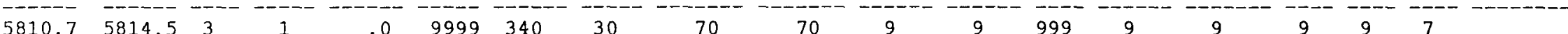

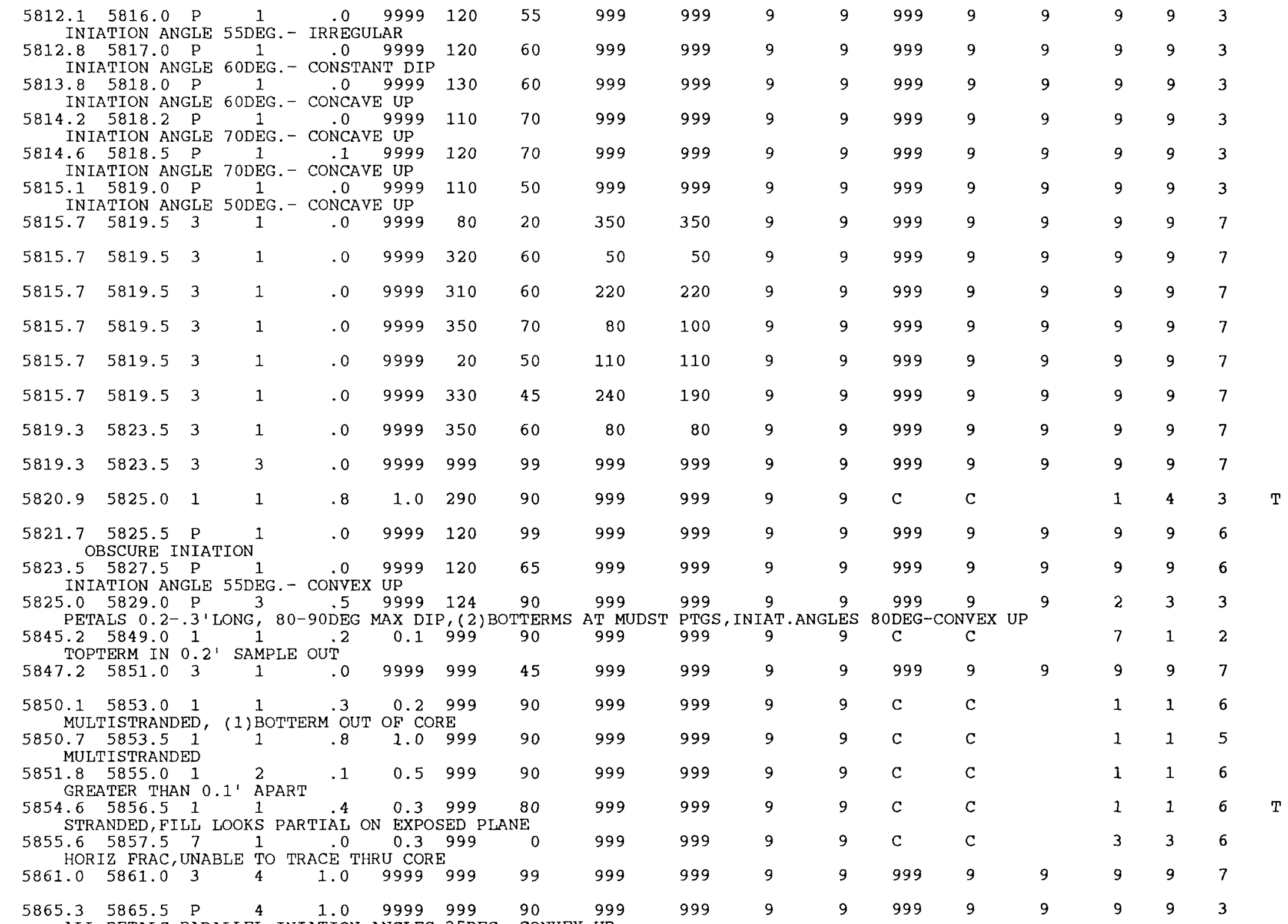
ALL PETALS PARALLEL INIATION ANGLES $35 \mathrm{DEg} .-$ CONVEX UP 


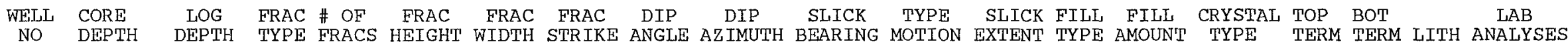

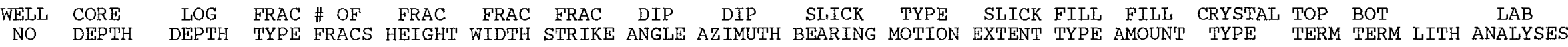

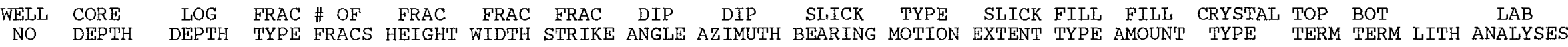

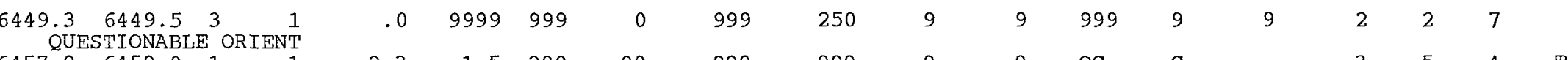

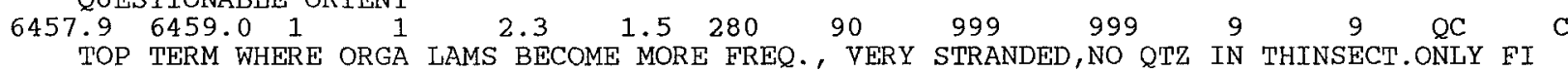

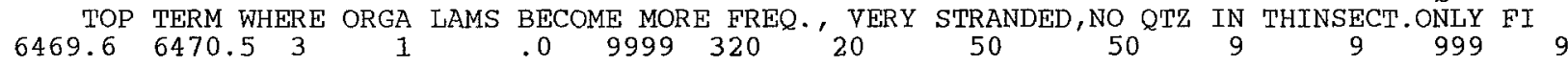

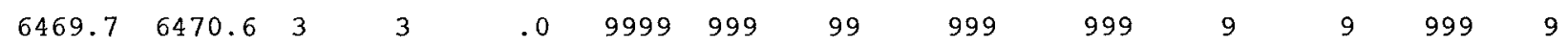

